
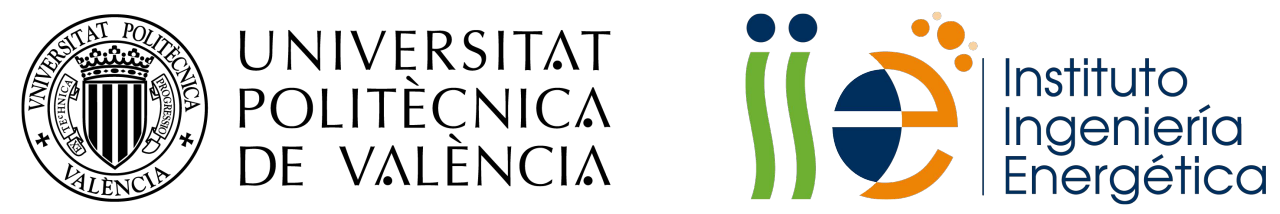

Universitat PolitècnicA DE VAlÈnCIA

\title{
Control and energy optimization of ground source heat pump systems for heating and cooling in buildings
}

\section{Doctoral Thesis}

\section{by}

Javier Cervera Vázquez

Supervisors:

Prof. Mr. José Miguel Corberán Salvador Assistant Prof. Ms. Carla Isabel Montagud Montalvá 

To my people...

and specially to my wife and my future baby.

"You cannot change the world, but you can paint your barn."

[Unknown] 



\section{Acknowledgements}

I want to thank all the people I should thank. I will not mention any names, partly for laziness, partly to avoid unnecessary embarrassment for forgetting to mention someone. They all know who they are, and they all know that I am so grateful for their help and friendship.

To all of you, just a piece of advice: paint your barn.

To all of you, thanks! 



\section{Abstract}

In a context of global warming concern and global energy policies, in which heating and cooling systems in buildings account for a significant amount of the global energy consumption, ground source heat pump (GSHP) systems are widely considered as being among the most efficient and comfortable heating and cooling renewable technologies currently available. Nevertheless, both an optimal design of components and an optimal operation of the system as a whole become crucial so that these systems can have a significant contribution to the attenuation of the global energy problem.

The overall objective of this $\mathrm{PhD}$ dissertation is to perform the control and energy optimization of an experimental GSHP system installed at the Universitat Politècnica de València, making the control system adaptive to the thermal demand of the building and to the climate conditions. For that purpose, different control strategies are proposed, described, developed, implemented and tested in the system.

The optimization of any system requires a comprehensive study of its behaviour, by means of a thorough analysis of all the variables and parameters implied on its performance. Therefore, the first step is to analyse the short-term performance of the system, but also the long-term performance based on the experimental data collected at the installation.

Second and prior to developing any optimization strategies, it is important to analyse the optimal configuration of the system according to the objectives targeted. This objective includes the study of the best location for the temperature control sensor and the buffer tank, as well as an adequate size for this buffer tank.

Finally, once the behaviour of the system has been fully understood, the components of the system are the most efficient according to the possibilities of the research work and they have been connected adequately, the final objective is to develop control and optimization strategies which optimize the operation of the experimental GSHP system. These strategies target the control of the heat pump compressor, but also and more importantly, the energy optimization of the complete system. The focus is not in optimizing the performance of each individual component, but in optimizing the energy performance of the system working as a whole.

In this direction, a first approach which combined a temperature compensation strategy and the variation of the frequency of the water circulation pumps, and hence the flow 
rate, as a function of the thermal load of the building, was first attempted. The application of this first approach resulted in significant energy savings, but also in a lack of user comfort in some of the offices under extreme weather conditions during summer. Consequently, the control and optimization methodology has been upgraded in a global algorithm (which is the final result of this $\mathrm{PhD}$ thesis) which couples both strategies in order to ensure the user comfort while keeping significant energy savings.

In brief, this $\mathrm{PhD}$ work provides a comprehensive experimental study for the energy optimization of a GSHP system for both cooling and heating operation. Experimental results for a one-year operation period demonstrate important energy savings when compared to the standard control operation, up to $35 \%$ in the summer season and $53 \%$ in the winter season, while keeping the user comfort. 


\section{Resumen}

En un contexto de creciente preocupación por el calentamiento global y de políticas energéticas internacionales, en el cual los sistemas de climatización en edificios representan una parte importante del consumo energético global, los sistemas de bomba de calor geotérmica están ampliamente considerados como una de las tecnologias de climatización de espacios más eficientes disponibles en la actualidad. Sin embargo, tanto un buen diseño de los componentes como una óptima operación del sistema son de vital importancia para que estos sistemas puedan contribuir de manera significativa a atenuar el problema energético global.

El objetivo general de esta tesis doctoral es el control y la optimización energética de una instalación experimental de bomba de calor geotérmica construida en la Universitat Politècnica de València, haciendo que el sistema de control se adapte a la demanda térmica del edificio y a las condiciones climatológicas. Para ello, se proponen diferentes estrategias de control, las cuáles son descritas, desarrolladas, implementadas y evaluadas a lo largo de este trabajo de investigación.

La optimización de cualquier sistema requiere un amplio estudio de su comportamiento, analizando concienzudamente todas las variables y parámetros implicados en su funcionamiento. Por tanto, el primer paso llevado a cabo es el análisis de los días típicos de funcionamiento de la instalación, pero también su comportamiento a más largo plazo, a partir de los datos experimentales recogidos.

En segundo lugar, y como paso previo al desarrollo de las estrategias de optimización, es importante analizar la configuración óptima del sistema de acuerdo con los objetivos perseguidos. Este objetivo incluye el estudio de la posición del sensor de temperatura empleado para el control y del depósito de inercia, así como el dimensionamiento adecuado de este depósito.

Finalmente, una vez se ha analizado en profundidad el funcionamiento del sistema, los componentes del mismo son lo más eficientes posible, y éstos han sido conectados de manera adecuada, el objetivo final es el desarrollo de estrategias de control y optimización energética que optimicen la operación de la instalación experimental de bomba de calor geotérmica. Estas estrategias se dirigen principalmente a la optimización del sistema completo. El objetivo no es optimizar el funcionamiento de cada componente de manera 
individual, sino optimizar el comportamiento energético del sistema trabajando como un todo.

En este sentido, se desarrolló una primera metodología que combinaba la compensación de la temperatura de consigna de la bomba de calor en función de la temperatura ambiente exterior, y la variación de la frecuencia de las bombas de circulación (y por tanto el caudal de agua) en función de la carga térmica del edificio. La aplicación de esta primera estrategia resultó en una importante mejora del rendimiento energético, pero también en la pérdida de confort en algunas de las oficinas climatizadas cuando las condiciones climatológicas eran extremas durante el verano. En consecuencia, la metodología de control y optimización desarrollada fue mejorada dando como resultado un algoritmo global de optimización energética (que es el resultado final de esta tesis), el cual acopla ambas estrategias anteriores de manera que se cumpla el confort del usuario y se mantenga un ahorro de energía significativo.

En resumen, esta tesis doctoral proporciona un estudio experimental exhaustivo de la optimización energética de un sistema de bomba de calor geotérmica para la climatización de un edificio de oficinas. Los resultados experimentales para un año completo de funcionamiento del sistema muestran un ahorro de energía significativo en comparación con el modo de control de referencia, hasta un $35 \%$ en modo refrigeración y un $53 \%$ en modo calefacción, a la vez que se mantiene el confort de los usuarios. 


\section{Resum}

En un context de creixent preocupació per l'escalfament global i de polítiques energètiques internacionals, en el qual els sistemes de climatització en edificis representen una part important del consum energètic global, els sistemes de bomba de calor geotèrmica estan amplament considerats com una de les tecnologies de climatització més eficients disponibles en la actualitat pel que fa a la climatització d'espais. No obstant això, tant un bon disseny dels components com una operació òptima del sistema són de vital importància per tal que aquests sistemes puguen contribuir de manera significativa a atenuar el problema energètic global.

L'objectiu general d'aquesta tesi doctoral és el control i l'optimització energètica d'una instal-lació experimental de bomba de calor geotèrmica construïda a la Universitat Politècnica de València, fent que el sistema de control s'adapte a la demanda tèrmica de l'edifici i a les condicions climatològiques. Amb aquest objectiu, es proposen diferents estratègies de control, les quals són descrites, desenvolupades, implementades i avaluades al llarg d'aquest treball d'investigació.

L'optimització de qualsevol sistema requereix un ampli estudi del seu comportament, analitzant conscienciosament totes les variables i paràmetres implicats en el seu funcionament. Per tant, el primer pas duit a terme és l'anàlisi dels dies típics de funcionament de la instal-lació, però també el seu comportament a més llarg termini, a partir de les dades experimentals recollides.

En segon lloc, i com pas previ al desenvolupament de les estratègies d'optimització, és important analitzar la configuració òptima del sistema d'acord als objectius perseguits. Aquest objectiu inclou l'estudi de la posició del sensor de temperatura emprat pel control i del dipòsit d'inèrcia, així com el correcte dimensionament d'aquest dipòsit.

Finalment, una vegada s'ha analitzat en profunditat el funcionament del sistema, els components d'aquest són el més eficients possible, i han sigut connectats de manera adequada, l'objectiu final és el desenvolupament d'estratègies de control i optimització energètica les quals optimitzen l'operació de la instal-lació experimental de bomba de calor geotèrmica. Aquestes estratègies es dirigeixen principalment a l'optimització del sistema complet. L'objectiu no és optimitzar el funcionament de cada component de manera aïllada, sinó més bé optimitzar el comportament energètic del sistema treballant 
com un tot.

En aquest sentit, es va desenvolupar una primera metodologia que combinava la compensació de la temperatura de consigna de la bomba de calor en funció de la temperatura ambient exterior, i la variació de la freqüència de les bombes de circulació (i per tant del cabdal d'aigua) en funció de la càrrega tèrmica de l'edifici. L'aplicació d'aquest primer apropament va resultar en una important millora del rendiment energètic, però també en la pèrdua de confort en algunes de les oficines climatitzades quan les condicions climatològiques eren extremes durant l'estiu. En conseqüència, la metodologia de control i optimització desenvolupada va ser millorada resultant en un algoritme global d'optimització energètica (resultat principal d'aquesta tesi), el qual acobla ambdues estratègies anteriors de manera que es complisca el confort de l'usuari i es mantinga un important estalvi d'energia.

En resum, aquesta tesi doctoral proporciona un estudi experimental exhaustiu de l'optimització energètica d'un sistema de bomba de calor geotèrmica per la climatització d'un edifici d'oficines. Els resultats experimentals per un any complet de funcionament del sistema mostren un estalvi d'energia significatiu en comparació amb el mode de control de referencia, fins un $35 \%$ en mode refrigeració i un $53 \%$ en mode calefacció, a la vegada que es manté el confort dels usuaris. 


\section{Contents}

Acknowledgements iv

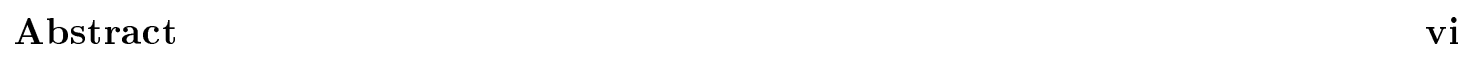

Resumen viii

Resum $\quad x$

$\begin{array}{lll}1 & \text { Introduction } & 1\end{array}$

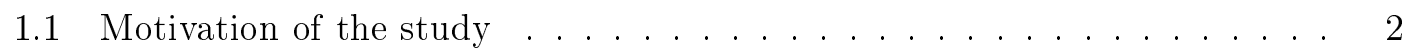

1.2 State of the art $\ldots \ldots \ldots \ldots \ldots \ldots \ldots \ldots$

1.3 Aim of the study $\ldots \ldots \ldots \ldots \ldots \ldots \ldots$

1.4 Structure of the thesis $\ldots \ldots \ldots \ldots$. . . . . . . . . . 8

\begin{tabular}{|lll}
2 & Description of the system and analysis of the system performance & 9
\end{tabular}

2.1 Description and characterization of the system . . . . . . . . . . 10

2.1 .1 Geothermal experimental plant. Background . . . . . . . . . . 10

2.1 .2 Geothermal experimental plant. Description . . . . . . . . . . . . . . . 10

2.1 .3 Data acquisition system . . . . . . . . . . . . . . . . . 22

2.2 Analysis of the system performance . . . . . . . . . . . . . . . . 24

2.2 .1 System variables $\ldots \ldots \ldots \ldots \ldots \ldots$

2.2 .2 Heat pump control . . . . . . . . . . . . . . . . . . . . 27

2.2 .3 Energy efficiency . . . . . . . . . . . . . . . . . . 36

2.2 .4 Partial load ratio . . . . . . . . . . . . . . . . . . . . . . . . 39

2.2 .5 Historical performance . . . . . . . . . . . . . . . . . . 48

2.2 .6 Short-term performance. Analysis of typical days . . . . . . . . . . 51

2.2 .7 Long-term performance. Analysis of yearly evolution . . . . . . . . 64

\begin{tabular}{|lll}
\hline & Energy optimization and control algorithms & 69
\end{tabular}

3.1 Introduction to energy optimization and control algorithms . . . . . . . . 70

3.2 Buffer tank sizing . . . . . . . . . . . . . . . . . . . . 70

3.2 .1 Theoretical approach $\ldots \ldots \ldots \ldots . \ldots \ldots 72$

3.2 .2 Manufacturers' guidelines review . . . . . . . . . . . . . 75 
3.2 .3 Results for buffer tank sizing . . . . . . . . . . . . . . . . . 81

3.3 Control sensor and buffer tank position . . . . . . . . . . . . . . . 84

3.3.1 Buffer tank position when the control sensor is on the return line . 85

3.3.2 Control sensor position when the buffer tank is on the supply line. 86

3.3.3 Results for control sensor and buffer tank position . . . . . . . . . 92

3.4 Compressor control . . . . . . . . . . . . . . . . . . . 93

3.4.1 Supply temperature control with sensor on the return line . . . . . 96

3.4 .2 Control board upgrade to control the supply temperature . . . . . 98

3.5 Temperature compensation . . . . . . . . . . . . . . . . . . 101

3.5 .1 Results for temperature compensation . . . . . . . . . . . 105

3.6 In situ optimization methodology for the water circulation pumps frequency 106

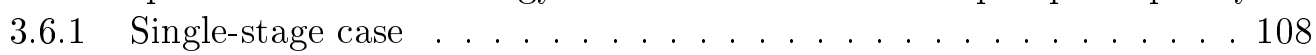

3.6.2 Multi-stage case . . . . . . . . . . . . . . . . . . . . . . . . . 114

3.7 Integrated control and optimization strategies . . . . . . . . . . . . . . . 125

3.7 .1 Temperature compensation and frequency variation: a first approach 126

3.7 .2 Upgrade to ensure user comfort . . . . . . . . . . . . . . . . . 133

3.7 .3 Results for upgrade to ensure user comfort . . . . . . . . . . . . . . 152

3.8 Implementation in the system control board . . . . . . . . . . . . . . . . . 161

\begin{tabular}{llr}
\hline & Conclusions & 169
\end{tabular}

4.1 Conclusions of this research work . . . . . . . . . . . . . . . . 170

4.2 Further research $\ldots \ldots \ldots \ldots \ldots$. . . . . . . . . . . . . . . . . . . 172

\begin{tabular}{lr}
\hline Bibliography & 173
\end{tabular}

$\begin{array}{lr}\text { Nomenclature } & 179\end{array}$

\begin{tabular}{lr}
\hline Appendixes & 184
\end{tabular}

\begin{tabular}{|l|l|}
\hline A Experimental correlations for the GROUND-MED heat pump & 185
\end{tabular}

\begin{tabular}{|ll}
\hline B Correlations for the effectiveness of the fan coil units & 187
\end{tabular}

$\begin{array}{ll}\text { C Publications derived from this research work } & 195\end{array}$

C.1 Scientific indexed journals publications . . . . . . . . . . . . . . . . . . 195

C.2 Workshops and conferences publications . . . . . . . . . . . . . 195 


\section{List of Figures}

$2.1 \quad$ Ground Source Heat Pump (GSHP) system schematic. . . . . . . . . . . . . 11

2.2 Department of Applied Thermodynamics building. . . . . . . . . . . . . . 12

2.3 Department of Applied Thermodynamics site plan. . . . . . . . . . . . . . . 13

2.4 Reversible ground source heat pump. Source: [53] . . . . . . . . . . . . . . 14

2.5 Ground Source Heat Exchanger (GSHX) diagram. . . . . . . . . . . . . 16

2.6 Circulation pumps performance curves as a function of frequency: (a) ICP flow rate; (b) ECP flow rate; (c) ICP power consumption; (d) ECP power

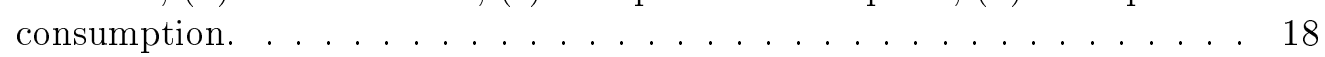

$2.7 \quad$ Original FCUs remote control. $\ldots \ldots \ldots \ldots$

2.8 FCUs hydraulic schematic. . . . . . . . . . . . . . . . . . 20

2.9 Ground Source Heat Pump (GSHP) system diagram. . . . . . . . . . . . . 23

2.10 Internal circuit temperatures variations in a typical cooling day. . . . . . . 28

2.11 Simplified building loop schematic. . . . . . . . . . . . . . . . . 29

2.12 Influence of the thermal load in the control temperature: (a) Low load cooling; (b) Low load heating; (c) Medium load cooling; (d) Medium load heating; (e) High load cooling; (f) High load heating. . . . . . . . . . . . 30

2.13 GROUND-MED heat pump control: (a) Cooling mode; (b) Heating mode. 33

2.14 Heat pumps control comparison. . . . . . . . . . . . . . . . 34

2.15 GROUND-MED heat pump control: temperature setpoint and tempera-

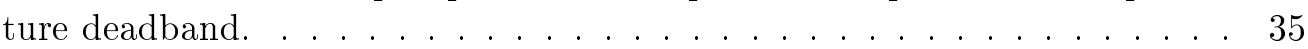

2.16 Deterioration of the DPF in a typical cooling day. . . . . . . . . . . 39

2.17 Control volumes proposed to determine the thermal load of the building. . $\quad 40$

2.18 Water temperature along the length of the building loop (cooling mode). . 41

2.19 Different approximations to determine the thermal load of the building:

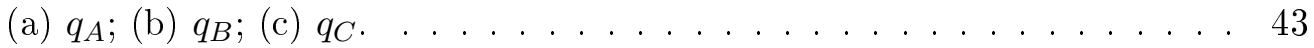

2.20 Thermal load of the building $\left(q_{A}\right)$ filtered with a moving mean of period 14. 44

2.21 Heat pump operation state for the GROUD-MED heat pump. . . . . . . . 46

2.22 Relation between $\alpha_{1}$ and $\alpha$ as a function of the operation state $(n)$. . . . 48

2.23 System water temperatures in cooling mode: (a) Low load $(2012 / 10 / 18)$; (b) Medium load (2013/06/13). . . . . . . . . . . . . . . . 52

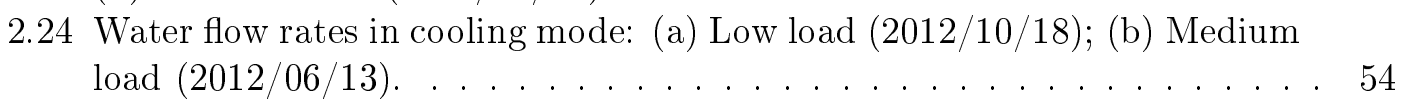


2.25 Cooling capacity: (a) Low load (2012/10/18); (b) Medium load (2012/06/13). 55

2.26 Power consumption in cooling mode: (a) Low load $(2012 / 10 / 18)$; (b) Medium load $(2012 / 06 / 13) . \ldots \ldots \ldots \ldots \ldots 6$

2.27 High load day in cooling mode (2012/07/10): (a) System temperatures;

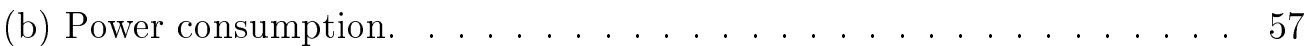

2.28 Different load ratios in cooling mode: (a) Low load (2012/10/18); (b) Medium load (2012/06/13); (c) High load (2012/07/10). . . . . . . . . . 58

2.29 System water temperatures in heating mode: (a) Low load $(2012 / 10 / 31)$; (b) Medium load $(2012 / 12 / 20) . \ldots \ldots \ldots \ldots \ldots$. . . . . . . . 59

2.30 Water flow rates in heating mode: (a) Low load (2012/10/31); (b) Medium

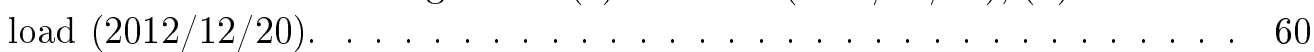

2.31 Heating capacity: (a) Low load (2012/10/31); (b) Medium load (2012/12/20). 61

2.32 Power consumption in heating mode: (a) Low load $(2012 / 10 / 31)$; (b)

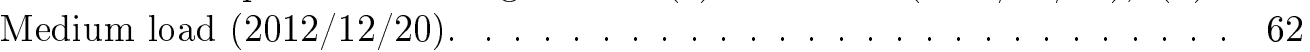

2.33 Different load ratios in heating mode: (a) Low load (2012/10/31); (b)

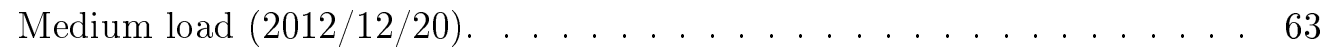

2.34 System water temperatures from 2011 to 2015: (a) External circuit; (b) Internal circuit. . . . . . . . . . . . . . . . . . 65

2.35 System thermal loads from 2011 to 2015: (a) Thermal load in MJ; (b) Partial load ratio $(\alpha) . \ldots \ldots \ldots \ldots \ldots 6 \ldots \ldots \ldots \ldots$

2.36 Heat pump capacity from 2011 to 2015 . . . . . . . . . . . . . . . 67

2.37 Daily performance factors $\left(D P F_{1}\right.$ to $\left.D P F_{4}\right)$ from 2011 to 2015 . . . . . . 68

3.1 Different connection principles: (a) Tank return; (b) Tank supply; (c)

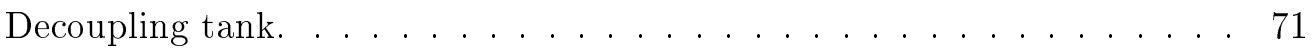

3.2 Example of required system volume as a function of the partial load ratio for a $20 \mathrm{~kW}$ heat pump. . . . . . . . . . . . . . . . 75

3.3 Control sensor located on the return line. . . . . . . . . . . . . . . . 85

3.4 Tank located on the supply line. . . . . . . . . . . . . . . . 86

3.5 Internal circuit temperatures for different values of $\alpha$ with control sensor on supply line: (a) $\alpha=0.2$; (b) $\alpha=0.5$; (c) $\alpha=0.8$. . . . . . . . . . 87

3.6 Internal circuit temperatures for different values of $\alpha$ with control sensor on return line: (a) $\alpha=0.2$; (b) $\alpha=0.5$; (c) $\alpha=0.8$. . . . . . . . . . 89

3.7 Internal circuit temperatures for different values of frequency with control sensor on return line: (a) freq. $=50 \mathrm{~Hz}$; (b) freq. $=20 \mathrm{~Hz}$. . . . . . . 90

3.8 Sensor supply vs. sensor return. . . . . . . . . . . . . . . 91

3.9 Variation of the supply building temperature with $\alpha$ and the internal fre-

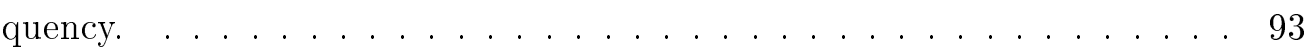

3.10 Experimental values of the internal circuit temperatures for different days with different thermal loads: (a) Low thermal load (2012/10/18); (b) High thermal load $(2012 / 09 / 18) . . \ldots \ldots \ldots \ldots \ldots \ldots$

3.11 Numeric example of the GROUND-MED heat pump control: (a) Cooling mode; (b) Heating mode. . . . . . . . . . . . . . . . . . . 95 
3.12 Experimental values of the internal circuit temperatures for different days with different thermal loads applying corrected temperature setpoint: (a)

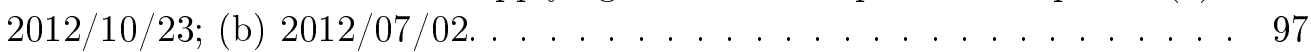

3.13 GROUND-MED heat pump control after upgrading the heat pump controller: (a) Cooling mode; (b) Heating mode. . . . . . . . . . . . . . . 99

3.14 GROUND-MED heat pump control after upgrading the heat pump controller: experimental results for cooling mode $(2013 / 07 / 09)$. . . . . . . . . 100

3.15 Temperature compensation (outdoor temperature reset) curve for cooling

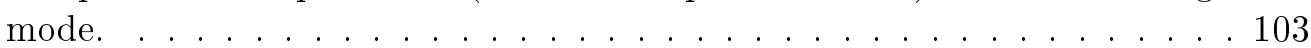

3.16 Temperature compensation (outdoor temperature reset) curve for heating

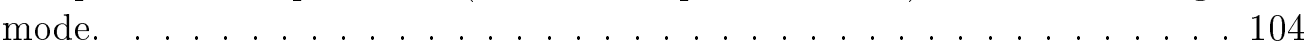

3.17 Experimental results after applying temperature compensation (outdoor temperature reset): (a) Cooling mode $(2014 / 05 / 26)$; (b) Heating mode

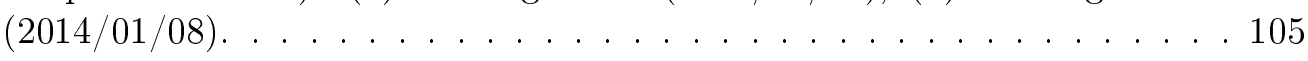

3.18 Influence of the water circulating flow rate on the heat pump and system

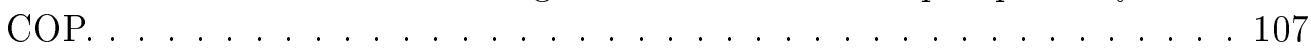

3.19 Frequency variation strategy in heating mode. Source: $|61|$. . . . . . . . 108

$3.20 \mathrm{COP}_{\text {sys }}$ quasi-steady state maps as a function of pump frequency: (a) Heating mode; (b) Cooling mode. Source: $\mid 61 \| \ldots \ldots$. . . . . . . 110

$3.21 P F_{\text {sys }}$ maps as a function of pumps frequency for cooling mode (singlestage case): (a) $\alpha=0.8$; (b) $\alpha=0.5$; (c) $\alpha=0.2$; (d) $\alpha=0.1$. Source: $\mid 61 \| 112$

$3.22 P F_{\text {sys }}$ maps as a function of pumps frequency for heating mode (singlestage case): (a) $\alpha=0.8$; (b) $\alpha=0.5$; (c) $\alpha=0.2$; (d) $\alpha=0.1$. Source: $[61] \mid 113$

3.23 Optimal frequencies for heating and cooling mode operation at different partial load ratios. Source: $[61]] \ldots \ldots \ldots \ldots \ldots$. . . . . . . . . . . . . .

3.24 Flowchart for the in situ optimization methodology. . . . . . . . . . . . . 115

3.25 Example of a possible test for the variation of the circulation pumps frequency for a two tandem compressors heat pump unit. . . . . . . . . . . 116

$3.26 C O P_{\text {sys }}$ quasi-steady state maps as a function of pumps frequency (tandem case): (a) Heating 1 compressor; (b) Heating 2 compressors; (c) Cooling 1 compressor; (d) Cooling 2 compressors. . . . . . . . . . . . . 117

$3.27 P F_{\text {sys }}$ maps as a function of pumps frequency for cooling mode (tandem case): (a) $\alpha=0.1$; (b) $\alpha=0.3$; (c) $\alpha=0.5$; (d) $\alpha=0.8$. . . . . . . . . 120

$3.28 P F_{\text {sys }}$ maps as a function of pumps frequency for heating mode (tandem case): (a) $\alpha=0.1$; (b) $\alpha=0.3$; (c) $\alpha=0.5$; (d) $\alpha=0.8$. . . . . . . . . 121

3.29 Circulation pumps frequency as a function of the partial load ratio (tandem case): (a) ICP heating; (b) ECP heating; (c) ICP cooling; (d) ECP cooling.

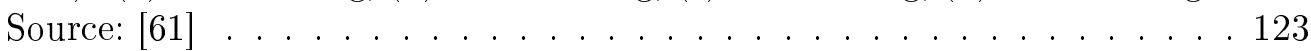

3.30 Experimental results after applying frequency variation: (a) Cooling mode (2014/05/26); (b) Heating mode $(2014 / 01 / 08) . \ldots \ldots$. . . . . . . 123

3.31 Proposed test for the variation of the circulation pumps frequency for a multi-stage heat pump unit with $N$ compressors. . . . . . . . . . . . . 125

3.32 Flow diagram of the optimized control first approach (cooling mode). . . . 126 
3.33 Experimental results of the integrated control first approach (cooling mode). 128

3.34 Experimental results of the integrated control first approach (heating mode). 129

3.35 Daily performance factor (first approach): (a) cooling mode test campaign; (b) heating mode test campaign. . . . . . . . . . . . . . 131

3.36 Seasonal performance factor (first approach): (a) cooling mode test campaign; (b) heating mode test campaign. $\ldots \ldots \ldots \ldots$. . . . . . . 132

3.37 Fan coil effectiveness in cooling mode. . . . . . . . . . . . . . . . . 134

$3.38 P_{3}$ as a function of $f_{I C P}$ for optimal $f_{E C P}$ (cooling mode). . . . . . . 138

3.39 (a) $P F_{\text {sys }}$ as a function of $T_{S B}$; and (b) $\partial P F_{\text {sys }} / \partial T_{S B}$ as a function of $T_{S B}$ (both for cooling mode). $\ldots \ldots \ldots \ldots \ldots \ldots \ldots \ldots$

3.40 Optimal value of $f_{I C P}$ (cooling mode). . . . . . . . . . . . . . . . . 140

3.41 Resulting optimal $f_{I C P}$ with the new control compared to the former one (cooling mode). . . . . . . . . . . . . . . . 141

3.42 Resulting optimal $T_{S B}$ with the new control compared to the former one (cooling mode). . . . . . . . . . . . . . . . . . 142

3.43 Control surfaces for $f_{I C P}$ (cooling mode). . . . . . . . . . . . . . . 143

3.44 Flow diagram of the new optimized control (cooling mode). . . . . . . . 144

$3.45 P F_{3}$ as a function of $f_{I C P}$ for optimal $f_{E C P}$ (heating mode). . . . . . 146

3.46 (a) $P F_{\text {sys }}$ as a function of $T_{S B}$; and (b) $\partial P F_{\text {sys }} / \partial T_{S B}$ as a function of $T_{S B}$ (both for heating mode). . . . . . . . . . . . 147

3.47 Optimal value of $f_{I C P}$ (heating mode). . . . . . . . . . . . . . 148

3.48 Resulting optimal $f_{I C P}$ with the new control compared to the former one (heating mode). . . . . . . . . . . . . . . . . . . 149

3.49 Resulting optimal $T_{S B}$ with the new control compared to the former one (heating mode). . . . . . . . . . . . . . . . 150

3.50 Control surfaces for $f_{I C P}$ (heating mode). . . . . . . . . . . . . . . 151

3.51 Flow diagram of the new optimized control (heating mode). . . . . . . . . 152

3.52 Experimental results of the upgraded integrated control (cooling mode). .154

3.53 Experimental results of the upgraded integrated control (heating mode). .155

3.54 Room temperature and relative humidity measurements on a typical cooling day: (a) Values with the former control algorithm; (b) Values with the

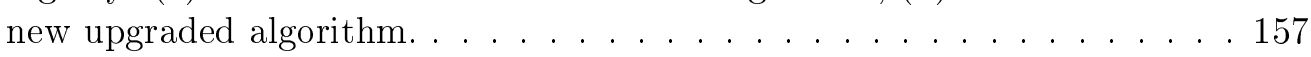

3.55 Daily performance factor (upgrade): (a) cooling mode test campaign; (b) heating mode test campaign. $\ldots \ldots \ldots \ldots \ldots \ldots \ldots$

3.56 Seasonal performance factor (upgrade): (a) cooling mode test campaign; (b) heating mode test campaign. . . . . . . . . . . . . . . . 160

3.57 Control system schematic. . . . . . . . . . . . . . . . . . . . . . 161

3.58 Control system GUI (Graphic User Interface). . . . . . . . . . . . . . . . 162

3.59 Simplified flow diagram of the main LabVIEW ${ }^{\mathbb{R}}$ program. . . . . . . . . . 163

3.60 Sample of the main LabVIEW ${ }^{\mathbb{R}}$ program. . . . . . . . . . . . . . 165

3.61 Different types of cycles performed by the GROUD-MED heat pump. . . . 166

B.1 Technical data screen in software Elite $\left.{ }^{(}\right)$. . . . . . . . . . . . . 188 
B.2 Utilization conditions screen in software Elite ${ }^{\circledR}$. . . . . . . . . . . . . . . . 188

B.3 Solutions screen in software Elite ${ }^{\circledR}$. . . . . . . . . . . . . . . . . . . . . 189

B.4 Fan coil effectiveness in cooling mode. . . . . . . . . . . . . . . . . . . 190

B.5 Correlations for the fan coil effectiveness in cooling mode. . . . . . . . . . 191

B.6 $\quad$ Fan coil effectiveness in heating mode. . . . . . . . . . . . . . . . . . . 192

B.7 Correlations for the fan coil effectiveness in heating mode. . . . . . . . . 193 


\section{List of Tables}

2.1 Original FCUs performance characteristics. . . . . . . . . . . . . . . . . . 19

2.2 New FCUs performance characteristics. . . . . . . . . . . . . . . . 20

3.1 Summary of guidelines from manufacturers and installers. . . . . . . . . . 80

3.2 Minimum system volume in terms of the heat pump capacity (example use of a $20 \mathrm{~kW}$ heat pump with a single compressor). . . . . . . . . . . . 82

$3.3 \quad$ Possibilities for buffer tank and control sensor position. . . . . . . . . . . . 84

A.1 Coefficients of the polynomial correlations for the GROUND-MED heat

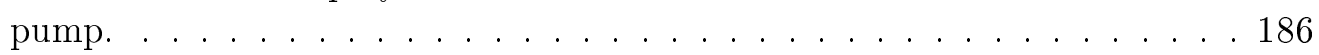




\section{Chapter 1}

\section{Introduction}

The introductory chapter to this $\mathrm{PhD}$ dissertation presents the motivation of the study, analyses the state of the art on the topic, states the aim of the study and finally presents the structure of the dissertation. 


\subsection{Motivation of the study}

The world is facing unprecedented challenges resulting from increased dependence on energy, scarce energy resources, and the need to limit climate change and to overcome the economic crisis. Both renewable energy and energy efficiency are a valuable means to address these challenges. Aware of that, the European Union started to agree many years ago, and with more intensity from the nineties onwards, several targets towards a sustainable development. These targets included the reduction in greenhouse gas emissions, the use of renewable energies and the efficient use of energy resources, among others. This awareness was materialized mainly through different energy policies and an increasing investment for research in energy related topics.

In the regulatory field, European Directives such as 2001/77/EC, 2003/30/EC, 2009/28/EC, 2004/8/EC, 2006/32/EC, 2009/125/EC, 2010/31/EU or 2012/27/EU, among many others, have provided guidelines and targets on fields like energy efficiency and use of energy from renewable sources. Moreover, these directives have been continuously revised, giving rise to new ones, amending or repealing previous ones. Based on these directives, each Member State has implemented these objectives at national level, including them in their National Reform Programmes. In Spain, this implementation has included strategies and action plans such as the Plan de Acción de Ahorro y Eficiencia Energética (PAE) and the Plan de Energías Renovables (PER) revised for different periods (2000-2005, 2005-2010 and 2011-2020).

These concerns have been reflected in the investment efforts, which have been progressively increasing, creating a Strategic Energy Technology Plan (SET-Plan) [1]. Through investment programmes such as FP5 (1999-2001), FP6 (2002-2006) and FP7 (2007-2013) (Fifth, Sixth and Seventh Framework Programmes respectively), and earlier programmes stretching back to 1990, the European Union has expressed its commitment to contribute to a sustainable development [2]. The current programme, known as Horizon 2020 (H2020), is the biggest EU Research and Innovation programme ever with nearly 80 billion Euro of funding available over 7 years (2014 to 2020). In all these investment programmes, sustainable energy systems have been considered as one of the top priorities for research. The current program, H2020, establishes the following targets in this field to be attained by year 2020: greenhouse gas emissions reductions of $20 \%$ compared to 1990 levels, a share of renewable energy consumption of $20 \%$ and improvements in energy efficiency of $20 \%$. For year 2030 the targeted percentages are even higher: $40 \%$ for the greenhouse gas emissions reduction, $27 \%$ for the share of renewable energy and $27 \%$ for the improvement in energy efficiency.

In brief, the European Union is creating binding regulations so that each Member State contribute to attenuate the energy problem. This concern has been reflected in their policies in the years prior to the fulfillment of this PhD dissertation and continues to be of paramount importance nowadays, as included in the EU official website as one of the top 10 priorities for the European Commission [3]. Actually, the worry for the energy 
problem has become even more demanding in the last years.

\subsection{State of the art}

In a context of global warming concern and global energy policies, renewable energies are playing an important role in order to solve or at least attenuate the global energy problem. In terms of electricity generation, they are already making an important contribution. According to the Spanish Institute for Diversification and Saving of Energy (IDAE) on its Plan de Energías Renovables 2011-2020, in 2010 the contribution of renewable energies to the total electricity generated in Spain was $33.3 \%$ [4].

Nevertheless, there are other sectors, which represent an important primary energy consumption, which can be upgraded by using renewable energies and by applying measures of energy efficiency. This is the case of heating and cooling in buildings. According to the International Energy Agency, buildings account for almost a third of the final global energy consumption, and they are an equally important source of $\mathrm{CO}_{2}$ emissions [5]. In the European Union, buildings account for $40 \%$ of total energy consumption [6]. The sector is expanding, which is bound to increase its energy consumption. Therefore, reduction of energy consumption and the use of energy from renewable sources in the buildings sector constitute important measures needed to reduce the greenhouse gas emissions.

In particular, heating, ventilating and air-conditioning systems (HVAC) are estimated by the International Energy Agency to account for roughly half of global energy consumption in buildings [5]. When it comes to space heating and cooling, shallow geothermal energy, as a renewable energy source, provides an interesting technology: ground source heat pump (GSHP) systems. GSHP systems use the ground as a heat source or heat sink, depending on the season, in order to provide buildings with heating and cooling more efficiently from the point of view of electricity consumption. These systems are widely considered as being among the most efficient and comfortable heating and cooling renewable technologies currently available.

In recent years, many GSHP systems have been built in different countries around the world. Traditionally, GSHP systems have been used in systems where only heating was required, such as those presented in [7], [8], [9], [10] and [11]. In these systems, an alternative heat source, such as solar thermal energy, is required in order to heat up the ground during summer so that it is thermally balanced [12]. Some years ago, GSHP systems started being used in places with a considerable cooling demand. In this case, the ground thermal balance should be guaranteed by a correct design of the system. Some examples of GSHP systems in cooling dominated areas are presented in [13], [14] and [15]. Another example is the installation studied in the present PhD work, which was built in Valencia (Spain) in the framework of GEOCOOL project [16], whose main objective was the development of a commercial size, economic, energy efficient and environmentally friendly, fully integrated turnkey GSHP system for cooling and heating, 
targeted specifically at coastal applications in the Southern European region.

A GSHP system consists mainly of the ground heat exchanger, the heat pump and the terminal units. In addition, some auxiliary equipment is needed, such as circulation pumps. In brief, a GSHP system is an HVAC system in which the heat pump exchanges heat with a heat exchanger built below ground. Therefore, most of the research on HVAC systems can be considered for GSHP systems.

GSHP systems have proved to be more efficient than conventional air-to-water heat pumps, as demonstrated in [17], [18] and [19]. As presented by Urchueguía et al. [19], GSHP systems can lead to a $40 \%$ savings in annual electricity consumption, in comparison to air to water conventional heat pumps. Nevertheless, one of the main disadvantages of ground source heat pumps is their high economic cost. Therefore, a reduction in both construction and operation costs is required for these systems to be successful, above all in Spain where the market of GSHP systems has not taken off yet. Optimizing the energy consumption in these systems becomes thus of paramount importance.

A possible approach to saving energy in GSHP installations is to combine it with another thermal source, in the case of heating dominated areas, such as solar thermal energy as reported in [20], [21] and [22]. In the case of heating and cooling systems, a common practice is to combine ground source heat pumps with thermal energy storage, mainly by means of phase change materials, as in the examples described in [23], [24] and [25]. In fact, both a hybrid system and a thermal storage device can be combined as described in [26]. However, this is not always possible and it contributes to increase the economic cost of the system.

Another possible strategy, which provides considerable energy savings is energy management through scheduling techniques. Haniff et al. [27] presented a review of different scheduling techniques that can be used in HVAC systems in buildings in order to improve its energy efficiency. Escrivá-Escrivá et al. [28] reported reductions in energy consumption of about $15-20 \%$ by applying an integral management system at the Polytechnic University of Valencia. In [29], Huang et al. evaluated a control strategy including five energy management control (EMC) functions on a simulation platform, reporting energy savings of $17 \%$.

This research work focuses however on maximizing the energy performance in GSHP systems by different means. On the one hand, an optimal design of the system components and the configuration of the system is targeted. On the other hand, and more importantly, an optimal operation of the system working as a whole, which makes it adaptive to the real working conditions, such as the thermal demand or the weather conditions, is also targeted.

In order to achieve an optimal system energy performance, the first step is to have a good design based on the optimal selection of components. Once the installation is designed, the second step consists of building it correctly. Finally, the third step is to run the system in order to obtain a good operation. When it comes to system operation in 
GSHP systems, commercial installations are normally designed to cover peak thermal loads. However, they usually work at lower loads over the course of a heating or cooling season, which can degrade the energy performance of the system as highlighted by Henze and Floss in [30]. In order to save energy, some systems are designed to cover base loads and use a backup system for the peaks.

Alternatively, one of the best ways to achieve an optimal operation is allowing to adapt the performance of the system to the thermal demand of the building, as pointed out in [31] and [32]. In order to achieve that, different control and optimization strategies can be developed in such a way that the system would operate at its optimal point hence improving its energy performance.

Over the last years, research has focused on capacity control, mainly by means of variable speed compressors. For instance, in [33] and [34], Fahlén and Karlsson compared control for $\mathrm{ON} / \mathrm{OFF}$ compressor with variable speed control for a brine-to-water heat pump. In [35], Zhao et al. performed both a theoretical and an experimental analysis in order to match the capacity of a geothermal heat pump system, which used as a low temperature heat source the geothermal discharge water, with the actual load requirement by adjusting the compressor rotation speed by means of a transducer. Lee [36] reported a reduction of $27 \%$ at least in the compressor energy input when adopting a variable-speed part-load control to the GSHP in both the cooling and heating mode operations. Madani et al. [37] carried out a comparative analysis between $\mathrm{ON} / \mathrm{OFF}$ controlled and variable capacity GSHP systems. In [38], the same author carried out a comparative analysis of three common control strategies for an ON/OFF controlled ground source heat pump system.

Several studies by Bernier and Bourret [39], Brodrick and Westphalen [40] and Bahnfleth and Peyer [41] highlighted the important amount of energy consumed by the auxiliaries (such as water circulation pumps) in air conditioning systems and the necessity of reducing this energy consumption, above all in GSHP systems in which two circulation pumps are required. In the Ph.D. work by Karlsson [42], a theoretical study showed that there is a potential for applying an optimization method for keeping the compressor and pump speeds at the optimal combination. The key point to find this optimal combination is to consider the pump circulation rates optimizing the total power consumption of the system and not only the heat pump power consumption. In [43], Granryd presented analytical expressions for possible optimum flow rates on the secondary loop.

In the search for an optimal energy performance of GSHP systems by means of control and energy optimization strategies which target the system working as a whole, instead of targeting each individual component, many studies have approached the issue through simulation models and platforms. In [31], Fraisse et al. presented a new controller based on fuzzy logic which took into account both the thermal state of buildings and the outdoor ambient temperature. Fong et al. [44] described a strategy to control the chilled water temperature and the supply air temperature by means of evolutionary programming, reporting an energy savings potential of about $7 \%$ as compared to the existing operational settings. Corberán et al. [45] carried out several analyses in order to examine GSHP 
system capacity and performance sensitivity to different control strategies, including control of room air temperature and water supply temperature to a fan coils distribution circuit in an office building. In [46], Pardo et al. tested in a GSHP system a control strategy which included the management of airflow in the fan coil, the water mass flow in the internal and external hydraulic systems, and the setpoint temperature in the heat pump and estimated energy savings around 30\% were obtained. Edwards and Finn [47] evaluated a control strategy to obtain optimal water flow rates under part load operation in single speed and tandem speed GSHP simulation models in both heating and cooling mode. An increase of between $20 \%$ and $40 \%$ in the seasonal system performance was reported when using the optimal strategy. In [48] and [49], Del Col et al. developed an integrated control strategy, including the variation of compressor speed, water pumps speed, fan coils speed and heat pump temperature setpoint, which was partly based on experimental measurements. However, this control strategy developed was evaluated by means of a dynamic model of the GSHP system and not experimentally in a real GSHP installation. So, specific real values of energy savings or system energy performance improvement were not reported.

The use of simulation models may be very useful in optimization studies, above all during the first steps of the study. It allows carrying out different kinds of analysis without affecting the real installation and therefore avoiding possible damages. However, even with a very detailed model, it is not possible to take into account the wide group and variety of parameters which in practice affect the performance of a GSHP installation, as for instance, the users' daily activity, the real ambient temperature variations along the day or the actual heat transfer to the ground. For that reason, an energy optimization study carried out directly on the experimental installation will be able to take into consideration the real characteristics and the real operating conditions of the system, which will turn into a more accurate way of analyzing the impact of energy optimization strategies in the performance of the system, as well as in determining the energy savings obtained.

Fewer studies have approached the issue of energy optimization of GSHP systems experimentally. It is in this context that GROUND-MED project [50] was conceived, aiming at demonstrating the next generation of GSHP systems for heating and cooling in 8 demonstration sites of South Europe. One of those demonstration sites in GROUND-MED project was the installation built in Valencia during GEOCOOL project [16].

The main target of GROUND-MED project was to achieve a measured seasonal performance (SPF) higher than 5. As established in the definition of the project, the SPF is determined not only by the heat pump unit, but by its operating conditions imposed by both the ground heat exchanger and the heating/cooling system of the building. Therefore, GROUND-MED project aimed at develop, design, construct, install, monitor and evaluate integrated GSHP systems incorporating the following technological solutions:

1. prototype water source heat pumps of improved seasonal efficiency; key technologies include the next generation of compressors, heat exchangers and automation; 
2. borehole heat exchangers and heating/cooling systems operating with minimum temperature difference between them, which also follows the heating/cooling demand from the building; design aspects, thermal storage and system controls are important;

3. minimum power consumption to auxiliary system components; key parts are the fan-coil and air-handling units.

This dissertation is framed in the framework of GROUND-MED project [51].

In this context of energy optimization of GSHP systems, both an optimal design of components and an optimal operation of the system as a whole become crucial so that the market gets off the ground in places where it is still lifeless, contributing to attain the targets established by the EU regulations, and to attenuate the global energy problem. Here it is that this PhD work comes into play, dealing with the control and energy optimization of ground source heat pump systems for heating and cooling in an experimental GSHP installation. In brief, this $\mathrm{PhD}$ work proposes, describes, develops, implements and evaluates a new integrated optimization strategy in order to make the GSHP system operate at its optimal point, which has been tested in situ in the experimental GSHP installation built during GEOCOOL project and upgraded during GROUND-MED project, obtaining significant energy savings when compared to the standard control operation, up to $35 \%$ in the summer season and $53 \%$ in the winter season, while keeping the user comfort.

\subsection{Aim of the study}

The main objective of this $\mathrm{PhD}$ dissertation is to perform the control and energy optimization of a GSHP system installed at the Universitat Politècnica de València, making the system adaptive to the thermal demand of the building and to the climate conditions. For that purpose, different control strategies need to be developed, implemented and tested in the system. In order to attain that main objective, different steps need to be followed.

First, understanding the performance of the system in detail. The optimization of any system requires a comprehensive study of its behaviour, by means of a thorough analysis of all the variables and parameters implied on its performance. Therefore, the first objective is to analyse the short-term performance of the system, but also the long-term performance based on the experimental data collected at the installation.

Second and prior to developing any optimization strategies, analysing the optimal configuration of the system according to the objectives targeted. The selection of efficient components and a proper connection of them is indeed the first step towards an optimal system, always restricted by the funding constraints of a real environment. This objective includes the study of the best location for the temperature control sensor and the 
buffer tank, as well as an adequate size for this buffer tank.

Finally, optimizing the operation of the experimental GSHP system. Once the behaviour of the system has been fully understood, the components of the system are the most efficient according to the possibilities of the research work and they have been connected adequately, the final objective is to develop control and optimization strategies. These strategies target the control of the heat pump compressor, but also and more importantly, the energy optimization of the complete system. The focus is not in optimizing the performance of each individual component, but in optimizing the energy performance of the system working as a whole.

In summary, this $\mathrm{PhD}$ work provides a comprehensive in situ study for the energy optimization of a GSHP system for both cooling and heating operation. Experimental results for a one-year operation period demonstrate important energy savings, up to $35 \%$ in the summer season and $53 \%$ in the winter season, while keeping the user comfort.

\subsection{Structure of the thesis}

This research work is structured in 4 chapters.

The introductory Chapter 1 presents the motivation of the study, analyses the state of the art on the topic, states the aim of the study and finally presents the structure of the dissertation.

Chapter 2 is divided in two parts. The first one focuses on the description and characterization of the geothermal plant. All the components of the GSHP system are described in detail in this chapter, including the data acquisition system. In the second part, the main variables and parameters of the system are introduced and the basic functioning of the heat pump control is described. Then, an analysis of both short-term and longterm performance of the geothermal system is carried out and experimental results are presented.

Chapter 3 stands for the main core of this PhD work. It includes all the control strategies developed in order to obtain the energy optimization of the GSHP system studied. Different subsystems susceptible of being optimized are analysed in Chapter 3 . Characteristics like the buffer tank sizing and the position of both the buffer tank and the control sensor are studied. Then, two alternatives to the common compressor ON/OFF control are presented. Finally, an integrated optimization strategy combining outdoor temperature reset and an in situ opimization methodology for the water circulation pumps frequency is presented for both single-stage and multi-stage heat pump units. Additionally, the implementation of these strategies in the control board of the system is included in this chapter.

Finally, Chapter 4 presents the conclusions of this research work and suggests possible lines for future research in the field. 


\section{Chapter 2}

\section{Description of the system and analysis of the system performance}

This chapter is separated in two main parts: the description of the system and the analysis of the system performance.

The first part describes the GSHP experimental installation studied in this $\mathrm{PhD}$ work, providing the characteristics of each component in the system. First, the background of the geothermal plant is summarized in Section 2.1.1. Then, the installation is briefly described in Section 2.1.2, before describing each component in detail, including the data acquisition system (section 2.1.3). In addition to this description, the characterization of the heat pump, the circulation pumps and the fan coils, is carried out in order to obtain mathematical expressions that can be employed within the energy optimization strategies developed in this dissertation at a later point.

The second part analyses the different variables and parameters related to the energy performance of the system. Firstly, the main variables of the system are presented in Section 2.2.1. After that, the heat pump control is described in detail for both singlestage and multi-stage cases (Section 2.2.2). Next, the evaluation of energy efficiency parameters such as the energy efficiency (Section 2.2.3) and the partial load ratio 2.2.4 is performed. Finally, the analysis of the experimental performance of the system from typical monitored data is carried out. The historical performance of the geothermal plant since it was firstly built is briefly described in Section 2.2.5, whereas the short-term and long-term performances are studied in Sections 2.2.6 and 2.2.7 respectively. 


\subsection{Description and characterization of the system}

\subsubsection{Geothermal experimental plant. Background}

The geothermal plant studied in this work was built in year 2004 during a European Fifth Framework project called GEOCOOL [16] at the Universitat Politècnica de València (Valencia Polytechnic University), Valencia, Spain. The main target of GEOCOOL was the development of a commercial size, economic, energy efficient and environmentally friendly, fully integrated turnkey ground source heat pump (GSHP) system for cooling and heating, targeted specifically at coastal applications in the South European region.

The design of the installation was carried out in Maria Teresa Magraner's PhD work [52], where the construction process of the installation and some preliminary performance studies were presented.

After GEOCOOL project finished, the research work in the geothermal plant continued under the European Seventh Framework Programme through another project called GROUND-MED [50], during years 2009 to 2014.

GROUND-MED project aimed at verifying the sustainability of heat pump technology for heating and cooling in buildings in a Mediterranean climate and to demonstrate the next generation of geothermal heat pump (GSHP) systems for heating and cooling. The main change in the geothermal experimental plant was the replacement of the former heat pump (single-stage ON/OFF controlled) with a new one consisting of two compressors of the same capacity working in tandem.

This dissertation is framed in the framework of GROUND-MED project.

\subsubsection{Geothermal experimental plant. Description}

The GSHP installation studied in this research work air-conditions a set of spaces in the Department of Applied Thermodynamics at the Universitat Politècnica de València, Valencia, Spain, with a total area of approximately $250 \mathrm{~m}^{2}$. The system provides both cooling and heating depending on the season: cooling mode from May to October and heating mode from November to April. All rooms are equipped with fan coil units (FCU) supplied by the GSHP system. The geothermal system consists of a reversible water-towater heat pump, a vertical borehole heat exchanger and two hydraulic groups, as shown in the diagram of the installation in Fig. 2.1.

As it can be observed in Fig. 2.1, the system can be divided into two main circuits: an internal circuit (or building loop) which consists of a series of 12 parallel connected fan coil units, an internal hydraulic loop and a water storage tank, and an external circuit (or ground loop) which consists of the ground source heat exchanger (GSHX) which is coupled to the heat pump by an external hydraulic loop. A timer controls the overall system operation, which was programmed to operate from $7 \mathrm{am}$ to $10 \mathrm{pm}$ (6am to $9 \mathrm{pm}$ 


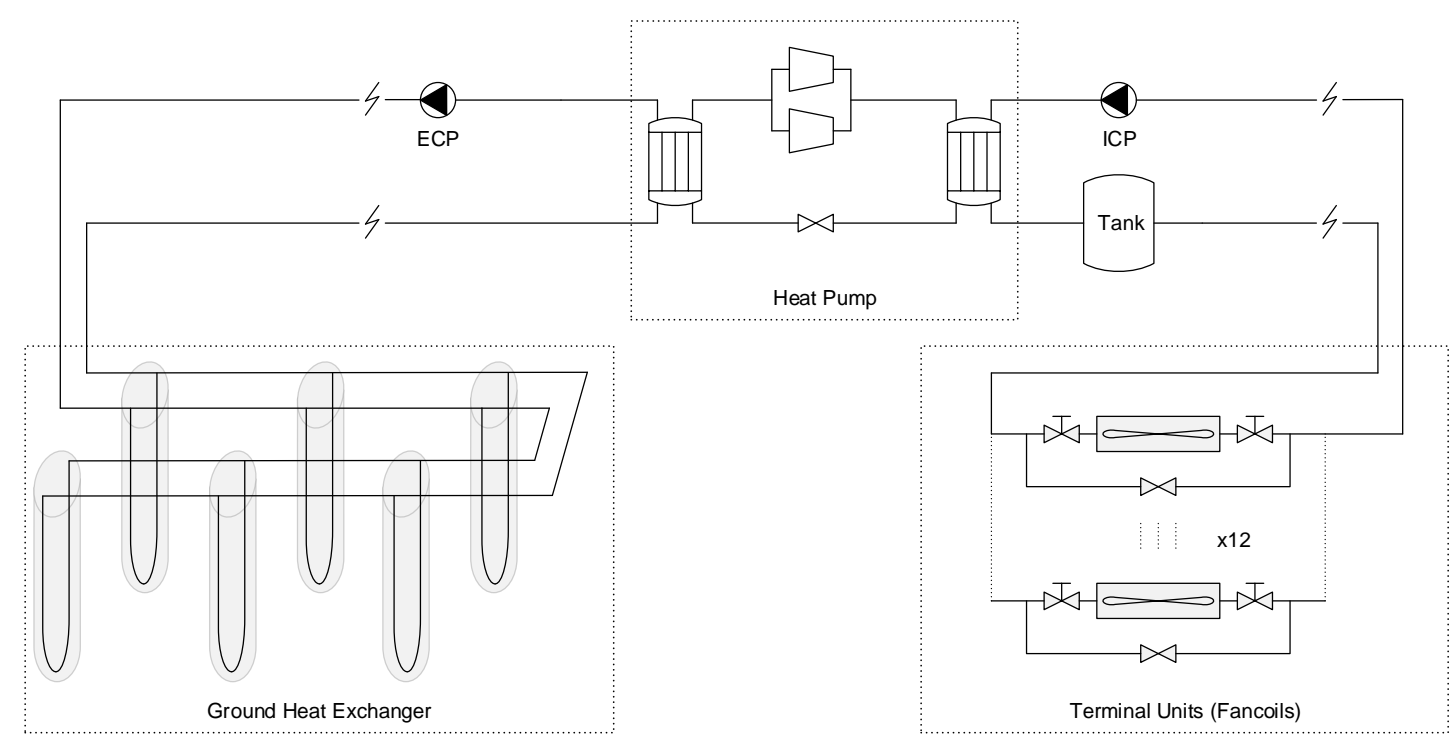

Figure 2.1: Ground Source Heat Pump (GSHP) system schematic.

in heating mode), 5 days per week (from Monday to Friday). The system is switched off during the weekends.

Both circuits, internal and external, are provided with circulation pumps which make the water circulate towards the fan coil units (FCU) and the GSHX. While the internal circulation pump (ICP) works continuously during the 15 hours per day of system operation, the external circulation pump (ECP) is controlled by the heat pump controller, which makes it work only when the compressor is running. Two frequency inverters, one for each circulation pump, were installed in order to vary the water flow rates in both the internal and the external circuit.

The main components of the system are explained in detail in the following subsections. 


\section{Building}

The thermal demand that the GSHP system has to cover depends on the weather conditions, the system users' daily activity and the features of the building. As previously stated, the building where the GSHP installation studied in this work was built (Fig. 2.2 is located at the Universitat Politècnica de València.

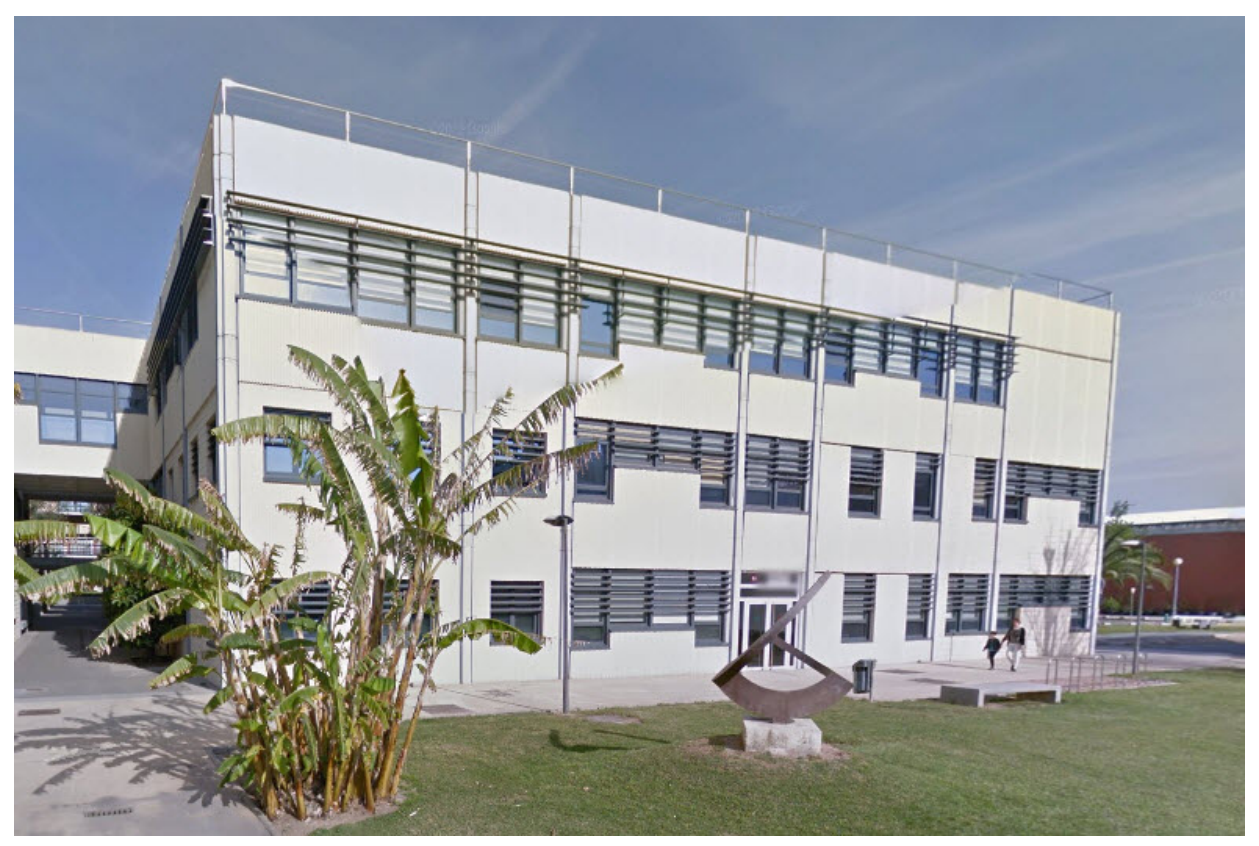

Figure 2.2: Department of Applied Thermodynamics building.

The air-conditioned zone is on the first floor of the building. It consists of nine offices belonging to the Department of Applied Thermodynamics, all of them located on the east façade of the building (R1-R9). A site plan of the zone is presented in Fig. 2.3. It also includes a corridor, a computer room $(\mathrm{CpR})$ and a common room with a photocopier and some office equipment $(\mathrm{CmR})$, both interior. Each office, along with the common room, is equipped with one fan coil, except for the computer room which has two installed fan coils. The corridor is not air conditioned. 


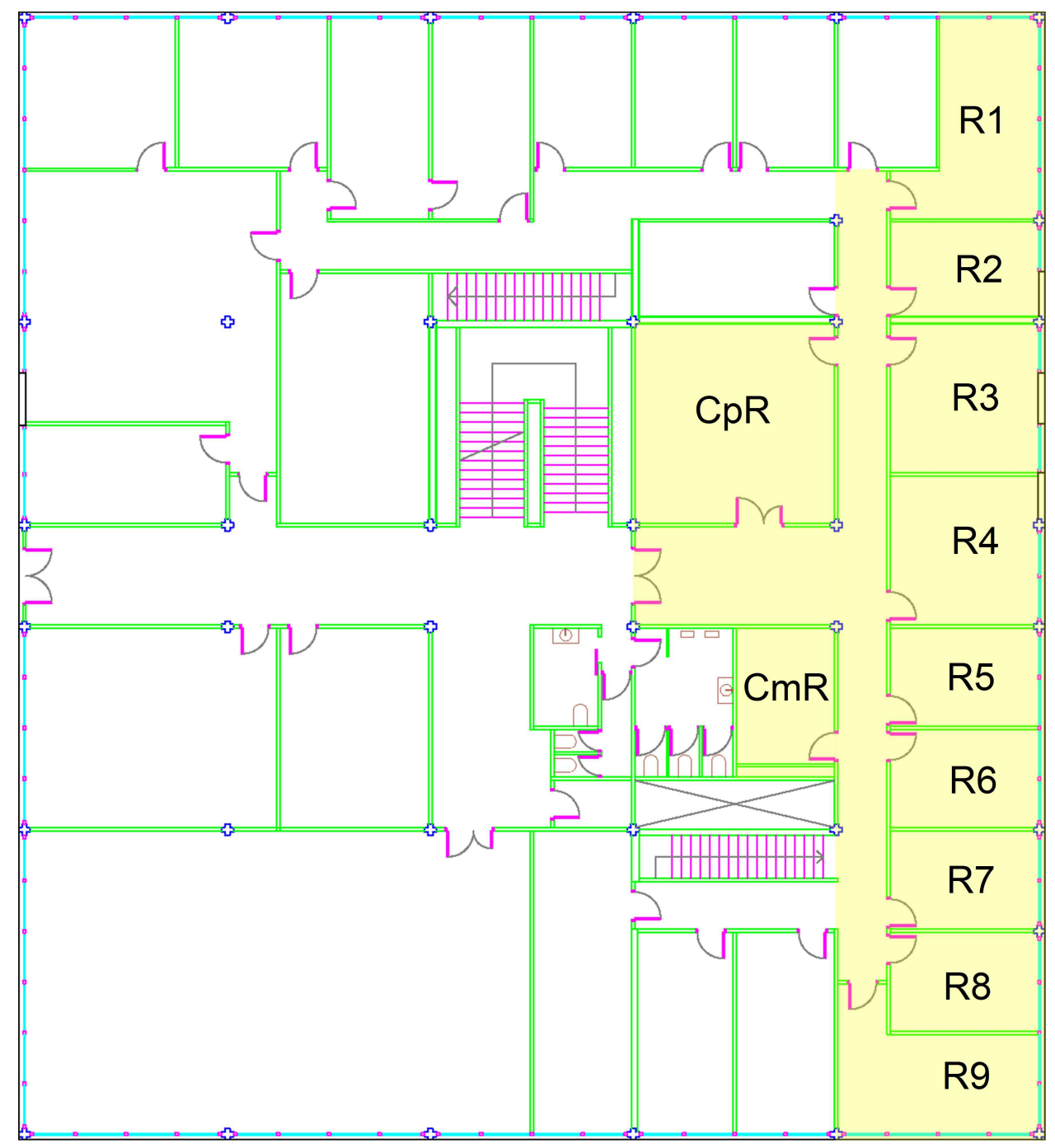

Figure 2.3: Department of Applied Thermodynamics site plan. 


\section{Heat pump}

As stated earlier, during GEOCOOL project the heat pump installed at the geothermal plant was a single-stage ON/OFF unit. However, at the beginning of GROUND-MED project, the former heat pump was replaced with a multi-stage ON/OFF unit with two compressors of the same capacity working in tandem. Both heat pumps are reversible water to water heat pumps. This means that they operate in cooling mode during summer (cooling season from May to October) and in heating mode during winter (heating season from November to April). Cooling mode presents the higher thermal load peaks, as it tipically happens in southern European countries. That is why cooling mode was considered for the design of the heat pump maximum capacity. For that reason, cooling mode will be considered, in general, more important throughout this $\mathrm{PhD}$ dissertation, and the explanations will be carried out firstly and mainly for cooling mode. Fig. 2.4 depicts how a reversible water to water ground source heat pump works.
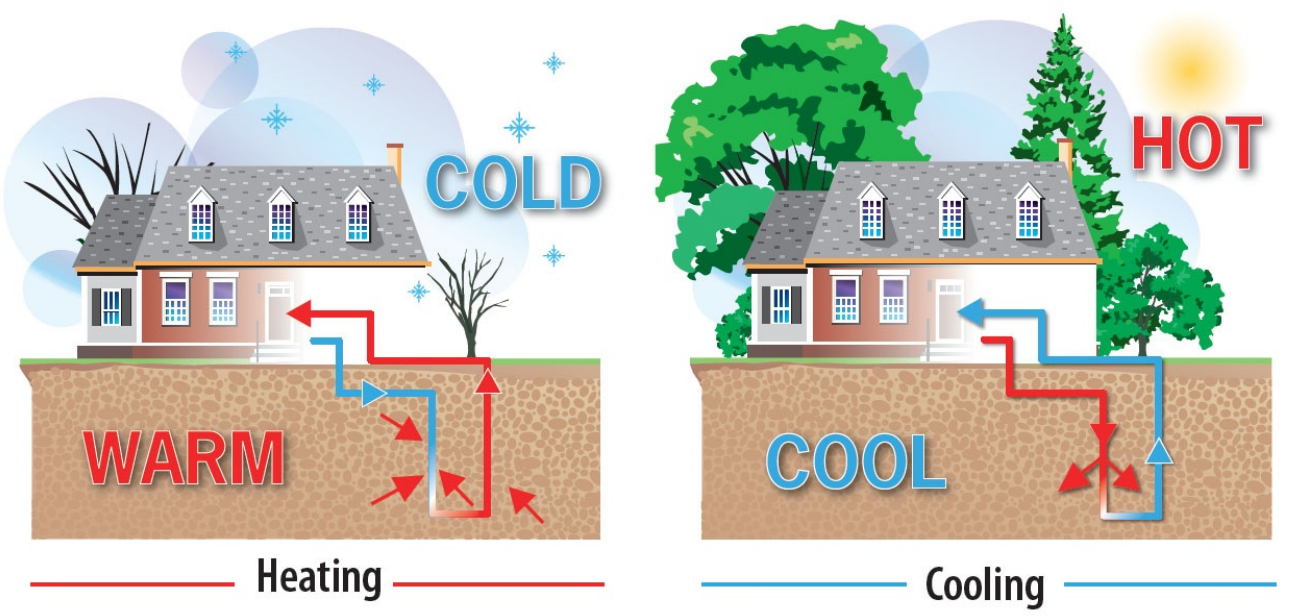

Figure 2.4: Reversible ground source heat pump. Source: [53]

As it can be observed in Figure 2.4, when the system is working in cooling mode, the system expels heat from the inside of the building to the ground. In this case, the useful heat is the cooling heat (cooling capacity of the heat pump). The evaporator is connected to the building loop, extracting heat from the offices and injecting it into the ground through the condenser, which is coupled to the ground loop.

On the other hand, when the system is working in heating mode, the system absorbs heat from the ground and carries it to the inside. The useful heat is the heat exchanged in the condenser (heating capacity of the heat pump). In this case, the evaporator is connected to the ground loop whereas the condenser is coupled to building loop. This means that heat is absorbed from the ground and delivered to the building in order to heat up the offices. 
- GEOCOOL heat pump

The heat pump (HP) installed in the geothermal plant during GEOCOOL project was a prototype developed by the Department of Applied Thermodynamics, based in model AUREA IZE-80, manufactured by CIATESA, upgraded by using propane as refrigerant. It was a reversible water to water heat pump with the following characteristics:

- Nominal capacity: cooling: $14.7 \mathrm{~kW}\left(14^{\circ} \mathrm{C} / 25^{\circ} \mathrm{C}\right.$ return $)$; heating: $17 \mathrm{~kW}$ $\left(35^{\circ} \mathrm{C} / 17^{\circ} \mathrm{C}\right.$ return $)$

- Hermetic scroll compressor, $97.7 \mathrm{~cm}^{3}, 2900 \mathrm{rpm}$, manufactured by Copeland

- Two plate heat exchangers, model Swep V80x26

- Two-way thermal expansion valve model TRE10 manufactured by Danfoss

- Four-way reversing valve Ranco ${ }^{\circledR}$

- Refrigerant gas: R290 (propane); $418 \mathrm{~g}$

- Electronic controller manufactured by Carel

The operation of the heat pump is controlled by the electronic controller, which switches on and off the compressor depending on the control temperature in order to keep it inside the thermostat band. Further explanation on how the temperature evolve is provided in section 2.2 .2

- GROUND-MED heat pump

In May 2011, in the framework of GROUND-MED project, the former GEOCOOL heat pump was replaced with a new unit manufactured by HiRef, an Italian manufacturer partner in the GROUND-MED project consortium. After carefully studying the optimal design of the heat pump for Valencia's installation, where the system works at part load during most of the year, it was decided that the best option was a reversible water to water multi-stage unit consisting of two compressors of the same capacity working in tandem [54].

The characteristics of the new heat pump are the following:

- Nominal capacity: cooling: $15.4 \mathrm{~kW}\left(14^{\circ} \mathrm{C} / 25^{\circ} \mathrm{C}\right.$ return $)$; heating: $18 \mathrm{~kW}$ $\left(35^{\circ} \mathrm{C} / 17^{\circ} \mathrm{C}\right.$ return $)$

- Two hermetic scroll compressors, $27.6 \mathrm{~cm}^{3}, 2900 \mathrm{rpm}$, manufactured by Copeland

- Two stainless steel plate heat exchangers, model AC70 (42 plates), manufactured by Alfa Laval

- Thermal expansion valve

- Four-way reversing valve, also for the water side 
- Refrigerant: R410A; $3.8 \mathrm{~kg}$

- Electronic controller manufactured by Carel

The control of the new GROUND-MED heat pump is similar to that of the former GEOCOOL heat pump, also based on thermostat control. Further details on how this control is performed are given in section 2.2 .2

Finally, it should be stressed that a mathematical model of the heat pump performance is required for control issues and is employed at a later point in this research work. This mathematical model was developed in the form of experimental polynomial correlations. These experimental correlations are presented in Appendix A.

\section{Ground source heat exchanger}

The GSHX is made up of six vertical boreholes, connected in a balanced parallel configuration. Each borehole has a depth of $50 \mathrm{~m}$ and contains a single polyethylene U-tube of $25.4 \mathrm{~mm}$ internal diameter (32 $\mathrm{mm}$ external diameter), with a $7 \mathrm{~cm}$ separation between the upward and downward tubes. The overall diameter of the borehole is $15 \mathrm{~cm}$.

The six boreholes are arranged in a $2 \times 3$ rectangular grid $\left(18 \mathrm{~m}^{2}\right)$, with a $3 \mathrm{~m}$ separation between boreholes (see Fig. 2.5. All boreholes are filled with sand and finished with a bentonite layer at the top to avoid intrusion of pollutants in the aquifers.

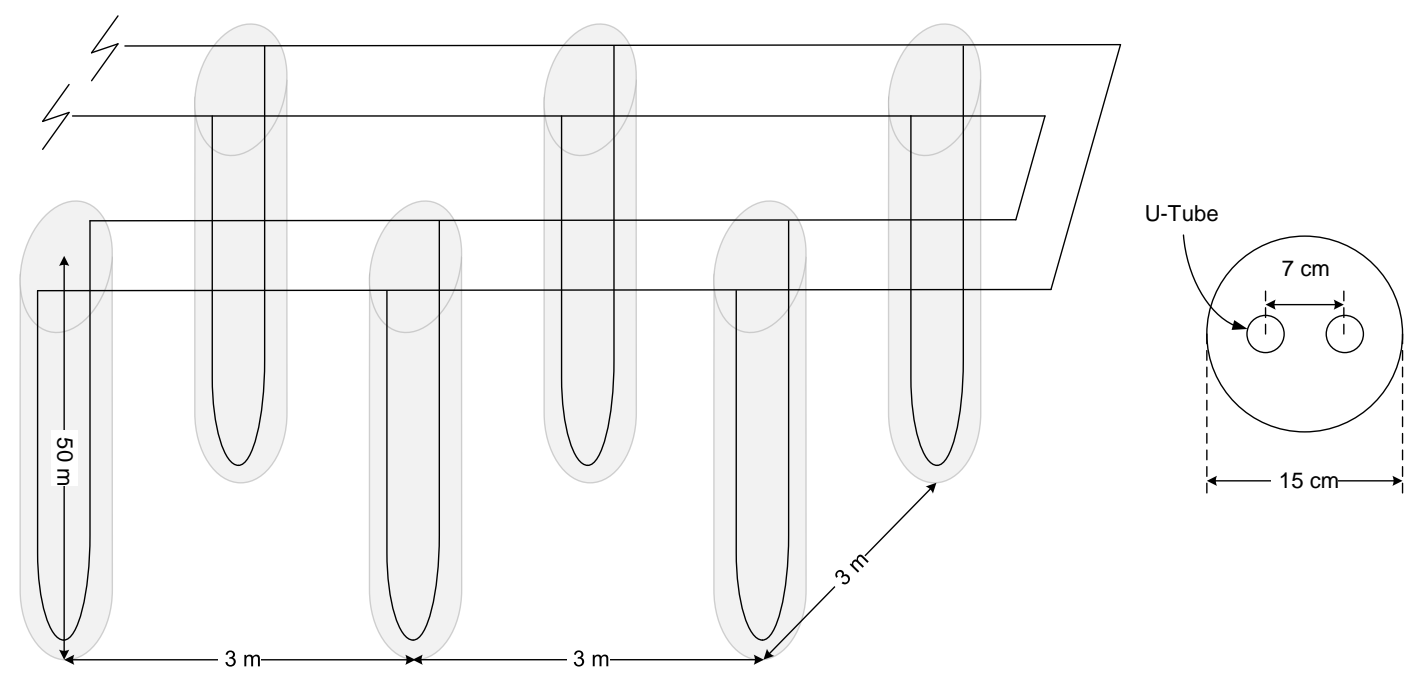

Figure 2.5: Ground Source Heat Exchanger (GSHX) diagram.

The values of the thermal properties of the ground (conductivity of $1.43 \mathrm{~W} / \mathrm{mK}$ and vol- 
umetric heat capacity of $2.25 \mathrm{MJ} / \mathrm{m}^{3} \mathrm{~K}$ ) were obtained by means of a laboratory analysis performed on soil samples, although a high uncertainty (around 20\%) in the estimation of the ground thermal conductivity was observed. Measurements of the undisturbed ground temperature were undertaken at the GEOCOOL plant and the registered values (around $18.5^{\circ} \mathrm{C}$ ) were very close to the water temperature coming from the ground loop, which is around $20^{\circ} \mathrm{C}[55,56]$.

\section{Circulation pumps}

As previously introduced, there are two water circulation pumps in the system, the internal circulation pump (ICP) in the building loop and the external circulation pump (ECP) in the ground loop.

The internal circulation pump is a 3-phase powered model CH4-30 manufactured by Grundfos. Its nominal mass flow rate (at $50 \mathrm{~Hz}$ of frequency) in the installation is around $3000 \mathrm{~kg} / \mathrm{h}$, which corresponds to a power consumption of $360 \mathrm{~W}$.

The external circulation pump is a 3-phase powered model CH2-30 manufactured by Grundfos. Its nominal mass flow rate in the installation (at $50 \mathrm{~Hz}$ of frequency) is around $2530 \mathrm{~kg} / \mathrm{h}$, which corresponds to a power consumption of $170 \mathrm{~W}$.

The speed of both pumps can be varied by means of two frequency inverters, being the operating range of frequencies from 20 to $55 \mathrm{~Hz}$. Figure 2.6 shows, for both circulation pumps, the experimental curves frequency - flow rate and frequency - power consumption which were measured in the installation under real operating conditions. The mathematical expressions for each curve are presented in Fig. 2.6 as well, with the aim of using them later in the optimization strategies developed in this research work, by means of which the speed of both pumps, and thus their flow rate, is varied. 

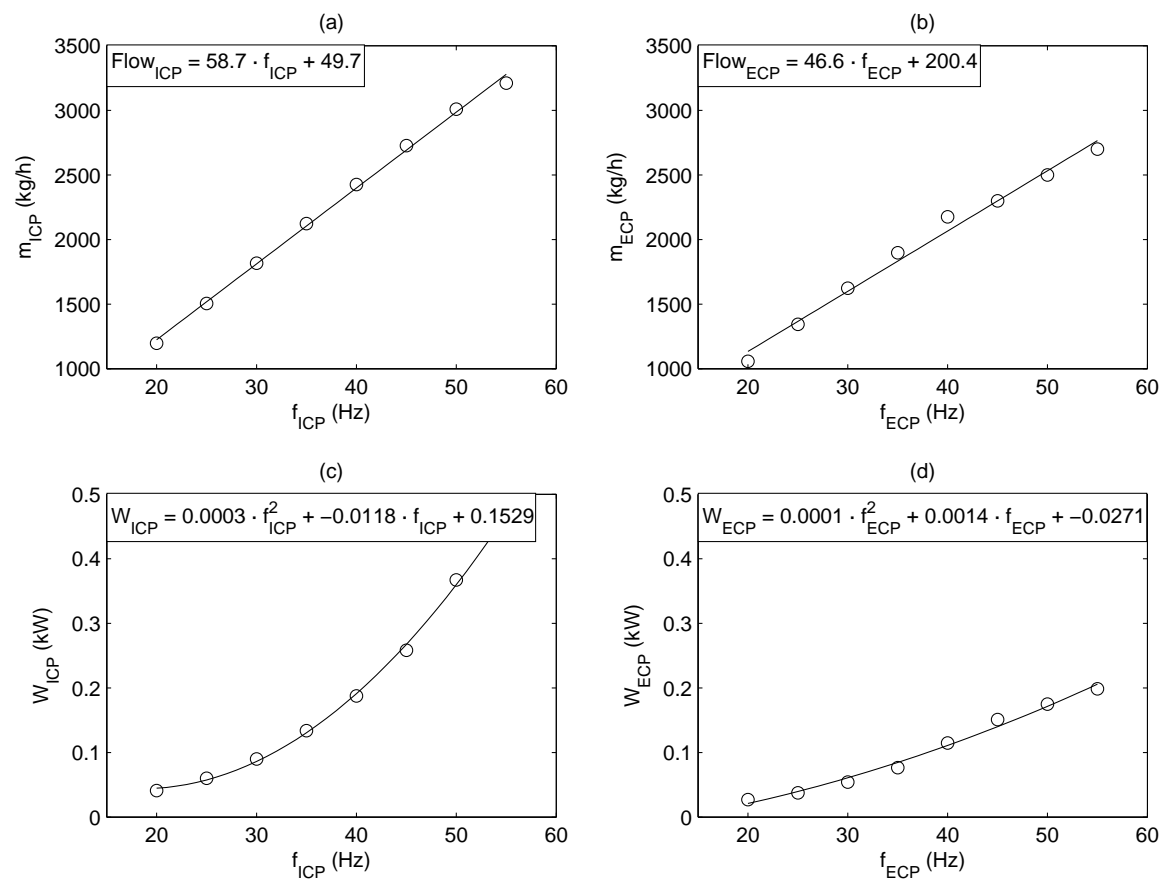

Figure 2.6: Circulation pumps performance curves as a function of frequency: (a) ICP flow rate; (b) ECP flow rate; (c) ICP power consumption; (d) ECP power consumption. 


\section{Fan coil units}

The GSHP system studied in this research work uses fan coils as terminal units. The installation has a total of twelve fan coil units (FCU), one per room except for the computer room (CpR), which includes two FCUs (see building site plan in Fig. 2.3).

\section{- Original FCUs}

The fan coil units originally installed in the geothermal plant correspond to the model MAJOR-329 CH manufactured by CIAT. They have three possible operating velocities in order to adjust the air flow rate trough the coil. The performance characteristics are presented in Table 2.1.

\begin{tabular}{|c|c|c|c|c|c|c|}
\hline \multirow{2}{*}{ Velocity } & \multirow{2}{*}{$\begin{array}{l}\text { Air flow } \\
\text { rate }\left(\mathrm{m}^{3} / \mathrm{h}\right)\end{array}$} & \multicolumn{2}{|c|}{ Heating capacity $(\mathrm{kW})$} & \multicolumn{2}{c|}{ Cooling capacity $(\mathrm{kW})$} & \multirow{2}{*}{$\begin{array}{l}\text { Power cons- } \\
\text { umption }(\mathrm{W})\end{array}$} \\
\hline V1 & 290 & 4.63 & 2.30 & 2.03 & 1.44 & 41 \\
\hline V2 & 430 & 6.42 & 3.33 & 2.78 & 2.04 & 57 \\
\hline V3 & 590 & 7.69 & 4.36 & 3.47 & 2.64 & 85 \\
\hline
\end{tabular}

Table 2.1: Original FCUs performance characteristics.

Each FCU is regulated individually by a thermostat. The fan velocity and setpoint temperature are selected manually by the user, by means of the remote control shown in figure 2.7. The thermostat controls a three-way valve that bypasses the water in the coil depending on the zone air temperature. The hydraulic schematic of the fan coil is shown in Fig. 2.8 .

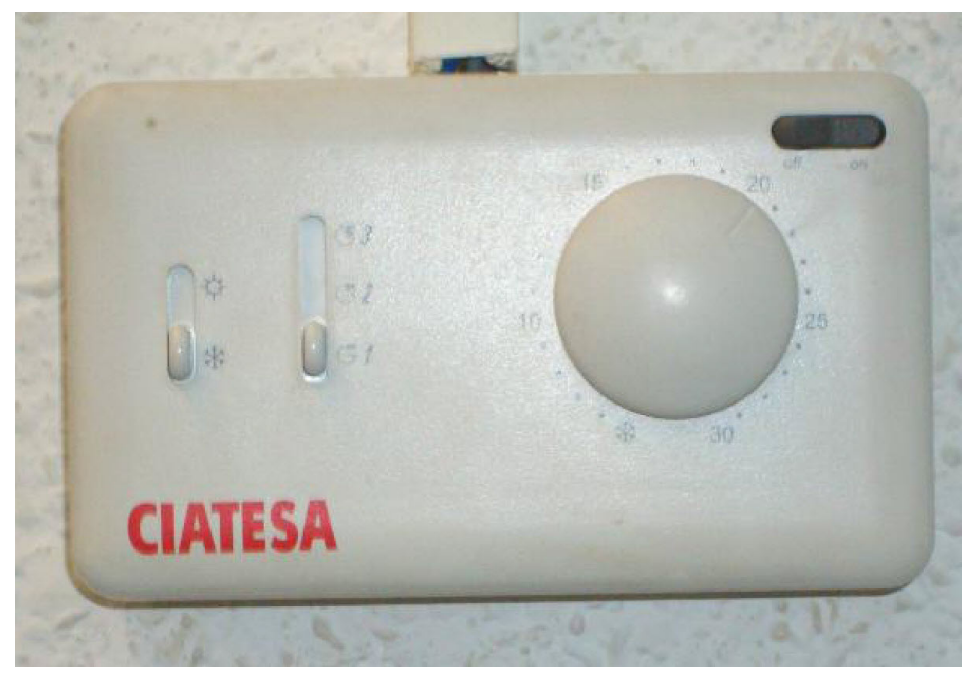

Figure 2.7: Original FCUs remote control. 


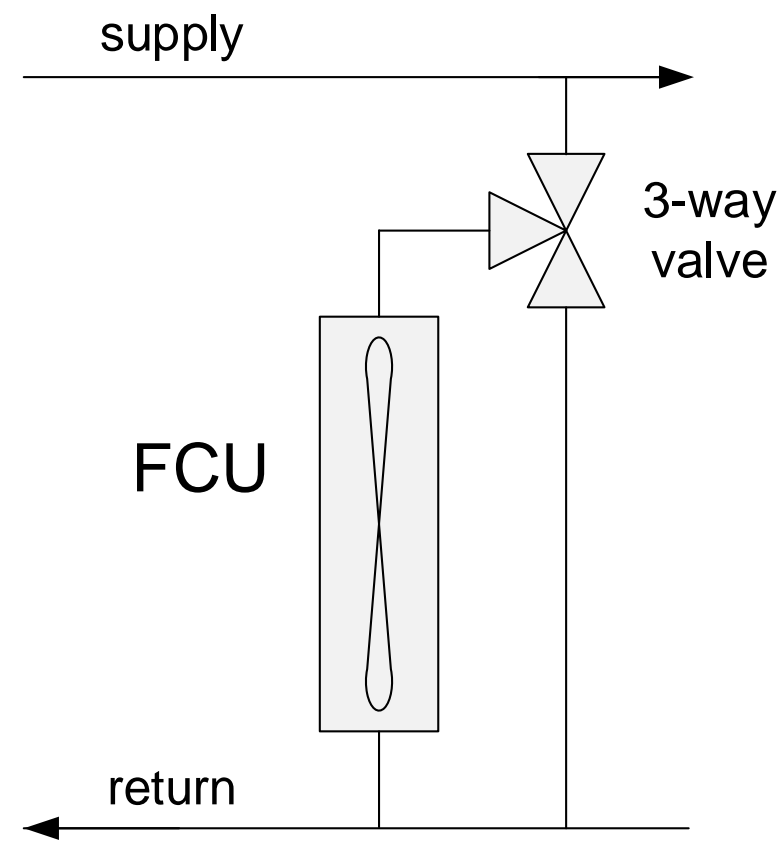

Figure 2.8: FCUs hydraulic schematic.

\begin{tabular}{|c|c|c|c|c|c|}
\hline \multirow{2}{*}{ Velocity } & \multirow{2}{*}{$\begin{array}{l}\text { Air flow } \\
\text { rate }\left(\mathrm{m}^{3} / \mathrm{h}\right)\end{array}$} & Heating capacity $(\mathrm{kW})$ & \multicolumn{2}{|c|}{ Cooling capacity $(\mathrm{kW})$} & \multirow{2}{*}{$\begin{array}{l}\text { Power cons- } \\
\text { umption }(\mathrm{W})\end{array}$} \\
\hline V1 & 240 & $90 / 70^{\circ} \mathrm{C}$ & Total & Sensible & 27 \\
\hline V2 & 355 & 4.63 & 2.30 & 1.85 & 36 \\
\hline V3 & 495 & 6.86 & 3.33 & 2.6 & 58 \\
\hline
\end{tabular}

Table 2.2: New FCUs performance characteristics.

- $\underline{\text { New FCUs }}$

In the framework of GROUND-MED project, in October 2012, three of those original FCUs were replaced with brand-new fan coils provided by CIAT. The offices chosen for the replacement were R3, R6 and R7 (see Fig. 2.3.

The new FCUs are model MAJOR LINE 202D manufactured by CIAT. These new fan coil units have motors with brushless technology and are very efficient. The performance characteristics are presented in Table 2.2 .

The temperature setpoint is manually controlled by the user. Regarding fan speed control, the user can either set it manually to any of the possible velocities, or set the automatic control which varies the velocity according to their internal algorithms. As in the original FCUs, the thermostat controls a valve that bypasses the water 
in the coil depending on the zone air temperature (see Fig. 2.8).

The aim of this FCUs replacement was to make the GSHP system more energy efficient as well as improving the user comfort regarding both thermal sensation and noise produced by the device. The new FCUs are much more efficient, as it is observed in table 2.2 , being the power consumption a $34 \%$ lower, and thus enabling to reduce the global electrical consumption of the system.

Nevertheless, the only action taken with a view to improve the energy efficiency of the FCUs was the replacement of these three fan coils. The control of all the fan coils (velocity and setpoint temperature) depends on the criterion of the user and has not been included in the global energy optimization strategies developed in this dissertation.

The manufacturer of the fan coils provides a piece of software called Elite ${ }^{\circledR}$ which includes a model of the fan coils based on experimental data taken at their laboratories. Elite ${ }^{\circledR}$ was used in order to characterize the performance of the FCUs. The details on the characterization of the FCUs performance are provided in Appendix B. The data from this FCUs performance characterization will be used in Chapter 3 as part of the energy optimization strategies proposed in this work.

The plan is to replace the whole set of old fan coils with brand-new ones as soon as the budget allows doing so. That is the reason why they were chosen in order to develop the optimization strategies in this work. On the other hand, the capacity of model MAJOR LINE 202D (new FCUs) is slightly higher than that of model MAJOR-329 CH (old FCUs). This means that, until the replacement is completely carried out in the future, the fact that the optimization strategies are developed considering the new FCUs would not penalize the user comfort.

\section{Water storage tank}

The internal hydraulic circuit includes a water storage tank. The dimensions of the tank are $80 \mathrm{~cm}$ in height, $50 \mathrm{~cm}$ in diameter and 189 litres in volume. Prior to the beginning of this research work and the beginning of GROUND-MED project, there was another tank with a volume of 160 litres. In addition, formerly there was also a 371 litres tank in the external circuit, but it was removed from the system since it was not necessary for the purposes of GROUND-MED project.

The water storage tank is also known as buffer tank as its main purpose is to provide thermal inertia to the system in order to avoid sharp temperature variations. This allows a softer variation of the control temperature that decides the start and stop of the compressor, thus avoiding an excessive ON/OFF cycling of the compressors.

The buffer tank was originally located at the end of the return line, that is to say, at the inlet of the heat pump. Then, the controlled temperature was the return temperature, that is to say, the temperature at the inlet of the heat pump. Nevertheless, in May 2009, 
in the framework of GROUND-MED project, the buffer tank was moved to the supply line, just at the outlet of the heat pump (see Fig. 2.1). The aim of this change was to use the temperature at the outlet of the tank as the new control temperature, in order to control the temperature of the water supplied to the fan coils with a view to improve the comfort of the user.

The position and sizing of the buffer tank is further studied in Sections 3.2 and 3.3 .

\section{Piping system}

The piping system in the building loop distributes the water from the heat pump to the fan coils and return. The pipes are $40 \mathrm{~mm}$ in nominal diameter, $70 \mathrm{~m}$ in length and are covered by an insulation layer of Armaflex ${ }^{\circledR} 1.65 \mathrm{~cm}$ thick. In the offices floor, the water is distributed in pipes of $26 \mathrm{~mm}$ of nominal diameter, with a total length of $77 \mathrm{~m}$, also covered in Armaflex ${ }^{\circledR}$.

On the other hand, the hydraulic circuit in the ground loop consists of polyethylene pipes PE100, $65 \mathrm{~mm}$ of outside diameter and 2 inches of internal diameter. The total length of the pipes in the external distribution system from the heat pump to the GSHX is 125 $\mathrm{m}$ and they are buried $0.5 \mathrm{~m}$ deep.

\subsubsection{Data acquisition system}

A comprehensive measuring of all the main variables is required so that an optimal control of the system is achieved. For that reason, a network of sensors was set up so that the installation is completely monitored: water temperature, mass flow rate and power consumption.

The temperature of the water at the inlet and outlet of the heat pump on both sides (evaporator and condenser), as well as the temperature at the outlet of the tank, are measured by means of four-wire PT100 with accuracy of $\pm 0.1^{\circ} \mathrm{C}$. There are five sensors, one for each temperature measurement. In addition, and in order to characterize the performance of each borehole during GEOCOOL project, several of these probes were installed in the boreholes. There is one at the inlet and outlet of each borehole, and also at different depths in three of the boreholes. However, these temperature probes in the boreholes have not been used during GROUND-MED project.

The water mass flow rates are measured via two Coriolis flow meters by Danfoss, model massflo MASS 6000 , with accuracy $<0.1 \%$. There is one flow meter for each one of the two hydraulic circuits.

The power consumption is measured by two multifunctional power meters by Gossen Metrawatt, model A2000, with accuracy $\pm 0.5 \%$ of the nominal value. One of them registers the power consumption of the internal circulation pump and the fan coils. The other 
one collects the consumption of the external circulation pump and the heat pump. The power consumption of each of the circulation pumps is recorded by their own frequency inverters, which include a feature to measure the power consumption. This way, subtracting from the data acquired by the power meters, all four power consumptions (HP, ECP, ICP and FCU) can be registered separately.

The location of temperature sensors and flow meters on the hydraulic circuits, as well as the power meters, can be observed in Fig. 2.9 .

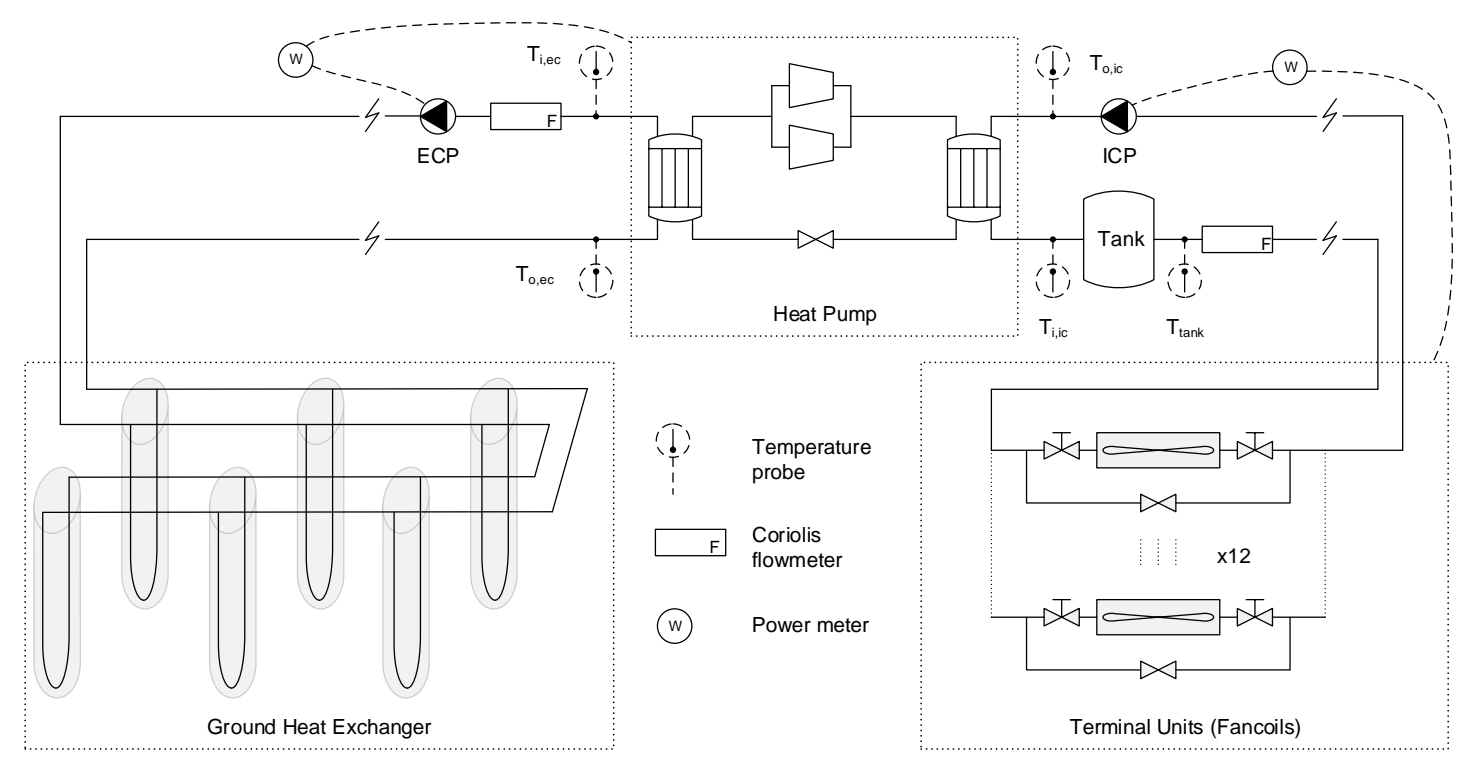

Figure 2.9: Ground Source Heat Pump (GSHP) system diagram.

In addition, the temperature and relative humidity in the offices is measured as well.

The data from this sensor network is collected by a data acquisition unit Agilent HP34970A with plug-in modules HP34901A. In order to automatically register and store the experimental data, a specific acquisition software was developed in Agilent VEE Pro ${ }^{\circledR}$ by the personnel involved in GEOCOOL project [19]. This software is capable of displaying the real-time evolution of the system performance parameters and record these values for further analysis. The data are collected every 20 seconds and are stored in an Excel file for each day of operation of the system.

This data acquisition system was firstly developed in the framework of GEOCOOL project, and later modified in order to adapt it to the requirements of GROUND-MED project. It has resulted in a huge database with information of the main variables of the geothermal plant, covering a period of operation of 11 years up to the moment. This data have brought about a couple of publications, one by Ruiz-Calvo and Montagud covering 
the first five years of operation [57] and another one by Ruiz-Calvo et al. covering the whole period of 11 years [58], in which the performance of the geothermal system has been analysed.

In addition to this data acquisition system (DAQ), a control system was included in the installation in the framework of GROUND-MED project. This includes a NI CompactRIO programmable automation controller by National Instruments and the software LabVIEW ${ }^{\circledR}[59]$. Further details on the control system are provided in Section 3.8 .

\subsection{Analysis of the system performance}

\subsubsection{System variables}

In order to analyse the system performance, with the aim of optimizing its operation, the main variables of the system are measured and collected by the DAQ system presented in section 2.1.3. The main variables are the water flow rate circulating through each hydraulic loop, the water temperature at different points in the hydraulic circuits and the power consumption of the different components of the system. In addition, a range of parameters, like the partial load ratio and some energy efficiency parameters are calculated to analyse the performance of the system.

On the one hand, some of the variables are direct readings from the network of sensors: water flow rate, temperature and power consumption of the circulation pumps. On the other hand, some other variables are obtained indirectly from the readings: power consumption of the heat pump and the fan coils. Finally, the system parameters are calculated indirectly from the readings and from other indirectly calculated variables: heat pump capacity, energy efficiency parameters and partial load ratio.

\section{Water flow rate}

The water flow rate is a direct reading from the flow meter. As introduced in section 2.1.3, there are two flow meters installed in the system. Their location can be seen in Fig. 2.9. There is one for the internal circuit and one for the external circuit.

As introduced in section 2.1.2, both the internal flow rate $\left(\dot{m}_{i c}\right)$ and the external flow rate $\left(\dot{m}_{e c}\right)$ are varied by means of two frequency inverters. Figures $2.6 \mathrm{a}$ and $2.6 \mathrm{p}$ present the values of the mass flow rate of both circulation pumps measured at different frequencies (20-55 Hz) at the geothermal plant, being those for $50 \mathrm{~Hz}$ the nominal ones.

As it is depicted in Figs. 2.6 and 2.6 $\mathrm{b}$, the higher the inverter frequency, the greater the circulating water flow rate. The variation of the water circulation pumps flow rate is one of the main optimization strategies proposed in this research work. It is further studied in Chapter 3 . 
Finally, it should be noticed that the internal flow meter measures the total flow rate circulating through the circuit. As there are 12 FCUs in the system, it is assumed that the water flow rate circulating through each FCU will be one twelfth of the total internal circulation pump flow rate.

\section{Water temperature}

In order to characterize the performance of the heat pump, it is very important to know the values of the temperature at its inlet and outlet on both sides, condenser and evaporator. The variables are named from the point of view of the system, instead of the heat pump: the temperature probes provide the values of the temperature at the inlet $\left(T_{i, i c}\right)$ and outlet $\left(T_{o, i c}\right)$ of the internal circuit, and at the inlet $\left(T_{i, e c}\right)$ and outlet $\left(T_{o, e c}\right)$ of the external circuit.

In addition, the temperature at the outlet of the buffer tank $\left(T_{\text {tank }}\right)$ is also important since, with the current configuration, this is the temperature of the water supplied to the building. Therefore, it plays an important role in the comfort of the user.

The values of all five temperatures are directly measured by means of the sensors depicted in section 2.1.3. The location of the temperature probes can be observed in Fig. 2.9.

\section{Power consumption}

Energy efficiency studies are based on measurements of the power consumption of the different components of a given system. The main consumptions of the GSHP system analysed in this research work come from: the heat pump $\left(\dot{W}_{H P}\right)$, the external $\left(\dot{W}_{E C P}\right)$ and internal $\left(\dot{W}_{I C P}\right)$ circulation pumps and the fan coil units $\left(\dot{W}_{F C U}\right)$.

The power consumption of the heat pump can be divided into two different power consumptions: the consumption of the compressor or compressors that are running $\left(\dot{W}_{\text {comp }}\right)$, and the consumption of the electronic devices of the heat pump, such as the control board, when no compressors are running, referred to as parasitic losses $\left(\dot{W}_{\text {par }}\right)$, as shown in Eq. 2.1 .

$$
\dot{W}_{H P}=\dot{W}_{c o m p}+\dot{W}_{\text {par }}
$$

The parasitic losses have a value around $60 \mathrm{~W}$ and are present during all the operational time of the unit. They may become an important source of energy losses, given that the system is working 15 hours per day, as mentioned by Corberán et al. [60].

The values of the power consumption of the water circulation pumps are directly obtained from the frequency inverters, which include a feature to measure power consumption. The internal pump is running continuously during the 15 hours per day of system operation, whereas the external pump works only when at least one of the compressors is running. 
The two power meters described in section 2.1 .3 provide compound measurements of power consumptions:

- One of them registers the power consumption of the internal pump and the fan coils. In order to obtain the power consumption of the fan coil units, the power consumption of the internal pump has to be subtracted from the reading of the power meter.

- The other one collects the consumption of the external circulation pump and the heat pump. In order to obtain the power consumption of the heat pump, the power consumption of the external pump has to be subtracted from the data collected by the power meter.

\section{Heat pump capacity}

The two plate heat exchangers in the heat pump can act either as evaporator or as condenser depending on the mode of operation. In cooling mode, the heat exchanger connected to the building loop functions as evaporator, absorbing the heat coming from the offices, whereas the one connected to the ground loop serves as condenser, delivering the heat to the ground. In heating mode the behaviour is the opposite: the heat exchanger connected to the internal circuit serves as condenser while the one connected to the external circuit functions as evaporator. For that reason, the term internal/external circuit heat will be used instead of evaporator/condenser heat in order to refer to the heat exchanged in the system independently from the mode of operation.

The heat delivered or absorbed by the heat pump can be calculated as a function of the temperature difference and the water flow rate circulating trough the corresponding heat exchanger according to the general expression provided by equation 2.2 .

$$
\dot{Q}=\dot{m} \cdot c_{p, w} \cdot \Delta T
$$

Where:

$\dot{m}$ is the flow rate of water circulating through the corresponding heat exchanger,

$c_{p, w}$ is the specific heat at constant pressure for the water, which is assumed as constant in all the range of operating temperatures and frequencies,

and $\Delta T$ is the temperature difference between the inlet and outlet of the corresponding heat exchanger.

Applying equation 2.2 to both sides of the heat pump, equations 2.3 and 2.4 provide the heat transferred in the internal and the external circuit respectively.

$$
\begin{aligned}
& \dot{Q}_{i c}=\dot{m}_{i c} \cdot c_{p, w} \cdot\left(T_{o, i c}-T_{i, i c}\right) \\
& \dot{Q}_{e c}=\dot{m}_{e c} \cdot c_{p, w} \cdot\left(T_{i, e c}-T_{o, e c}\right)
\end{aligned}
$$


Where:

$\dot{m}_{i c} / \dot{m}_{e c}$ is the flow rate of water circulating through the internal and the external circuit respectively,

and $T_{i, i c}, T_{o, i c}, T_{i, e c}$ and $T_{o, e c}$ are the temperatures at the inlet and outlet of the heat pump on both sides of it, internal and external.

Equations 2.3 and 2.4 provide positive values of heat for cooling mode operation. In general, positive values of heat will be used throughout this dissertation, adding or subtracting values of heat when necessary according to its sign. In order to obtain positive values for the heat, the position of the temperatures in the subtraction operation should be exchanged when calculating heat transferred in heating mode.

On the other hand, it is possible to estimate the uncertainty associated to the calculation of the heat transferred, considering the accuracy of the different sensors described in section 2.1.3. The software Engineering Equation Solver ${ }^{\circledR}$ has been used for that purpose and the uncertainty obtained is $\pm 3 \%$, which is acceptable for the system performance analysis carried out in this work.

Finally, it should be said that Eqs. 2.3 and 2.4 provide instantaneous values, that is to say thermal power. In order to obtain the thermal energy transferred in the system, these equations can be integrated in time, as presented in Eqs. 2.5 and 2.6.

$$
\begin{aligned}
Q_{i c} & =\int_{0}^{t} \dot{m}_{i c} \cdot c_{p, w} \cdot\left(T_{o, i c}-T_{i, i c}\right) \cdot d t \\
Q_{e c} & =\int_{0}^{t} \dot{m}_{e c} \cdot c_{p, w} \cdot\left(T_{i, e c}-T_{o, e c}\right) \cdot d t
\end{aligned}
$$

Due to the discrete nature of data acquisition, the integrals in Eqs. 2.5 and 2.6 turn into summations. This fact applies to all the integrals presented throughout this research work.

\subsubsection{Heat pump control}

The system operation is based on switching on and off the heat pump depending on the control temperature. In order to perform the basic ON/OFF control of the heat pump, two parameters are required: the temperature setpoint and the temperature deadband.

The probe for the control temperature can be situated at different locations in the system. This issue is further discussed in Section 3.3 .

As mentioned earlier in this work, there are two different heat pumps to be analysed: the GEOCOOL heat pump and the GROUND-MED heat pump. The GEOCOOL heat pump represents the single-stage compressor case, as it only has one compressor that switches on and off depending on the control temperature. The GROUND-MED heat pump 
represents the multi-stage compressor case, for the particular case of two compressors of the same capacity working in tandem.

On the other hand, the type of heat pump analysed (and this applies for both heat pumps) is a reversible unit, meaning that it can provide both cooling and heating to the building.

In the following, the control of the heat pump is described in detail, by means of the evolution with time of the control temperature (wherever it is measured), for both types of heat pump unit, and for both modes, cooling and heating.

\section{Single-stage compressor case}

Fig. 2.10 shows the evolution with time of the temperatures at the inlet and outlet of the heat pump in the building loop $\left(T_{i, i c}\right.$ and $T_{o, i c}$ respectively) for a typical cooling day. The cycles performed by the heat pump can be clearly observed. The control temperature (in this case the temperature at the inlet of the heat pump in the internal circuit, $T_{i, i c}$ ) depicts how the water is cooled down when the heat pump is running, and how its temperature increases when it is switched off. In summer the water is heated up during the night, when the heat pump is off. As it is observed in Fig. 2.10 for cooling mode, the heat pump cools down the water at the beginning of the morning, until it reaches the lower limit of the band, moment at which the heat pump is switched off. When the heat pump is off, both temperatures $\left(T_{i, i c}\right.$ and $\left.T_{o, i c}\right)$ become equal, and the temperature of the water increases due to the thermal demand of the building. When the control temperature $\left(T_{\text {control }}\right)$ reaches the upper limit of the thermostat band, the heat pump starts, beginning to cool down the water again, and a new cycle starts. The operation is opposite in heating mode.

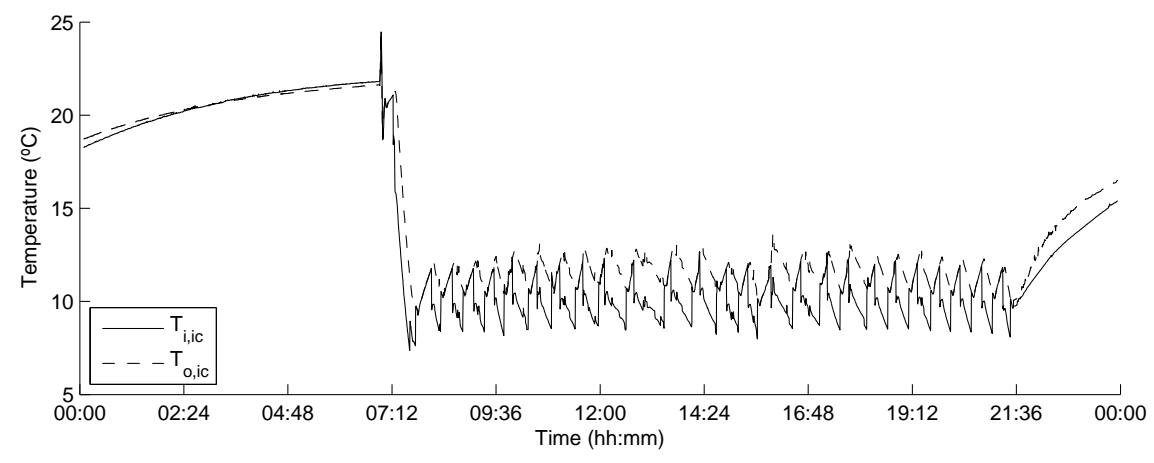

Figure 2.10: Internal circuit temperatures variations in a typical cooling day.

It is important to notice that the duration of the cycles in Fig. 2.10 is not the same throughout the day, what points out that the thermal load of the building influences the 
duration of the cycles. The cooling cycles (ON cycles) are longer in the middle of the day as a bigger load causes the heat pump to require a longer time to cool down the water.

The explanation to this behaviour can be found in a basic energy balance, as the one presented in Eq. 2.7. The sign criterion adopted is the following: the thermal load $(\dot{q})$ is positive when it is heat delivered to the internal circuit (cooling mode) and negative when the heat is absorbed from the circuit (heating mode); on the other hand, the heat pump capacity $\left(\dot{Q}_{H P}\right)$ is positive when the heat pump absorbs heat from the internal circuit (cooling mode), and negative when the heat is delivered to the circuit (heating mode). Fig. 2.11 shows a simplified schematic of the building loop where the heat flux is marked (both $\dot{q}$ and $\dot{Q}_{H P}$ are positive in cooling mode and negative in heating mode).

$$
M_{w} \cdot c_{p, w} \cdot \frac{d T_{\text {control }}}{d t}=\dot{q}-\dot{Q}_{H P}
$$

Where:

$M_{w}$ is the total mass of water in the internal circuit,

$c_{p, w}$ is the specific heat of water at constant pressure,

$d T_{\text {control }} / d t$ is the variation of the control temperature with time,

$\dot{q}$ is the thermal load of the building

and $\dot{Q}_{H P}$ is the capacity of the heat pump.

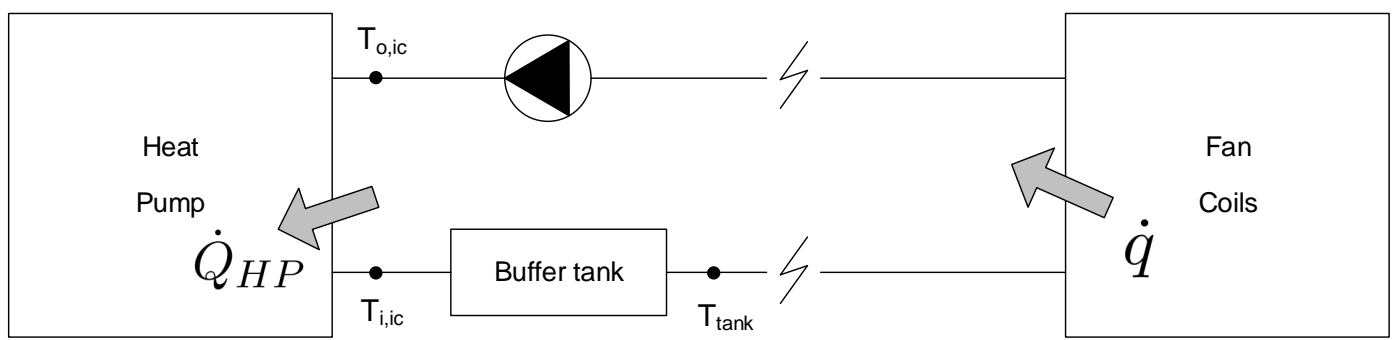

Figure 2.11: Simplified building loop schematic.

Fig. 2.12 depicts the influence of the thermal load in the control temperature for different values of the thermal load (low, medium and high load), and for both operation modes, cooling and heating. This influence is described in the following. The variation of the control temperature is analysed according to the energy balance presented in Eq. 2.7 for two different periods: when the heat pump is running (ON time) and when the heat pump is switched off (OFF time).

During the ON time, the heat capacity is not zero $\left(\dot{Q}_{H P} \neq 0\right)$. Therefore, the energy balance remains unchanged and the variation of the control temperature is given by Eq. 
(a)

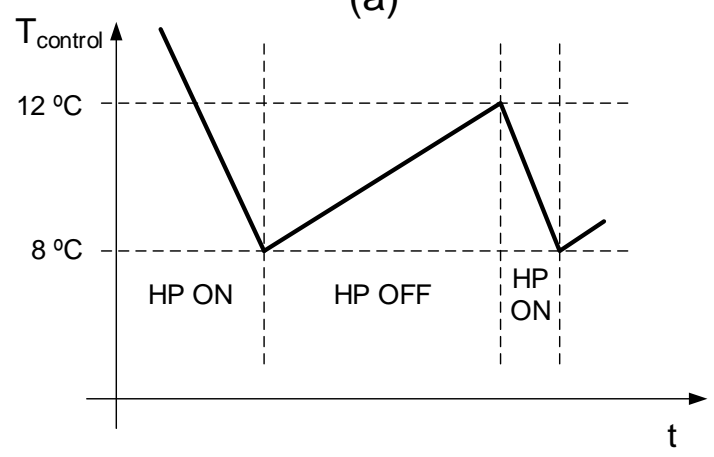

(c)

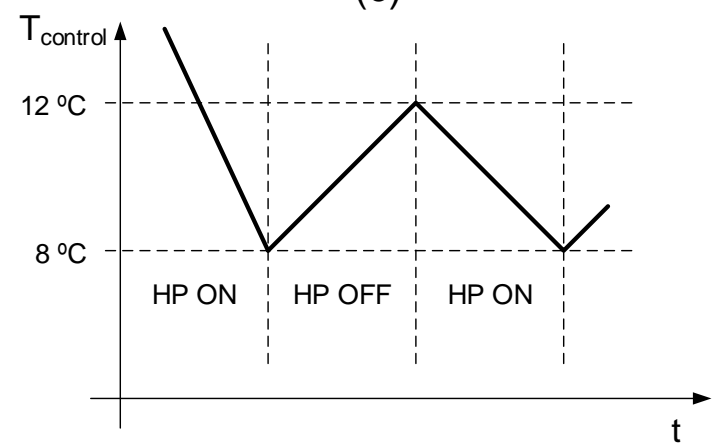

(e)

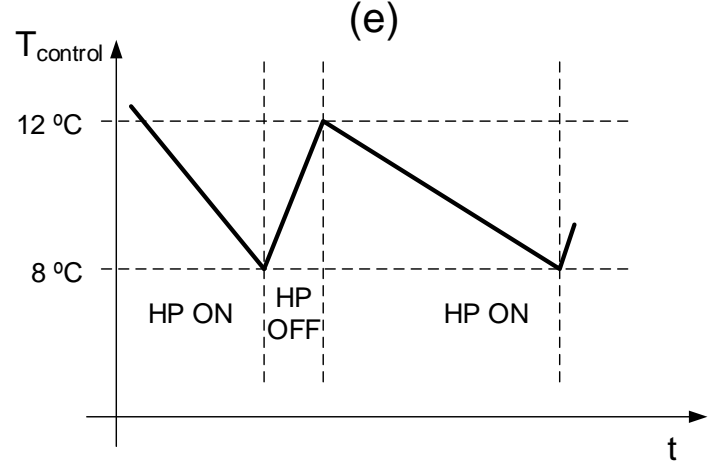

(b)

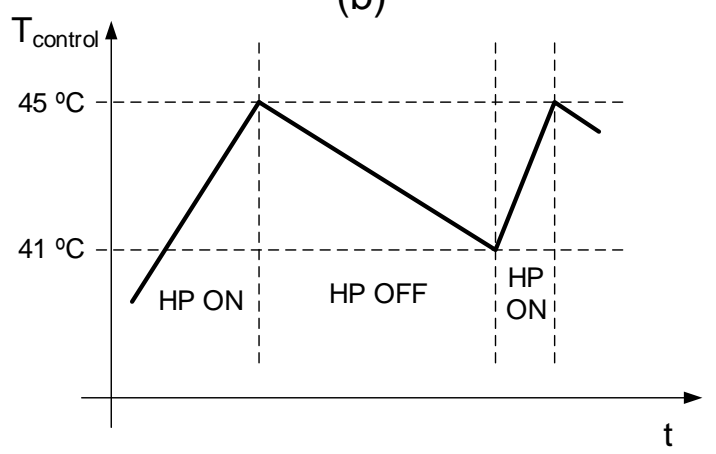

(d)

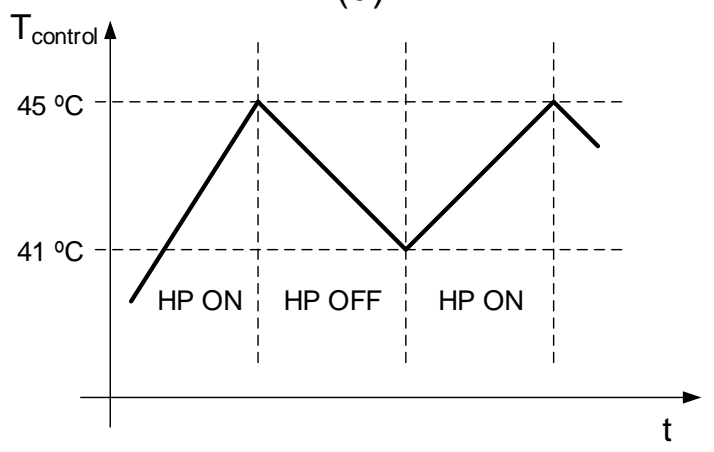

(f)

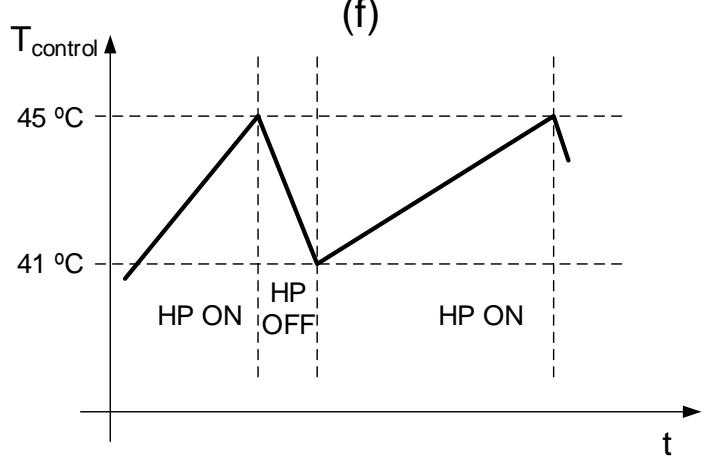

Figure 2.12: Influence of the thermal load in the control temperature: (a) Low load cooling; (b) Low load heating; (c) Medium load cooling; (d) Medium load heating; (e) High load cooling; (f) High load heating. 
2.8. This variation of temperature provides the slope of the evolution with time of the control temperature $\left(\frac{d T_{\text {control }}}{d t}\right)$, and thus the length of the cycle.

$$
\frac{d T_{\text {control }}}{d t}=\frac{\dot{q}-\dot{Q}_{H P}}{M_{w} \cdot c_{p, w}}
$$

During the OFF time, the heat pump capacity is zero $\left(\dot{Q}_{H P}=0\right)$, hence the energy balance remains as expressed in Eq. 2.9 .

$$
\frac{d T_{\text {control }}}{d t}=\frac{\dot{q}}{M_{w} \cdot c_{p, w}}
$$

\section{- Low thermal load}

When the thermal load $(\dot{q})$ is low, the heat pump capacity is much greater than the thermal load $\left(\dot{Q}_{H P}>>>\dot{q}\right)$.

According to Eq. 2.9, a low value of $\dot{q}$ produces a gentle slope during the OFF time. Following the sign criterion adopted, this gentle slope would be positive in cooling mode $(\dot{q}>0)$ and negative in heating mode $(\dot{q}<0)$. This effect is observed in the periods where the heat pump is switched off in Fig. 2.12 for cooling mode and in Fig. $2.12 \mathrm{~b}$ for heating mode. As an example, the control temperature varies between $8^{\circ} \mathrm{C}$ and $12^{\circ} \mathrm{C}$ in cooling mode and between $41^{\circ} \mathrm{C}$ and $45^{\circ} \mathrm{C}$ in heating mode.

During the ON time, Eq. 2.8 is applied. In cooling mode, the heat pump capacity was defined as positive $\left(Q_{H P}>0\right)$. Therefore, as $\dot{Q}_{H P}>>>\dot{q}$, the slope would be steeper than that of the OFF period, as observed in Fig. 2.12 . In heating mode, the behaviour is opposite. The heat pump capacity is much greater than the thermal load, but it is negative. Hence, the slope would be positive and sharper than that of the OFF time.

In other words, a low load causes that the heat pump requires shorter time to cool down the water in cooling mode (or to heat it up in heating mode). When the heat pump is switched off, it will take longer for a lower load to heat up the water (or to cool it down in heating mode).

- Medium thermal load

There might be the case that the value of the thermal load is just half the value of the heat pump capacity $\left(\dot{q}=\dot{Q}_{H P} / 2\right)$.

As stated earlier, in cooling mode the control temperature increases during the OFF time and decreases during the ON time. In heating mode it is just the opposite.

However, in this case, the duration of both the ON time and the OFF time would be exactly the same. The explanation to this effect is provided in the following for 
cooling mode, where both the thermal load and the heat pump capacity are greater than zero $\left(\dot{q}>0\right.$ and $\left.\dot{Q}_{H P}>0\right)$.

During the OFF time, Eq. 2.9 is applied, hence the slope would be positive and equal to $\dot{q} /\left(M_{w} \cdot c_{p, w}\right)$. During the ON time, Eq. 2.8 is applied. Using the relation $\dot{Q}_{H P}=2 \cdot \dot{q}$ (medium load), the slope would remain $-\dot{q} /\left(M_{w} \cdot c_{p, w}\right)$, which is the same value as in the OFF time. Therefore, the duration of both periods (ON time and OFF time) will be same.

The evolution with time of the control temperature for medium load can be observed in Fig. 2.12k for cooling mode and in Fig. 2.12 for heating mode.

- High thermal load

Finally, when the thermal load is high, the heat pump capacity is approximately equal to the thermal load $\left(\dot{Q}_{H P} \approx \dot{q}\right)$.

During the OFF time, a high value of the thermal load would produce a steep slope according to Eq. 2.9. This slope would be positive in cooling mode.

On the other hand, during the ON time the slope would be negative because $\dot{Q}_{H P}>$ $\dot{q}$, according to Eq. 2.8 . However, this slope would be gentle because $\dot{Q}_{H P} \approx \dot{q}$.

In other words, a big load causes the heat pump to require longer time to cool down the water in cooling mode (or to heat it up in heating mode). When the heat pump is switched off, it will take shorter for a bigger load to heat up the water (or to cool it down in heating mode).

The evolution with time of the control temperature for medium load can be observed in Fig. 2.12 for cooling mode. For heating mode the behaviour is opposite (see Fig. 2.12f).

\section{Multi-stage compressor case}

As stated earlier, the new GROUND-MED heat pump is a multi-stage unit with two compressors of the same capacity working in tandem. Its control is similar to that of the former GEOCOOL heat pump. However, it uses two different thermostat bands instead of one, one for each compressor (see Fig. 2.13).

In the cooling season (Fig. 2.13a), the temperature of the water increases during the night. When the value of the control temperature is above the upper limit (e.g. at the beginning of the morning), both compressors start, cooling down the water until it reaches the medium limit, moment at which the second compressor $(\mathrm{C} 2)$ stops. At this moment, if the instantaneous thermal demand is big enough, $\mathrm{C} 2$ will continue to cycle on and off and the first compressor (C1) will run continuously. On the other hand, if the thermal load is small, $\mathrm{C} 1$ will continue to cool down the water until it reaches the lower limit, thus stopping. Then, the temperature of the water will start to increase until it 
(a)

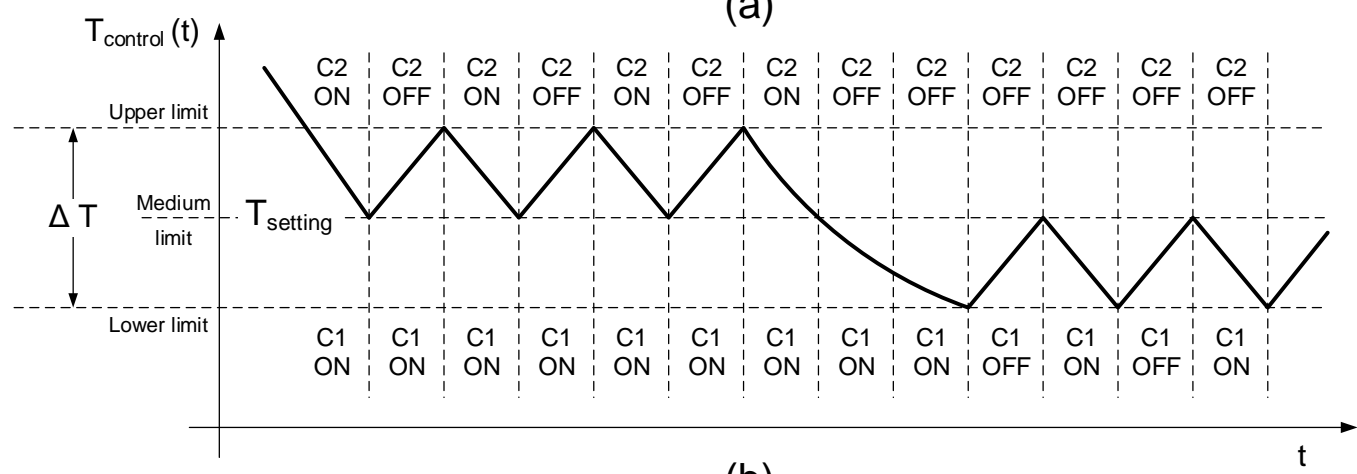

(b)

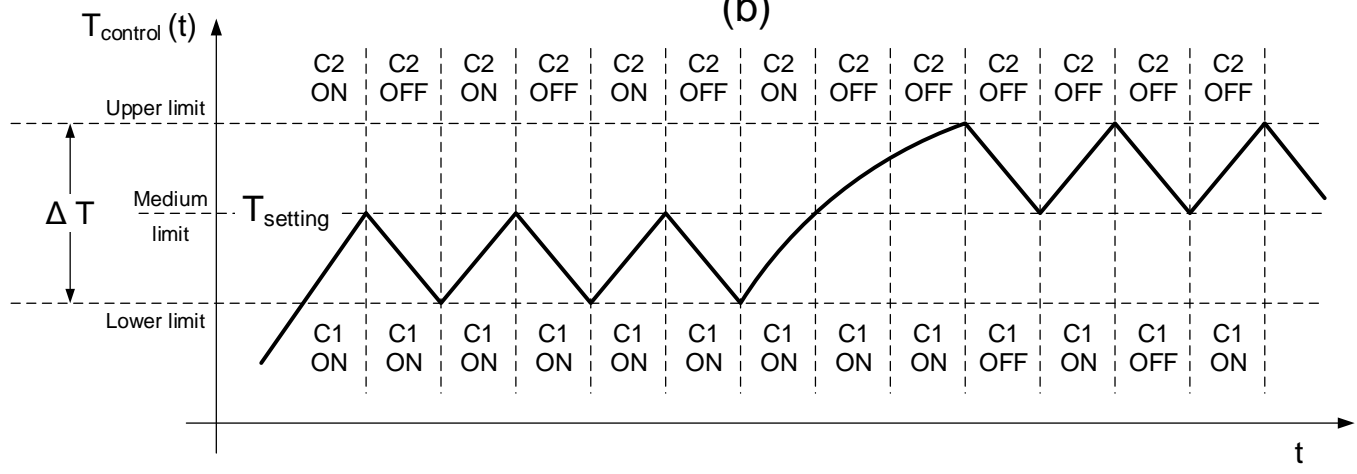

Figure 2.13: GROUND-MED heat pump control: (a) Cooling mode; (b) Heating mode.

reaches the medium limit of the band and the heat pump starts again beginning a new cycle.

Eq. 2.10 shows the variation of the control temperature depending on the number of compressors which are running at each moment $(n)$, where $N$ is the total number of compressors, equal to 2 for the multi-stage heat pump analysed.

$$
\frac{d T_{\text {control }}}{d t}=\frac{\dot{q}-\dot{Q}_{H P} \cdot \frac{n}{N}}{M_{w} \cdot c_{p, w}}
$$

When both compressors are running $(n=2)$, the capacity of the heat pump is the total capacity. When only one compressor is running $(n=1)$, the capacity of the heat pump is considered to be approximately half the total capacity $\left(\frac{\dot{Q}_{H P}}{2}\right)$. In fact it is not exactly "half" the total capacity, but it is assumed in order to simplify the problem. Finally, when both compressors are switched off $(n=0)$, the capacity of the heat pump is zero.

The control of the GROUND-MED heat pump in heating mode is similar to cooling mode, but reversing the temperature limits in such a way that $\mathrm{C} 2$ starts when the temperature decreases below the lower limit. 
Fig. 2.14 briefly depicts the comparison of the control of both heat pumps. It can be observed that, whereas the compressor of the GEOCOOL heat pump uses the whole deadband for controlling, the GROUND-MED heat pump divides the band into two smaller bands which are used to control the two different compressors.

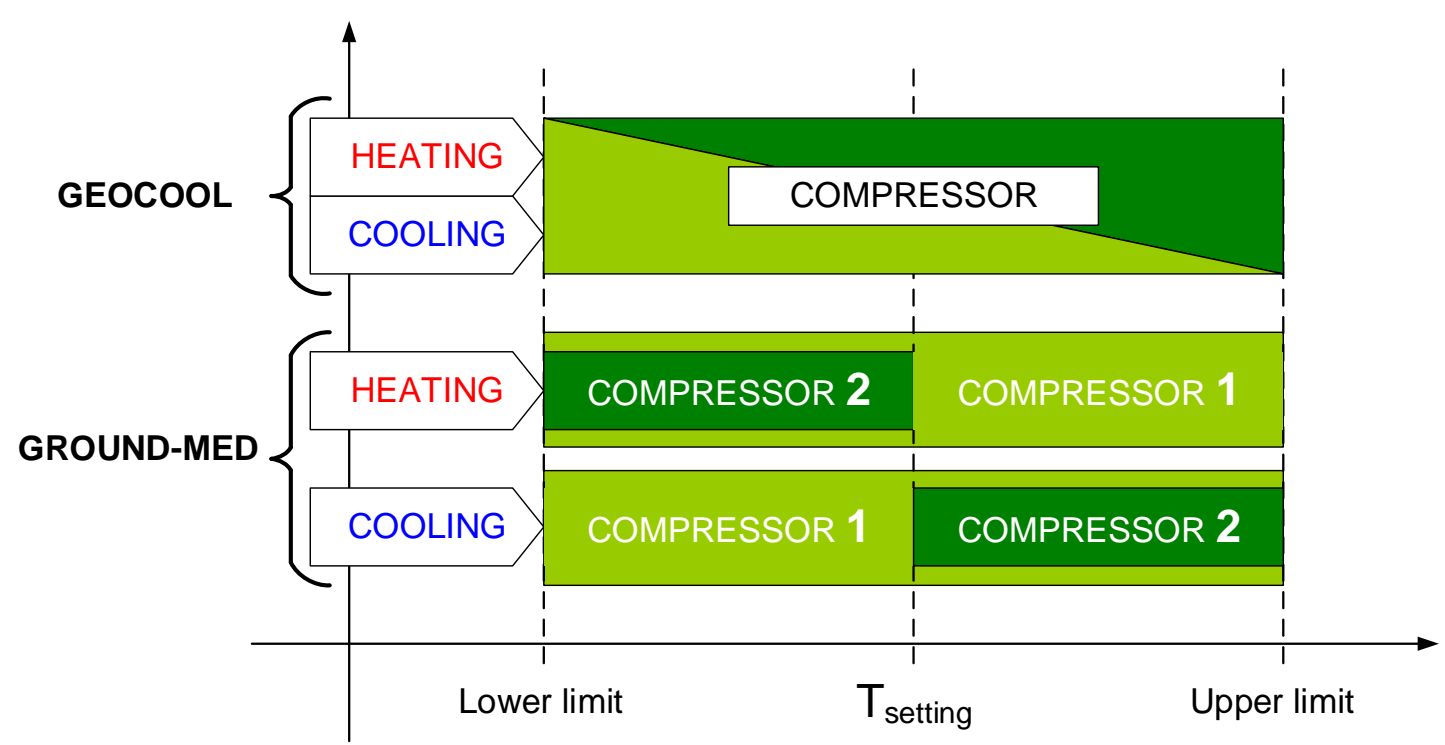

Figure 2.14: Heat pumps control comparison.

Finally, the way the GROUND-MED heat pump controller controls the temperature should be analysed, that is to say, the way the heat pump controller interprets the parameters that are sent to it. It differs from Fig. 2.14, where it was presented so that it could be better compared to GEOCOOL heat pump.

As mentioned earlier, these parameters that the heat pump controller receives are the temperature setpoint $\left(T_{\text {set }}\right)$ and the temperature deadband $\left(\Delta T_{d b}\right)$. Then, the temperature deadband is divided into equal parts according to the total number of compressors of the unit $(N)$, in such a way that $\Delta T_{d b, n}=\Delta T_{d b} / N$. In the case of the GROUD-MED heat pump, the total number of compressors is $N=2$. Fig 2.15 shows qualitatively the relation between the temperature at the inlet $(T o, i c)$ and outlet $(T i, i c)$ of the heat pump and how the return temperature $(T o, i c)$ is used as the control temperature for the example case of cooling mode.

Looking at Fig. 2.15, the average value of the control temperature can be defined as a function of the temperature setpoint $\left(T_{\text {set }}\right)$, the temperature deadband $\left(\Delta T_{d b}\right)$ and the operation state of the heat pump $(n)$ as presented in Eq. 2.11. This means that the control temperature will vary around a different temperature depending on the operation 


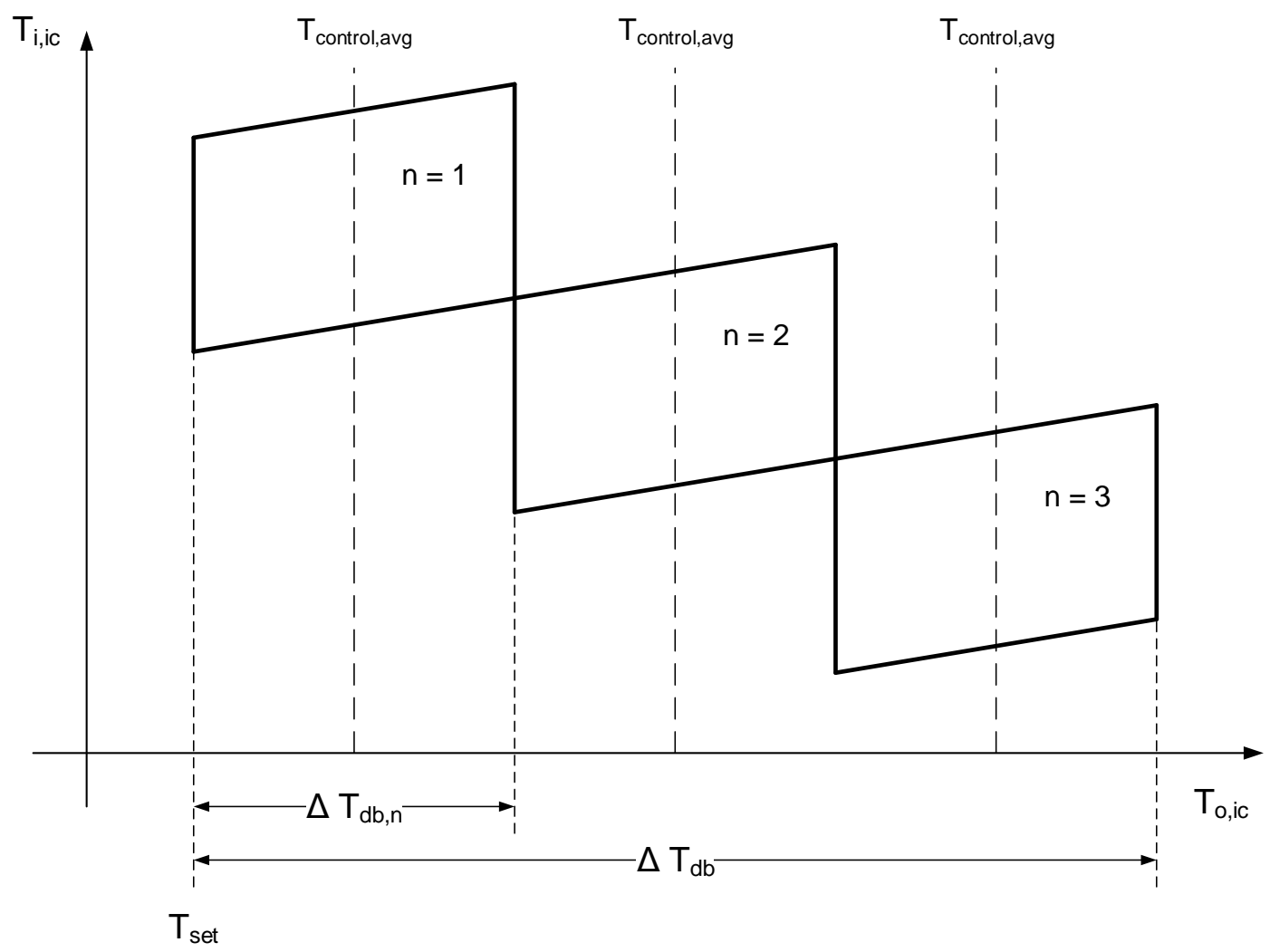

Figure 2.15: GROUND-MED heat pump control: temperature setpoint and temperature deadband. 
state of the heat pump.

$$
T_{\text {control,avg }}=T_{\text {set }}+\Delta T_{d b} \cdot\left(n-\frac{1}{2}\right)
$$

\subsubsection{Energy efficiency}

Energy efficiency is characterized by the energy performance factor, defined as the ratio between the thermal load and the electrical energy consumption during a time interval. Energy efficiency parameters are therefore calculated taking into account the heat transferred from the heat pump to the internal circuit, and the power consumption readings.

When instantaneous values are considered, the performance of the heat pump is characterized by the coefficient of performance (COP), which is the ratio between the thermal capacity and the power consumption, expressed in equation 2.12 .

$$
C O P_{H P}=\frac{\dot{Q}_{i c}}{\dot{W}_{H P}}
$$

Nevertheless, as the heat pump starts and stops several times throughout the day, the instantaneous value of the COP may vary since the moment the heat pump is switched on until it reaches a quasi-steady state. For that reason, the COP can be integrated during the $\mathrm{ON}$ time operation $\left(t_{O N}\right)$ in a single cycle of the heat pump. This provides the $\mathrm{COP}$ of the heat pump in quasi-steady state conditions $\left(C O P_{H P, s t d y}\right)$ as presented in equation 2.13 .

$$
C O P_{H P, s t d y}=\frac{\int_{0}^{t_{O N}} \dot{Q}_{i c}(t) \cdot d t}{\int_{0}^{t_{O N}} \dot{W}_{H P}(t) \cdot d t}
$$

On the other hand, the COP may as well be different in different cycles along the day, and in different days along the season, depending on the load and on the heat pump settings. In order to analyse the performance of the heat pump during longer time intervals, another performance parameter is employed: the energy performance factor $(\mathrm{PF})$, which is calculated integrating the COP for any period of time $t$, as presented in Eq. 2.14

$$
P F=\frac{\int_{0}^{t} \dot{Q}_{i c}(t) \cdot d t}{\int_{0}^{t} \dot{W}_{H P}(t) \cdot d t}
$$

Depending on the duration of the time interval considered for the calculation, the energy performance factor can be daily, monthly, seasonal, etc. The energy efficiency parameters considered in this research work are the daily performance factor (DPF) and the seasonal 
performance factor (SPF), depending on whether the time period considered is a single day or a whole season respectively.

When calculating the performance factor for a single ON/OFF cycle, if only the ON time period is considered, the performance factor integrated for one cycle will be the same as the COP at quasi-steady state conditions $\left(P F_{H P}=C O P_{H P, s t d y}\right)$. In fact, it was proved in [60] that water to water heat pump units have negligible start up losses, so that partialization losses only depend on the parasitic losses due to the electronics (or maybe the crankcase heater consumption in those cases where it is installed). During the ON period, the unit works as in quasi-steady state conditions with condensing and evaporating temperatures gliding with the respective inlet water temperatures variation.

The previous expressions provide the energy performance factor of the heat pump, that is to say, only the power consumption of the heat pump is considered in the denominator, as in Eq. 2.15). The performance factor of the heat pump is also called performance factor $1\left(P F_{1}=P F_{H P}\right)$.

$$
P F_{1}=\frac{\int_{0}^{t} \dot{Q}_{i c}(t) \cdot d t}{\int_{0}^{t} \dot{W}_{H P}(t) \cdot d t}
$$

However, a GSHP system includes not only the heat pump, but also the auxiliaries (water circulation pumps) and the terminal units (fan coil units). The aim of the energy optimization strategies is to optimize the global energy performance of the system, and not only that of the heat pump. Therefore, different parameters need to be defined depending on the different components consuming power or transferring heat that are considered. This way, it is possible to study the influence of each component on the performance of the system.

Performance factor $2\left(\mathrm{PF}_{2}\right)$ includes the external circulation pump. Therefore, its power consumption is included in the denominator as presented in equation 2.16 .

$$
P F_{2}=\frac{\int_{0}^{t} \dot{Q}_{i c}(t) \cdot d t}{\int_{0}^{t}\left(\dot{W}_{H P}(t)+\dot{W}_{E C P}(t)\right) \cdot d t}
$$

The value of $P F_{2}$ stands for the performance of the ground loop together with the heat pump, typical components of GSHP systems. Therefore, this definition of performance factor can be very useful in order to compare different GSHP installations.

Performance factor $3\left(P F_{3}\right)$ adds the internal circulation pump to the calculation of the energy performance factor. Therefore, its power consumption is included in the denominator as presented in equation 2.17. In addition, the heat transferred to the 
internal circuit by the internal circulation pump is included in the numerator.

$$
P F_{3}=\frac{\int_{0}^{t}\left(\dot{Q}_{i c}(t) \pm \dot{Q}_{I C P}(t)\right) \cdot d t}{\int_{0}^{t}\left(\dot{W}_{H P}(t)+\dot{W}_{E C P}(t)+\dot{W}_{I C P}(t)\right) \cdot d t}
$$

As a matter of fact, the internal circulation pump losses contribute to heat up the water circulating through the internal hydraulic circuit. For that reason, this heat needs to be added to the heat pump capacity during heating mode while it needs to be subtracted during cooling mode (that is the reason why the sign \pm appears in the equation). However, not all the electrical power consumed by the circulation pump is transferred to the fluid, since part of these losses go to the surroundings, mainly the electrical losses generated at the motor which are transferred to the air through the motor envelope and the fan [61]. The heat delivered by the internal pump can be calculated by applying the thermal and electrical efficiency of the water circulation pump, $\eta_{t h}$ and $\eta_{e l}$ respectively, as presented ni Eq. 2.18 .

$$
\dot{Q}_{I C P}(t)=\eta_{t h} \cdot \eta_{e l} \cdot \dot{W}_{I C P}
$$

The pipes in the circuit are well insulated, hence the thermal losses are negligible. Therefore, nearly all the pump power is employed in heating up the water and the thermal efficiency is assumed to be $1\left(\eta_{t h}=1\right)$. On the other hand, the electrical efficiency is very high and its influence on the results is almost negligible comparing order of magnitudes of the compressor and pumps consumption. Still, a value of $\eta_{e l}=0.9$ has been considered for the study carried out in this dissertation.

Finally, a $4^{\text {th }}$ performance factor can be defined. This performance factor $4\left(\mathrm{PF}_{4}\right)$ would include the fan coil units. Therefore, its power consumption is included in the denominator as presented in equation 2.19 .

$$
P F_{4}=\frac{\int_{0}^{t}\left(\dot{Q}_{i c}(t) \pm \dot{Q}_{I C P}(t)\right) \cdot d t}{\int_{0}^{t}\left(\dot{W}_{H P}(t)+\dot{W}_{E C P}(t)+\dot{W}_{I C P}(t)+\dot{W}_{F C U}(t)\right) \cdot d t}
$$

However, as previously mentioned, the control of the FCUs is completely carried out by the users: fan speed and temperature setpoint. The control system only supplies the required flow rate of water at the required temperature. Therefore, this last energy efficiency parameter $\left(\mathrm{PF}_{4}\right)$ is not considered in this research work, as the FCUs are not included in the energy optimization strategies developed.

All the results regarding energy performance will be obtained for performance factor 3 . Therefore, performance factor 3 is considered as the performance factor of the system $\left(P F_{\text {sys }}=P F_{3}\right)$. This is the most important energy efficiency parameter, since the 
objective is to optimize the global energy performance of the system and $P F_{\text {sys }}$ covers the performance of the complete system working as a whole.

In Eqs. 2.15), 2.16), 2.17) and 2.19, $t$ stands for any integration period required. If the integration period considered is a single day, the PFs will turn into DPFs, and if the whole season is considered, they will turn into SPFs.

Fig. 2.16 shows daily performance factors 1,2 and 3 for a typical cooling day. As it can be observed, the heat pump DPF $\left(D P F_{1}\right)$ is 5.6 , while the system DPF $\left(D P F_{3}\right)$ is deteriorated down to 3.1 , when all the auxiliary equipment (circulation pumps) is considered in the calculation, representing a drop of $45 \%$ in the performance factor of the system. This demonstrates the importance of optimizing the energy performance of the system.

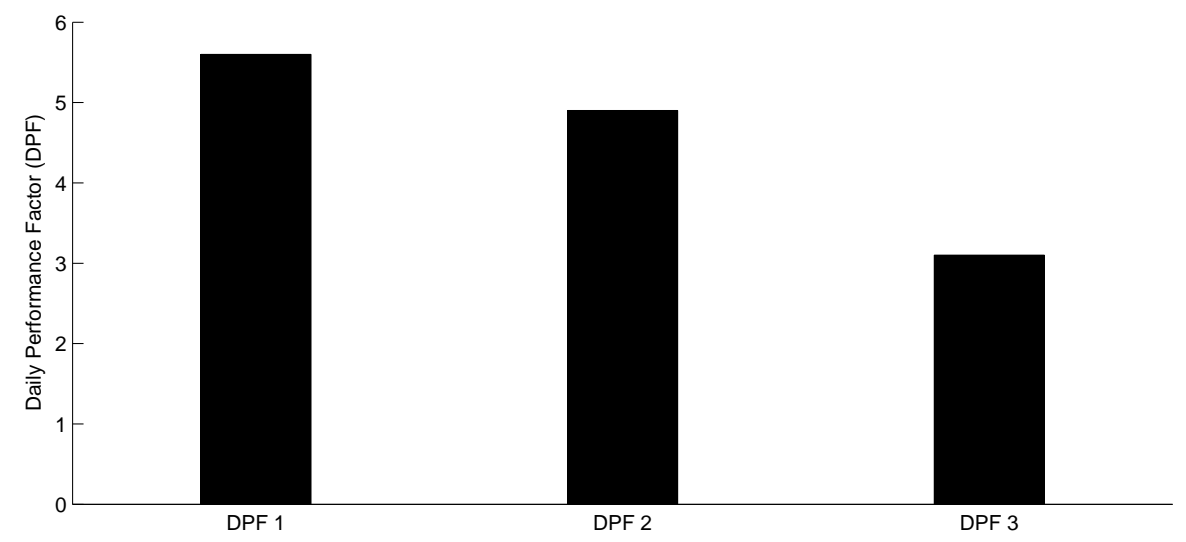

Figure 2.16: Deterioration of the DPF in a typical cooling day.

\subsubsection{Partial load ratio}

In order to optimize the energy performance of the system, a good strategy is trying to adapt its operation to the thermal demand (or thermal load) of the building in real time. This is actually the basis of most of the energy optimization strategies developed in Chapter 3. The thermal load of the building can be either calculated directly from the readings of temperature and flow rate, or indirectly by means of parameters like the partial load ratio (or part load ratio), which provides an accurate estimation of it.

This section presents the estimation of the partial load ratio from experimental data by means of three different approaches for the single-stage case. Then, the estimation is performed for the heat pump with two compressors working in tandem. 


\section{Single-stage compressor case.}

Both the influence of the thermal load of the building in the system operation and the aim of using it as part of the energy optimization strategies justify the importance of a thorough calculation of the partial load ratio. In order to determine the thermal load of the building directly from the experimental readings, it is necessary to establish a control volume. An energy balance applied to this control volume would provide the thermal load. The three control volumes presented in Fig. 2.17 are proposed in order to estimate the thermal load of the building.

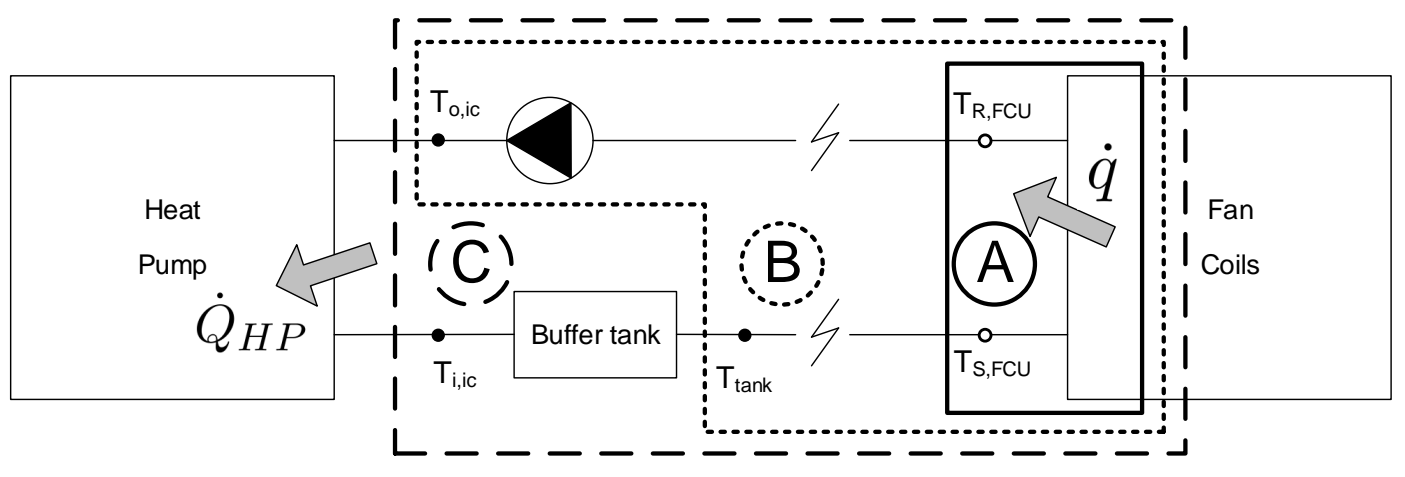

Figure 2.17: Control volumes proposed to determine the thermal load of the building.

Three different estimations of the thermal load are obtained from the three control volumes shown in Fig. 2.17.

1. The first control volume (A) only considers the water circulating through the FCUs, exchanging heat with the air in the offices. Applying the energy balance to control volume A, Eq. 2.20 is obtained for the thermal demand.

$$
\dot{q}_{A}=\dot{m}_{i c} \cdot c_{p, w} \cdot\left(T_{R, F C U}-T_{S, F C U}\right) \approx \dot{m}_{i c} \cdot c_{p, w} \cdot\left(T_{o, i c}-T_{\text {tank }}\right)
$$

Since the values of the water temperatures just at the inlet $\left(T_{S, F C U}\right)$ and outlet $\left(T_{R, F C U}\right)$ of the FCUs are not available, these values are approximated to the temperatures at the outlet of the tank $\left(T_{\text {tank }}\right)$ and the inlet of the heat pump $\left(T_{o, i c}\right)$. The heat losses in the pipes and the variation in the water temperature when going through the circulation pump are neglected for the calculation.

However, the length of the piping system cannot be neglected: there will be a certain delay in the temperature readings at a given moment. Fig. 2.18 depicts the evolution of the water temperature with time $(t)$ and with the length of the pipes $(x)$, for the example of cooling mode.

In order to take into account this delay, the values of temperature considered in Eq. 2.20 should be taken at different moments or time steps. The time that the 


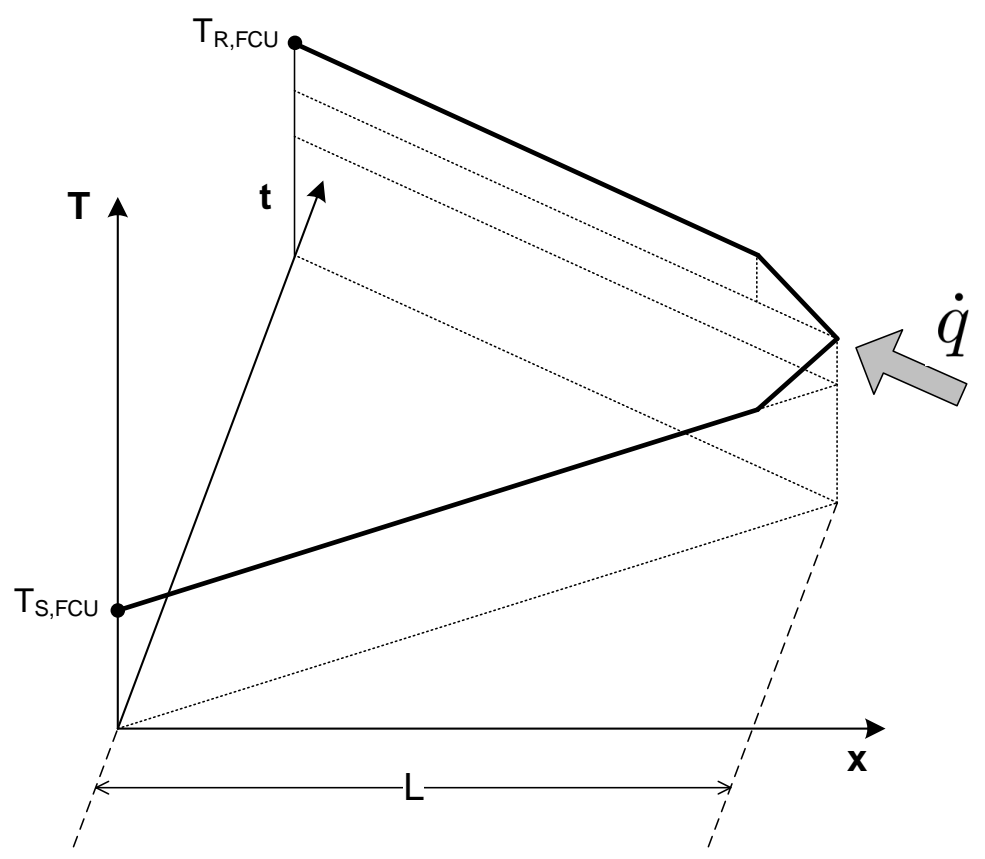

Figure 2.18: Water temperature along the length of the building loop (cooling mode).

water needs to cross the building loop and return to the heat pump depends on its speed $(v)$ and the length of the pipes $(L)$. Therefore, the estimation of the thermal load for control volume A is calculated as provided by Eq. 2.21, where the total length considered is $2 \cdot L$ (return line plus supply line).

$$
\dot{q}_{A} \approx \dot{m}_{i c} \cdot c_{p, w} \cdot\left(T_{o, i c}(t)-T_{\text {tank }}\left(t-\frac{2 \cdot L}{v}\right)\right)
$$

2. The second control volume (B) adds the mass of water in the piping system $\left(M_{w, \text { pipes }}\right)$ to the previous control volume. Therefore, the inertia introduced by this mass of water is taken into account for the new energy balance proposed in Eq. 2.22 .

$$
M_{w, p i p e s} \cdot c_{p, w} \cdot \frac{d T_{o, i c}}{d t}=\dot{q}_{B}-\dot{m}_{i c} \cdot c_{p, w} \cdot\left(T_{o, i c}-T_{\text {tank }}\right)
$$

In this case, the variation of the temperature of the water in the pipes can be determined from the temperature at the outlet of the piping system, that is to say at the inlet of the heat pump $\left(T_{o, i c}\right)$. This way, all the required variables are direct readings from the DAQ system. Finally, the estimation of the thermal load for control volume B is calculated as provided by Eq. 2.23 .

$$
\dot{q}_{B}=M_{w, p i p e s} \cdot c_{p, w} \cdot \frac{d T_{o, i c}}{d t}+\dot{m}_{i c} \cdot c_{p, w} \cdot\left(T_{o, i c}-T_{\text {tank }}\right)
$$


3. Finally, the last option considered (control volume $\mathrm{C}$ ) includes the mass of water inside the buffer tank as well $\left(M_{w, \text { tank }}\right)$. The energy balance for this case is presented in Eq. 2.24.

$$
M_{w, \text { tank }} \cdot c_{p, w} \cdot \frac{d T_{\text {tank }}}{d t}+M_{w, p i p e s} \cdot c_{p, w} \cdot \frac{d T_{o, i c}}{d t}=\dot{q}_{C}-\dot{m}_{i c} \cdot c_{p, w} \cdot\left(T_{o, i c}-T_{\text {tank }}\right)
$$

In this case, the variation of the temperature of the water inside the tank has been estimated by means of the temperature at its outlet $\left(T_{\text {tank }}\right)$. Finally, solving Eq. 2.24 for $\dot{q}_{C}$, Eq. 2.25 is obtained in order to determine the thermal load of the building for control volume $\mathrm{C}$.

$$
\dot{q}_{C}=M_{w, \operatorname{tank}} \cdot c_{p, w} \cdot \frac{d T_{\text {tank }}}{d t}+M_{w, p i p e s} \cdot c_{p, w} \cdot \frac{d T_{o, i c}}{d t}+\dot{m}_{I C P} \cdot c_{p, w} \cdot\left(T_{o, i c}-T_{\text {tank }}\right)
$$

In order to carry out the study of the different estimations proposed for the direct calculation of the thermal load of the building from the experimental readings, experimental data from a typical cooling day in the geothermal plant were used. Fig. 2.19 presents the estimated value of the thermal load for the three proposals, control volumes A, B and $\mathrm{C}$, determined by means of Eqs. 2.21, 2.23 and 2.25 respectively.

It can be observed in Fig. 2.19 that the three estimations show similar values. In addition, the results present a high variability in all cases, mostly due to the noise in the readings of temperatures and flow rates. In the case of $\dot{q}_{B}$ and $\dot{q}_{C}$, the presence of derivatives amplifies the effect of the measurement noise, distorting the obtained results. This is observed comparing Figs. 2.19a, 2.19b and 2.19k, where the results for $\dot{q}_{A}$ are more stable than for $\dot{q}_{B}$ and $\dot{q}_{C}$.

On the other hand, the final objective of calculating the thermal load is the implementation of optimization algorithms which adapt the operation of the system to the thermal demand at each moment. For that purpose, the simpler the better. The fact of having derivatives would complicate the implementation of these algorithms and would make them more unstable. For that reason, the estimation of the thermal demand finally chosen is the first one, $\dot{q}_{A}$, which does not have derivative terms.

Still, the resulting data for $\dot{q}_{A}$ present excessive noise. That is the reason why, in order to reduce the noise introduced by the measuring system, the results are filtered by applying a moving mean with a period of 14 readings. A number of 14 readings was manually chosen because it provided a good value of the noise-signal ratio in the resulting thermal load. For greater values, the accuracy of the results decreased sharply, as the resulting graph was very different from the original graph. The results after applying this filter are shown in Fig. 2.20.

After filtering the data, the variability in the results is considerably reduced. However, the implementation of Eq. 2.21 still means introducing a high uncertainty in the calculations, due to both the possible uncertainties in the experimental data measurements and the 
(a)

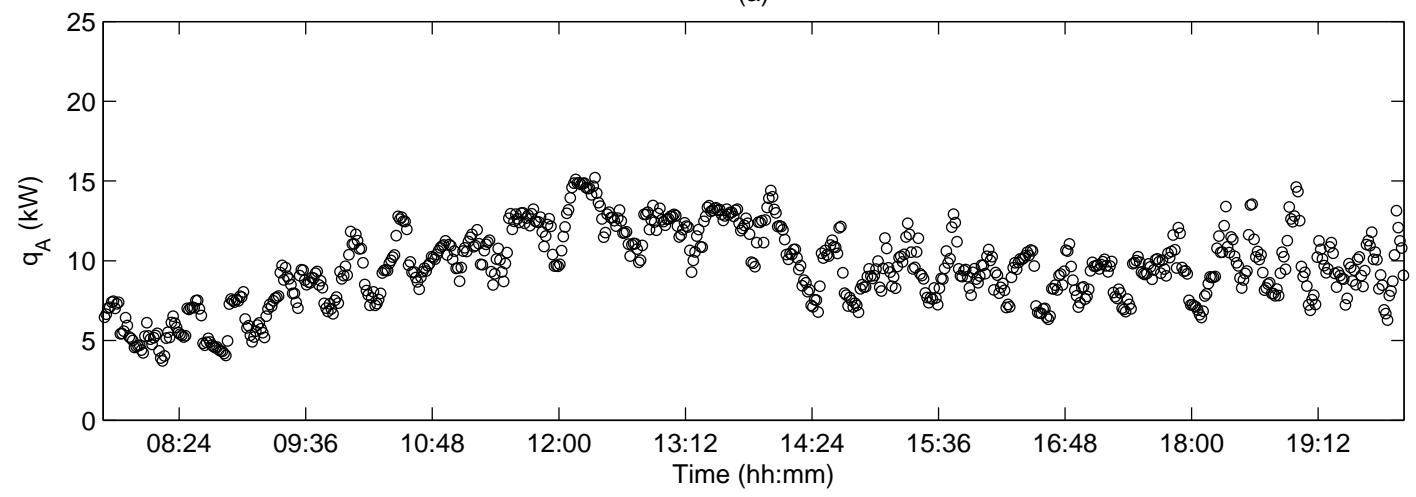

(b)

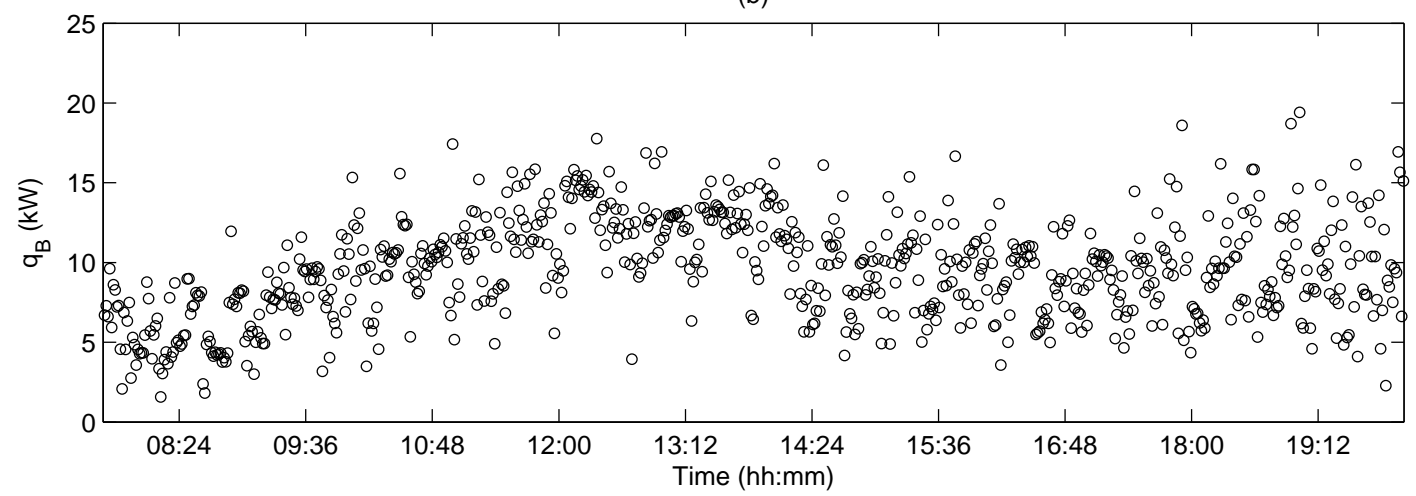

(c)

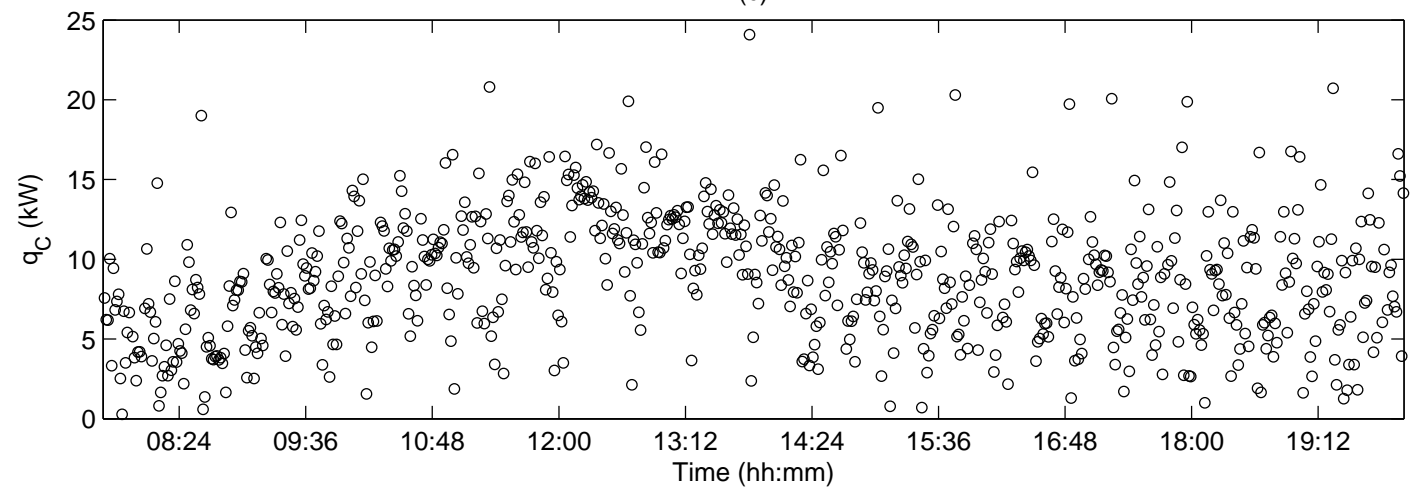

Figure 2.19: Different approximations to determine the thermal load of the building: (a) $q_{A}$; (b) $q_{B}$; (c) $q_{C}$. 


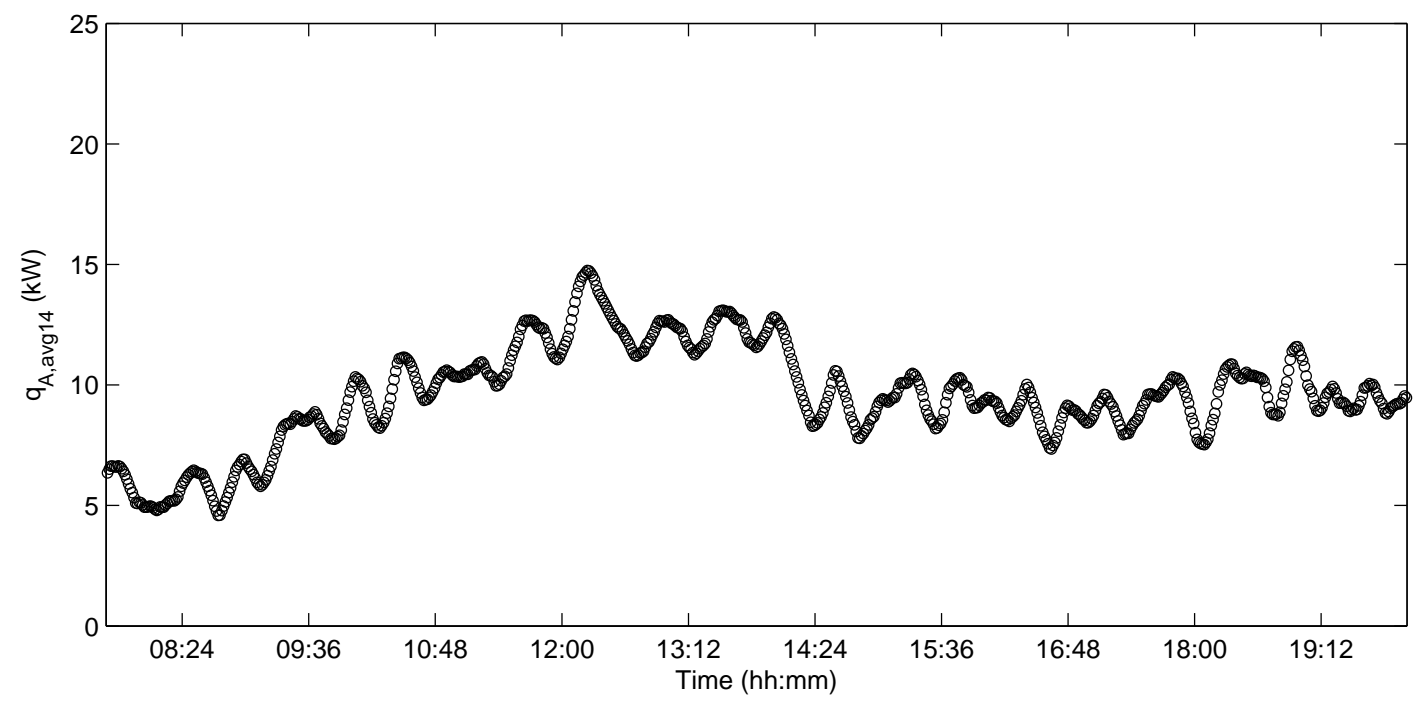

Figure 2.20: Thermal load of the building $\left(q_{A}\right)$ filtered with a moving mean of period 14 .

approximations considered. Moreover, the delay considered in Eq. 2.21 might not be an exact multiple of the data acquisition time step, what would increase the uncertainty in the estimation even more. Therefore, the direct estimation of the thermal load is discarded and an indirect method is considered instead.

In the search for a parameter that could reduce the uncertainly caused by the experimental readings when estimating the thermal demand of the building, the control signal of the heat pump is quite reliable. As it is a digital signal, it is not so sensitive to the presence of measurement noise, so it highly reduces the uncertainty. By using this signal, it is possible to measure the time that the heat pump remains running (ON time) or stopped (OFF time). As described earlier (see Figs. 2.10 and 2.12), the duration of the cycles, and more precisely, the amount of time that the heat pump remains on and off, is directly related to the thermal load of the building. The parameter that quantifies the relation between the ON and OFF times and the thermal load is the partial load ratio $(\alpha)$.

The partial load ratio characterizes the instantaneous thermal load that the system has to cope with $(\dot{q})$ as a percentage of the maximum heat pump capacity $\left(\dot{Q}_{H P}\right)$. The definition of the partial load ratio is presented in Eq. 2.26.

$$
\alpha=\frac{\dot{q}}{\dot{Q}_{H P}}
$$

Assuming that system was designed in such a way that its maximum capacity coincides with the maximum possible thermal load of the building, the partial load ratio would equal 1 for the maximum thermal load and 0 when there is no thermal load at all. A value 
of $\alpha=1$ would be physically possible but very unlikely to happen. However, a value of $\alpha=0$ would not make physical sense. Even in the case that all the FCUs are switched off, there would be a small load due to the thermal losses in the hydraulic circuit. The value of $\alpha$ would be very low in this case, lower than 0.1 , but not zero.

Although the partial load ratio is an instantaneous value by definition, for practical reasons it will be calculated for each cycle of the heat pump, taking into account the total duration of the cycle $\left(t_{T O T A L}\right)$.

$$
\alpha=\frac{\int_{t_{T O T A L}} \dot{q} \cdot d t}{\int_{t_{T O T A L}} \dot{Q}_{H P} \cdot d t}
$$

Looking at any of the graphs in Fig. 2.12, it can be observed that each cycle can be divided into two sections, the ON time $\left(t_{O N}\right)$, when the heat pump is running (HP ON), and the OFF time $\left(t_{O F F}\right)$, when the heat pump is switched off (HP OFF). The addition of both periods of time is the total duration of the cycle $\left(t_{T O T A L}=t_{O N}+t_{O F F}\right)$. The partial load ratio can be obtained by applying an energy balance to each section of the cycle. The energy balance for the $\mathrm{ON}$ and OFF time periods is presented in Eqs. 2.28 and 2.29 respectively, where it is assumed that both the thermal load and the heat pump capacity are constant throughout the cycle.

$$
\begin{gathered}
\left.M_{w} \cdot c_{p, w} \cdot \frac{d T_{\text {control }}}{d t}\right|_{t_{O N}}=\dot{q}-\dot{Q}_{H P} \\
\left.M_{w} \cdot c_{p, w} \cdot \frac{d T_{\text {control }}}{d t}\right|_{t_{O F F}}=\dot{q}
\end{gathered}
$$

In a given cycle, the variation of temperature with time corresponds to the temperature deadband set for the heat pump, but with opposite signs for the different sections of the cycle $\left(\left.\Delta T\right|_{t_{O N}}=-\left.\Delta T\right|_{t_{O F F}}\right)$, as it is observed in Fig. 2.12. Taking into account this fact and integrating Eqs. 2.28 and 2.29, Eq. 2.30 is obtained.

$$
\int_{t_{O N}} \frac{\dot{q}-\dot{Q}_{H P}}{M_{w} \cdot c_{p, w}}=\int_{t_{O F F}} \frac{-\dot{q}}{M_{w} \cdot c_{p, w}}
$$

Finally, the relation between the thermal demand of the building and the maximum heat pump capacity can be obtained by means of solving Eq. 2.30. After solving Eq. 2.30, Eq. 2.31 provides the expression to calculate the partial load ratio of the system as a function of the operating periods, $t_{O N}$ and $t_{O F F}$. In the case of the single-stage heat pump (GEOCOOL heat pump), the partial load ratio is called $\alpha_{\text {single. }}$ It should be noticed that it is assumed that both the thermal load and the heat pump capacity are considered constant throughout the cycle.

$$
\alpha_{\text {single }}=\frac{\dot{q}}{\dot{Q}_{H P}}=\frac{t_{O N}}{t_{O N}+t_{O F F}}
$$


This study for the determination of the partial load ratio was presented in [62].

\section{Multi-stage compressor case}

The expression provided in Eq. 2.31 to calculate the partial load ratio is only true for single-stage ON/OFF controlled units. However, as depicted in Fig. 2.13, a multi-stage heat pump has a slightly different performance.

When analysing a multi-stage heat pump unit, which consists of a specific number of compressors $(N)$ working in tandem, the thermal demand of the building will determine the number of stages in operation and thus the compressor consumption. In this case it is necessary to define a parameter that characterizes the operation state of the heat pump, referred to in the following as $n$. For a given state $n$, there will be $n-1$ compressors running continuously and the $n$th compressor cycling $\mathrm{ON} / \mathrm{OFF}$.

In the particular case considered in this PhD work (two compressors working in tandem), there will be two different operation states: the periods when there is one compressor cycling $\mathrm{ON} / \mathrm{OFF}$, as if it was a single stage unit (state $n=1$ ), and the time when there is one compressor continuously running and the other one switching on and off (state $n=2$ ). Fig. 2.21 shows an example of the evolution of the two different states via the control signal of the compressors.

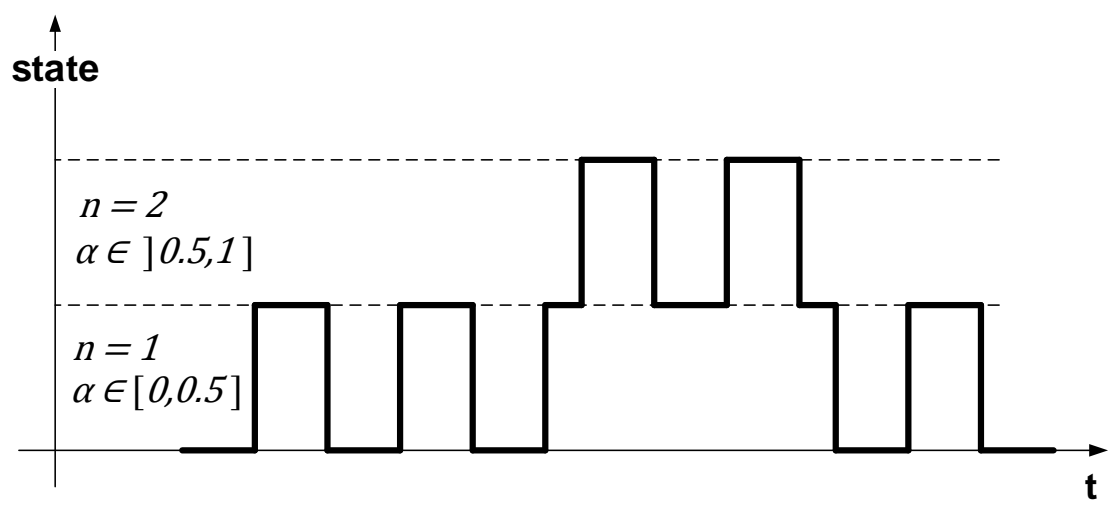

Figure 2.21: Heat pump operation state for the GROUD-MED heat pump.

As it can be observed in Fig. 2.21, the heat pump remains in state $n=1$ for partial load ratios lower than or equal to $50 \%(\alpha<=0.5)$. On the other hand, the heat pump enters state $n=2$ for values of the partial load ratio of the system greater than $0.5(\alpha>0.5)$. Therefore, Eq. 2.31 would only be valid for calculating the partial load ratio of each one of the stages, which will be referred to in the following as $\alpha_{1}$. 
In brief, when determining the partial load ratio of a multi-stage heat pump unit, two different parameters should be distinguished: the partial load ratio of the system $(\alpha)$ and the partial load ratio of each one of the operation states $\left(\alpha_{1}\right)$. The partial load ratio of each state is calculated by means of Eq. 2.32, considering the corresponding operating times $\left(t_{O N}\right.$ and $\left.t_{O F F}\right)$.

$$
\alpha_{1}=\frac{t_{O N}}{t_{O N}+t_{O F F}}
$$

In the particular case of the GROUND-MED heat pump (two compressors working in tandem), the operating times to consider are the following:

- For state $n=1, t_{O F F}$ is the time during which the heat pump is switched off and $t_{O N}$ is the time during which only one stage is running.

- For state $n=2, t_{O F F}$ is the time during which the second stage is switched off and the first stage is continuously running; and $t_{O N}$ is the time during which both compressors are running.

On the other hand, the partial load ratio of the system $(\alpha)$ needs to be calculated, since it is the parameter that actually represents the thermal load of the system. In order to calculate $\alpha$, an expression that relates the partial load ratio of each state with that of the entire system is required.

In order to characterize the thermal demand of the building in this kind of multi-stage heat pump systems, an energy balance can be applied to the system as presented in Eq. 2.33. The left hand side term in Eq. 2.33 stands for the thermal energy provided by the heat pump, whereas the right hand side term stands for the thermal energy demanded by the building for a given ON/OFF cycle, assuming that the energy losses to the ambient are negligible.

$$
t_{O N} \cdot \frac{\dot{Q}_{H P}}{M_{w} \cdot c_{p, w}} \cdot \frac{n}{N}+t_{O F F} \cdot \frac{\dot{Q}_{H P}}{M_{w} \cdot c_{p, w}} \cdot \frac{n-1}{N}=\left(t_{O N}+t_{O F F}\right) \cdot \frac{\alpha \cdot \dot{q}}{M_{w} \cdot c_{p, w}}
$$

In Eq. 2.33, $\dot{Q}_{H P}$ is the total capacity of the heat pump (with two stages running), and $N$ stands for the total number of compressors of the multi-stage heat pump unit assuming all of them of the same capacity as a hypothesis for the calculation, as it allows to simplify the problem. This will facilitate the programming of the optimization algorithms in the control board of the system, making it more reliable.

Considering Eq. 2.33 and the definition of the partial load ratio of each state $\left(\alpha_{1}\right)$ given by Eq. 2.32 , Eq. 2.34 is obtained, which provides the relation between the partial load ratio of each state $\left(\alpha_{1}\right)$ and that of the entire system $(\alpha)$ in a multi-stage heat pump unit with two compressors working in tandem.

$$
\alpha=\left(1-\alpha_{1}\right) \cdot \frac{n-1}{N}+\alpha_{1} \cdot \frac{n}{N}
$$


The relation between $\alpha$ and $\alpha_{1}$ given by Eq. 2.34 is graphically depicted in Fig. 2.22, It can be observed that values of $\alpha_{1}$ from 0 to 1 result in values of $\alpha$ from 0 to 0.5

It can also be observed that there is a discontinuity in Eq. 2.34: a value of $\alpha=0.5$ can be obtained either for a value of $\alpha_{1}=1$ when the operation state is $n=1$, or for a value of $\alpha_{1}=0$ when the operation state is $n=2$. This discontinuity is solved as shown in the intervals written in Fig. 2.21 the value of $\alpha=0.5$ is considered for state $n=1$ (the state is $n=1$ when $\alpha<=0.5$ ). For state $n=2$, the value of $\alpha=0.5$ that would result for $\alpha_{1}=0$ is disregarded (the state is $n=2$ when $\alpha>0.5$ ). In fact, this decision does make sense. A value of $\alpha_{1}=1$ would be physically possible according to its definition if the first compressor is continuously running during a whole day (there is no OFF time in Eq. 2.32 because the thermal load of the building keeps a constant value exactly equal to half of the HP capacity). However, a value of $\alpha_{1}=0$ would not make physical sense, since that would mean that there is no ON time and this could only happen if the heat pump is out of order. In fact, even in the case that all the FCUs are switched off, there would be a small load due to the thermal losses in the hydraulic circuit. The value of $\alpha_{1}$ would be very low in this case, lower than 0.1 , but not zero.

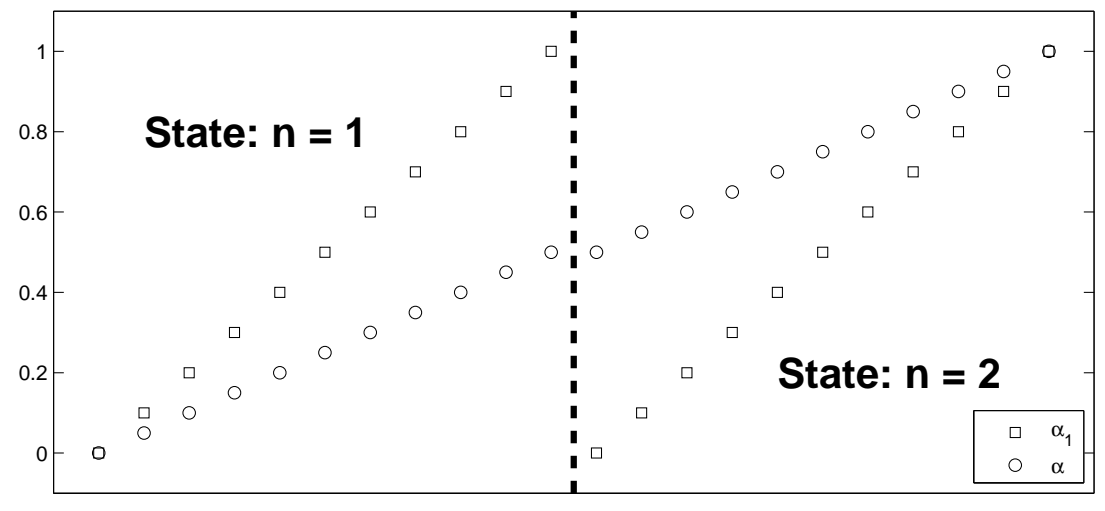

Figure 2.22: Relation between $\alpha_{1}$ and $\alpha$ as a function of the operation state $(n)$.

In conclusion, by means of the operation times $\left(t_{O N}\right.$ and $\left.t_{O F F}\right)$ and knowing the operation state at which the heat pump is working $(n)$, it is possible to obtain the partial load ratio of the system by applying Eqs. 2.32 and 2.34 The value obtained is a reliable value that can be implemented in the control board of the system in order to apply energy optimization strategies that make the system adaptive to the thermal demand of the building.

\subsubsection{Historical performance}

The geothermal plant studied in this $\mathrm{PhD}$ work has been completely monitored since it began its regular operation in February 2005. Therefore, a great bunch of data sets have 
been collected, allowing the analysis and determination of the most relevant parameters of the system performance and the study of their evolution along the years.

In [57], a computer tool based on spreadsheets is presented by F. Ruiz-Calvo in order to analyze the data. The data presented in that paper correspond to the period 2005-2011. In the following, a summary of the main eventualities that have occurred at the plant during this period is presented. Moreover, a brief description of the main eventualities happened during the period 2012-2015, during which this research work has been carried out, is also presented.

$2005 \rightarrow$ A comparison study was performed during the first year of operation of the system, switching between an air to water heat pump and the GSHP, thus, there were some days when the GSHP was not working. Conclusions of this study were presented in [19].

2006-2007 $\rightarrow$ After the first year and up until June 2007, there are very few days of normal operation registered, since the installation was subjected to several maintenance and tuning operations.

2007-2009 $\rightarrow$ The system has been working more or less continuously since June 2007 . Still there are days not representative of the typical daily performance of the installation, mainly due to maintenance operations being carried out, to DAQ system failures, or to some frecuency optimization tests performed (see more details in [61]).

2009-2010 $\rightarrow$ Some optimization strategies where carried out during 2009 and 2010, modifying the temperature settings, in the framework of the GROUND-MED project [50]. Moreover, the internal tank was changed in May 2009, and it was moved to the supply line, right after the heat pump, in order to allow a more accurate control of the water temperature supply to the building.

$2011 \rightarrow$ The original heat pump was replaced with a new one, with two compressors, in May 2011, also in the framework of the GROUND-MED project. During the first month of operation of the new heat pump, the external circulation pump was not cycling off with the heat pump, which leads to data sets considerably different than the standard ones. After this was corrected, and during the remaining months of the cooling season, the system operation was mostly the typical one, as described in Section 2.2.6.

$2012 \rightarrow$ Starting from year 2012, a series of optimization studies continued in the installation also in the framework of GROUND-MED project. During the summer, some optimization strategies were applied to the system, modifying both the temperature settings and the flow rates through both the internal and the external circuit. Is should also be pointed out that there are no valid days for the month of August, as the installation was turned off during holidays. This efficiency measure of switching off the installation during the vacation month of August has been kept up to currently. 
$2013 \rightarrow$ The optimization studies carried out during year 2012 led to the use of the optimized algorithm on a regular basis during most of year 2013. In order to compare the performance of the optimized system to a standard operation, the system is programmed in such a way that a standard algorithm was applied on odd days and the optimized algorithm was used on even days. This is a good method for randomly choosing when to apply each strategy and obtaining, in the long term, $50 \%$ of the days working with each one, getting a rather fair comparison. The standard control was configured according to the requirements of GROUNDMED project as far as the temperature setpoint was concerned: maximum setpoint of $40^{\circ} \mathrm{C}$ in heating mode, and minimum setpoint of $10^{\circ} \mathrm{C}$ in cooling mode. This restrictions also applied to the limits configured in the algorithm of the optimised control.

At the beginning of the year, the daily timetable of the system operation was modified. The system used to operate 15 hours per day: from $7 \mathrm{am}$ to $10 \mathrm{pm}$ in cooling mode, and from $6 \mathrm{am}$ to $9 \mathrm{pm}$ in heating mode. However, the use of the heating and cooling system was revised and it was decided to reduce the time of operation down to 13 hours per day, in order to save energy adapting the timetable to the users daily activity.

In April 2013, the heat pump controller, manufactured by Carel, was reprogrammed, including the possibility to use the control strategy presented in Section 3.4.2, but also keeping the possibility of using the former control. Moreover, this new controller allowed the user choosing whether to use as the control sensor the temperature probe located on the return line or the one located on the supply line, (the study of the location of the control temperature sensor is presented in Section 3.3.

During the month of August, some maintenance operations had to be carried out. Finally, during the months of November and December, the optimized algorithm was applied everyday following the guidelines of GROUND-MED project. This strategy was followed during the first months of year 2014 .

$2014 \rightarrow$ During the first months of year 2014 (from January to April), the optimized algorithm continued to be applied on a daily basis in order to complete the tests campaign for heating mode. On June 2014, the test campaign was stopped in order to develop and include some upgrades in the optimized algorithm. The reason to do this was that it was found that there was a lack of comfort conditions in some of the offices, above all in extreme weather conditions during summer. Therefore, the standard algorithm was applied for the rest of the year, except for some isolated days employed to tune up the upgraded optimized algorithm. GROUND-MED project finished on December 2014.

$2015 \rightarrow$ The upgraded optimized algorithm to ensure the user comfort was finally developed and implemented in the system control board in year 2015. It started its regular application (that is to say, on alternating days: standard algorithm on odd days and optimized algorithm on even days)on May 2015 and it continues currently. 
With the end of GROUND-MED project on December 2014, the standard control introduced earlier was redefined. It was decided that the limits established by GROUND-MED where out of the scope of common operation. Therefore, following a more general criterion, and after consulting the FCUs manufacturer, CIAT, the following new limits for the building supply temperatures were defined: maximum setpoint of $45^{\circ} \mathrm{C}$ in heating mode, and minimum setpoint of $7^{\circ} \mathrm{C}$ in cooling mode.

\subsubsection{Short-term performance. Analysis of typical days}

In order to optimize the energy performance of the GSHP installation studied in this research work, a previous step is to know exactly how the system works. In order to do this, a thorough analysis of the evolution with time of the main variables is carried out. The main system temperatures, that is to say, the temperatures at the inlet and outlet of both the internal and the external circuit $\left(T_{i, i c}, T_{o, i c}, T_{i, e c}\right.$ and $\left.T_{o, e c}\right)$, are analysed. The water flow rates and the heat pump capacity are also studied. Moreover, the partial load ratio is presented for the studied days.

This analysis is carried out for both operation modes, cooling and heating, and only for the GROUND-MED heat pump, as it was the one installed at the geothermal plant when this research work started. Several typical days, with different thermal loads, are analysed for both modes.

As for the GEOCOOL heat pump, Felix Ruiz-Calvo presented in his PhD thesis 63 the analysis of its performance. From the results, it was concluded that the system was working with partial load ratios lower than 0.5 during most of the time. That was the reason why, in the framework of GROUND-MED project, the former heat pump (GEOCOOL heat pump) was replaced by the current heat pump with two compressors working in tandem (GROUND-MED heat pump), which was expected to fit better to the instantaneous thermal demand.

\section{Cooling mode performance}

Fig. 2.23 depicts the evolution with time of the main system temperatures: temperature at the inlet of the internal circuit $\left(T_{i, i c}\right)$, at the outlet of the internal circuit $\left(T_{o, i c}\right)$, at the inlet of the external circuit $\left(T_{i, e c}\right)$, and at the outlet of the external circuit $\left(T_{o, e c}\right)$, for two typical days in cooling mode: one with low thermal load (Fig. 2.23 ), and one with medium thermal load (Fig. 2.23 b).

As it can be observed in Fig. 2.23 , the system starts at 7 am and stops at $10 \mathrm{pm}$. During the night, the four temperatures tend to the same value, as the system is turned off during the night. Focusing on the evolution of the temperatures in the internal circuit in Fig. 2.23 , it can be observed that, when the installation starts in the early morning, the system has to cool down all the water that was heated up during the night, as the 
(a)

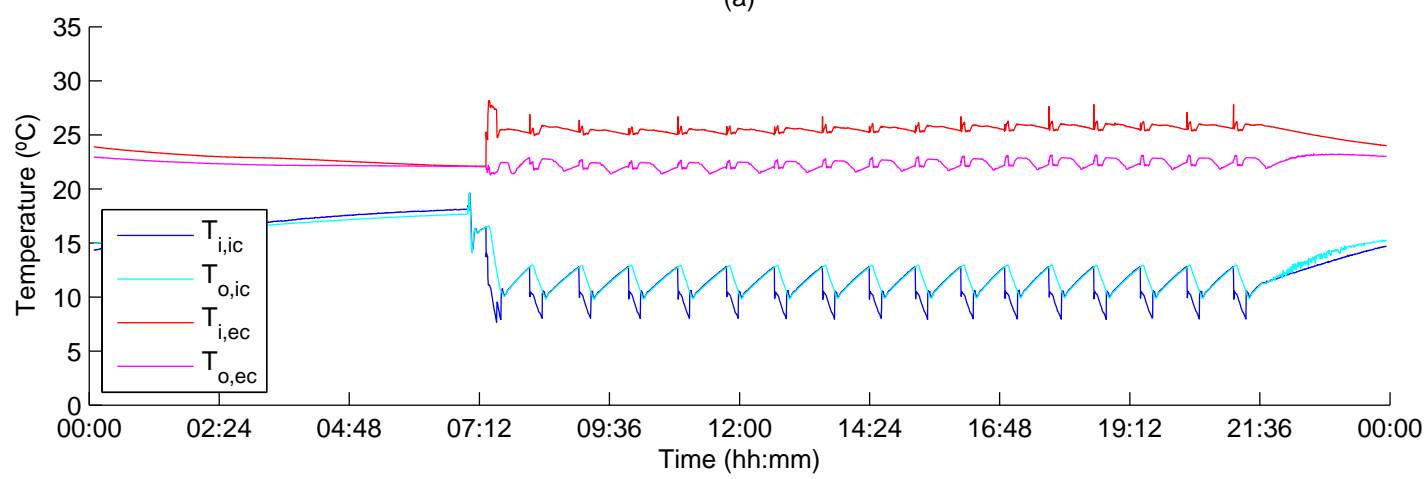

(b)

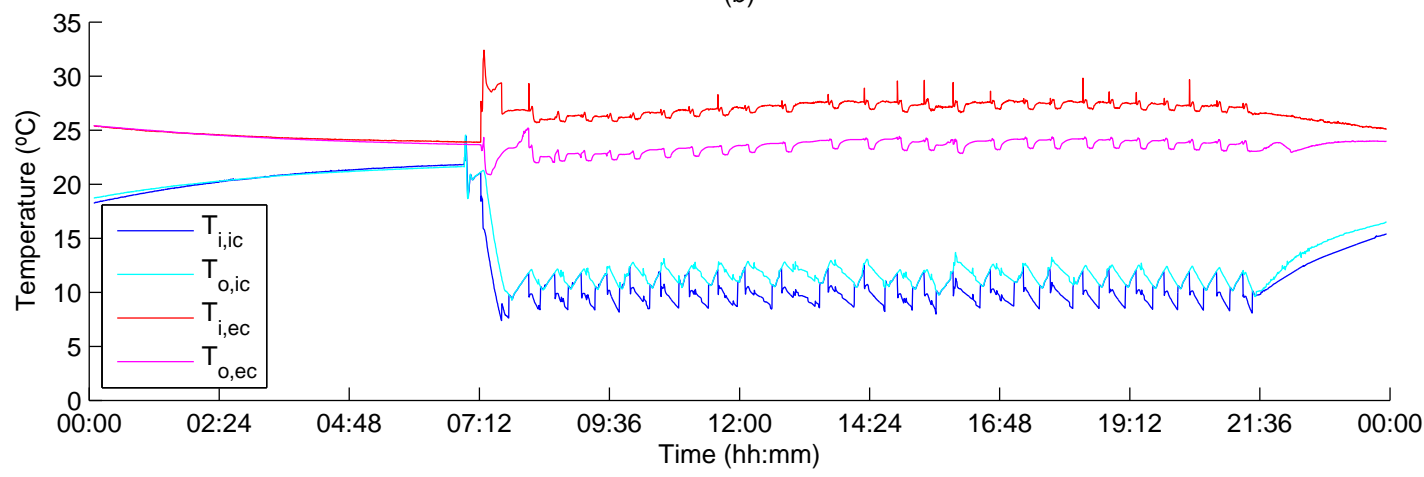

Figure 2.23: System water temperatures in cooling mode: (a) Low load (2012/10/18); (b) Medium load (2013/06/13). 
installation was switched off. The system cools down the water until it reaches the value of the temperature setpoint. In this case, the temperature setpoint is $10^{\circ} \mathrm{C}$, as required by the specifications of GROUND-MED project. In that moment, the heat pump switches off, the values of the temperatures $T_{i, i c}$ and $T_{o, i c}$ become equal and they start to increase, heated up by the effect of the thermal demand of the building. This cycling of the heat pump continues during the whole day. See section 2.2.2 to remember how the heat pump control works.

In Fig. 2.23 , the ON time periods are rather short compared to the OFF time periods. In Fig. 2.23b however, which represent a medium load, presents longer ON time periods and shorter OFF periods. This increase in the length of the ON periods is due to a higher thermal load, which makes the heat pump need more time to cool down the water.

Regarding the temperatures in the external circuit, they reflect the behaviour of the ground heat exchanger and the external circuit. It can be observed in both Fig. 2.23a and Fig. $2.23 \mathrm{p}$ that the temperatures $T_{i, e c}$ and $T_{o, e c}$ do not become equal, as it might be expected. This is because the external circulation pump is switched off at the same time that the heat pump is switched off. This means that the water stops circulating through the pipes in the external circuit. Therefore, the temperature of the water at the outlet of the external circuit varies very slowly and it does not get the value of the temperature at the inlet.

The cycling of the external circulation pump can be observed in Fig. 2.24, which shows the water flow rates in both the internal $\left(\dot{m}_{i c}\right)$ and the external $\left(\dot{m}_{e c}\right)$ circuit.

The same typical days presented earlier are presented in Fig. 2.24. low thermal load (Fig. $2.24 \mathrm{a}$ ) and medium thermal load (Fig. 2.24 b). It can be observed that, while the external pump switches on and off with the heat pump, the internal pump is running during the 15 hours of system operation. This means an important source of power consumption that needs to be reduced, as it will be seen later.

Fig. 2.25 shows the capacity of the heat pump, calculated as presented in 2.3 in section 2.2.1 Both the heat exchanged with the internal circuit $\left(\dot{Q}_{i c}\right)$ and the external circuit $\left(Q_{e c}\right)$ are depicted.

It can be observed in Fig. 2.25 that the first cycle performed by the heat pump in the early morning is a special one, as the second compressor is switched on. This happens because the temperature of the water in the piping increases during the night, as the heat pump is switched off. In the morning, when the system starts, the temperature of the water is far from the setpoint, and above its upper limit, what means that both compressors start in order to cool down the water at a quicker pace (see Fig. 2.23). When the temperature of the water reaches the medium limit (see 2.2.2), the second compressor stops. Finally, when the temperature of the water reaches the lower limit, the remaining compressor stops too. In fact, this happens soon after the second compressor has stopped, what means that this behaviour is not representative of the real thermal load, but a side effect of switching off the heat pump during the night. For that reason, this first cycle 
(a)

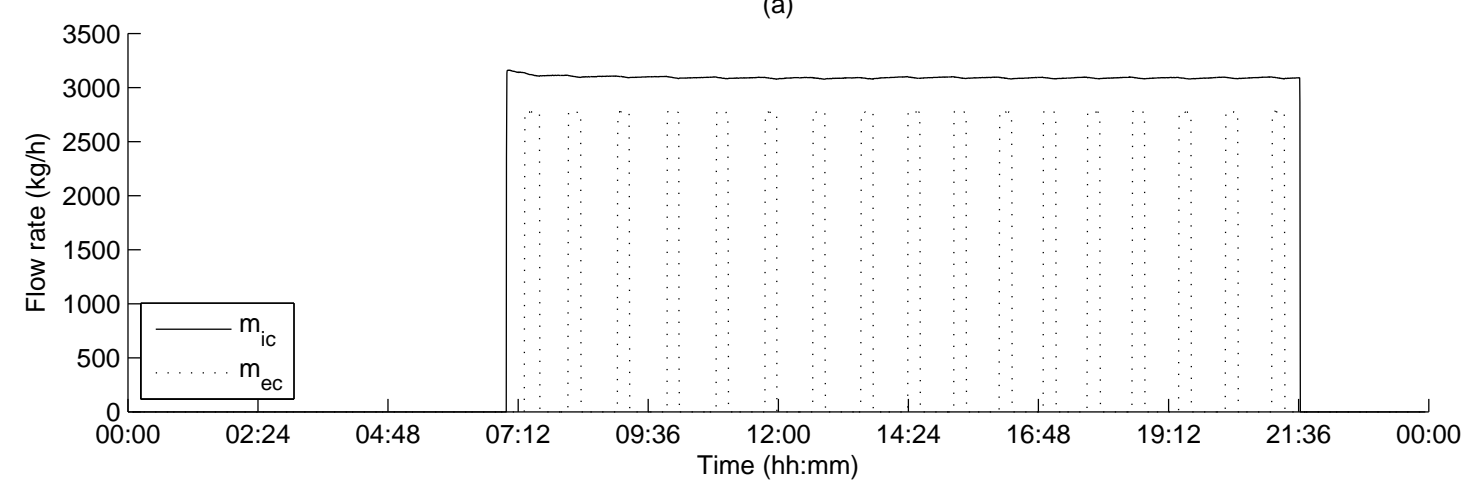

(b)

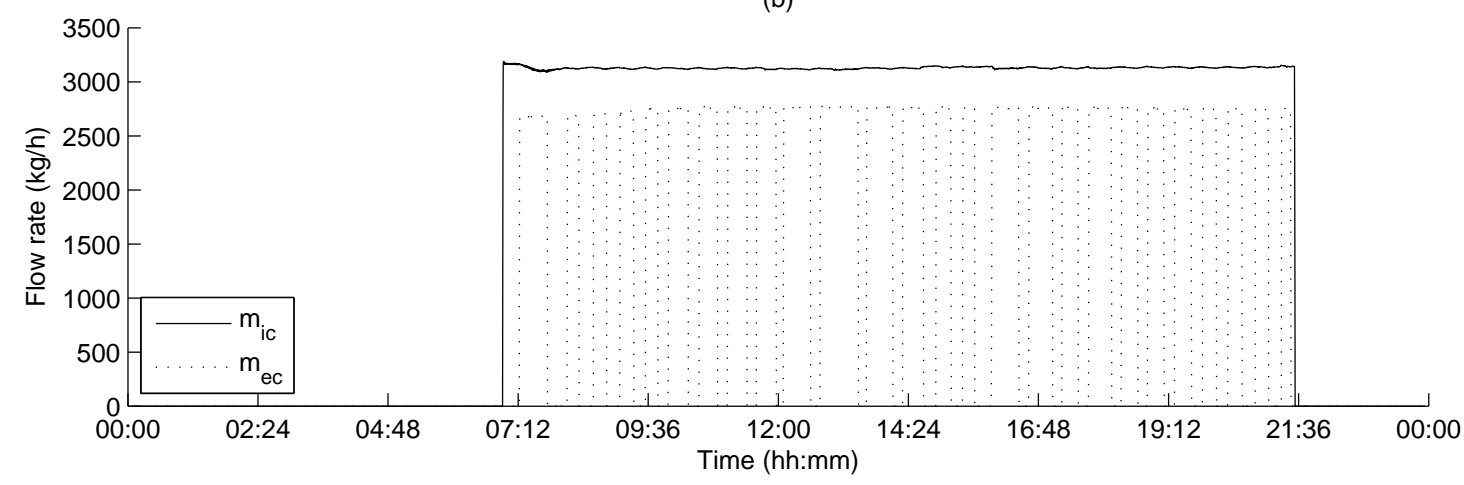

Figure 2.24: Water flow rates in cooling mode: (a) Low load (2012/10/18); (b) Medium load $(2012 / 06 / 13)$. 
(a)

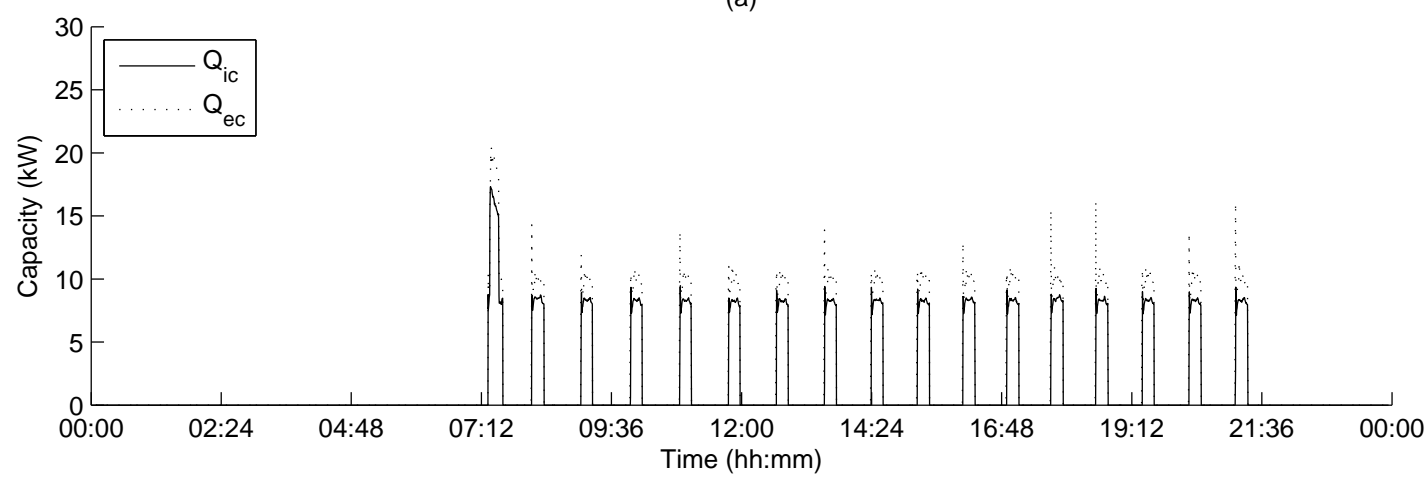

(b)

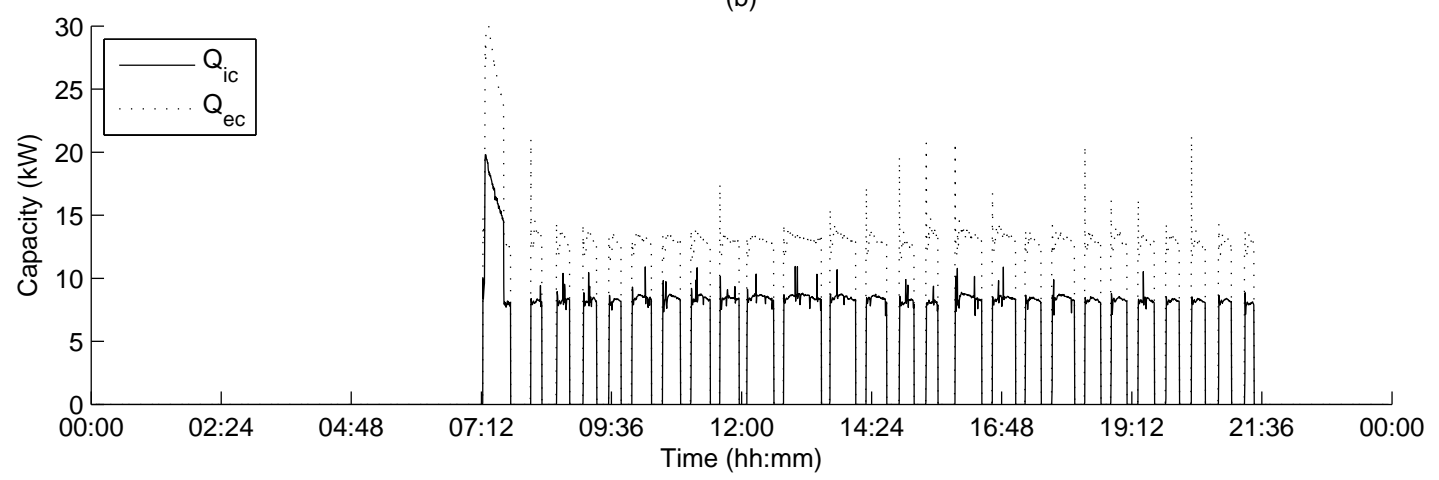

Figure 2.25: Cooling capacity: (a) Low load (2012/10/18); (b) Medium load (2012/06/13). 
will not be considered when calculating the average thermal load of the day.

Fig. 2.26 shows the main power consumptions of the system: the heat pump $\left(\dot{W}_{H P}\right)$, the external circulation pump $\left(\dot{W}_{\text {ecp }}\right)$, the internal circulation pump $\left(\dot{W}_{i c p}\right)$ and the fan coil units $\left(\dot{W}_{F C}\right)$. This four consumptions are the ones providing the definition of the four performance factors introduced in Section 2.2.3. The same typical days are depicted in this figure.

(a)

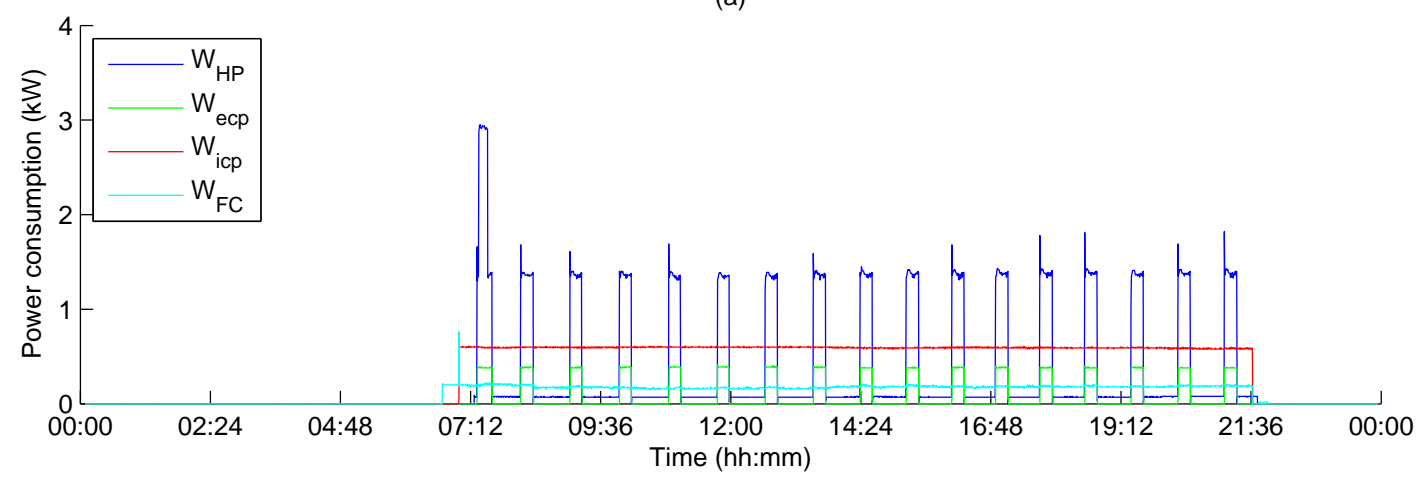

(b)

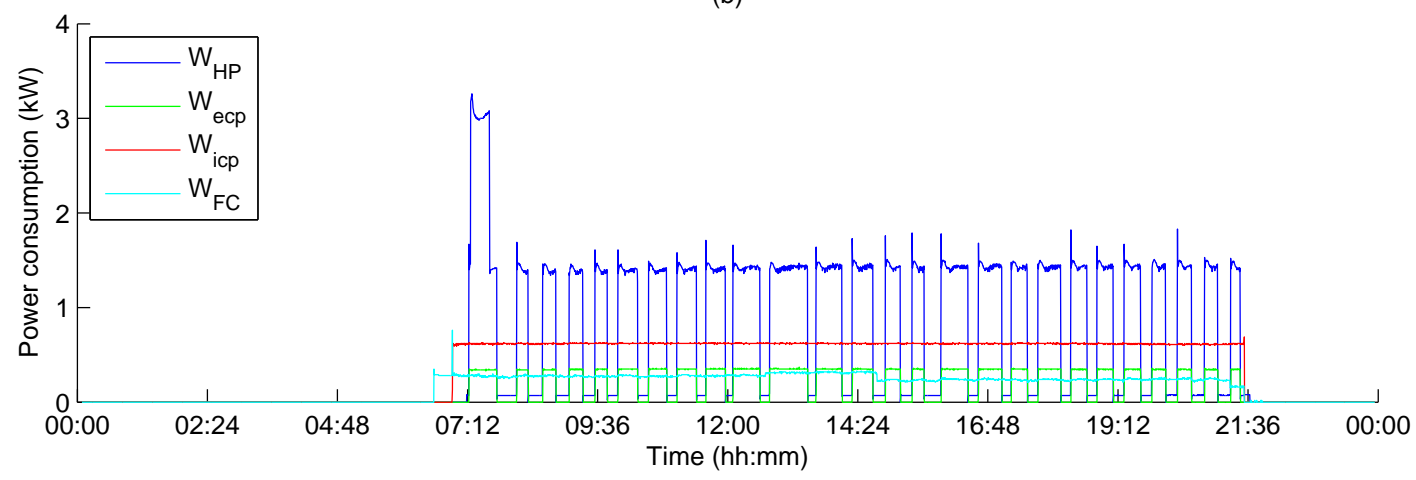

Figure 2.26: Power consumption in cooling mode: (a) Low load $(2012 / 10 / 18)$; (b) Medium load (2012/06/13).

As it can be observed in Fig. 2.26, the highest consumption comes, as expected, from the heat pump $\left(\dot{W}_{H P}\right)$. The consumption of the heat pump in cooling mode is around $1.5 \mathrm{~kW}$ for one compressor, and around $3 \mathrm{~kW}$ when the two compressors are running. As for the circulation pumps, a simple calculation is enough to realise that they represent an important energy consumption. Together, they consume $0.8 \mathrm{~kW}$ of power, what represents $35 \%$ of the total power consumption (without considering the fan coil units). This points out what was already mentioned during the analysis of the state of the art in section 1.2. the consumption of the auxiliary equipment is an important source of energy consumption that needs to be reduced. There is a huge potential for improvement in this part of the system, which will be exploited in Chapter 3 of this dissertation. 
Regarding the FCUs, their power consumption is also important. Nevertheless, as mentioned in section 2.1.2, the only action taken with a view to improve the energy efficiency of the FCUs was the replacement of three fan coils with three more efficient ones. The control of all the fan coils (velocity and setpoint temperature) is changed manually by the user and has not been included in the global energy optimization strategies developed in this dissertation.

In Fig. 2.27, another typical cooling day is presented, this time with a higher load, typical of the month of July. Fig. 2.27 a shows the system water temperatures $\left(T_{i, i c}, T_{o, i c}, T_{i, e c}\right.$ and $\left.T_{o, e c}\right)$, while Fig. $2.27 \mathrm{~b}$ depicts the main power consumptions of the system $\left(\dot{W}_{H P}\right.$, $\left.\left.\dot{W}_{\text {ecp }}\right), \dot{W}_{i c p}\right)$ and $\dot{W}_{F C}$ ).

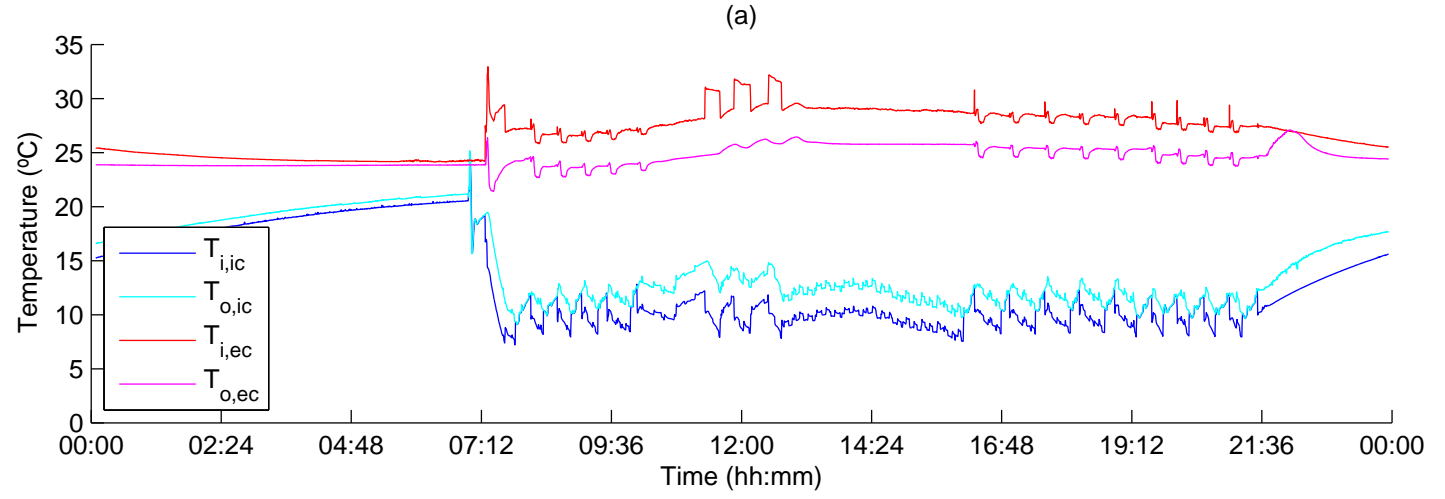

(b)

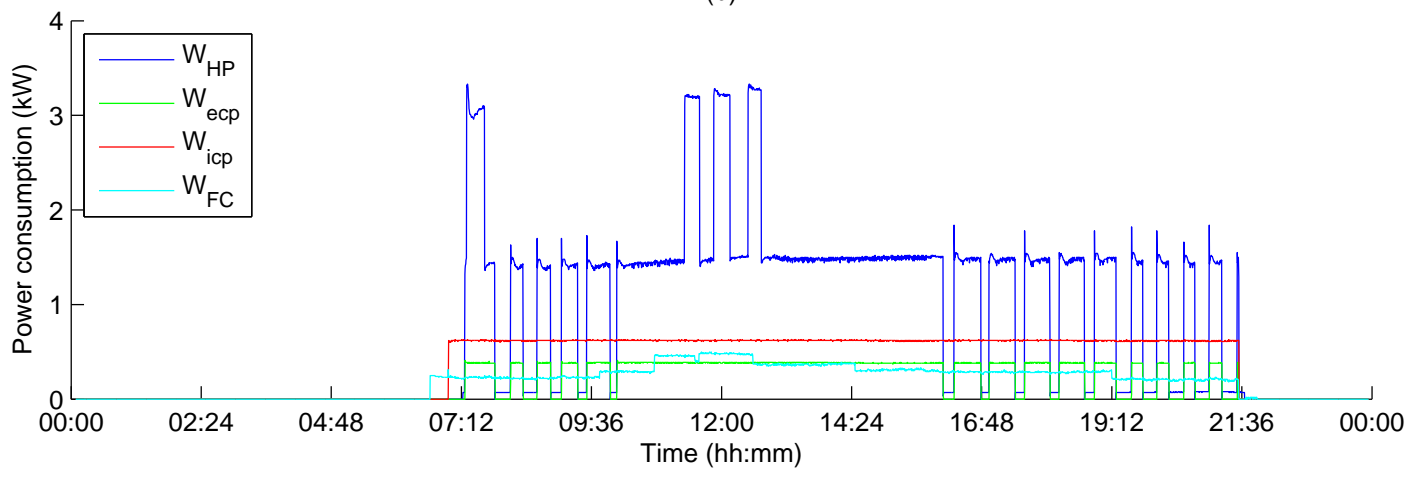

Figure 2.27: High load day in cooling mode (2012/07/10): (a) System temperatures; (b) Power consumption.

It can be observed in Fig. 2.27 that, when both compressors are running in the middle part of the day, the temperature of the water at the outlet of the internal circuit is higher than when there is only one compressor running. This effect was commented earlier in this section and described in Section 2.2.2. In fact, it would be preferable to keep the same band of temperatures independently of the number of compressors running. The improvement of this behaviour is part of the optimization strategies described in Chapter 
3 .

In addition, it can also be observed in Fig. 2.27 that, during this period in which the heat pump alternates between one and two compressors, the temperature difference between the water at the inlet and outlet of the internal circuit (temperature difference in both sides of the evaporator in cooling mode) is higher with two compressors than with one compressor running. Moreover, the temperatures $T_{i, i c}$ and $T_{o, i c}$ never get equal values in this period, as there is always at least one compressor running.

As for the power consumptions, the consumption of the heat pump when two compressors are running is around $3 \mathrm{~kW}$. This would mean an impact of the circulation pumps in the total power consumption of $21 \%$. Nevertheless, it should be said that the installation works normally with one compressor, and it is only during July that the second compressor operates on a regular basis, as the thermal demand is as big as to do so. Very few days, except for this month, the need of switching on the second compressor arises.

Finally, Fig. 2.28 shows the evolution of the thermal load along the three typical days analysed earlier, by using the partial load ratio calculated as presented in Section 2.2.4.
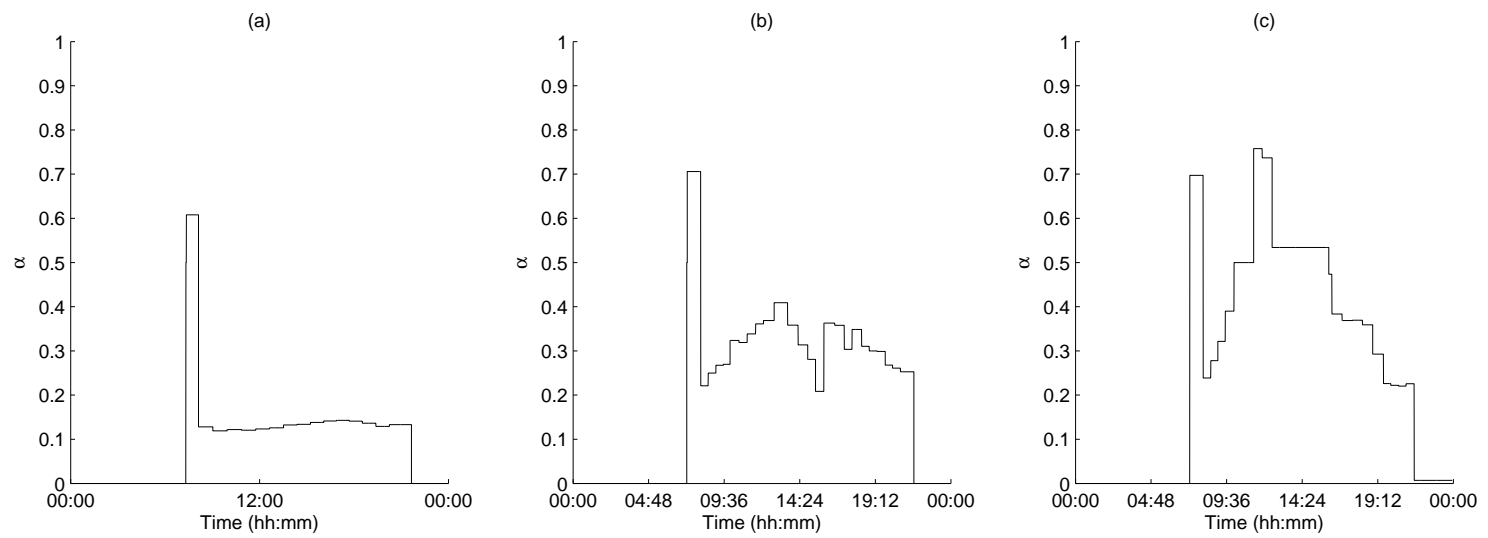

Figure 2.28: Different load ratios in cooling mode: (a) Low load $(2012 / 10 / 18)$; (b) Medium load (2012/06/13); (c) High load (2012/07/10).

It can be observed in Fig. 2.28 that the thermal demand is higher during central hours of the days and part of the early afternoon, as the partial load ratio in these periods is higher. It can also be observed that the first cycle in the morning presents a value of the partial load ratio which does not seem to be representative, as it differs from the rest of cycles in the day. As mentioned earlier in this section, this cycle will not be considered for average load calculations. 


\section{Heating mode performance}

In heating mode, a similar analysis of the system performance can be carried out. Fig. 2.29 depicts the evolution with time of the main system temperatures $\left(T_{i, i c}, T_{o, i c}, T_{i, e c}\right.$ and $\left.T_{o, e c}\right)$. Two typical days in heating mode are presented: one with low thermal load (Fig. 2.29 ), and one with medium thermal load (Fig. 2.29p). In this case, the ON cycles correspond to the heat pump heating up the water in the system.

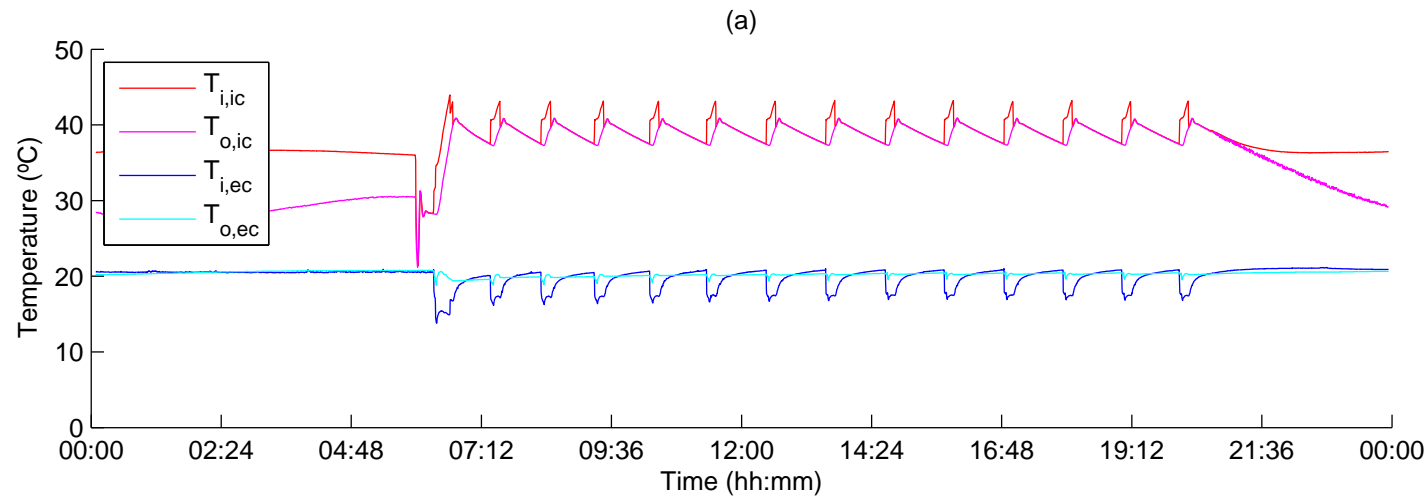

(b)

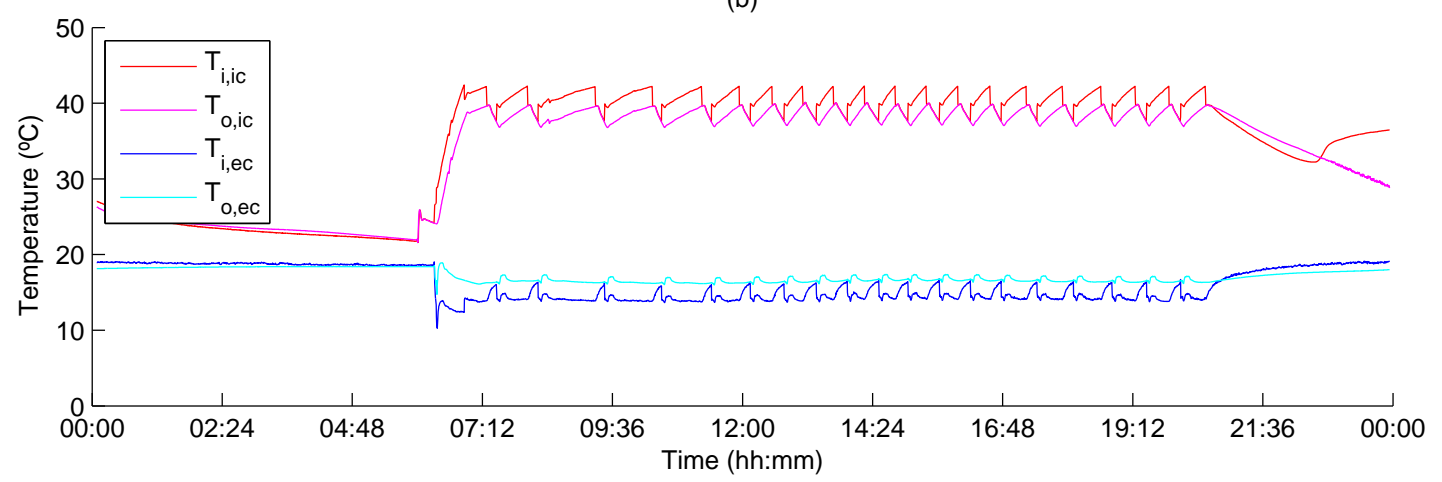

Figure 2.29: System water temperatures in heating mode: (a) Low load (2012/10/31); (b) Medium load (2012/12/20).

As it can be observed in Fig. 2.29, the system starts at 6 am and stops at 9 pm. This is the default timetable for heating mode.

When comparing Fig. 2.29 to its analogous in cooling mode (Fig. 2.23, it can be observed that, in the case of heating mode, the temperatures of the external circuit are lower than the temperatures of the internal circuit (it was opposite in cooling mode). In the case of heating mode, the temperature setpoint is $40^{\circ} \mathrm{C}$ (see $T_{o, i c}$ in the figures), following the specifications of GROUND-MED project.

The increase in the duration of the cycles from Fig. 2.29 to Fig. 2.29 $\mathrm{b}$ comes from the 
increase from a low thermal load in the first case (shorter cycles) to a medium thermal load in the second case (longer cycles).

The cycling of the external circulation pump with the heat pump is also considered in heating mode, as it can be observed in Fig. 2.30. Both water circulation pumps flow rates $\left(\dot{m}_{i c}\right.$ and $\left.\dot{m}_{e c}\right)$ are depicted in Fig. 2.30 for both typical heating days.
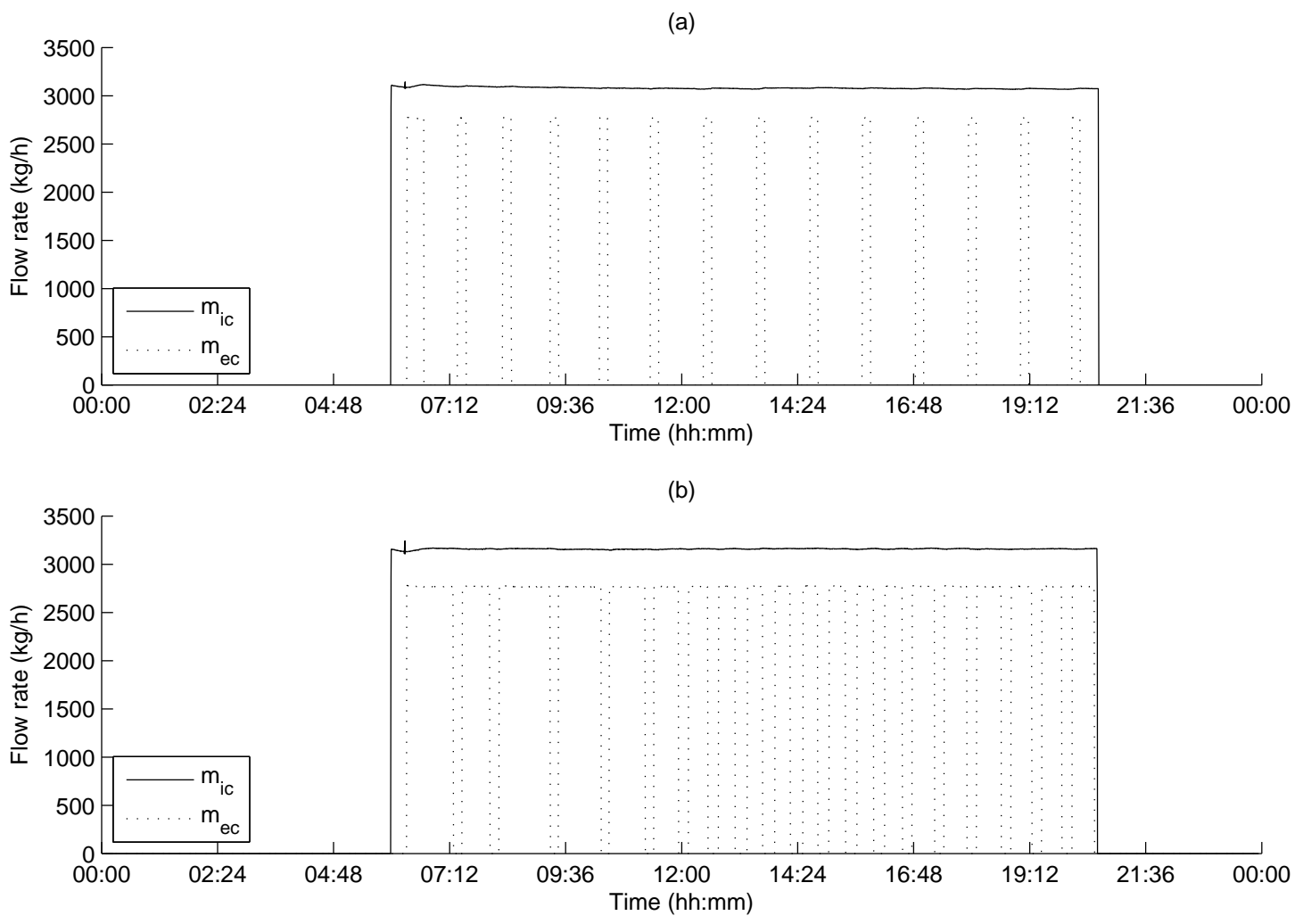

Figure 2.30: Water flow rates in heating mode: (a) Low load (2012/10/31); (b) Medium load $(2012 / 12 / 20)$.

It can also be observed in Fig. 2.30 that, as it happened in cooling mode, while the external pump switches on and off with the heat pump, the internal pump is running during the 15 hours of system operation (from 6 am to 9 pm in the case of heating mode). This means, again, an important source of power consumption that needs to be reduced.

Fig. 2.31 shows the capacity of the heat pump for both circuits $\left(\dot{Q}_{i c}\right.$ and $\left.\dot{Q}_{e c}\right)$, calculated as presented in 2.3 in section 2.2.1. The cycles of the heat pump can be clearly observed here, including the first cycle in the morning where the two compressors switch on in order to heat up the water that has cooled down during the night. In heating mode, this first cycle will not be considered either for the calculation of average thermal loads, as it is not representative of the thermal demand. 
(a)

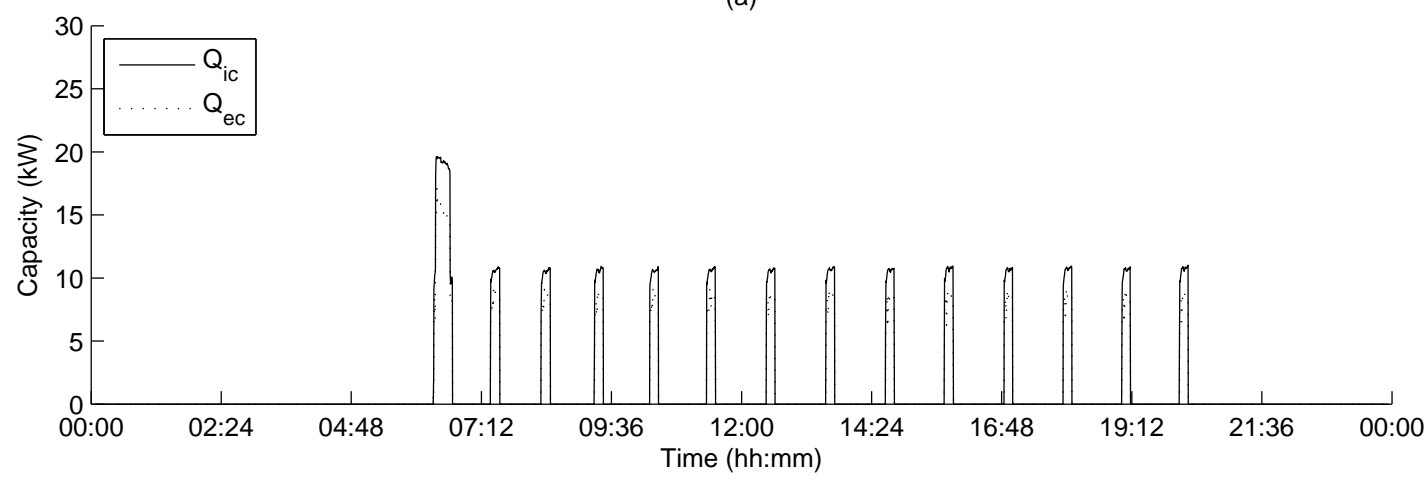

(b)

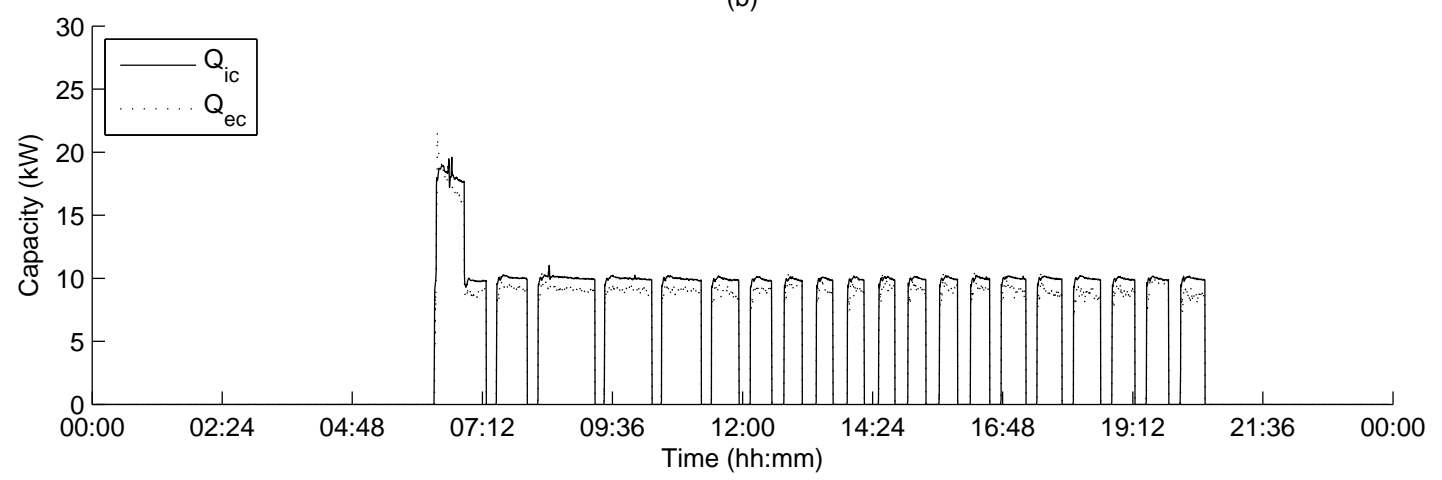

Figure 2.31: Heating capacity: (a) Low load (2012/10/31); (b) Medium load (2012/12/20). 
Fig. 2.32 shows the main power consumptions of the system $\left(\dot{W}_{H P}, \dot{W}_{\text {ecp }}, \dot{W}_{i c p}\right)$ and $\left(\dot{W}_{F C}\right)$ for the two typical heating days analysed.

(a)

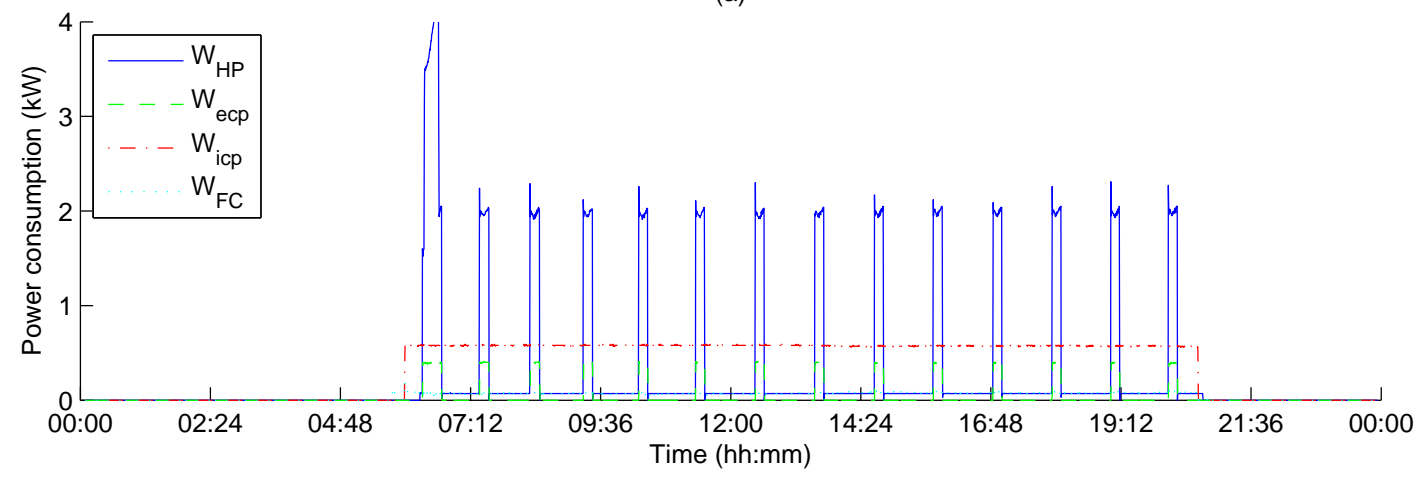

(b)

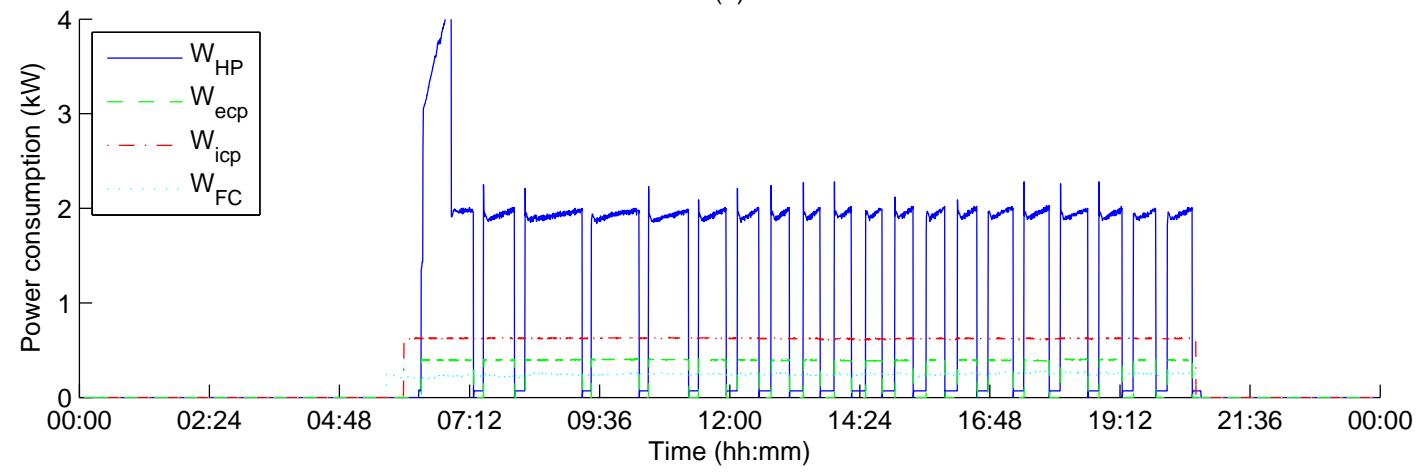

Figure 2.32: Power consumption in heating mode: (a) Low load (2012/10/31); (b) Medium load $(2012 / 12 / 20)$.

As it can be observed in Fig. 2.32, the highest consumption comes from the heat pump. The consumption of the heat pump is higher in heating mode (around $2 \mathrm{~kW}$ with one compressor or $4 \mathrm{~kW}$ with two compressors) than in cooling mode $(1.5 \mathrm{~kW}$ with one compressor and $3 \mathrm{~kW}$ with two compressors). This makes that the importance of the auxiliaries (water circulation pumps) is not as important as in cooling mode, as they represent $28 \%$ of the total power consumption when only one compressor works. Nevertheless, there is still room for improvement, as the second compressor rarely switches on during the heating season (except for the first cycle of the day), due to the lower demand because of the mild weather existing in Valencia during the heating season. That is the reason why no typical heating day is presented for high load, because it is not a typical performance.

Finally, Fig. 2.33 shows the evolution of the thermal load along the two typical days analysed, by using the partial load ratio calculated as presented in Section 2.2.4 Compared to cooling mode, it can be observed that the thermal load is higher during the 
early morning and in the evening, as these are the coldest periods of the day, colder than the central hours.

It can also be observed that the first cycle in the morning presents a value of the partial load ratio which does not seem to be representative, as it differs from the rest of cycles in the day. As done for cooling mode, this cycle will not be considered for average load calculations in heating mode either.
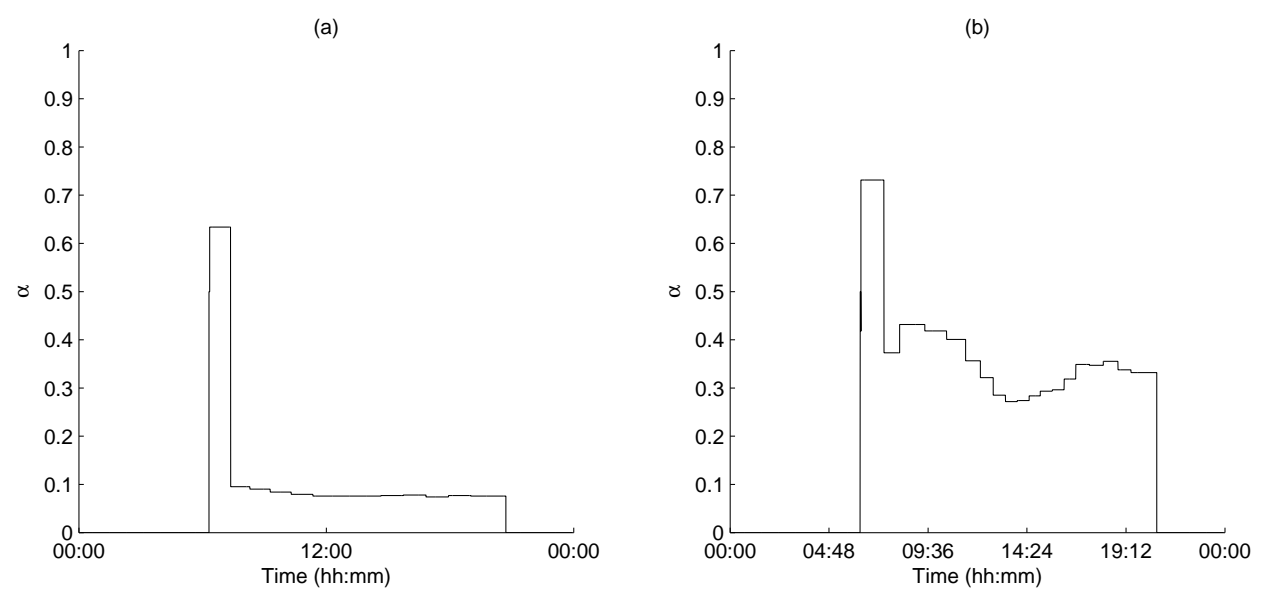

Figure 2.33: Different load ratios in heating mode: (a) Low load $(2012 / 10 / 31)$; (b) Medium load $(2012 / 12 / 20)$. 


\subsubsection{Long-term performance. Analysis of yearly evolution}

The GSHP installation studied in this research work has been in operation since the beginning of year 2005. During this time, different changes have been carried out in the system, as it was presented in Section 2.2.5. Apart from the short-term performance analysis presented in the previous section, a long-term performance analysis of the main system variables and parameters seems to be very useful in order to have a better understanding of the performance of the system, identifying the main characteristics of the typical operation of the system, so that they can be taken into account for the development of energy optimization strategies.

Felix Ruiz-Calvo presented in his $\mathrm{PhD}$ thesis 63 the long-term performance analysis of the installation for the period during which the old GEOCOOL heat pump was installed. The analysis carried out in this section covers the period since the GROUND-MED heat pump was installed in year 2011 until June 2015, period during which the installation has been working continuously, without being switched off for excessively long periods of time.

For the study of the characteristic variables and performance parameters of the installation, the monthly values of those parameters are obtained by averaging the corresponding daily values for each month. However, when averaging the daily values, not all the working days of the system should be considered. Before obtaining the monthly average values, it is necessary to separate the representative days from those that are not representative of the system typical performance (those where maintenance operations, frequency optimization tests or other experiments have been performed). Only the representative days will be taken into account on the analysis of the long-term performance of the system characteristic parameters.

Fig. 2.34 depicts the evolution with time of the main system temperatures over the studied period: temperature at the inlet of the internal circuit $\left(T_{i, i c}\right)$, at the outlet of the internal circuit $\left(T_{o, i c}\right)$, at the inlet of the external circuit $\left(T_{i, e c}\right)$, and at the outlet of the external circuit $\left(T_{o, e c}\right)$. Fig. 2.34 a shows the temperatures in the external circuit, whereas Fig. 2.34 p presents the internal circuit temperatures.

The water temperature exiting the external circuit directly depends on the ground temperature, hence its evolution along the years reflects the evolution of the ground temperature itself. As it can be observed in Fig. 2.34 , the average ground temperature remains constant over the years, thus verifying the correct design and sizing of the ground source heat exchanger.

On the other hand, the internal circuit water temperatures depend on the values of the temperature setpoint established by the control algorithm. Fig. 2.34b shows the evolution of these variables along the years of operation of the system. Due to the implementation of different control and optimization strategies, the values of the water temperature during the last year 2015 present a higher variability than those of the first years. 

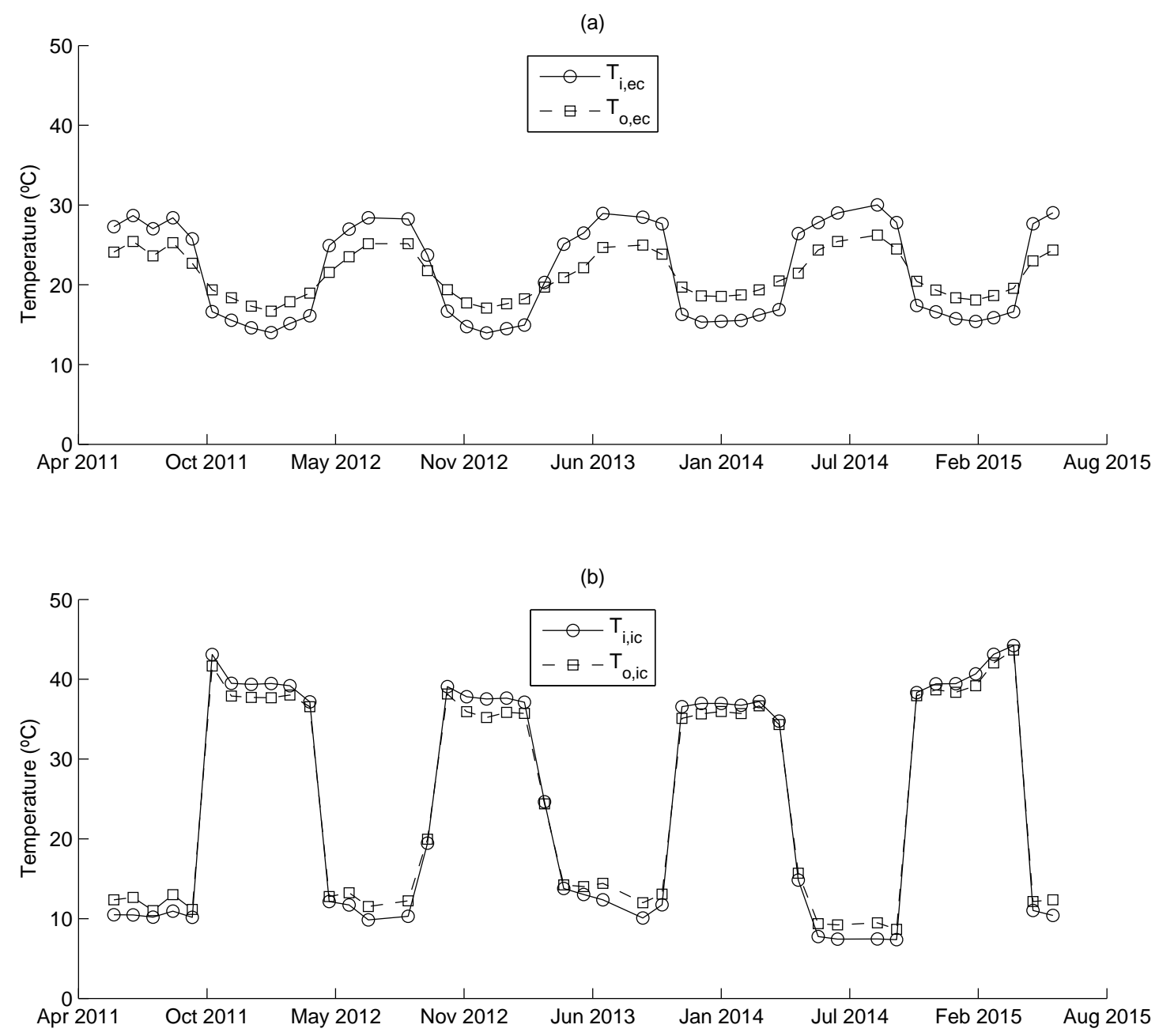

Figure 2.34: System water temperatures from 2011 to 2015: (a) External circuit; (b) Internal circuit. 
Fig. 2.35 presents the thermal load corresponding to both the internal and external circuits, measured at both sides of the heat pump. The thermal load of the internal circuit directly depends on the thermal energy demand of the building. Therefore, it can be used as an indicator of the thermal load of the building, which mainly depends on the weather conditions and the users' behaviour.
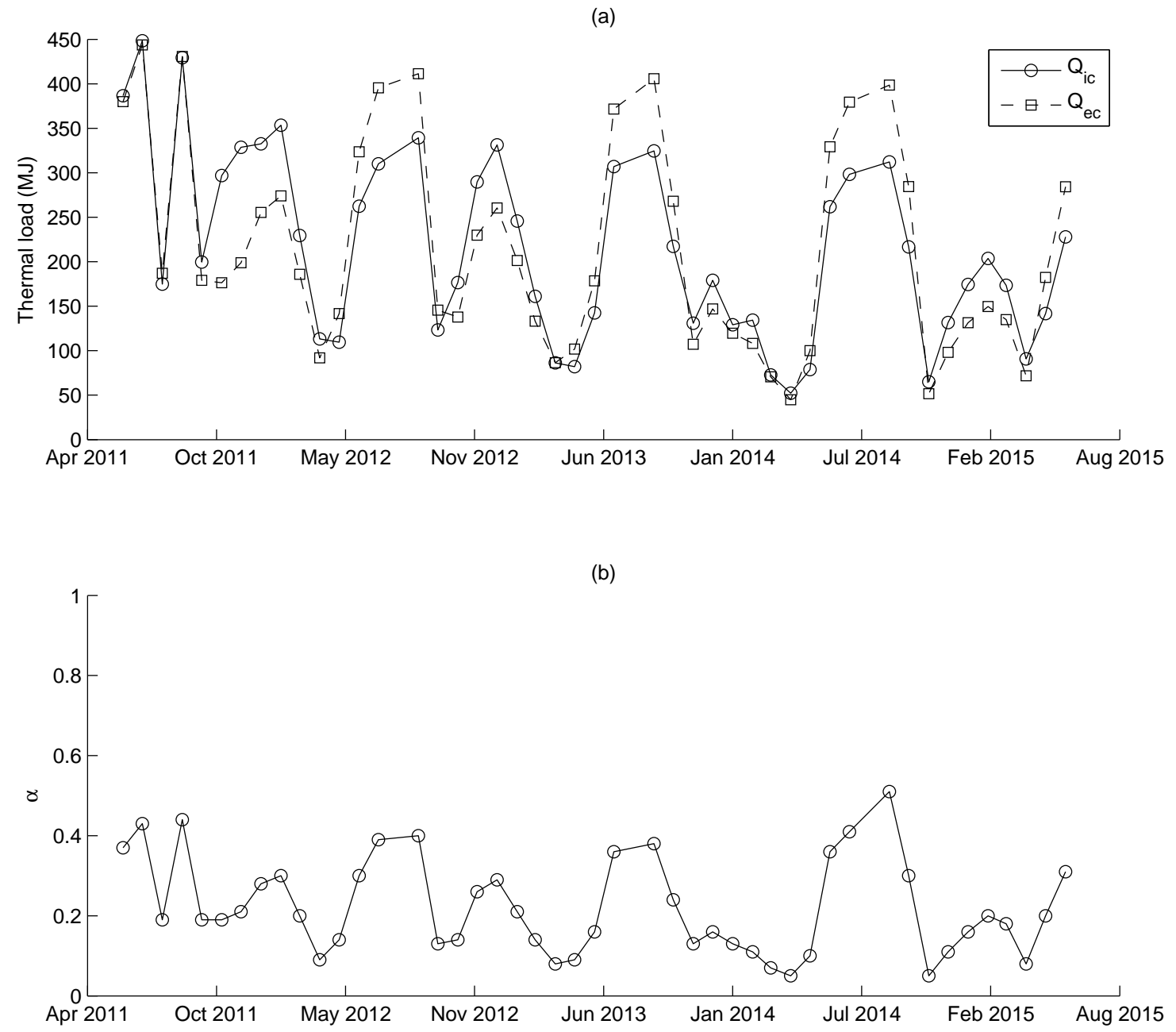

Figure 2.35: System thermal loads from 2011 to 2015: (a) Thermal load in MJ; (b) Partial load ratio $(\alpha)$.

As it can be observed in Fig. 2.35a, the evolution of the thermal load is very similar over the years, while there is still some variability associated to changes of the ambient temperatures and the users' daily activity. These changes, combined with the increase of the system's efficiency, account for the progressive reduction of the thermal load over the years observed in Fig. 2.35 
The thermal load of the building can also be studied through the partial load ratio (Fig. $2.35 \mathrm{~b})$. The partial load ratio is also directly related to the thermal energy demand of the building and, thus, it presents the same evolution. As it can be observed in Fig. 2.35p, the partial load ratio is lower than 0.5 during most of the time. As mentioned in the previous section, it is only during the hottest month of the year, July, that the partial load ratio takes values higher than 0.5 . Still, this does not happen everyday during this month. Hence, when calculating the monthly averages, there is only one case, in July 2014 , in which the partial load ratio takes a value higher than 0.5 .

Fig. 2.36 shows the heat pump capacity both at the internal and external circuits. Since the heat exchanger coupled to each hydraulic circuit changes depending on the operation mode, the heating capacity corresponds to that of the internal circuit in heating mode and to that of the external circuit in cooling mode. Analogously, the cooling capacity corresponds to that of the external circuit in heating mode and to that of the internal circuit in cooling mode.

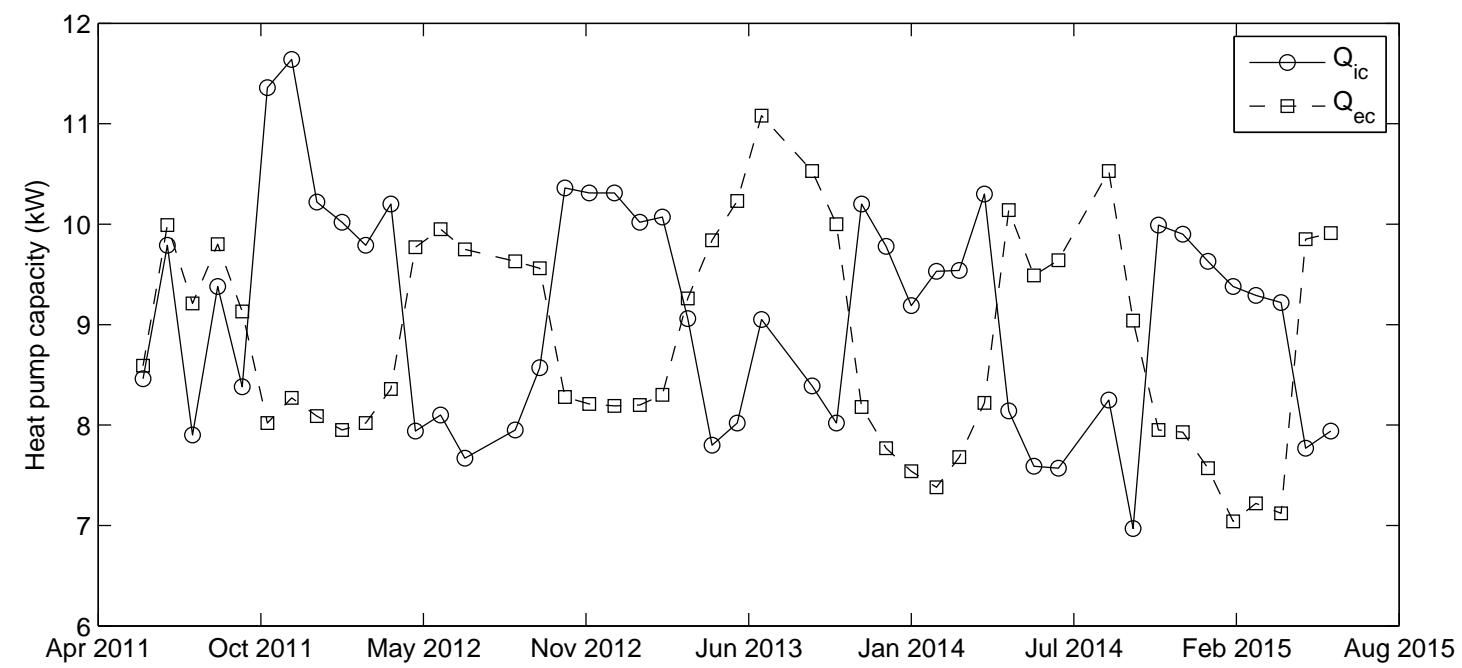

Figure 2.36: Heat pump capacity from 2011 to 2015.

As it can be observed in Fig. 2.36, the heat pump capacity takes values around $10 \mathrm{~kW}$ in heating mode and $8 \mathrm{~kW}$ in cooling mode, as an average. The high variability observed is due to two reasons. The first one is that different operating conditions (in terms of water temperatures and mass flow rates) produce variations on the heat pump capacity. The second reason is that the heat pump has two compressors working in tandem. The fact that the heat pump may work at full load (two compressors running at the same time) on some days may affect the monthly average value.

Finally, the DPFs calculated for the studied period are shown in Fig. 2.37. The four defined parameters are studied: $D P F_{1}$ (only the heat pump is considered), $D P F_{2}$ (the 
external circulation pump is also considered), $D P F_{3}$ (the internal circulation pump is added to the calculation) and $\mathrm{DPF}_{4}$ (the FCUs are also included).

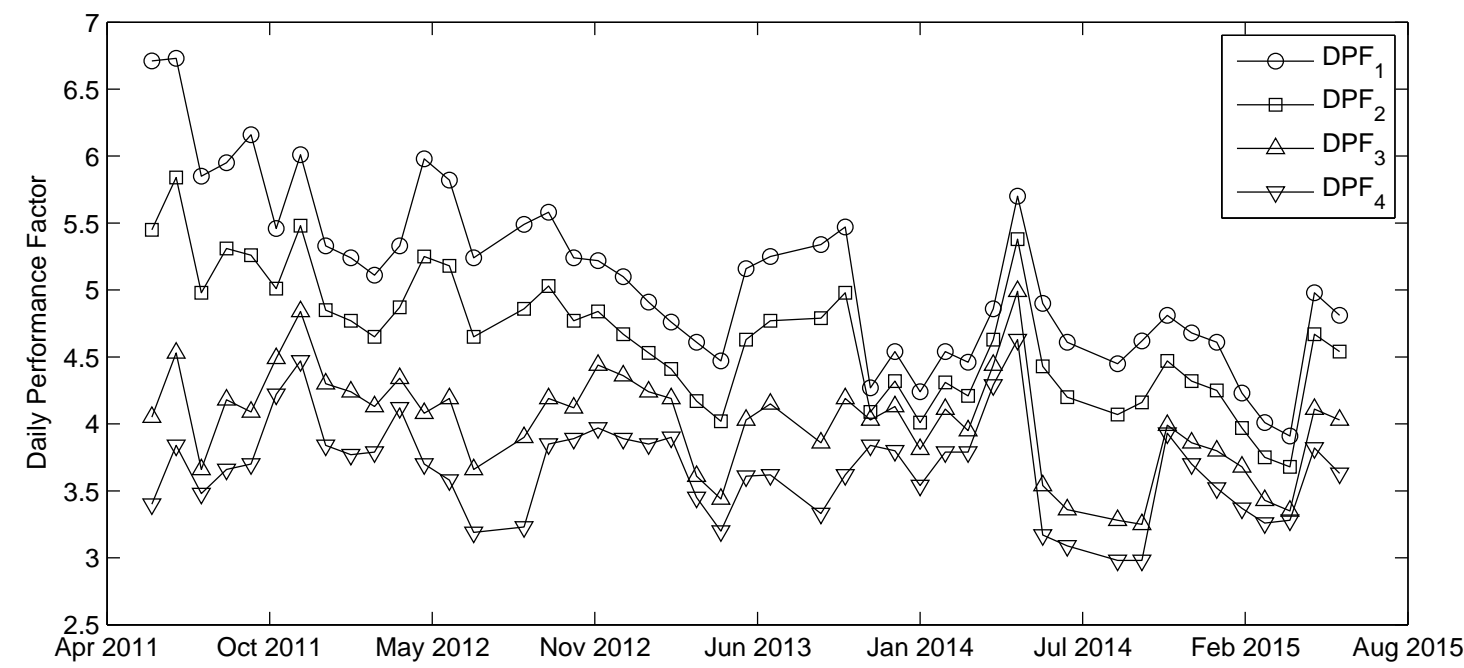

Figure 2.37: Daily performance factors $\left(D P F_{1}\right.$ to $\left.D P F_{4}\right)$ from 2011 to 2015.

As it can be observed in Fig. 2.37, $D P F_{1}$ and $D P F_{2}$ show lower values in heating mode than in cooling mode (around 15\% lower), due to the higher temperature lift that the compressor has to overcome during winter. When adding the internal circulation pump to the calculation, the heat introduced by this component counteracts this effect and, so, the values of $D P F_{3}$ and $D P F_{4}$ do not show this seasonal variation.

Comparing the DPFs, it is possible to analyse the effect that each component has on the global efficiency of the system: adding the external circulation pump produces a decrease of $9 \%$ between $D P F_{1}$ and $D P F_{2}$ as an average. The inclusion of the internal circulation pump reduces an extra $14 \%$ when comparing $D P F_{2}$ and $D P F_{3}$. Finally, including the fancoils results in a decrease of $8 \%$ from $D P F_{3}$ and $D P F_{4}$. This analysis points out, again, the necessity of implementing energy optimization strategies in order to optimize the performance of the system and save energy. 


\section{Chapter 3}

\section{Energy optimization and control algorithms}

Chapter 3 stands for the main core of this PhD dissertation. It is devoted to the energy optimization and control algorithms.

After introducing the topic of the chapter in Section 3.1, system design and configuration issues, such as the sizing of the buffer tank (Section 3.2 or the position of the control sensor and the buffer tank (Section 3.3), are analysed. In addition, two alternatives are proposed and studied in order to control the temperature of the water supplied to the building, instead of the return temperature.

Then, two control strategies are described separately: a temperature compensation strategy (Section 3.5) and an in situ optimization methodology for the water circulation pumps frequency (Section 3.6). The combination of these two strategies, identified as first approach, is presented in Section 3.7.1. In order to enhance this first approach, improving user comfort while keeping substantial energy savings, the integrated control and optimization strategy is upgraded in Section 3.7.2. The results for each study are presented in its corresponding section.

Finally, the main steps and the main difficulties faced in the implementation of the algorithms developed in the control and optimization strategies are presented in Section 3.8 . 


\subsection{Introduction to energy optimization and control algo- rithms}

It goes without saying that global warming is a current reality. As mentioned in Chapter 1 governments are thus creating binding regulations in the field of energy. In this framework, an efficient use of energy, combined with the use of renewable energy sources, becomes of paramount importance. Ground source heat pump systems employ a renewable energy source to improve the efficiency of HVAC systems. However, without a proper control of the system, the energy savings might be spoilt, above all in GSHP systems in which two circulation pumps are required.

As presented in the section devoted to state of the art (Section 1.2), a possible approach to make an efficient use of the energy in HVAC systems in general, and in GSHP systems in particular, is energy management [27-29]. Nevertheless, this research work focuses however on maximizing the energy performance in GSHP systems mainly targeting an optimal operation of the system working as a whole. An optimal design of the system components and the configuration of the system is also targeted, such as the sizing of the buffer tank and the position of the control sensor and the buffer tank in the internal circuit.

In order to achieve an optimal operation, one of the best ways is allowing to adapt the performance of the system to the thermal demand of the building, as pointed out in [31, 32]. An interesting way to do this is controlling the heat pump capacity, which is mainly achieved by means of variable speed compressors [33 38]. However, as the auxiliary equipment accounts for an important amount of the energy consumed in GSHP systems [39-41], they should also be considered in the integrated control and optimization strategies. An integrated control including the variation of the temperature setpoint of the heat pump and the circulation pumps frequency for single-stage and multi-stage heat pumps is presented at the end of this chapter.

\subsection{Buffer tank sizing}

When it comes to the buffer tank and the piping circuit in $\mathrm{A} / \mathrm{C}$ systems in general, and in heat pump systems in particular, there are different connection principles as shown in Fig. 3.1. tank on the return line (Fig. 3.19), tank on the supply line (Fig. 3.1p) and decoupling tank (Fig. 3.1p). In the figure, and in the following, cooling mode has been considered for the analysis. Therefore, the thermal load of the building $(\dot{q})$ is heat added to the hydraulic loop, which is removed by the heat pump which has a cooling capacity $\dot{Q}_{H P}$. All three configurations shown in Fig. 3.1 are usual in small buildings and, although the analysis focuses on the most common approach, which is locating the tank on the return line (Fig. 3.1 a), the conclusions drawn are perfectly applicable to the rest of configurations. 
(a)

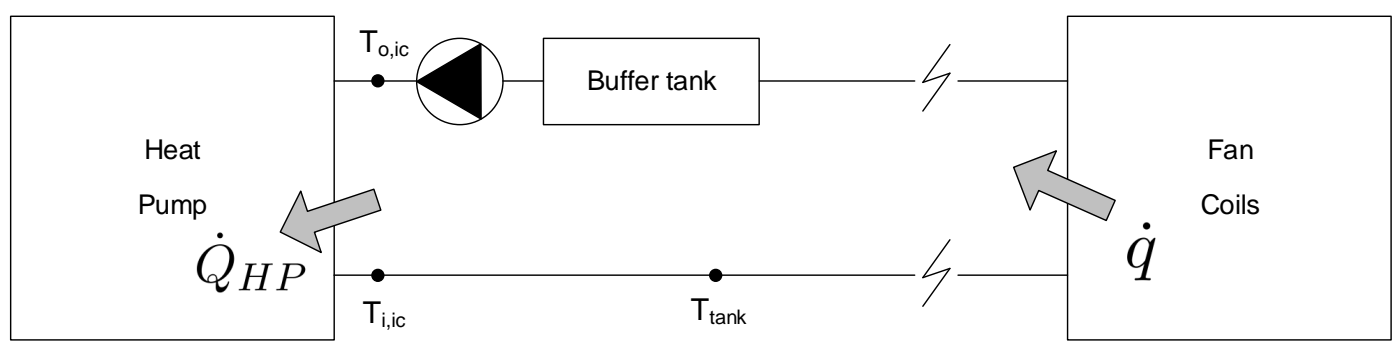

(b)

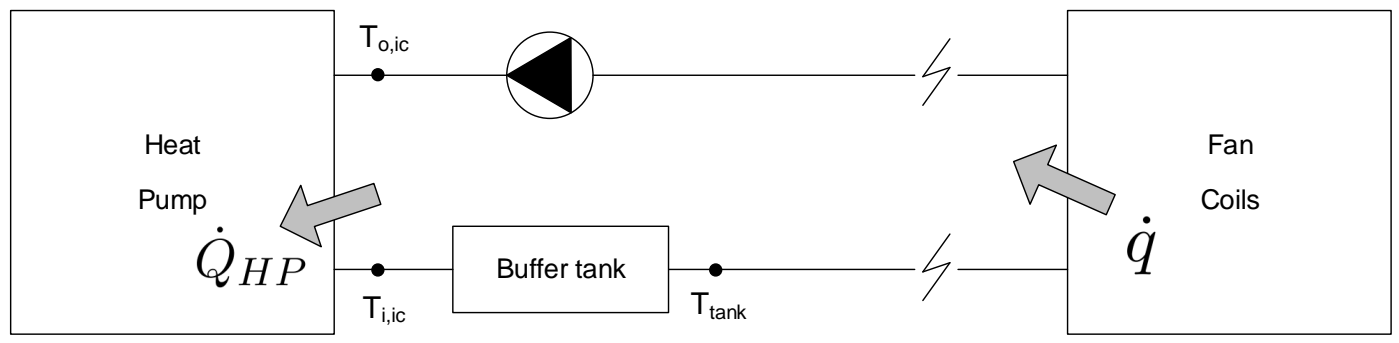

(c)

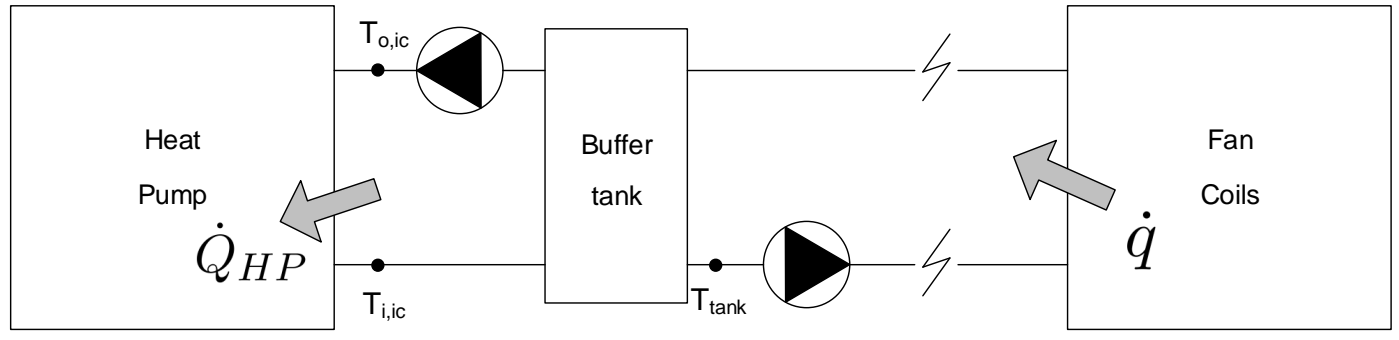

Figure 3.1: Different connection principles: (a) Tank return; (b) Tank supply; (c) Decoupling tank. 
As presented in Chapter 2, the GSHP system studied in this research work stops during the night. That is the reason why it is not recommended to oversize too much the tank volume because, otherwise, more time and energy would be required to heat up / cool down a greater amount of water (if the tank is larger) when the installation starts in the morning due to the heat won during the night. On the other hand, the tank should be large enough as to provide the system with the necessary thermal inertia to couple the building thermal load with the heat pump capacity. Therefore, an accurate determination of the necessary volume for the buffer tank is required in order to adjust its size as much as possible.

It should be clarified that, in a system as the one presented in Fig. 3.1, the total volume of the system must be expressed as the volume of the buffer tank $\left(V_{\text {tank }}\right)$ plus the volume of the piping circuit $\left(V_{\text {pipes }}\right): V=V_{\text {tank }}+V_{\text {pipes }}$. The piping circuit volume will depend on each installation (distance from the machinery room to the terminal units, pipes diameter, etc.). The equations and calculations considered in the following refer to the total volume of the system. However, in order to simplify the problem, it is assumed that all the volume of the system is concentrated in the buffer tank and that the piping volume is negligible. As a consequence, in order to obtain the volume of the actual buffer tank from the formulae developed, the volume of the piping circuit must be subtracted from the calculated system volume.

From the literature review carried out by the authors, it was found out that the main parameters to take into consideration when undertaking the design of the buffer tank are the minimum operating time of the compressor $\left(\Delta t_{m i n, O N}\right)$, the minimum OFF cycle time $\left(\Delta t_{\min , O F F}\right)$ and the maximum number of starts per hour of the compressor $\left(s p h_{\max }\right)$. Therefore, the influence of these three parameters in the sizing of the buffer tank is analysed in the following subsections following two different approaches: a theoretical one based on a simplified energy balance analysis and a second one regarding practical considerations. This analysis was published in [64].

\subsubsection{Theoretical approach}

In a system as the one presented in Fig. 3.1, an energy balance can be separately performed for the ON cycle time (time during which the compressor is working) and for the OFF cycle time (time during which the compressor is switched off). Considering $n$ which stands for the operation state of the heat pump as presented in Section 2.2.4, during the OFF time there will be only $n-1$ compressor stages running. The heat pump capacity can be estimated as $(n-1) \cdot \frac{\dot{Q}_{H P}}{N}$, assuming each stage with the same unitary capacity $\left(\dot{Q}_{1}=\frac{\dot{Q}_{H P}}{N}\right)$, where $N$ is the total number of stages of the compressor rack. Therefore, the energy conservation equation, assuming that all the water is concentrated in the buffer tank, can be expressed for the OFF time as presented in Eq. 3.1.

$$
\rho_{w} \cdot V \cdot c_{p, w} \cdot \frac{d T}{d t}=\dot{q}-(n-1) \cdot \frac{\dot{Q}_{H P}}{N}
$$


Where:

$\rho_{w} \cdot V$ is the mass of water $\left(M_{w}\right)$ in the system,

$c_{p, w}$ is the specific heat of water at constant pressure,

$d T / d t$ is the tank (system) water temperature variation with time,

$\dot{q}$ is the thermal load of the building

and $\dot{Q}_{H P}$ is the capacity of the heat pump.

The instantaneous thermal load of the building can be expressed as a fraction of the heat pump capacity, $\dot{q}=\alpha \cdot \dot{Q}_{H P}$, where $\alpha$ stands for the partial load of the system as presented in Section 2.2.4. Taking into account Eq. 2.34 in order to distinguish the partial load ratio of the system from that of each individual stage $\left(\alpha_{1}\right)$, Eq. 3.1 can be easily solved for the OFF cycle time leading to Eq. 3.2 , where $\Delta T_{d b}$ is the temperature increase experienced by the water in the system during the OFF time, which is equal to the temperature deadband set in the control board of the heat pump, and $\dot{Q}_{1}$ is the capacity of one single stage.

$$
\Delta t_{O F F}=\frac{\rho_{w} \cdot V \cdot c_{p, w} \cdot \Delta T_{d b}}{\dot{q}-(n-1) \cdot \frac{\dot{Q}_{H P}}{N}}=\frac{\rho_{w} \cdot V \cdot c_{p, w} \cdot \Delta T_{d b}}{\alpha_{1} \cdot \dot{Q}_{1}}
$$

Solving Eq. 3.2 for the volume, the minimum volume required for the system to provide a minimum $\mathrm{OFF}$ time can be estimated by means of Eq. 3.3 .

$$
V_{\text {min }}=\frac{\alpha_{1} \cdot \dot{Q}_{1}}{\rho_{w} \cdot c_{p, w} \cdot \Delta T_{d b}} \cdot \Delta t_{m i n, O F F}
$$

The same analysis can be performed for the ON cycle time, where the heat pump capacity enters the energy balance as a negative value and Eq. 3.4 is obtained.

$$
\rho_{w} \cdot V \cdot c_{p, w} \cdot \frac{d T}{d t}=\dot{q}-n \cdot Q_{1}
$$

Proceeding as previously presented for the OFF time and taking into account that the temperature variation will be negative, the ON cycle time is provided by Eq. 3.5 .

$$
\Delta t_{O N}=\frac{\rho_{w} \cdot V \cdot c_{p, w} \cdot \Delta T_{d b}}{\left(1-\alpha_{1}\right) \cdot \dot{Q}_{1}}
$$

Therefore, the minimum volume of the system required to provide a minimum ON time is given by Eq. 3.6 .

$$
V_{\min }=\frac{\left(1-\alpha_{1}\right) \cdot \dot{Q}_{1}}{\rho_{w} \cdot c_{p, w} \cdot \Delta T_{d b}} \cdot \Delta t_{m i n, O N}
$$


Finally, the minimum volume required for the system in order to avoid a maximum number of starts per hour of the compressor $(s p h)$ can be obtained by using the total duration of a complete cycle $\left(\Delta t=\Delta t_{O N}+\Delta t_{O F F}\right)$. By definition, the number of starts per hour is the number of complete cycles in an hour (3600 seconds) as presented in Eq. 3.7 .

$$
s p h=\frac{3600}{\Delta t_{O N}+\Delta t_{O F F}}
$$

Combining Eqs. 3.2, 3.5 and 3.7, Eq. 3.8 can be obtained, which provides the number of starts per hour as a function of the partial load ratio of the system.

$$
s p h=\frac{3600}{\frac{\rho_{w} \cdot V \cdot c_{p, w} \cdot \Delta T_{d b}}{\dot{Q}_{1}} \cdot\left(\frac{1}{\alpha_{1}}+\frac{1}{1-\alpha_{1}}\right)}=\frac{3600 \cdot \dot{Q}_{1} \cdot \alpha_{1} \cdot\left(1-\alpha_{1}\right)}{\rho_{w} \cdot V \cdot c_{p, w} \cdot \Delta T_{d b}}
$$

Then the minimum volume of the system required to avoid a maximum number of starts per hour of the compressor can be estimated by means of Eq. 3.9 .

$$
V_{\min }=\frac{3600}{\rho_{w} \cdot c_{p, w} \cdot \Delta T_{d b}} \cdot \frac{\alpha_{1} \cdot\left(1-\alpha_{1}\right) \cdot \dot{Q}_{1}}{s p h_{\max }}
$$

From the energy balance analysis proposed above, three different expressions to calculate the minimum volume of the system have been obtained according to three different criteria: $\Delta t_{\min , O F F}, \Delta t_{\min , O N}$ and $s p h_{\max }$, according to Eqs. 3.3, 3.6 and 3.9 respectively. As it can be observed, the minimum system volume is in all cases proportional to the capacity of one stage $\left(\dot{Q}_{1}\right)$ and the inverse of the temperature deadband. Additionally, it also depends on the thermal load, represented by the partial load ratio of the corresponding compressor state, $\alpha_{1}$. As an example, Fig. 3.2 depicts, for all three criteria, the minimum volume that the system would require as a function of the partial load ratio, for the example case of a heat pump with a single compressor working in cooling mode and the following typical values for the other parameters: $\dot{Q}_{H P}=\dot{Q}_{1}=20 \mathrm{~kW}$, $\Delta T_{d b}=3 K, \Delta t_{\min , O F F}=3 \min , \Delta t_{\min , O N}=2 \min$ and $s p h_{\max }=10$.

As it can be observed in Fig. 3.2, when considering the minimum ON time for the design (Eq. 3.6), the minimum volume of the system is directly proportional to $1-\alpha_{1}$, what means that the lower the partial load ratio, the higher the minimum volume. Conversely, with the criterion of the minimum OFF time, the minimum system volume would be directly proportional to the partial load ratio (Eq. 3.3). Therefore, the higher the load ratio, the higher the minimum volume required. Finally, when it comes to the number of starts per hour of the compressor, the volume is quadratically dependant on the partial load ratio $(3.9)$, hence presenting a maximum which comes for $\alpha_{1}=0.5$ independently of the values of the other parameters. Hence, the closer the load ratio to the value of 0.5 , the higher the minimum volume required for the system.

As it can be observed in this example, the most restrictive criterion would correspond to the minimum OFF cycle time, being the minimum total volume required equal to 0.287 


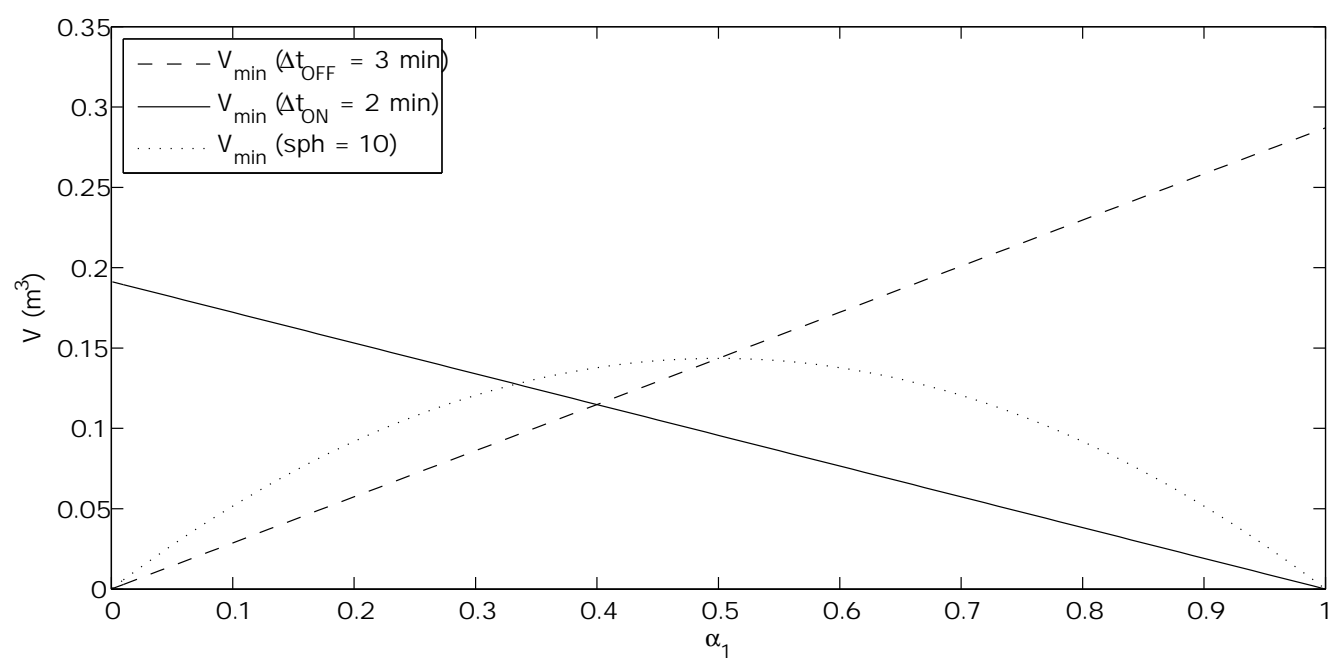

Figure 3.2: Example of required system volume as a function of the partial load ratio for a $20 \mathrm{~kW}$ heat pump.

$\mathrm{m}^{3}$. Given that the partial load ratio of the state $\left(\alpha_{1}\right)$ varies from 0 to 1 , the following expressions can be obtained for the minimum value of the volume corresponding to the three considered criteria, independently of the partial load ratio.

$$
\begin{gathered}
V_{\text {min }}=\frac{\alpha_{1} \cdot \dot{Q}_{1}}{\rho_{w} \cdot c_{p, w} \cdot \Delta T_{d b}} \cdot \Delta t_{\text {min }, O F F}=\frac{\dot{Q}_{1}}{\rho_{w} \cdot c_{p, w}} \cdot \frac{\Delta t_{\text {min }, O F F}}{\Delta T_{d b}} \\
V_{\text {min }}=\frac{\left(1-\alpha_{1}\right) \cdot \dot{Q}_{1}}{\rho_{w} \cdot c_{p, w} \cdot \Delta T_{d b}} \cdot \Delta t_{\text {min }, O N}=\frac{\dot{Q}_{1}}{\rho_{w} \cdot c_{p, w}} \cdot \frac{\Delta t_{\text {min }, O N}}{\Delta T_{d b}} \\
V_{\text {min }}=\frac{3600}{\rho_{w} \cdot c_{p, w} \cdot \Delta T_{d b}} \cdot \frac{\alpha_{1} \cdot\left(1-\alpha_{1}\right) \cdot \dot{Q}_{1}}{s p h_{\text {max }}}=\frac{\dot{Q}_{1}}{\rho_{w} \cdot c_{p, w}} \cdot \frac{\frac{900}{s p h_{\text {max }}}}{\Delta T_{d b}}
\end{gathered}
$$

\subsubsection{Manufacturers' guidelines review}

HVAC equipment manufacturers often publish guidelines on how to operate systems and how to size different components in order to achieve a better performance of their units. Likewise, installers usually give recommendations based on their broad practical experience. Some of these guidelines and recommendations when addressing the sizing of the buffer tank have been gathered for this work and are presented and discussed in the following.

\section{$\underline{\text { Popular design criterion }}$}

According to some HVAC engineering companies and installers consulted, the most general indication when facing buffer tank sizing is that the tank must supply the 
chilled water during the necessary off-time of the compressor. This is analytically represented by Eq. 3.13, where $\Delta T_{d b}$ is the deadband of the thermostat control, which is typically around $2 \mathrm{~K}$. Notice that it is the unitary capacity of the heat pump $\left(\dot{Q}_{1}\right)$ that is considered, and not that of the complete compressor rack $\left(\dot{Q}_{H P}\right)$.

$$
\rho_{w} \cdot V \cdot c_{p, w} \cdot \Delta T_{d b}=\dot{Q}_{1} \cdot \Delta t_{m i n, O F F}
$$

Therefore, there is a minimum volume of the tank which allows the system to meet the demand when the corresponding stage of the heat pump is switched off (OFF time). This minimum volume is provided by Eq. 3.14. In order to make a later comparison, this approach will be referred to as POPULAR.

$$
V_{\min }=\frac{\Delta t_{\min , O F F}}{\rho_{w} \cdot c_{p, w} \cdot \Delta T_{d b}} \cdot \dot{Q}_{1}
$$

\section{ASHRAE recommendations}

One of the most reliable sources of this kind of recommendations is the American Society of Heating, Refrigerating and Air-conditioning Engineers (ASHRAE). The following recommendation appears in [65]: Manufacturers of water chillers state that system water volume should be a minimum of 3 to 10 gal per installed ton of cooling (0.054 to $0.179 \mathrm{~L} / \mathrm{s}$ per $k W R$ [ $k W$ of Refrigeration]). In a system less than this and under light cooling load conditions, thermal inertia coupled with the reaction time of chiller controls may cause the units to short cycle or shut down on low-temperature safety control. In other words, $V_{\min }=[3 \div 10] \mathrm{gal} /$ toncool. After converting to International System units, Eq. 3.15 is obtained.

$$
V_{\text {min }}=[3.24 \div 10.8] \cdot \dot{Q}_{1}
$$

\section{CARRIER/INTERCLISA recommendations}

An interesting explanation for the matter was found in reference [66]. In this reference, it is argued that the minimum liquid volume for chiller plant installations should be that which just gives time to the temperature sensors to track temperature variations, recommending that the temperature variation should be lower than 1.5 ${ }^{\circ} \mathrm{C}$ per minute, i.e. $|d T / d t|<=1.5^{\circ} \mathrm{C} / \mathrm{min}=1.5 / 60 \mathrm{~K} / \mathrm{s}=0.025 \mathrm{~K} / \mathrm{s}$. Applying the energy balance equation to the system, Eq. 3.16 is obtained when $n$ stages are switched on.

$$
\rho_{w} \cdot V \cdot c_{p, w} \cdot \frac{d T}{d t}=\dot{q}-n \cdot \dot{Q}_{1}
$$

Considering Eq. 3.16, the maximum variation would take place when the thermal load tends to be $(n-1) \cdot \dot{Q}_{1}$ and the compressor of the stage $n$ is running (notice that the use of lower-case $n$ here by the author of reference [66] refers to the actual number of stages running and not to the operation state of the heat pump as defined earlier). Therefore, the minimum volume of the system would be given by Eq. 3.17

$$
V_{\text {min }}=\frac{\dot{Q}_{1}}{\left.\rho_{w} \cdot c_{p, w} \cdot \frac{d T}{d t}\right|_{\max }}
$$


For a later comparison this approach will be called CARRIER(1).

An alternative approach considered in the same reference (from now on referred to as CARRIER(2)) takes into account the minimum off-cycle time for one compressor partialization step. This is analytically expressed by Eq. 3.18 .

$$
\rho_{w} \cdot V \cdot c_{p, w} \cdot \frac{\Delta T_{d b}}{\Delta t_{\min , O F F}}=\dot{q}-\frac{n}{N} \cdot \dot{Q}_{H P}=\dot{q}-n \cdot \dot{Q}_{1}
$$

This expression is very interesting and clearly recognises that temperature variations are induced by load steps of the compressors rack. As in the previous approach, the maximum variation would take place when the building load tends to be $(n-1) \cdot \dot{Q}_{1}$ and the stage $n$ is running. Accordingly, Eq. 3.18 transforms into Eq. 3.19, which coincides with the POPULAR criterion.

$$
V_{\text {min }}=\frac{\dot{Q}_{1}}{\rho_{w} \cdot c_{p, w} \cdot \frac{\Delta T_{d b}}{\Delta t_{m i n, O F F}}}
$$

In the same reference, the author recommends a value of 5 minutes for the minimum OFF time $\left(\Delta t_{\min , O F F}\right)$.

\section{TRANE recommendations}

The authors have found recommendations on this regard by TRANE in the technical manuals of some of their chillers. They distinguish somewhat between high capacity (e.g. Model CGAF [15-60 ton] (53-211 kW)) and small capacity (e.g. Model CGA [10-15 ton] (35-53 kW)) units [67]. They state the following: The volume of water in the loop is critical to the stability of system operation. The minimum required water volume is dependant on the chiller controller and system GPM. Water volumes less than the minimum required for the system can cause nuisance problems including low pressure trips and freezestat trips. The cause of these trips is "Short Water Loops". The minimum required water volume (as a function of loop time and GPM) is as follows:

- CGAF: Minimum Loop Volume $=$ GPM $x 3$ Minute Loop Time

- CGA: Minimum Loop Volume $=$ GPM $x 5$ Minute Loop Time

For larger units, up to 120 ton ( $422 \mathrm{~kW})$, they recommend that a two-minute water loop circulation time is sufficient to prevent short water loop issues [68].

In summary, TRANE recommends different loop times depending on the size of the unit:

- 10 to 15 ton (35-53 kW): Minimum Loop Volume = GPM x 5 Minute Loop Time (TRANE(1))

- 15 to 60 ton (53-211 kW): Minimum Loop Volume $=$ GPM x 3 Minute Loop Time (TRANE(2)) 
- Up to 120 ton (422 kW): Minimum Loop Volume = GPM x 2 Minute Loop Time (TRANE(3))

Where GPM is the flow rate of water in gallons per minute.

Taking into consideration the above recommendations, it is clear that the minimum volume would depend on the flow rate and the total loop time. In other words, $V_{\min }=\dot{V} \cdot \Delta T_{H P}$. In contrast to previous recommendations, it is interesting to find that this time the recommendation of minimum volume is referred to the water flow rate. However, if one takes into account that the flow rate $(\dot{V})$ is related to the capacity $\left(\dot{Q}_{H P}\right)$ through the following relation, $\dot{V}=\dot{Q}_{H P} /\left(\rho_{w} \cdot c_{p, w} \cdot \Delta T_{H P}\right)$, where $\Delta T_{H P}$ is the water temperature difference across the heat pump, the formula for the minimum volume can also be expressed in the form of previous equations, as shown in Eq. 3.20 .

$$
V_{\text {min }}=\frac{\dot{Q}_{H P}}{\rho_{w} \cdot c_{p, w} \cdot \Delta T_{H P}} \cdot \Delta t
$$

Where the time period $(\Delta t)$ would depend on the size of the system, ranging from 2 to 5 minutes. The larger the size, the shorter the period. It is important to notice that, in the case of this reference, the capacity considered in the expression to calculate the minimum system volume corresponds to the total capacity of the compressors rack $\left(\dot{Q}_{H P}\right)$ and not to the unitary capacity $\left(\dot{Q}_{1}\right)$.

\section{Danfoss Commercial Compressors recommendations}

DCC state the following guidelines for their scroll compressors [69]:

- The system must be designed in a way that guarantees a minimum compressor running time of 2 minutes so as to provide for sufficient motor cooling after start-up along with proper oil return.

- There must be no more than 12 starts per hour; a number higher than 12 reduces the service life of the motor-compressor unit.

- A minimum three-minute (180 seconds) time out is recommended.

Summarizing, with the nomenclature employed in this work, the recommendations are as follows:

- $\Delta t_{\min , O N} \geq 2 \min$ (or oil return time)

- $\Delta t_{\min , O F F} \geq 3 \min$

- $s p h \geq 12$

\section{EMERSON recommendations}

Emerson Climate Technologies states the following guidelines for their Copeland scroll compressors [70]:

- There must be a maximum of 10 starts per hour. 
- There is no minimum off time because Scroll compressors start unloaded even if the system has unbalanced pressures.

- The most critical consideration is the minimum run time required to return oil to the compressor after start-up.

Summarizing, with the nomenclature employed in this work, the recommendations are as follows:

- $\Delta t_{\text {min }, O N} \geq$ Oil return time

- $\Delta t_{\text {min,OFF }}-$ No limit for scroll compressors

- $\operatorname{sph} \geq 10$

Table 3.1 shows a summary of the compiled guidelines and recommendations.

The following conclusions can be drawn from the analysis of Table 3.1 .

- On the one hand, HVAC system manufacturers provide design guidelines to determine the minimum volume of the system. On the other hand, compressor manufacturers just give recommended values for minimum $\mathrm{ON}$ and $\mathrm{OFF}$ cycle times as well as maximum number of starts per hour of the compressor, as the refrigeration circuit is unknown for them. That is the reason why they only provide recommendations for the compressor operation.

- All the expressions for the minimum volume of the system (buffer tank plus piping circuit) can be expressed as a function of the chiller unitary capacity $\left(\dot{Q}_{1}\right)$, which obviously is the main parameter for its sizing, with the exception of TRANE guidelines. In the case of TRANE recommendations, it is the total capacity $\dot{Q}_{H P}$ that is considered instead of the unitary capacity. Moreover, since this analysis focuses on small installations, as the GSHP system studied in this PhD work, only the recommendation for small capacity units (TRANE(1)) will be considered.

- As discussed when carrying out the theoretical approach, the time periods are a function of the system volume and capacity, but also of the setting of the temperature control deadband. The criteria POPULAR and CARRIER(2) also include this parameter. The typical value of the temperature deadband employed by manufacturers is $2 \mathrm{~K}$. However, most of the time the temperature probe of the thermostat is clamped to the pipe wall, what in practice means that the actual temperature variation of the water flow at the point of control is larger. The authors have accurately measured this difference in some installations and a typical setting of $2 \mathrm{~K}$ as the control deadband transforms into a $3 \mathrm{~K}$ to $4 \mathrm{~K}$ temperature variation in the actual water flow.

Taking into account that energy minimization requires to minimize the temperature difference between the chilled/hot water and the ambient air, this would require a more precise control of the supply temperature and therefore small values of the control deadband. Obviously this would require larger buffer tanks. A typical value 


\begin{tabular}{|c|c|c|c|c|c|}
\hline Label & Expression & $\Delta t_{\min , O N}$ & $\Delta t_{\min , O F F}$ & $s p h_{\max }$ & Other \\
\hline POPULAR & $V_{\text {min }}=\frac{\Delta t_{m i n, O F F}}{\rho_{w} \cdot c_{p, w} \cdot \Delta T} \cdot \dot{Q}_{1}$ & $\mathrm{n} / \mathrm{a}$ & $\mathrm{n} / \mathrm{a}$ & $\mathrm{n} / \mathrm{a}$ & $\begin{array}{l}\Delta T_{d b} \\
\Delta t_{m i n, O F F}\end{array}$ \\
\hline ASHRAE & $V_{\min }=[3.24 \ldots 10.8] \cdot \dot{Q}_{1}$ & $\mathrm{n} / \mathrm{a}$ & $\mathrm{n} / \mathrm{a}$ & $\mathrm{n} / \mathrm{a}$ & $\mathrm{n} / \mathrm{a}$ \\
\hline $\begin{array}{l}\text { CARRIER } \\
(1)\end{array}$ & $V_{\min }=\frac{1}{\left.\rho_{w} \cdot c_{p, w} \cdot \frac{d T}{d t}\right|_{\max }} \cdot \dot{Q}_{1}$ & $\mathrm{n} / \mathrm{a}$ & $\mathrm{n} / \mathrm{a}$ & $\mathrm{n} / \mathrm{a}$ & $\left.\frac{d T}{d t}\right|_{\max }=1.5 \frac{\mathrm{K}}{\min }$ \\
\hline $\begin{array}{c}\text { CARRIER } \\
(2)\end{array}$ & $V_{\min }=\frac{1}{\rho_{w} \cdot c_{p, w} \cdot \frac{\Delta T}{\Delta t_{\min , O F F}}} \cdot \dot{Q}_{1}$ & $\mathrm{n} / \mathrm{a}$ & $5 \min$ & $\mathrm{n} / \mathrm{a}$ & $\Delta T=3 K$ \\
\hline $\begin{array}{l}\text { TRANE }(1) \\
\quad \text { (small) }\end{array}$ & $V_{\text {min }}=\frac{\Delta t}{\rho_{w} \cdot c_{p, w} \cdot \Delta T} \cdot \dot{Q}_{1}$ & $\mathrm{n} / \mathrm{a}$ & $\mathrm{n} / \mathrm{a}$ & $\mathrm{n} / \mathrm{a}$ & $\begin{array}{c}\Delta T_{H P} \\
\Delta t=5 \min \end{array}$ \\
\hline $\begin{array}{l}\operatorname{TRANE}(2) \\
\text { (medium) }\end{array}$ & $V_{\text {min }}=\frac{\Delta t}{\rho_{w} \cdot c_{p, w} \cdot \Delta T} \cdot \dot{Q}_{1}$ & $\mathrm{n} / \mathrm{a}$ & $\mathrm{n} / \mathrm{a}$ & $\mathrm{n} / \mathrm{a}$ & $\begin{array}{c}\Delta T_{H P} \\
\Delta t=3 \min \end{array}$ \\
\hline $\begin{array}{l}\text { TRANE }(3) \\
\quad \text { (large) }\end{array}$ & $V_{\text {min }}=\frac{\Delta t}{\rho_{w} \cdot c_{p, w} \cdot \Delta T} \cdot \dot{Q}_{1}$ & $\mathrm{n} / \mathrm{a}$ & $\mathrm{n} / \mathrm{a}$ & $\mathrm{n} / \mathrm{a}$ & $\begin{array}{c}\Delta T_{H P} \\
\Delta t=2 \min \end{array}$ \\
\hline DCC & $\mathrm{n} / \mathrm{a}$ & $2 \min$ & $3 \min$ & 12 & $\mathrm{n} / \mathrm{a}$ \\
\hline EMERSON & $\mathrm{n} / \mathrm{a}$ & $\begin{array}{c}\text { Oil } \\
\text { return } \\
\text { time }\end{array}$ & $\begin{array}{c}\text { No } \\
\text { limit } \\
\text { for } \\
\text { scroll } \\
\text { comp. }\end{array}$ & 10 & $\mathrm{n} / \mathrm{a}$ \\
\hline
\end{tabular}

Table 3.1: Summary of guidelines from manufacturers and installers. 
of $3 \mathrm{~K}$ for the actual variation of the water temperature in the control point has been assumed as a good reference value for the rest of the following comparisons. In any case, this parameter will be retained as a second input to the formula since it is a control parameter and can be set at the installation.

- In regard to the other parameters, some of the manufacturers provide recommended values for them. However, in the following cases they need to be assumed:

- The temperature difference to be considered in TRANE formulae is the one between the heat pump inlet and outlet. The typical value employed by designers for the nominal flow rate is $\Delta T_{H P}=5 K$.

- POPULAR criterion requires an estimation of the minimum OFF time. The value employed in this work will be the one recommended by DCC, that is to say $\Delta t_{\min , O F F}=3 \mathrm{~min}$.

\subsubsection{Results for buffer tank sizing}

Table 3.2 summarizes the results for the expressions obtained from both the theoretical approach in Section 3.2.1 and the different criteria extracted from the Literature review in Section 3.2.2, after considering the values corresponding to the density and specific heat of the water as well as the recommended values for the operation parameters $\left(\Delta t_{\min , O F F}\right.$, $\Delta t_{\min , O N}, s p h_{\max }$ and $\left.\Delta T_{d b}\right)$.

For the theoretical approach criteria, the following values have been used: $\Delta t_{\min , O F F}=$ $3 \min , \Delta t_{\min , O N}=2 \min , s p h_{\max }=10$ and $\Delta T_{d b}=3 \mathrm{~K}$.

For the manufacturers' guidelines criteria, the values from Table 3.1 have been considered. The last column in Table 3.2 shows the resulting minimum volume, in litres, for the example use of a $20 \mathrm{~kW}$ heat pump with a single compressor working in cooling mode $\left(\dot{Q}_{H P}=\dot{Q}_{1}=20 \mathrm{~kW}\right)$.

After comparing the results obtained in Table 3.2, it can be observed that the most restrictive criterion regarding the maximum system volume is CARRIER(2). This is because an OFF time of 5 minutes has been considered, which might be excessive according to the authors since it almost doubles the resulting minimum volume recommended by the rest of the reviewed guidelines. Apart from this, the rest of criteria range from 3.24 to 14.35 times the value of the unitary capacity expressed in $\mathrm{kW}$. There are several sources with coincident results and, on the whole, all of them present relatively similar values. Therefore, a possible solution for the tank sizing might be considering, as a rule of thumb, Eq. 3.21, which would be conservative enough and would cover most of the reviewed guidelines for small and medium installations.

$$
V_{\text {min }}(\text { litres })=[7 \div 14] \cdot \dot{Q}_{1}(k W)
$$

However, it is worth following discussing the obtained formula and trying to develop a more accurate final design guideline. As it can be seen in Table 3.2 , the three analytical 


\begin{tabular}{|c|c|c|c|c|}
\hline Approach & Criterion & Expression & $\begin{array}{l}V_{\min }[L]= \\
f\left(\dot{Q}_{1}[k W]\right)\end{array}$ & $\begin{array}{c}\text { For } \\
\dot{Q}_{1}=20 k W\end{array}$ \\
\hline \multirow{3}{*}{$\begin{array}{l}\text { Theretical } \\
\text { approach }\end{array}$} & $\Delta t_{\min , O F F}$ & $V_{\text {min }}=\frac{\Delta t_{\min , O F F}}{\rho_{w} \cdot c_{p, w} \cdot \Delta T_{d b}} \cdot \dot{Q}_{1}$ & $V_{\min }=14.35 \cdot \dot{Q}_{1}$ & $287.1 \mathrm{~L}$ \\
\hline & $\Delta t_{m i n, O N}$ & $V_{\min }=\frac{\Delta t_{\min , O N}}{\rho_{w} \cdot c_{p, w} \cdot \Delta T_{d b}} \cdot \dot{Q}_{1}$ & $V_{\min }=9.57 \cdot \dot{Q}_{1}$ & $191.4 \mathrm{~L}$ \\
\hline & $s p h_{\max }$ & $V_{\text {min }}=\frac{\frac{900}{s p h_{\max }}}{\rho_{w} \cdot c_{p, w} \cdot \Delta T_{d b}} \cdot \dot{Q}_{1}$ & $V_{\min }=7.18 \cdot \dot{Q}_{1}$ & $143.5 \mathrm{~L}$ \\
\hline \multirow{5}{*}{$\begin{array}{c}\text { Manu- } \\
\text { facturers' } \\
\text { guidelines }\end{array}$} & POPULAR & $V_{\text {min }}=\frac{\Delta t_{\min , O F F}}{\rho_{w} \cdot c_{p, w} \cdot \Delta T_{d b}} \cdot \dot{Q}_{1}$ & $V_{\text {min }}=14.35 \cdot \dot{Q}_{1}$ & $287.1 \mathrm{~L}$ \\
\hline & ASHRAE & $V_{\min }=[3.24 \ldots 10.8] \cdot \dot{Q}_{1}$ & $\begin{array}{c}V_{\min }= \\
{[3.24 \ldots 10.8] \cdot \dot{Q}_{1}}\end{array}$ & $\begin{array}{c}{[64.8 \ldots 216]} \\
\mathrm{L}\end{array}$ \\
\hline & $\begin{array}{l}\text { CARRIER } \\
\text { (1) }\end{array}$ & $V_{\min }=\frac{1}{\left.\rho_{w} \cdot c_{p, w} \cdot \frac{d T}{d t}\right|_{\max }} \cdot \dot{Q}_{1}$ & $V_{\min }=9.57 \cdot \dot{Q}_{1}$ & $191.4 \mathrm{~L}$ \\
\hline & $\begin{array}{l}\text { CARRIER } \\
(2)\end{array}$ & $V_{\text {min }}=\frac{1}{\rho_{w} \cdot c_{p, w} \cdot \frac{\Delta T_{d b}}{\Delta t_{\min , O F F}}} \cdot \dot{Q}_{1}$ & $V_{\min }=23.9 \cdot \dot{Q}_{1}$ & $478.5 \mathrm{~L}$ \\
\hline & $\operatorname{TRANE}(1)$ & $V_{\text {min }}=\frac{\Delta t}{\rho_{w} \cdot c_{p, w} \cdot \Delta T_{H P}} \cdot \dot{Q}_{1}$ & $V_{\min }=14.35 \cdot \dot{Q}_{1}$ & $287.1 \mathrm{~L}$ \\
\hline
\end{tabular}

Table 3.2: Minimum system volume in terms of the heat pump capacity (example use of a $20 \mathrm{~kW}$ heat pump with a single compressor). 
expressions developed in Section 3.2.1 take into account the most important requirements for the sizing of the buffer tank volume: $\left(\Delta t_{\min , O F F}, \Delta t_{\min , O N}\right.$ and $\left.s p h_{\max }\right)$. Considering these expressions, the most restrictive approach appears to be the minimum OFF time criterion. Nevertheless, this does not seem to be so important for scroll compressors. In contrast, what is clearly important to accomplish, as it is stated by all compressors manufacturers, is a minimum $\mathrm{ON}$ cycle time in order to guarantee that the oil returns to the compressor.

In any case, studying carefully these analytical expressions (Eqs. 3.10, 3.11 and 3.12, it is clearly observed that all of them present the same form. Moreover, the minimum volume will be provided in the end by the worst-case compressor time $\left(\Delta t_{\text {comp }}\right)$ considered in the numerator, whether this is the minimum OFF time, the minimum ON time or the time given by the maximum number of starts per hour of the compressor. Therefore, considering the values of the water density and the specific heat, and expressing the result of the volume in liters, the time in minutes and the capacity in kilowatts, Eq. 3.22 provides the final design guideline recommended by the authors in order to calculate the minimum system volume required.

$$
V_{\text {min }}(\text { litres })=14.35 \cdot \frac{\Delta t_{c o m p}(\min )}{\Delta T_{d b}\left({ }^{\circ} \mathrm{C}\right)} \cdot \dot{Q}_{1}(k W)
$$

Where the compressor time, in minutes, is given by Eq. 3.23 .

$$
\Delta t_{c o m p}(\min )=\max \left(\frac{15}{s p h_{\max }}, \Delta t_{\min , O F F}, \Delta t_{\min , O N}\right)
$$

Recommended deadband values between $3^{\circ} \mathrm{C}$ and $5^{\circ} \mathrm{C}\left(\Delta T_{d b}=3^{\circ} \mathrm{C} \div 5^{\circ} \mathrm{C}\right)$, and compressor time values between 3 and 5 minutes $\left(\Delta t_{\text {comp }}=3 \mathrm{~min} \div 5 \mathrm{~min}\right)$, were considered in [64] by Cervera-Vázquez et al. Even though 3 minutes is time enough to guarantee a proper compressor oil return for most compressors, a longer time (5 minutes) would produce longer cycles thus avoiding possible short water loops issues as well as reducing the losses due to low partial load. It should be noticed that in installations with chiller modules provided with variable speed compressors, the unitary capacity $\left(\dot{Q}_{1}\right)$ to be considered is the one obtained for the minimum speed.

The analysis presented in this section was carried out in the framework of GROUNDMED project. Eq. 3.22 was applied for the geothermal plant studied in this research work, considering the following values for the different parameters: $\Delta t_{\text {comp }}=5 \mathrm{~min}$, $\Delta T_{d b}=3.5^{\circ} \mathrm{C}$ and $\dot{Q}_{1}=8 \mathrm{~kW}$. The result was a minimum volume of 164 litres. Finally, a commercial size tank of 189 litres was installed in the geothermal installation, as presented in Section 2.1.2. 


\subsection{Control sensor and buffer tank position}

There are several possibilities when facing the positioning of both the buffer tank and the control sensor. The schematic in Fig. 2.11 depicted the tank on the supply line, whereas Fig. 3.1 shows that different connection principles are possible for the buffer tank. In this section, the options of tank located on the return line (Fig. 3.1 a) and tank located on the supply line (Fig. 3.1p) are analysed, but not the decoupling tank option (Fig. 3.1 c), as it is out of the scope of this work. Additionally, the position of the temperature control sensor is analysed as well. This provides four different configurations which are shown in Table 3.3 .

\begin{tabular}{|l|c|c|}
\hline \multirow{2}{*}{$\begin{array}{l}\text { Buffer } \\
\text { tank }\end{array}$} & \multicolumn{2}{|c|}{ Control sensor } \\
\cline { 2 - 3 } & Supply & Return \\
\hline Supply & 1 & 2 \\
\hline Return & 3 & 4 \\
\hline
\end{tabular}

Table 3.3: Possibilities for buffer tank and control sensor position.

For a start, option 3, which is controlling on the supply while the buffer tank is located on the return line, must be discarded because the temperature at this point may vary instantaneously during the heat pump start and stop. This instability on the temperature control probe would result in undesired effects, such as excessive cycling of the compressor. The three remaining options are all viable since all of them present an adequate thermal inertia, whether it is provided by the buffer tank, the hydraulic circuit volume or both of them, which absorb quick variations in the controlled temperature.

Heat pump manufacturers are mostly concerned about the lifespan of their machines. Variations on the building thermal load make the temperature of the water returning to the heat pump present some quick fluctuations which may influence the compressor operation conditions and may result in lifespan shortening. That is the reason why they often include the buffer tank in the own heat pump case, locate the temperature control probe at the outlet of the tank and program the control board in such a way that only controlling on the return line is possible (as mentioned above, it would not be possible to control on the supply line if the tank is on the return line). In this way, the possible fluctuations on the return temperature due to building thermal load variations (caused, for instance, by fan coils manipulation by users) will be absorbed by the buffer tank and only stable values of temperature will appear on the return line to the heat pump.

Nonetheless, this is not always the best approach as far as the user comfort is concerned, as it will be shown in the following. Moreover, variations in the thermal load are not going to be really high during the same day and, in any case, the volume of water contained in the piping system should be enough to absorb such small fluctuations.

In the following sections, configurations 1,2 and 4 in Table 3.3 are analysed and compared, trying to highlight advantages and disadvantages for each one of them. This 
simulation analysis is carried out by means of a simplified simulation model of the system described in [45]. It should be noticed that, even though the whole analysis is performed for a single-stage heat pump and for cooling mode, the conclusions are also applicable to the GROUND-MED multi-stage heat pump and for heating mode too.

\subsubsection{Buffer tank position when the control sensor is on the return line}

In this section options 2 and 4 in Table 3.3 are compared. As Fig. 3.3 depicts, the control sensor is located on the return line following the guidelines of heat pump manufacturers, while an analysis is undertaken in order to decide where to locate the buffer tank.

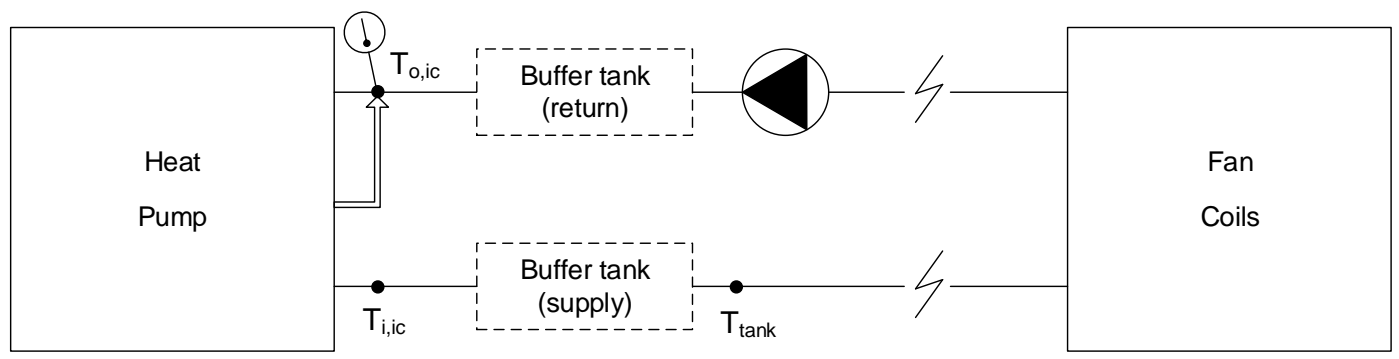

Figure 3.3: Control sensor located on the return line.

Several simulations were carried out in order to compare the energy performance of the system when the buffer tank is on the supply line (option 2) and when it is located on the return line (option 4). In both simulations all equations and parameters (including the temperature setpoint) in the simulation model were the same, except for the location of the buffer tank, which was tested to be on the return or on the supply line. Results confirmed that the energy performance of the system is exactly the same no matter where the buffer tank is located, since the daily performance factors coincide for both configurations.

Therefore it must be concluded that, since in both cases the energy performance of the system is very similar, it would be better to locate the tank on the supply line because it allows locating the control sensor in either the supply or the return line. If the option of locating the tank on the return was chosen, it would only be possible to control on the return line, as previously explained. 


\subsubsection{Control sensor position when the buffer tank is on the supply line}

In this section options 1 and 2 from Table 3.3 are compared. As Fig. 3.4 depicts, the buffer tank is located on the supply line and an analysis is carried out in order to decide where to locate the control sensor.

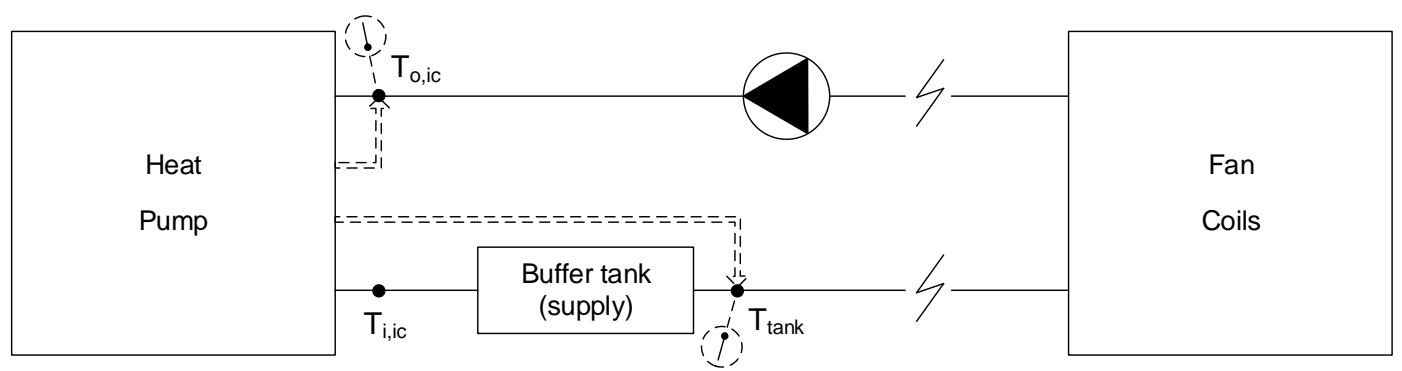

Figure 3.4: Tank located on the supply line.

First of all, it should be pointed out that both, the water flow rate and the thermal load of the building have an influence on the performance of the system. That is the reason why sensitivity analysis are undertaken and the evolution of the internal circuit temperatures with time is analysed by means of the same simulation model presented in [45]. These sensitivity analysis consist of varying one parameter (the one whose influence is analysed) while the rest are kept constant. Regarding the flow rate, since the installation studied allows variable frequencies for the circulation pumps, the effect of varying the flow rate is studied. With respect to the thermal load, it is taken into account by means of the partial load ratio $(\alpha)$. Results for cooling mode are presented in the following.

Fig. 3.5 depicts the results of several simulations for different values of the load ratio ( $\alpha=0.2, \alpha=0.5$ and $\alpha=0.8$ ) keeping a constant internal circulation pump frequency of $50 \mathrm{~Hz}$ (see relation between frequency and flow rate in Fig. 2.6). The temperature setting considered in all three cases is the same, $10^{\circ} \mathrm{C}$, with temperature dead band of $\pm 2^{\circ} \mathrm{C}$. The figure shows the time evolution of the temperature at the outlet of the heat pump $(T i, i c)$, at the outlet of the buffer tank, that is the temperature of the water supplied to the building $\left(T_{\text {tank }}\right)$, and the temperature at the inlet of the heat pump, that is the temperature of the water returning from the building $\left(T_{o, i c}\right)$. In addition, the ON/OFF signal of the compressor (Comp. ON/OFF) is also plotted in order to be able to follow the heat pump operation $(1=O N ; 0=O F F)$.

The same time scale is considered in all three graphs in Fig. 3.5 Focusing on the Comp. ON/OFF signal, the influence of the partial load ratio can be observed, since 


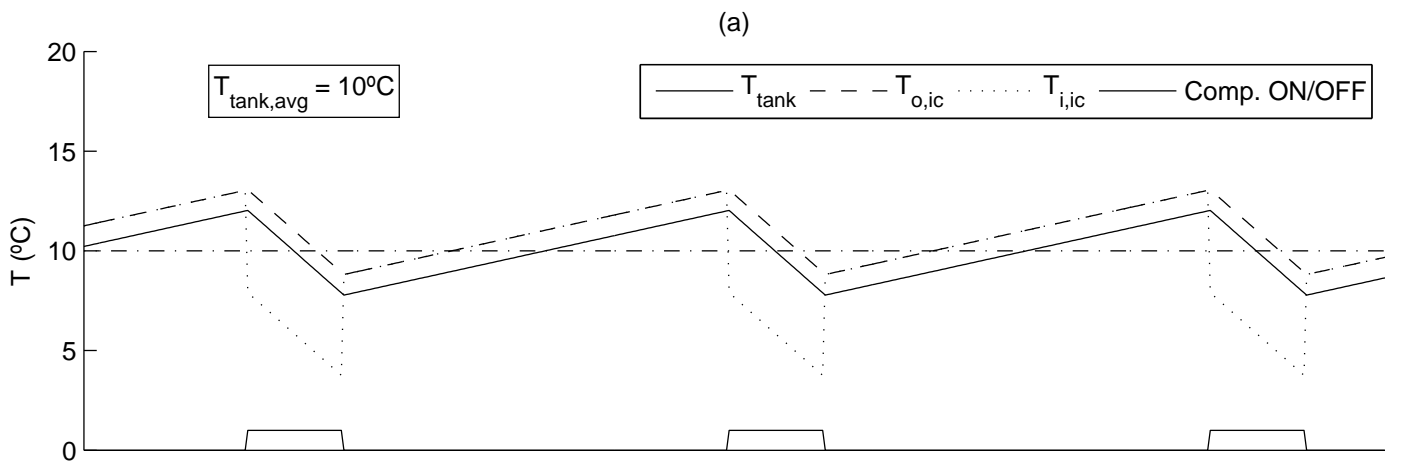

(b)

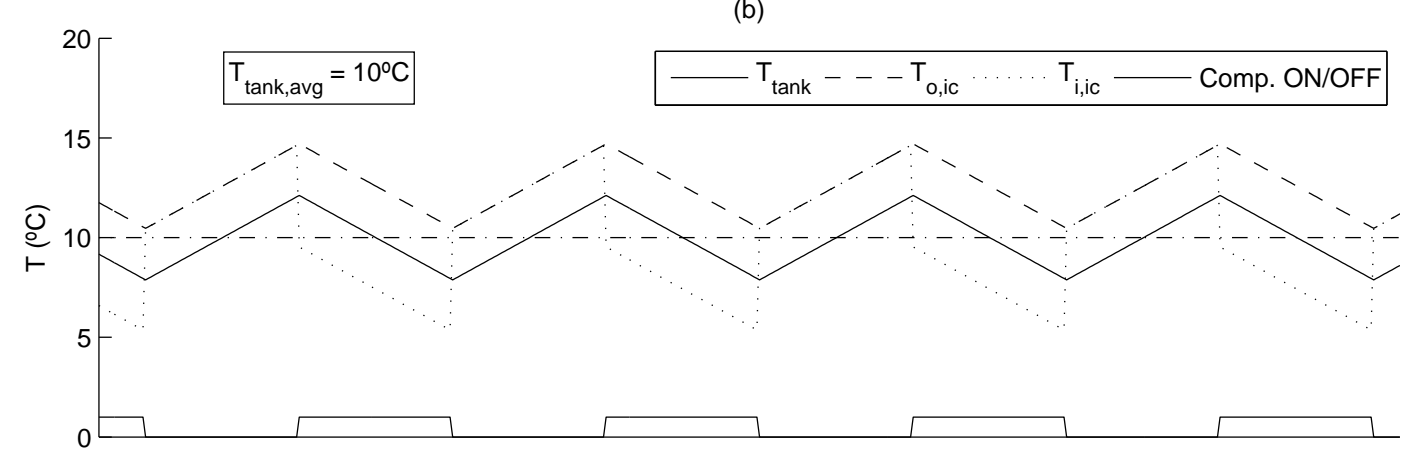

(c)

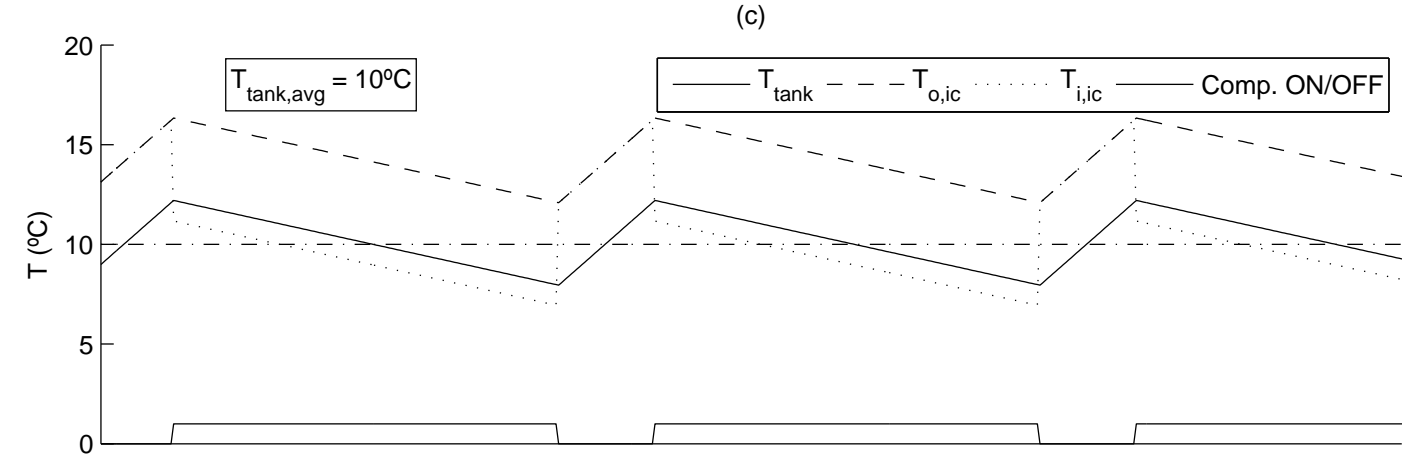

Figure 3.5: Internal circuit temperatures for different values of $\alpha$ with control sensor on supply line: (a) $\alpha=0.2$; (b) $\alpha=0.5$; (c) $\alpha=0.8$. 
the higher the value of $\alpha$, the longer the time during which the compressor is running (it takes longer to the heat pump to cool down the water when the thermal demand is higher). The compressor cycles can also be detected through the temperature at the outlet of the heat pump $\left(T_{i, i c}\right)$, since it coincides with the return temperature $\left(T_{o, i c}\right)$ when the compressor is off, but takes values around $5^{\circ} \mathrm{C}$ lower when the compressor is running.

It can also be observed that the average value of the temperature of the water supplied to the building $\left(T_{\text {tank }}\right)$ remains constant and equal to $10^{\circ} \mathrm{C}$ no matter the value of the partial load ratio. Results are similar in the case of setting a smaller frequency, for instance 20 $\mathrm{Hz}$. It is important to realize that this is really beneficial because the water at the inlet of the fan coils only presents the variation corresponding to the dead band of the heat pump controller $\left( \pm 2^{\circ} \mathrm{C}\right.$ in the example of Fig. 3.5), being the average temperature the same during all the operation period. Therefore, the thermal capacity of the fan coils will not be affected by a variation in the inlet temperature and will be more stable which is better in terms of user comfort.

On the contrary, when the control sensor is located on the return line (keeping the same temperature setpoint and dead band of $10 \pm 2^{\circ} \mathrm{C}$, which is the case of the simulation results shown in Fig. 3.6, it can be observed that the higher the load ratio, the lower the average value of the temperature supplied to the building. This means that the higher the thermal load, the lower the temperature of the water supplied to the building. This influence is given by Eq. 3.24 .

$$
T_{\text {tank }, a v g}=T_{o, i c, a v g}-\alpha \cdot \frac{\dot{Q}_{H P}}{\dot{m}_{i c} \cdot c_{p, w}}
$$

Regarding the influence of the internal frequency (and hence the internal flow rate), as presented earlier, there are two frequency inverters in order to vary the flow rate in the hydraulic circuits. For that reason, the influence of the flow rate variation should be studied as well.

For small thermal loads, low frequencies will be set. Lower frequencies mean lower flow rates and, according to Eq. 3.24, lower frequencies will result in lower temperatures of the water supplied to the building $\left(T_{\text {tank }}\right)$. Therefore, the performance would be worse for small thermal loads. Taking for instance a value of 0.2 for the partial load ratio, Fig. 3.7 shows the evolution with time of the system temperatures for $50 \mathrm{~Hz}$ (Fig. 3.7 a) and $20 \mathrm{~Hz}$ (Fig. 3.77).

As it can be observed in Fig. 3.7, when different frequencies are used, keeping the same temperature setpoint and deadband as previously $\left(10 \pm 2^{\circ} \mathrm{C}\right)$, the average temperature of the water supplied to the building $\left(T_{\text {tank }}\right)$ is not the same. Therefore, if the frequency is varied during the day as part of the energy optimization strategies, the user comfort could be affected if the control sensor is located on the return line. 


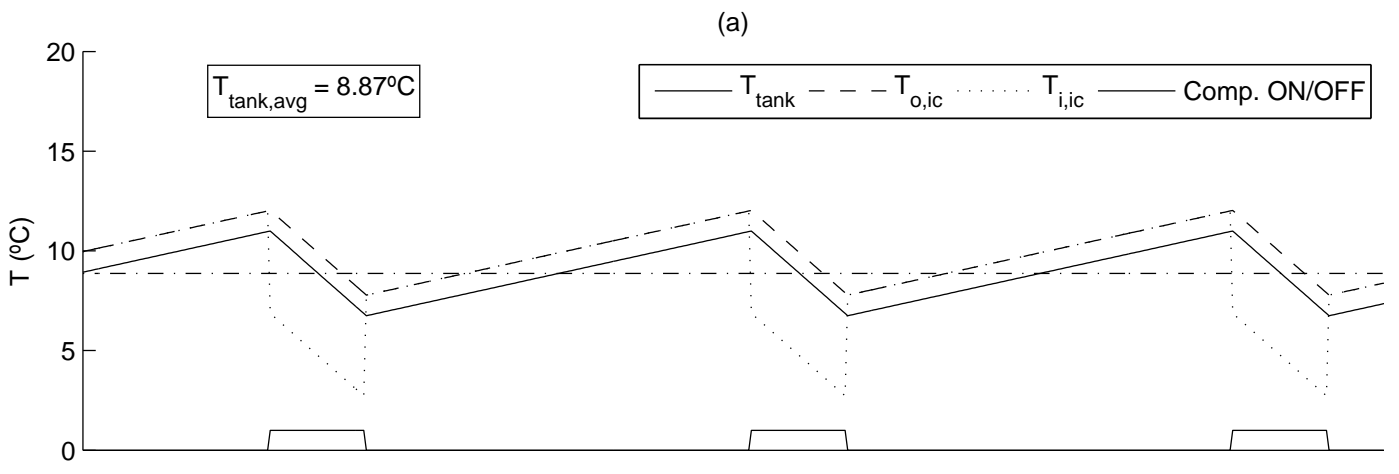

(b)

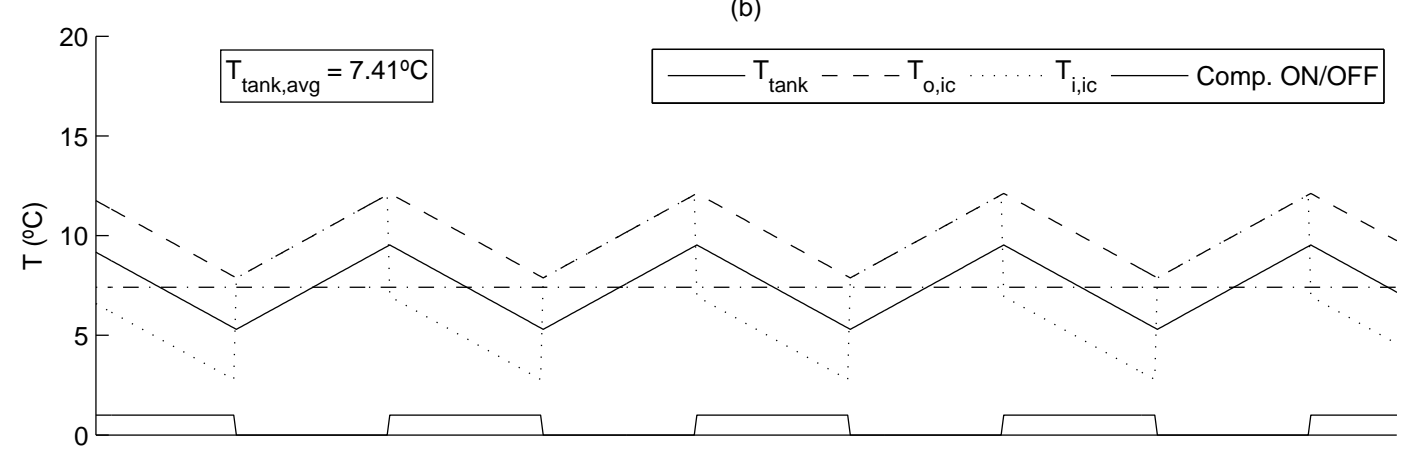

(c)

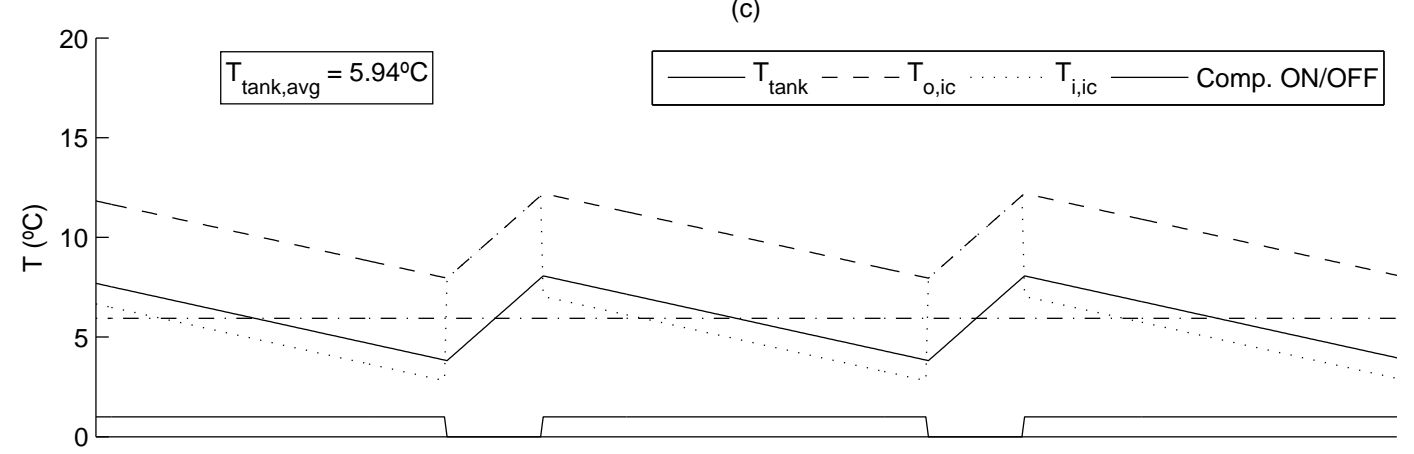

Figure 3.6: Internal circuit temperatures for different values of $\alpha$ with control sensor on return line: (a) $\alpha=0.2$; (b) $\alpha=0.5$; (c) $\alpha=0.8$. 
(a)

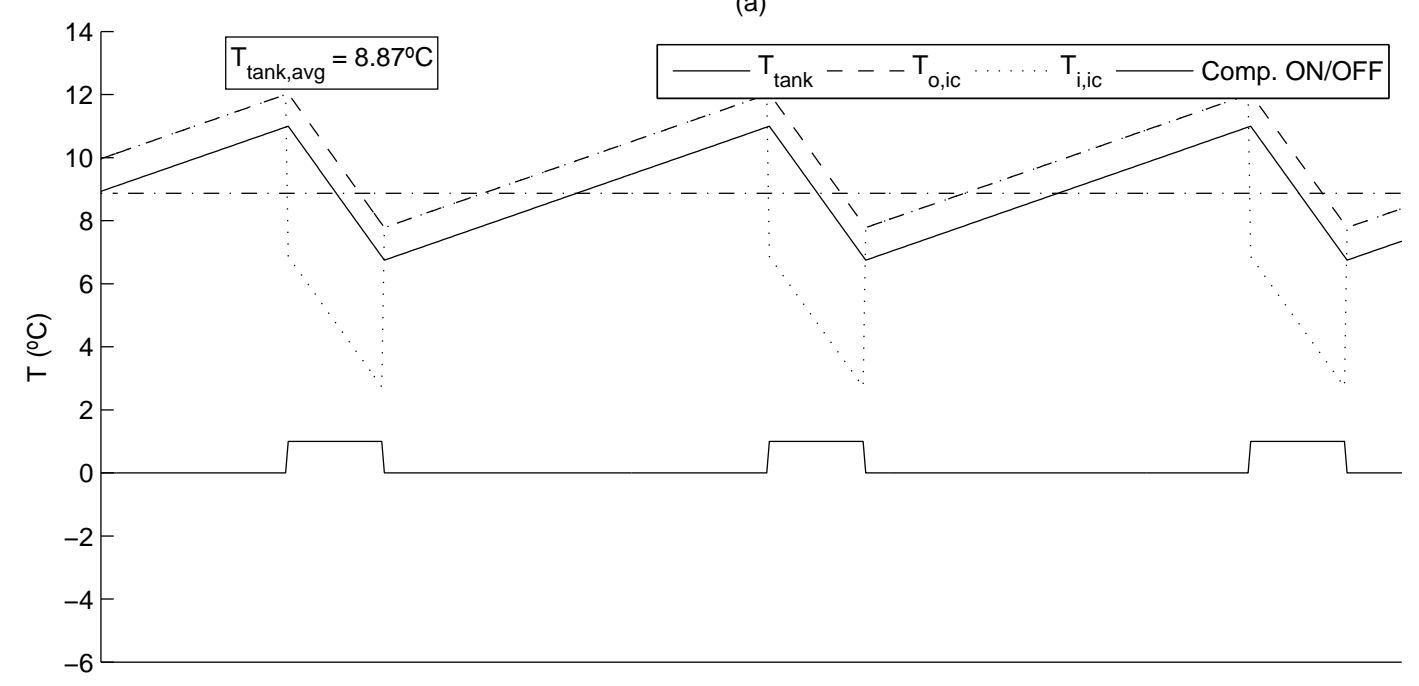

(b)

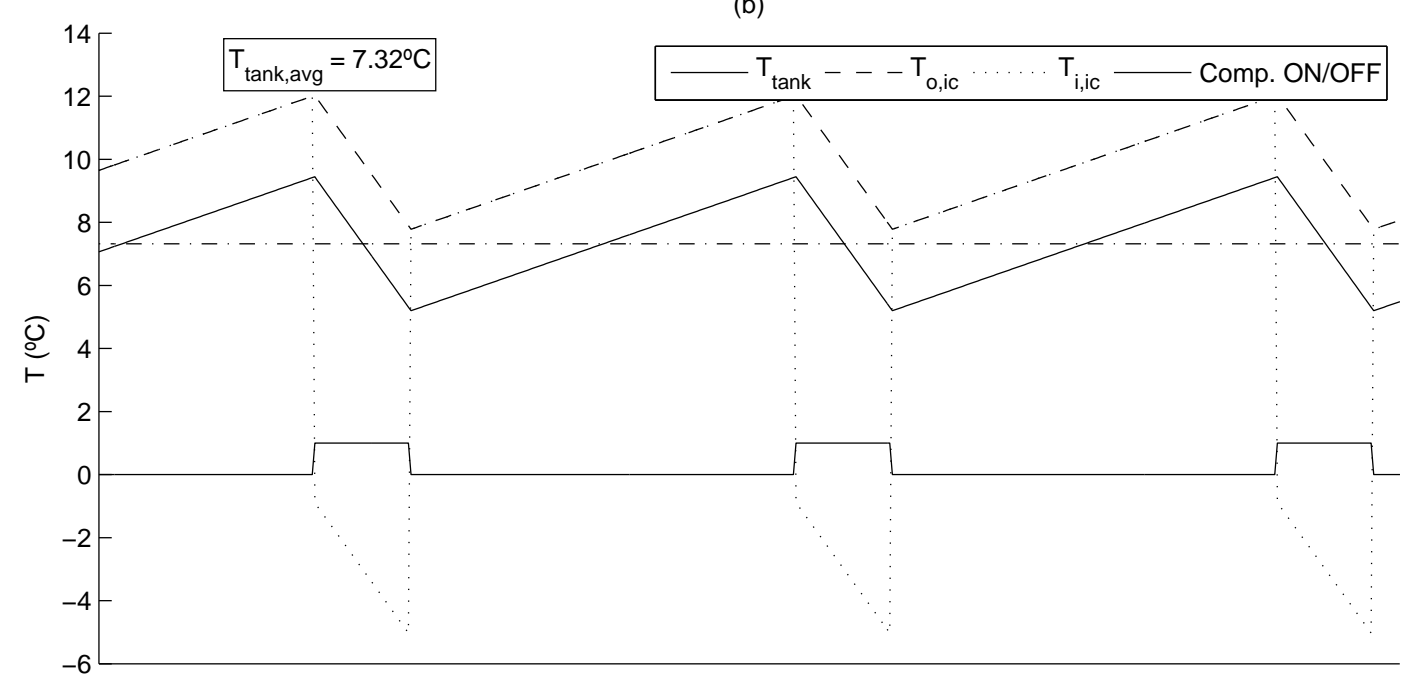

Figure 3.7: Internal circuit temperatures for different values of frequency with control sensor on return line: (a) freq. $=50 \mathrm{~Hz}$; (b) freq. $=20 \mathrm{~Hz}$. 
In addition, Fig. 3.7p shows up the possibility of having freezing problems when the internal frequency is decreased. For higher values of $\alpha$ this performance would be even worse. Therefore, the heat pump should include an anti-freezing alarm. Besides, the temperature setpoint should be readjusted when small frequencies are applied in order to avoid these freezing problems. Although results for a frequency of $20 \mathrm{~Hz}$ with the control sensor on the supply line are not shown, the same behaviour was observed in that case.

Summarising, when the control sensor is located on the return line, the temperature of the water supplied to the building may suffer strong variations, as the temperature variation includes the temperature difference introduced by the heat pump, which increases when the frequency, and hence the flow rate decreases. This behaviour may result in a degradation of the user comfort. Therefore, from the point of view of the user comfort it is better to locate the control sensor on the supply line.

However, only the user comfort has been analysed up to now in order to decide which is the best location for the control sensor, whether the supply or the return line. When it comes to the energy performance of the system, results are not so clear.

Fig. 3.8 compares the energy performance for options 1 and 2 in Table 3.3 for a typical cooling day. The values of the daily performance factors $D P F_{1}, D P F_{2}$ and $D P F_{3}$, calculated by means of Eqs. 2.15, 2.16 and 2.17, and considering a whole day as the integration period are depicted. Results are favourable for option 1 (sensor supply) whose performance factor is better. However, this is just because, since the temperature setpoint considered is the same in both cases, due to the position of the sensor the water must be cooled down to a lower temperature when the control sensor is on the return line.

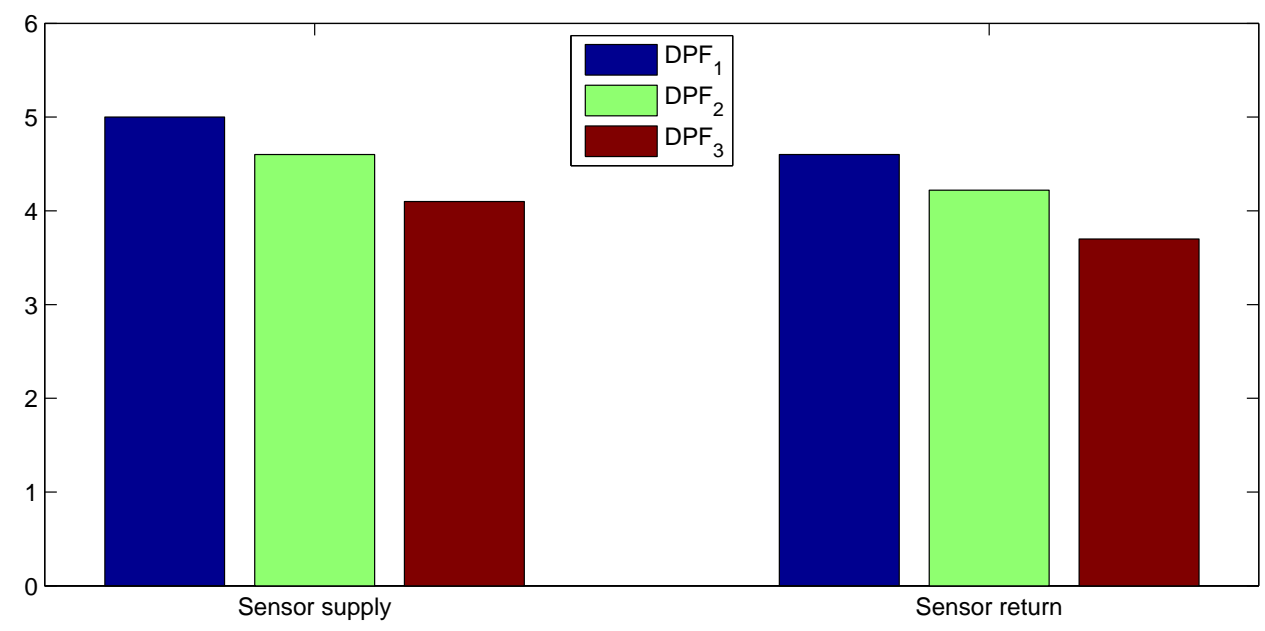

Figure 3.8: Sensor supply vs. sensor return.

Looking for instance at Fig. $3.5 \mathrm{~b}$ (sensor supply, $\alpha=0.5$ ), it can be observed that 
the water is cooled down to an average value of $10^{\circ} \mathrm{C}$. However, when the sensor is on the return (Fig. 3.6p), it is the return temperature that is kept at $10^{\circ} \mathrm{C}\left(T_{o, i c}\right)$, while the supply water is cooled down to an average value of $T_{\text {tank,avg }}=7.41^{\circ} \mathrm{C}$ resulting in an extra energy consumption of the compressor which deteriorates the heat pump daily performance factor $\left(D P F_{1}\right)$.

Therefore, the energy performance cannot be considered as a decision factor because, if a temperature setpoint readjustment was applied which achieves that the supply temperature remains constant, the energy performance of both options (sensor supply and sensor return) would be very similar. This setpoint readjustment is studied in Section 3.4.

As for this section, it is concluded that when the buffer tank is located on the supply line, the best configuration from the point of view of the user comfort is to locate the control sensor on the supply line, at the outlet of the tank. In this way, the temperature of the water supplied to the building will always have the same average temperature, which means improving comfort for the user.

\subsubsection{Results for control sensor and buffer tank position}

From the analysis carried out in the previous subsections, it is concluded that, from the point of view of the user comfort, the best position for both the buffer tank and the control sensor is the supply line. In the framework of GROUND-MED project, according to the results of this study, the buffer tank was located on the supply line and it works perfectly.

However, the heat pump in the installation was programmed in such a way that only controlling on the return line was possible. As introduced earlier, that is what most manufacturers do. Therefore, it appeared that the control sensor had to remain on the return line.

As explained in the previous section, this may cause some problems. Fig. 3.9 shows how, depending on the thermal load of the building (represented by the partial load ratio) and the flow rate of water (represented by the frequency), the building supply temperature varies (according to Eq. 3.24). As it can be seen, whereas the average return temperature $\left(T_{o, i c, a v g}\right)$ remains constant because it is the controlled temperature (notice the setpoint would be $10^{\circ} \mathrm{C}$ ), the higher the partial load ratio, the lower the average temperature of the water supplied to the building $\left(T_{\text {tank,avg }}\right)$. On the other hand, the lower the frequency (that is to say the lower the flow rate), the lower the average temperature of the water supplied to the building.

Nonetheless, the aim is to control the temperature of the water supplied to the building. For that purpose, in the following section (Section 3.4), two alternatives are proposed in order to keep the building supply temperature at the desired temperature. 


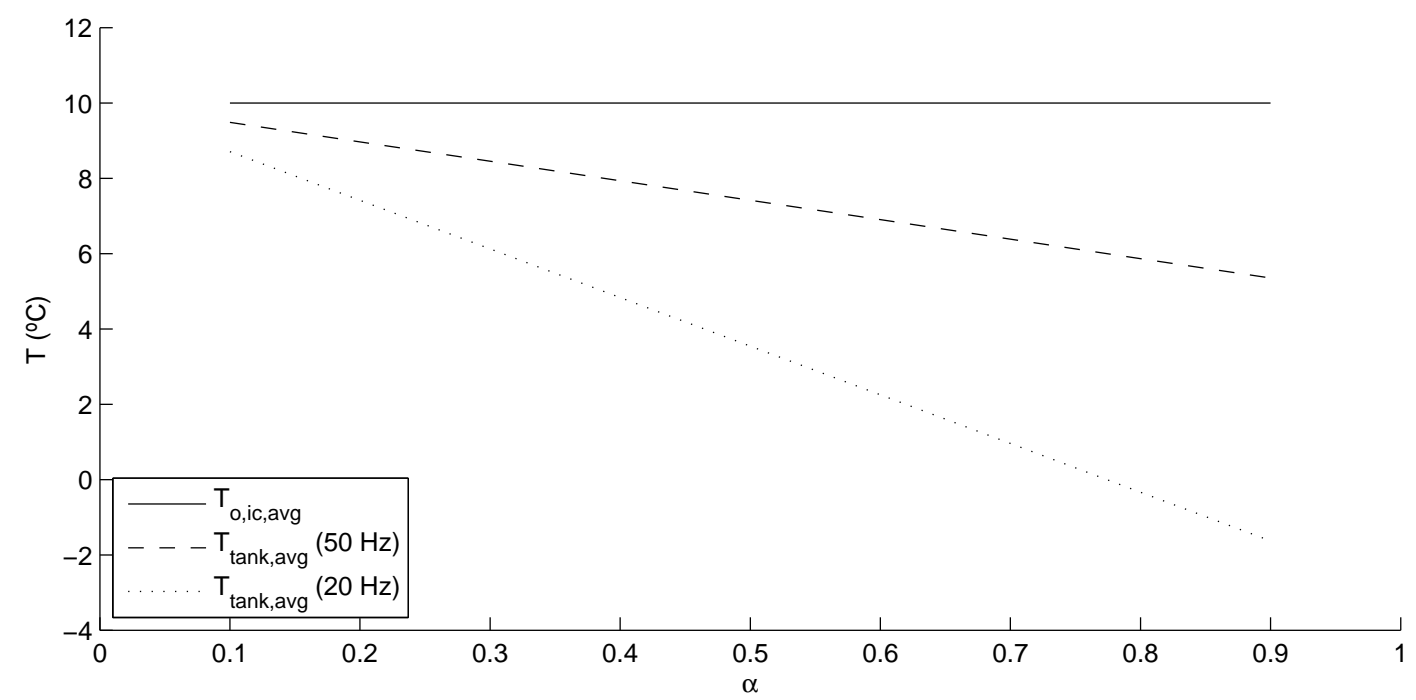

Figure 3.9: Variation of the supply building temperature with $\alpha$ and the internal frequency.

\subsection{Compressor control}

The control strategy followed by the heat pump controller in order to switch on and off the compressor (or compressors in the case of the GROUND-MED heat pump) was described in Section 2.2.2. It corresponds to an ON/OFF thermostat control. This control can be observed in Fig. 2.12 for GEOCOOL heat pump (single-stage) and Fig. 2.13 for GROUND-MED heat pump (tandem). However, several problems may spoil the optimal performance of the system if the default heat pump control is used.

The first problem has to do with the temperature used to control the start and stop of the heat pump. As shown in Figs. 3.6 and 3.9, using the return temperature as the control temperature may result in a steep decrease of the supply temperature for high loads and consequently deteriorate the user comfort. Moreover, the fact that the frequency of the water circulation pumps can be varied, may aggravate this effect by causing freezing problems in the heat pump for small frequencies (as shown in Figs. 3.8 and 3.9.

The decrease in the supply temperature described in Fig. 3.6 is presented in Fig. 3.10 by means of experimental data. The data correspond to 2012/10/18 (Fig. 3.10 a) and 2012/09/18 (Fig. 3.10p). As it can be observed, a higher load in September makes the building supply temperature (see $T_{\text {tank,avg }}$ in Fig. 3.10p) decrease for the same temperature setpoint.

The second problem appears only for the GROUND-MED heat pump and it is found if Fig. 3.11 is observed thoroughly. Taking for instance the example of cooling mode (Fig. 3.11 ), it can be assumed as an example a temperature setting of $10^{\circ} \mathrm{C}$ and a 
(a)

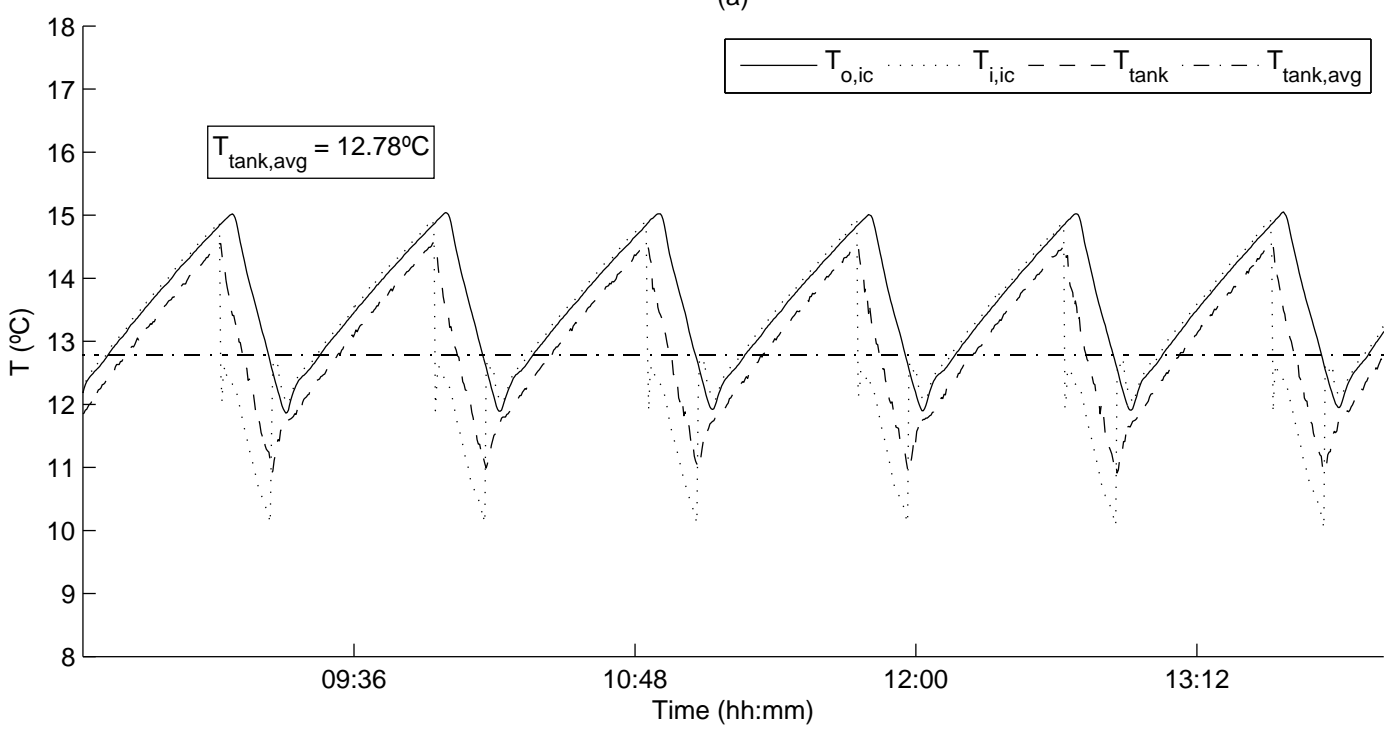

(b)

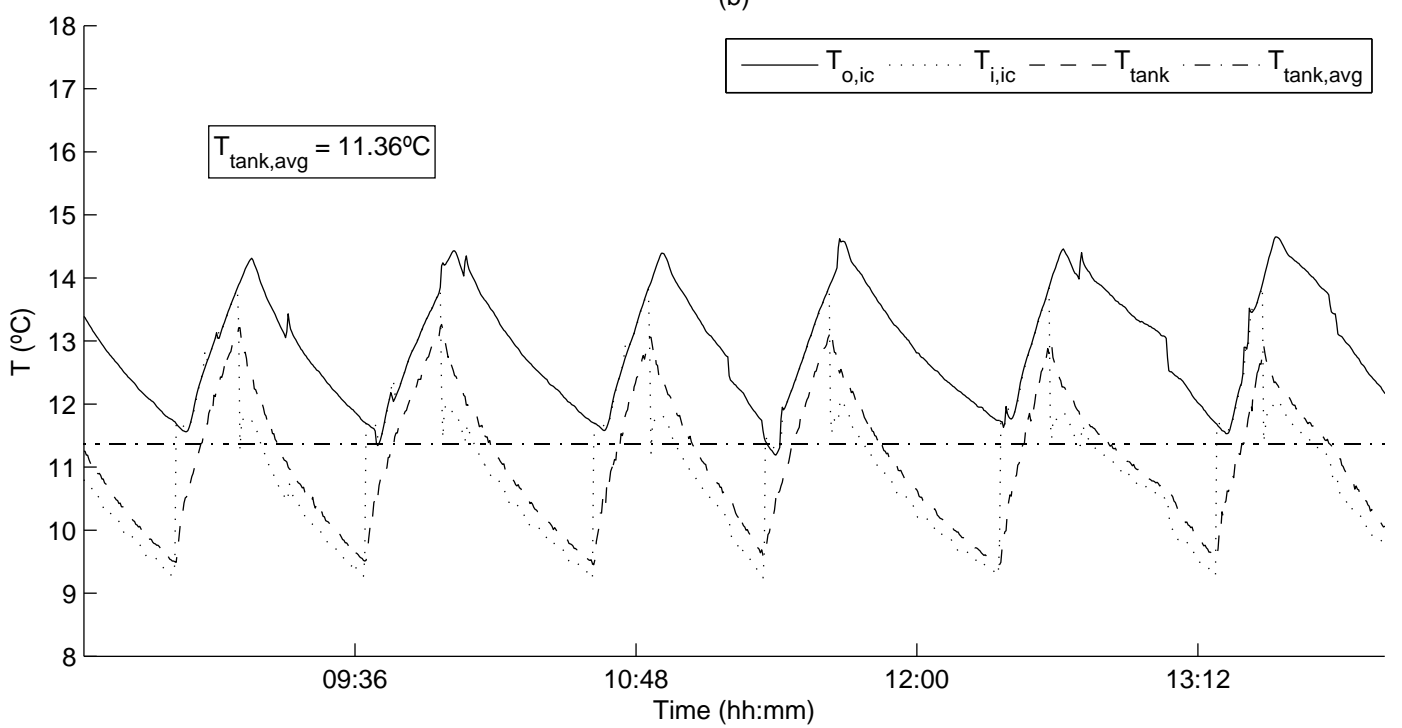

Figure 3.10: Experimental values of the internal circuit temperatures for different days with different thermal loads: (a) Low thermal load (2012/10/18); (b) High thermal load (2012/09/18). 
temperature deadband of $4^{\circ} \mathrm{C}$. As observed in Fig. 3.11 a, the heat pump controller divides the temperature deadband into two smaller bands and makes each compressor work inside each one of them. Therefore, this would result in a lower limit of $8^{\circ} \mathrm{C}$, an upper limit of $12^{\circ} \mathrm{C}$ and a medium limit of $10^{\circ} \mathrm{C}$.

(a)
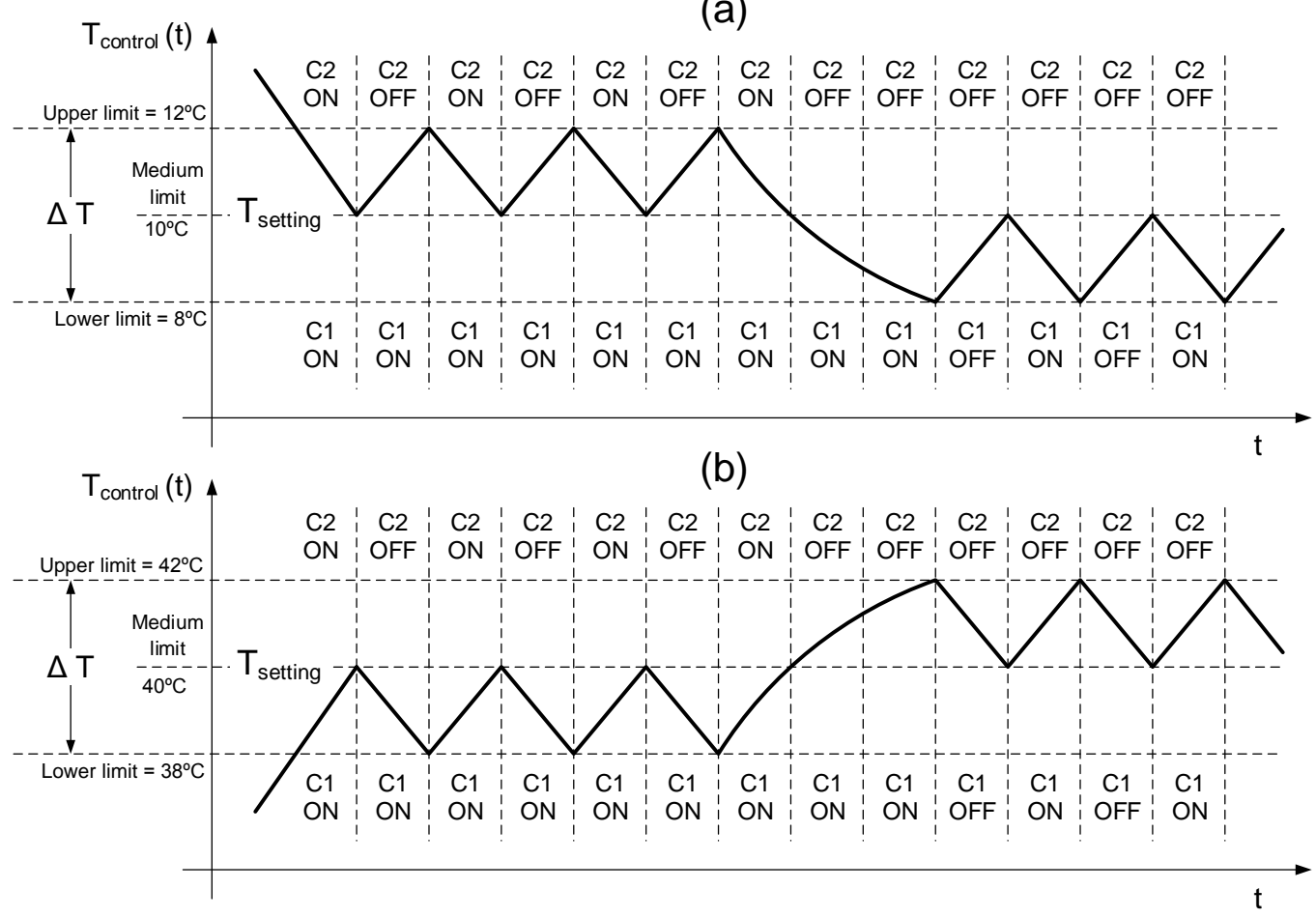

Figure 3.11: Numeric example of the GROUND-MED heat pump control: (a) Cooling mode; (b) Heating mode.

When one compressor is cycling on and off, the control temperature would vary between $8^{\circ} \mathrm{C}$ and $10^{\circ} \mathrm{C}$. On the other hand, when the thermal load increases and the second compressor starts cycling on and off while the first one is running continuously, the control temperature would vary between $10^{\circ} \mathrm{C}$ and $12^{\circ} \mathrm{C}$. Therefore, when there is a higher thermal demand, the water is supplied to the building at a higher temperature in cooling mode, what does not make much sense. The same behaviour occurs in heating mode, supplying the water at a lower temperature when the thermal demand is higher (see Fig. 3.11b). Moreover, this would happen as well if the control sensor was located on the supply line.

A possible solution could just be changing the temperature probe that the heat pump controller is using as control sensor to the supply line, at the outlet of the tank. This was tried at the geothermal plant only to realize that the internal programming of the 
heat pump was not prepared for that.

Nevertheless, a correction could be introduced in the temperature setpoint of the heat pump (measured on the return) which takes into account the variations in the thermal load and the flow rate, in order to maintain constant the building supply temperature, no matter the thermal load, the flow rate or whether there is one or there are two compressors running. This possible solution is described in Section 3.4.1.

On the other hand, another possible solution for these two problems would be asking the manufacturer to modify the internal programming of the heat pump controller. For that purpose, a new control strategy was developed. This control strategy is described in Section 3.4.2,

\subsubsection{Supply temperature control with sensor on the return line}

The first approach that one might think of in order to control the building supply temperature while the control sensor remains on the return line is setting each day a different temperature setpoint in the heat pump so that the supply temperature remains constant. However, this is not possible because the thermal load is difficult to predict at the beginning of the day and, what is more, it varies along the day, influencing the supply temperature according to Eq. 3.24 . Additionally, the thermostat band is different when two compressors are running hence varying also the supply temperature (see section 2.2 .2 .

Therefore, the option of using a fixed setpoint, different for each day, must be discarded as a strategy to control the supply temperature when the control sensor is on the return line. Instead, an algorithm that calculates on-line the temperature setpoint to set in the heat pump so that the supply temperature remains at the desired value at any time should be found.

As shown in Fig. 2.15 in section 2.2.2, the heat pump controller uses the return temperature $\left(T_{o, i c}\right)$ to control the start and stop of the heat pump $\left(T_{o, i c, a v g}=T_{\text {control,avg }}\right)$. This means that the heat pump controller is only concerned about keeping constant the temperature of the water at the inlet of the heat pump, that is to say the water returning from the building.

However, the aim is to control the supply temperature. For that purpose, Eq. 3.24 provided the relation between the average values of supply and return temperatures. Combining Eq. 3.24 and Eq. 2.11 in section 2.2.2, and solving for the temperature setpoint, Eq. 3.25 provides the value of the temperature setpoint that should be set in the heat pump controller so that the supply temperature is controlled even though the control sensor and the control logics at the heat pump control board are prepared to control on the return line.

$$
T_{\text {set }}=T_{\text {tank,avg }}-\Delta T_{d b} \cdot\left(n-\frac{1}{2}\right)+\frac{\alpha \cdot \dot{Q}_{H P}}{\dot{m}_{i c} \cdot c_{p, w}}
$$


Eq. 3.25 was programmed in the control board of the system and tested in the geothermal plant. Results are shown in Fig. 3.12 .

(a)

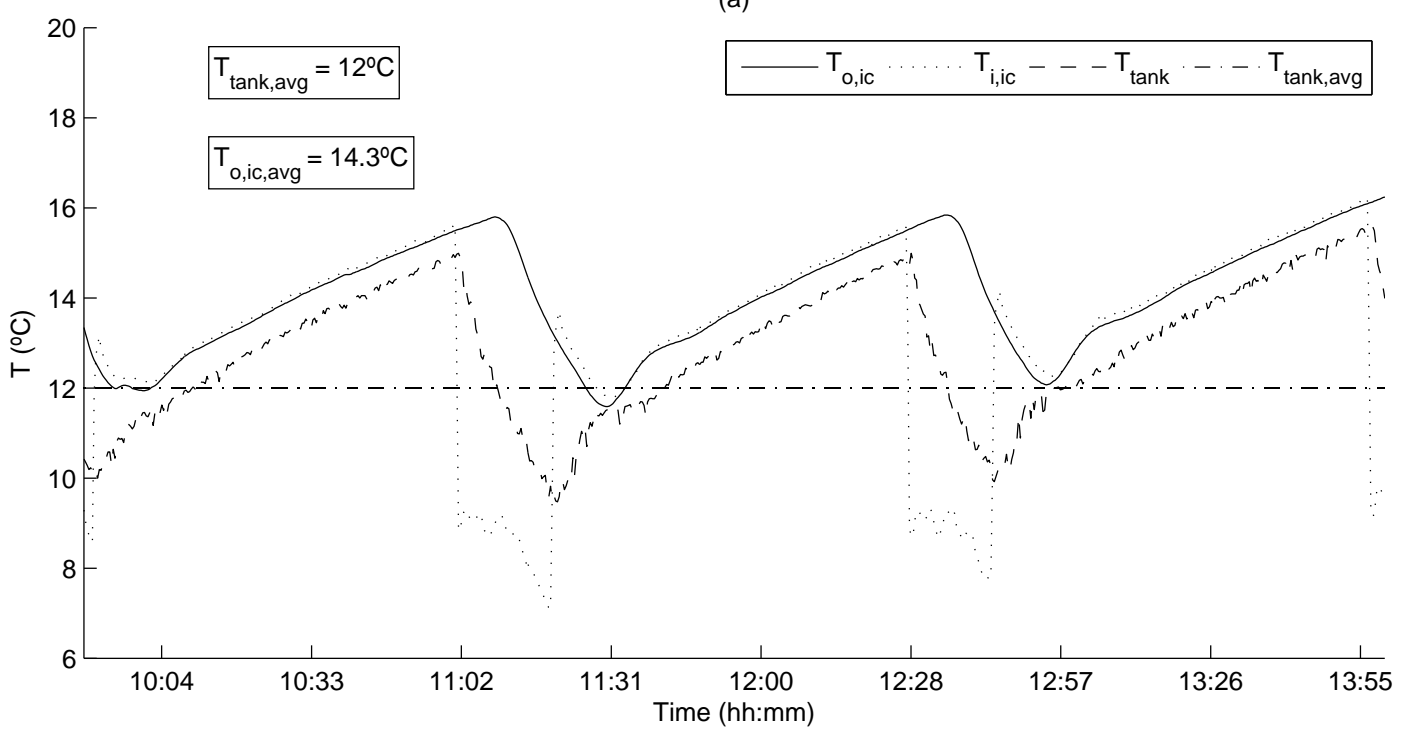

(b)

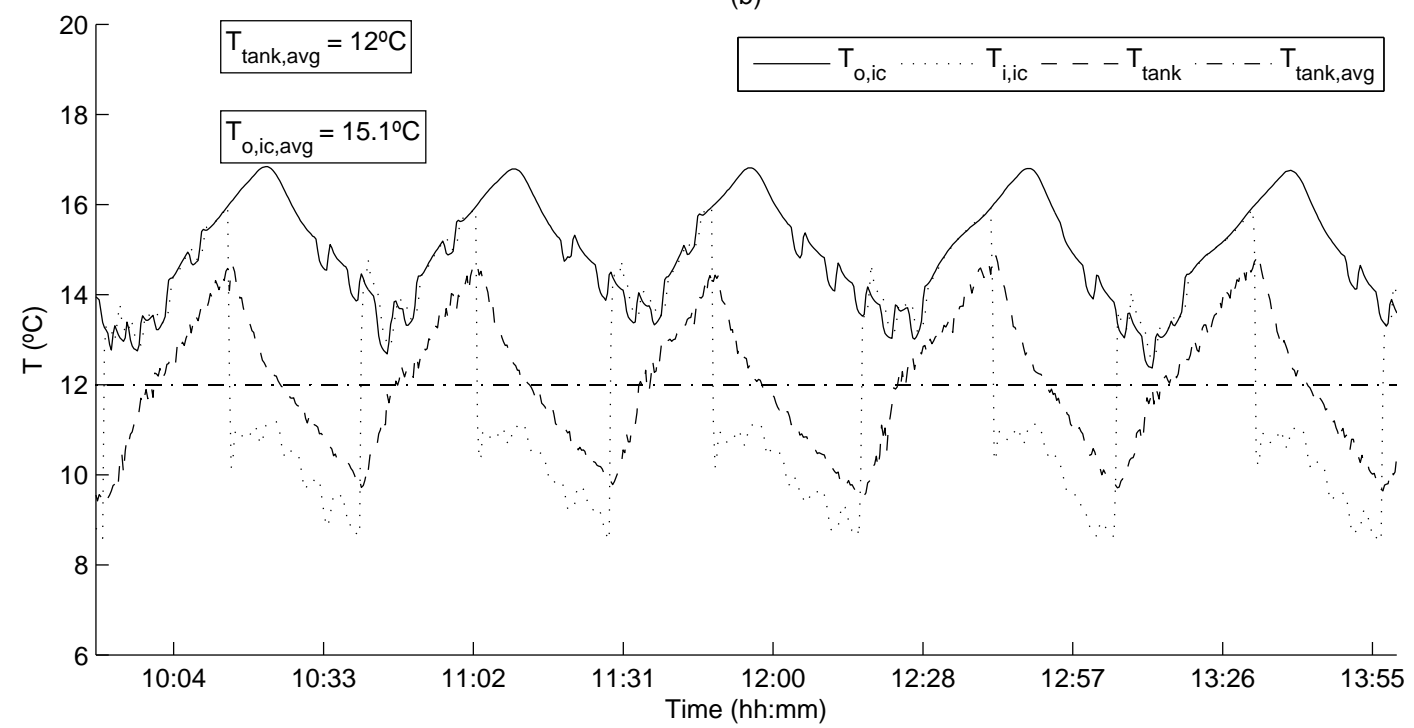

Figure 3.12: Experimental values of the internal circuit temperatures for different days with different thermal loads applying corrected temperature setpoint: (a) 2012/10/23; (b) $2012 / 07 / 02$. 
Fig. 3.12 shows the resulting temperatures of the internal circuit for two different days with different thermal loads after using the corrected temperature setpoint calculated by Eq. 3.25. The experimental data correspond to 2012/10/23 (Fig. 3.12a) and 2012/07/02 (Fig. 3.12p). As shown in Fig. 3.12, the average value of the supply temperature $\left(T_{\text {tank,avg }}\right)$ remains the same in both cases. It can be observed that, in order to achieve that, the temperature setpoint is varied as it is observed in the average value of the return temperature $\left(T_{o, i c, a v g}\right)$. This change in the temperature setpoint needs to be higher when the thermal load is higher, as depicted in Fig. $3.12 \mathrm{~b}$ for the case of July 2012.

Eq. 3.25 is valid for cooling mode. For heating mode the expression is the same by changing the signs of the last two addends, as expressed in Eq. 3.26 .

$$
T_{\text {set }}=T_{\text {tank }, a v g}+\Delta T_{d b} \cdot\left(n-\frac{1}{2}\right)-\frac{\alpha \cdot \dot{Q}_{H P}}{\dot{m}_{i c} \cdot c_{p, w}}
$$

\subsubsection{Control board upgrade to control the supply temperature}

The second solution proposed is asking the manufacturer of the heat pump (HiRef ${ }^{\circledR}$ ) to modify the internal programming of the heat pump in such a way that is possible to use the supply temperature as the control temperature. With this change, it would be possible to control the temperature of the water supplied to the building hence avoiding the influence of the thermal load and the flow rate variation in the water supplied to the fan coils.

However, the second problem presented earlier in the introduction to this section would remain: the GROUND-MED heat pump would still divide the temperature deadband into two smaller bands and supply the water at a higher temperature in cooling mode and at a lower temperature in heating mode when the second compressor starts because the thermal load is higher. In order to solve this problem, a new control strategy was developed so that the building supply temperature remained exactly the same independently of the number of compressors running. This control strategy, which is explained in detail in the following, was proposed to the manufacturer who finally implemented it in the internal programming of the heat pump controller.

The idea behind this strategy is that the average supply temperature remains at the same point when the second compressor starts. Therefore, the system should be able to detect when there is an increase in the thermal demand, hence switching on the second compressor. For that purpose, instead of dividing the temperature deadband into two smaller bands and making the heat pump work in one or the other according to the number of compressors running, a second band $\left(\Delta T_{\text {band2 }}\right)$ is included in the new control strategy in order to detect variations in the thermal load. Fig. 3.13 depicts how this new control strategy works for cooling (Fig. $3.13 \mathrm{a}$ ) and heating (Fig. $3.13 \mathrm{~b}$ ) modes. The description is carried out for cooling mode, but it is analogous for heating mode.

In the cooling season (Fig. 3.13 ), the temperature of the water increases during the 
(a)

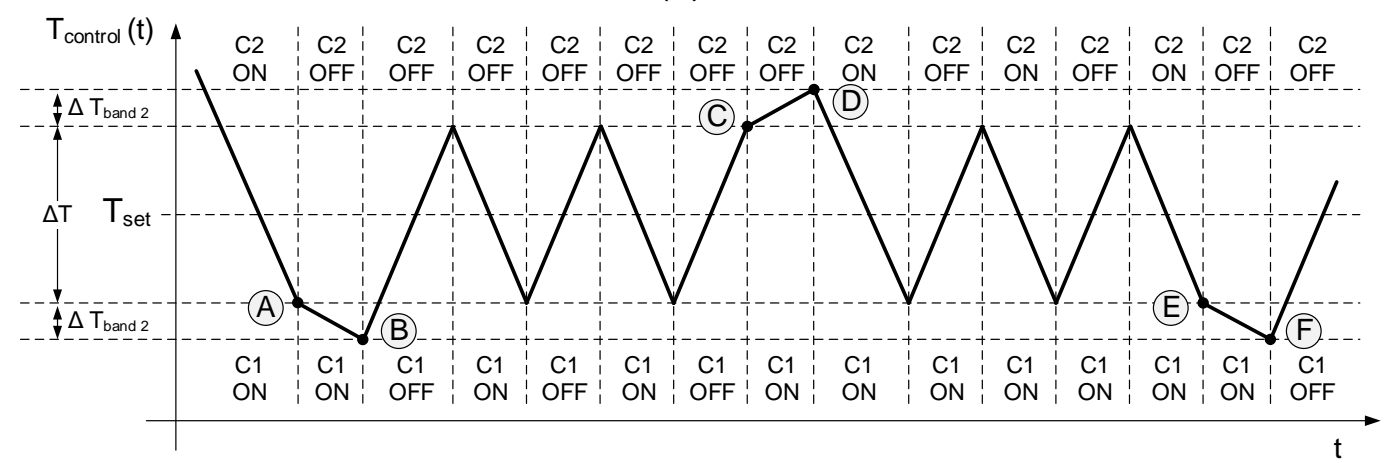

(b)

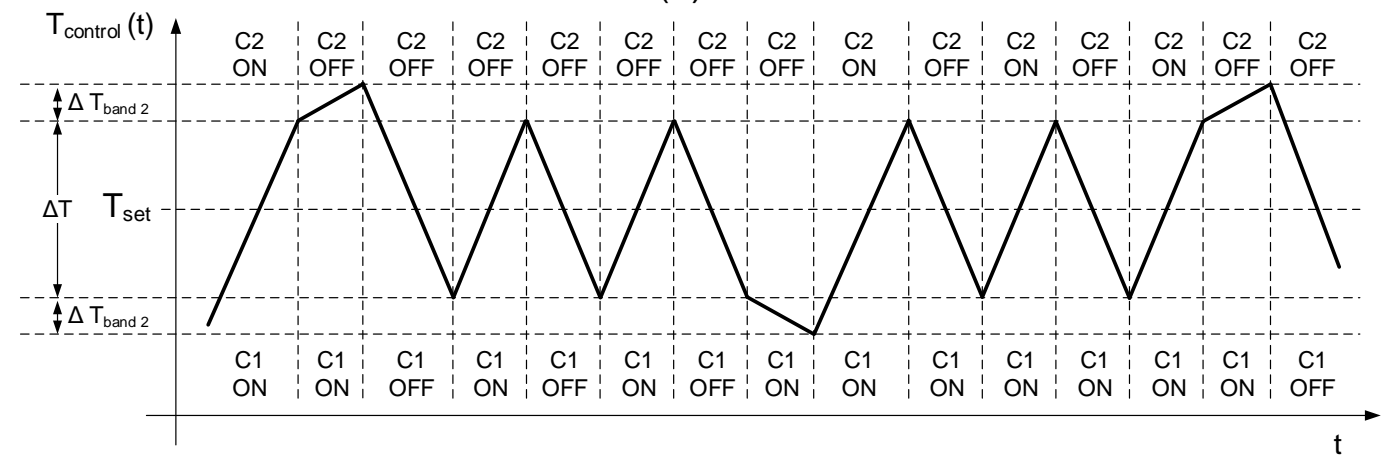

Figure 3.13: GROUND-MED heat pump control after upgrading the heat pump controller: (a) Cooling mode; (b) Heating mode.

night. When the value of the control temperature is above all the temperature limits (e.g. at the beginning of the morning), both compressors start, cooling down the water until it reaches point $\mathrm{A}$, moment at which the second compressor $(\mathrm{C} 2)$ stops. At this moment, if the instantaneous thermal demand was big enough, the system would continue to work in state $n=2$, that is to say, one compressor continuously running (C1) and the other one cycling on and off $(\mathrm{C} 2)$. However, if the thermal load is small, as it is the case depicted in Fig. [3.13a, $\mathrm{C} 1$ is able to cool down the water until point B is reached and $\mathrm{C} 1$ is switched off. This is achieved thanks to the second deadband $\Delta T_{\text {band } 2}$.

From point $\mathrm{B}$ on, the heat pump will work in state $n=1$, with $\mathrm{C} 1$ cycling on and off as long as the thermal load remains low. This happens between points B and C. At point $\mathrm{C}, \mathrm{C} 1$ starts but it is not able to cool down the water because the thermal load is higher now. Hence the water temperature starts to increase until $\Delta T_{\text {band } 2}$ detects this increase in the load when point D is reached. At this point, $\mathrm{C} 2$ is switched on and starts to cool down the water.

From point $\mathrm{D}$ on, the heat pump will work in state $n=2$, with $\mathrm{C} 1$ continuously running 
and $\mathrm{C} 2$ cycling on and off as long as the thermal load remains high. This happens between points $\mathrm{D}$ and $\mathrm{E}$. At point $\mathrm{E}, \mathrm{C} 2$ stops and $\mathrm{C} 1$ is able to cool down the water until it is switched off when the limit given by $\Delta T_{\text {band } 2}$ is reached (point $\mathrm{F}$ ).

This algorithm was implemented by the manufacturer in the internal programming of the heat pump controller and tested in the geothermal plant. By means of this new control strategy, a stable value of the building supply temperature is achieved independently of the number of compressors running, as long as temperature at the outlet of the tank is used as the control temperature. With the return temperature as the control temperature, the influence of the thermal load and the flow rate variation would not be avoided. Fig. 3.14 shows the experimental results obtained for cooling mode by means of this new control algorithm, using the supply temperature as the control temperature. The same points depicted in Fig. 3.13, from A to F, can be found in the experimental results presented in Fig. 3.14

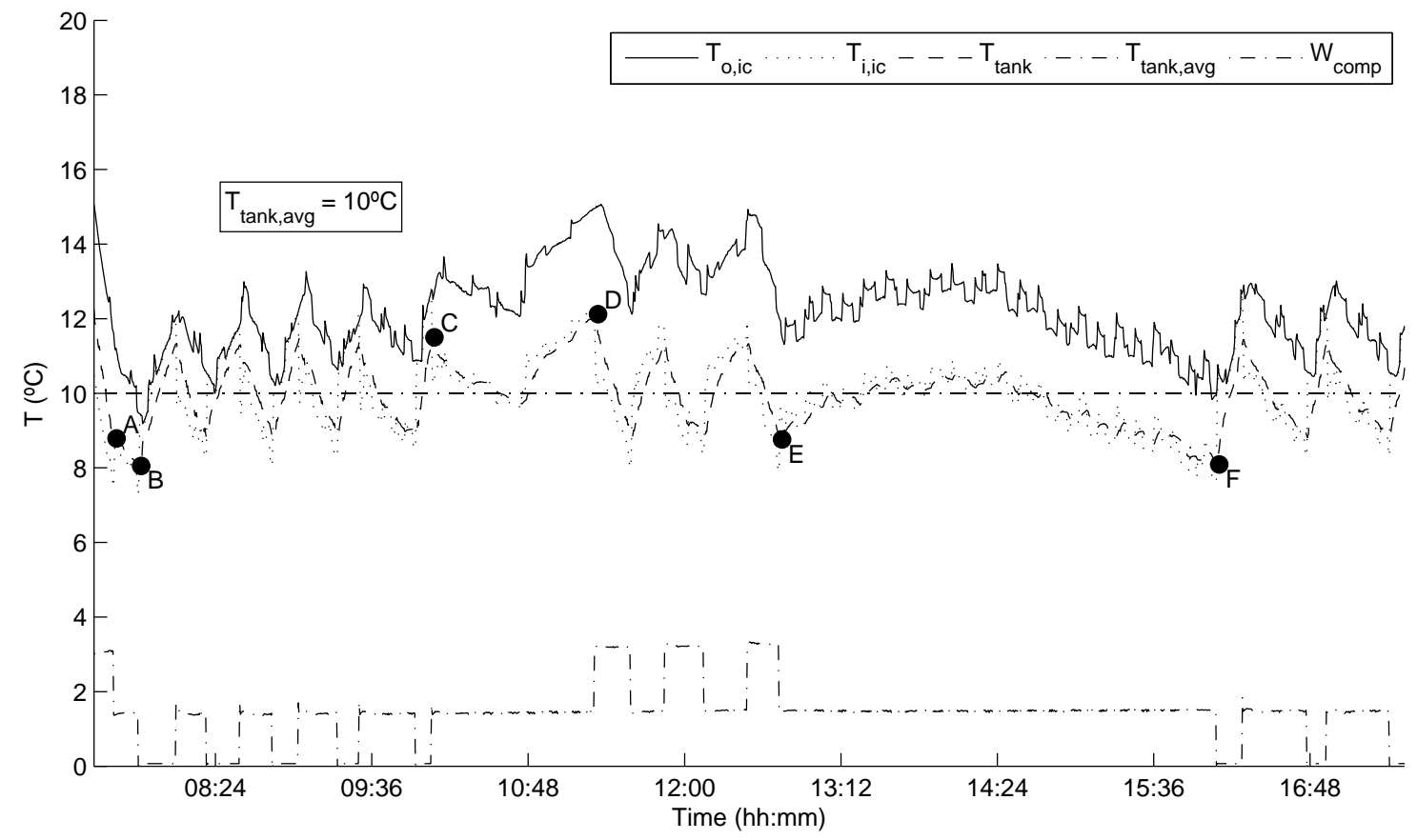

Figure 3.14: GROUND-MED heat pump control after upgrading the heat pump controller: experimental results for cooling mode (2013/07/09).

This new control strategy is used from now on in the energy optimization strategies developed in the following. Since the building supply temperature will be used from now on as the control temperature, it will be referred to in the following as temperature setpoint as well. 


\subsection{Temperature compensation}

In Section 3.4 two possible solutions were proposed in order to be able to control the temperature of the water supplied to the building. However, the value of the building supply temperature, that is to say the value of the temperature setpoint should not necessarily be fix to the same value during the whole day. Some variation of it could be done in order to improve the energy performance of the heat pump and thus of the system.

For instance, in cooling mode, the water could be supplied at a higher temperature when the ambient is not too hot and at a lower temperature when it is hotter, and vice versa for heating mode. The variation of the temperature setpoint as a function of the outdoor temperature in HVAC systems is commonly known as temperature compensation, outdoor temperature reset or just temperature reset. In this research work, the nomenclature temperature compensation will be used.

The objective of the temperature compensation is to take into consideration the weather conditions in order to save energy whenever it is possible. Therefore, the temperature at which the water is supplied to the building is set as low as possible during heating and as high as possible during cooling mode, as a function of the ambient temperature. The curves developed in order to apply temperature compensation in the geothermal plant studied in this research work are described in the following.

In order to obtain the temperature compensation curves, the air-conditioned zone is analysed. The thermal load of the whole air-conditioned zone can be expressed as the sum of the thermal load of each room, as shown in Eq. 3.27

$$
\dot{q}(t)=\sum_{i=1}^{11} \gamma_{i} \cdot\left[U A_{0} \cdot\left(T_{\text {amb }}(t)-T_{\text {room }}(t)\right)+G+k \cdot I_{s}(t)\right]_{i}
$$

Where:

$\gamma_{i}$ is the user factor for each room $i$,

$U A_{0}$ stands for the overall heat transfer conductance of the room,

$G$ stands for the internal gains due to people, computers and other devices,

$k$ stands for a factor that takes into account the part of the solar irradiation to consider,

and $I_{s}(t)$ corresponds to the the solar irradiation in the corresponding room

In order to simplify the problem, the internal gains and solar irradiation can be included in an effective $U A_{0}$ factor whose value would be higher than when only conduction and convection losses are considered. Then, the thermal load for each room would be as shown in Eq. 3.28. The example of cooling mode is chosen for the explanation. The 
resulting expressions for heating mode will also be included when required.

$$
\dot{Q}_{\text {room }}=U A_{0} \cdot\left(T_{\text {amb }}-T_{\text {room }}\right)
$$

On the other hand, the fan coil capacity can be expressed in terms of the air flow circulating through the coil $\left(\dot{m}_{a}\right)$, the specific heat of air at constant pressure $\left(c_{p, a}\right)$, the effectiveness of the fan coil $\left(\varepsilon_{F C}\right)$, which depends on the nominal heat capacity of air $\left(C_{a, n o m}=\dot{m}_{a, n o m} \cdot c_{p, a}\right)$ and the heat capacity of water $\left(C_{w}=\dot{m}_{w} \cdot c_{p, w}\right)$, and the temperature difference between the water and the air entering the coil $\left(T_{\text {room }}-T_{S B}\right)$, as presented in equation 3.29 .

$$
\dot{Q}_{F C}=\dot{m}_{a} \cdot c_{p, a} \cdot \varepsilon_{F C}\left(C_{a, n o m}, C_{w}\right) \cdot\left(T_{\text {room }}-T_{S B}\right)
$$

It should be noticed that $T_{S B}$ here would be the targeted building supply temperature, which would coincide with the average value of the building supply temperature $\left(T_{\text {tank,avg }}\right)$. This is the temperature resulting from the use of the temperature compensation curves and other strategies to be developed later in this work. $T_{S B}$ should be distinguished from the actual building supply temperature $\left(T_{\text {tank }}\right)$.

In order to achieve user comfort, the fan coil capacity should cover the room thermal load, as expressed in Eq. 3.30 .

$$
\dot{m}_{a} \cdot c_{p, a} \cdot \varepsilon_{F C}\left(C_{a, n o m}, C_{w}\right) \cdot\left(T_{\text {room }}-T_{S B}\right) \geq U A_{0} \cdot\left(T_{a m b}-T_{\text {room }}\right)
$$

This results in a building supply temperature that, in order to provide user comfort, should be lower than a certain value which will be given by Eq. 3.31 .

$$
T_{S B} \leq T_{\text {room }}-\frac{U A_{0} \cdot\left(T_{\text {amb }}-T_{\text {room }}\right)}{\dot{m}_{a, \text { nom }} \cdot c_{p, a} \cdot \varepsilon_{F C}\left(C_{a, \text { nom }}, C_{w}\right)}
$$

Eq. 3.31 provides the limit condition. Considering the design conditions of the fan coil (maximum ambient temperature $T_{a m b, m a x}$, e.g. $38^{\circ} \mathrm{C}$ in Valencia, minimum targeted building supply temperature $T_{S B, \min }$, e.g. $7^{\circ} \mathrm{C}$, and the maximum internal circulation pump flow rate), for which the fan coil has to provide comfort to the users in the worst case scenario (hottest day of the year), the inequation turns into Eq.3.32. Under these conditions, the effectiveness of the fan coil will be maximum $\left(\varepsilon_{F C, \max }\right)$.

$$
T_{S B, \min }=T_{\text {room }}-\frac{U A_{0} \cdot\left(T_{a m b, \max }-T_{\text {room }}\right)}{\dot{m}_{a, \text { nom }} \cdot c_{p, a} \cdot \varepsilon_{F C, \max }\left(C_{a, \text { nom }}, C_{w, \max }\right)}
$$

Then, Eq. 3.33 is deduced from Eq. 3.32 .

$$
\frac{U A_{0}}{\dot{m}_{a, \text { nom }} \cdot c_{p, a} \cdot \varepsilon_{F C, \text { max }}\left(C_{a, \text { nom }}, C_{w, \text { max }}\right)}=\frac{T_{\text {room }}-T_{S B, \text { min }}}{T_{a m b, \text { max }}-T_{\text {room }}}
$$

Assuming that the relation between the overall heat transfer conductance of the room $\left(U A_{0}\right)$ and the fan coil effectiveness $\left(\varepsilon_{F C, \max }\right)$ is approximately constant and equal to 
the value given by the design conditions, Eqs. 3.31 and 3.33 can be combined. This results in Eq. 3.34, which provides the targeted building supply temperature pursued with the temperature compensation strategy. It should be noticed that considering this assumption means assuming that the fan coil effectiveness remains constant and equal to its maximum value $\left(\varepsilon_{F C, \max }\left(C_{a, \text { nom }}, C_{w, \max }\right)\right)$.

$$
T_{S B} \leq(1+\beta) \cdot T_{\text {room }}-\beta \cdot T_{a m b}
$$

Eq. 3.34 corresponds to a linear equation where $\beta$ is the relation given by Eq. 3.35

$$
\beta=\frac{T_{\text {room }}-T_{S B, \min }}{T_{\text {amb }, \max }-T_{\text {room }}}
$$

Considering the values proposed earlier for the maximum ambient temperature and for the minimum targeted building supply temperature, that is to say $T_{a m b, \max }=38^{\circ} \mathrm{C}$ and $T_{S B \text {, min }}=7^{\circ} \mathrm{C}$ respectively, and considering a targeted room comfort temperature of $T_{\text {room }}=25^{\circ} \mathrm{C}$ as provided by the Spanish regulations [71], Eq. 3.34 is graphically represented in Fig. 3.15. It should be noticed that the supply building temperature is limited to $10^{\circ} \mathrm{C}$ due to the requirements established in the framework of GROUND-MED project.

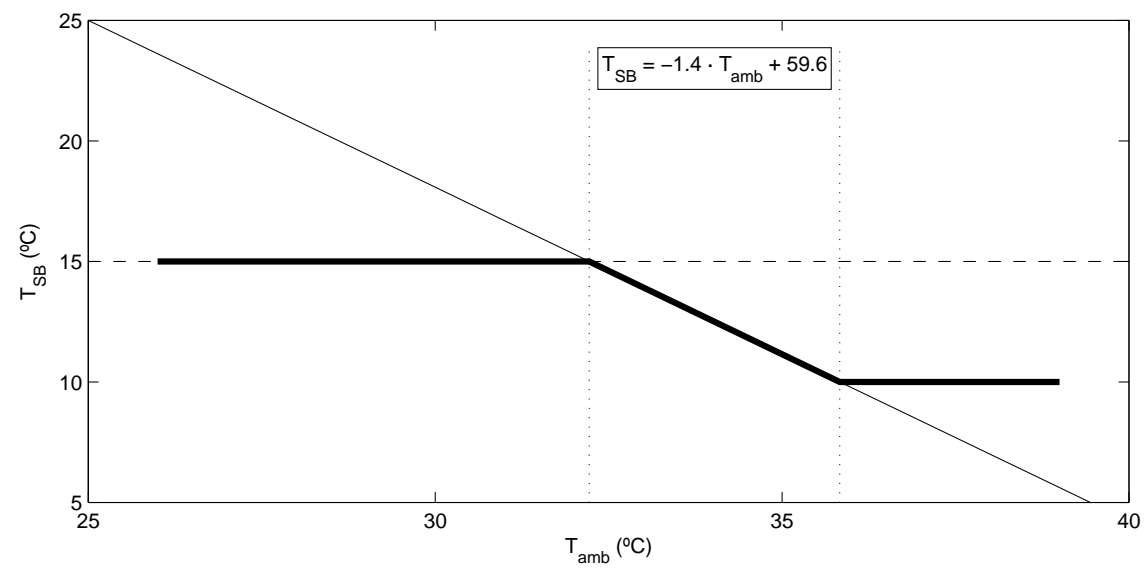

Figure 3.15: Temperature compensation (outdoor temperature reset) curve for cooling mode.

Fig. 3.15 depicts the temperature compensation curve for cooling mode. As it can be observed, the targeted supply temperature $T_{S B}$ is varied between $10^{\circ} \mathrm{C}$ and $15^{\circ} \mathrm{C}$ according to the ambient temperature. For values of the ambient temperature greater than $36^{\circ} \mathrm{C}$, the water is supplied at $10^{\circ} \mathrm{C}$, the minimum operating temperature of the heat pump at this time due to the requirements in GROUND-MED project.

On the other hand, the water should not be supplied at temperatures greater than $15^{\circ} \mathrm{C}$. Otherwise, the dehumidification of the air in the room would not be possible turning into 
user discomfort. That is the reason why, for values of the ambient temperature lower than around $32^{\circ} \mathrm{C}$, the water is supplied at $15^{\circ} \mathrm{C}$ and not at a higher value.

The previous explanation was carried out for cooling mode. The development is analogous for heating mode. The temperatures in the expressions of the thermal load of the room (Eq. 3.28) and the fan coil capacity (Eq. 3.29) would find its signs changed, so that Eq. 3.31 would turn into Eq. 3.36 for heating mode.

$$
T_{S B} \geq T_{\text {room }}+\frac{U A_{0} \cdot\left(T_{\text {room }}-T_{a m b}\right)}{\dot{m}_{a, \text { nom }} \cdot c_{p, a} \cdot \varepsilon_{F C}\left(C_{a, \text { nom }}, C_{w}\right)}
$$

In this case the limit condition is opposite: the temperature setpoint set should greater or equal than the value calculated by Eq. 3.36 .

The design conditions are also different for heating mode. Now the minimum ambient temperature and the maximum building supply temperature must be considered. The values considered for this parameters are $T_{a m b, \min }=5^{\circ} \mathrm{C}$ and $T_{S B, \max }=50^{\circ} \mathrm{C}$ respectively. This change in the design condition causes that Eqs. 3.34 and 3.35 has to be redefined, turning into Eqs. 3.37 and 3.38

$$
\begin{gathered}
T_{S B} \geq(1+\beta) \cdot T_{\text {room }}-\beta \cdot T_{\text {amb }} \\
\beta=\frac{T_{S B, \max }-T_{\text {room }}}{T_{\text {room }}-T_{\text {amb }, \text { min }}}
\end{gathered}
$$

Finally, considering a targeted room comfort temperature of $T_{\text {room }}=21^{\circ} \mathrm{C}$ as provided in [71], the temperature compensation curve for heating mode is presented in Fig. 3.16 . It should be noticed that the supply building temperature is limited to $40^{\circ} \mathrm{C}$ due to the requirements in GROUND-MED project.

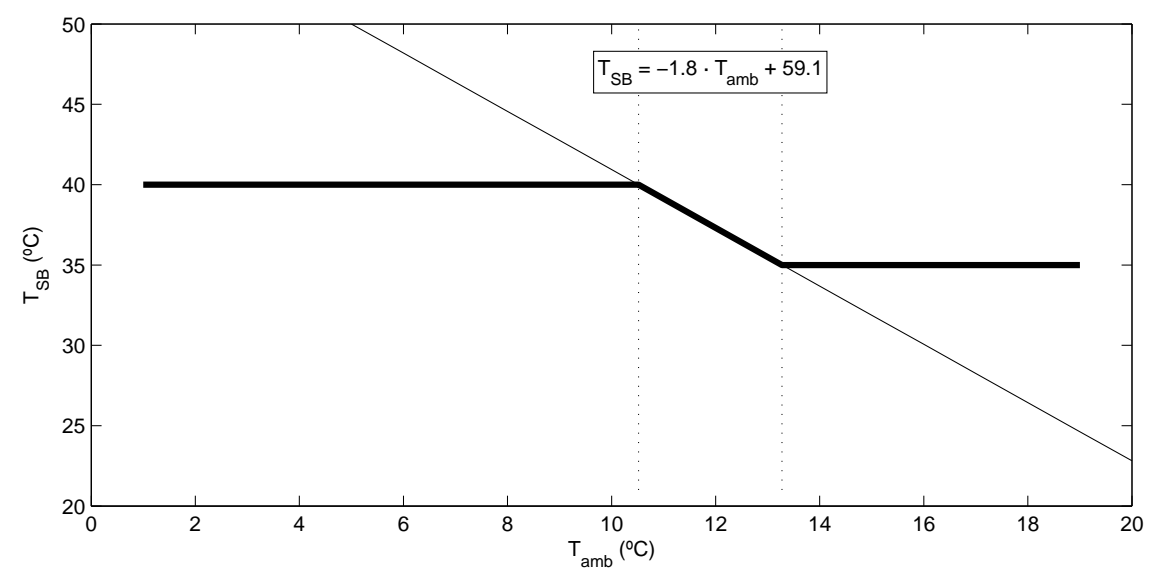

Figure 3.16: Temperature compensation (outdoor temperature reset) curve for heating mode. 


\subsubsection{Results for temperature compensation}

Fig. 3.17 shows the experimental results of the temperature compensation strategy developed both for cooling (Fig. 3.17p) and heating (Fig. 3.17b) mode.

(a)

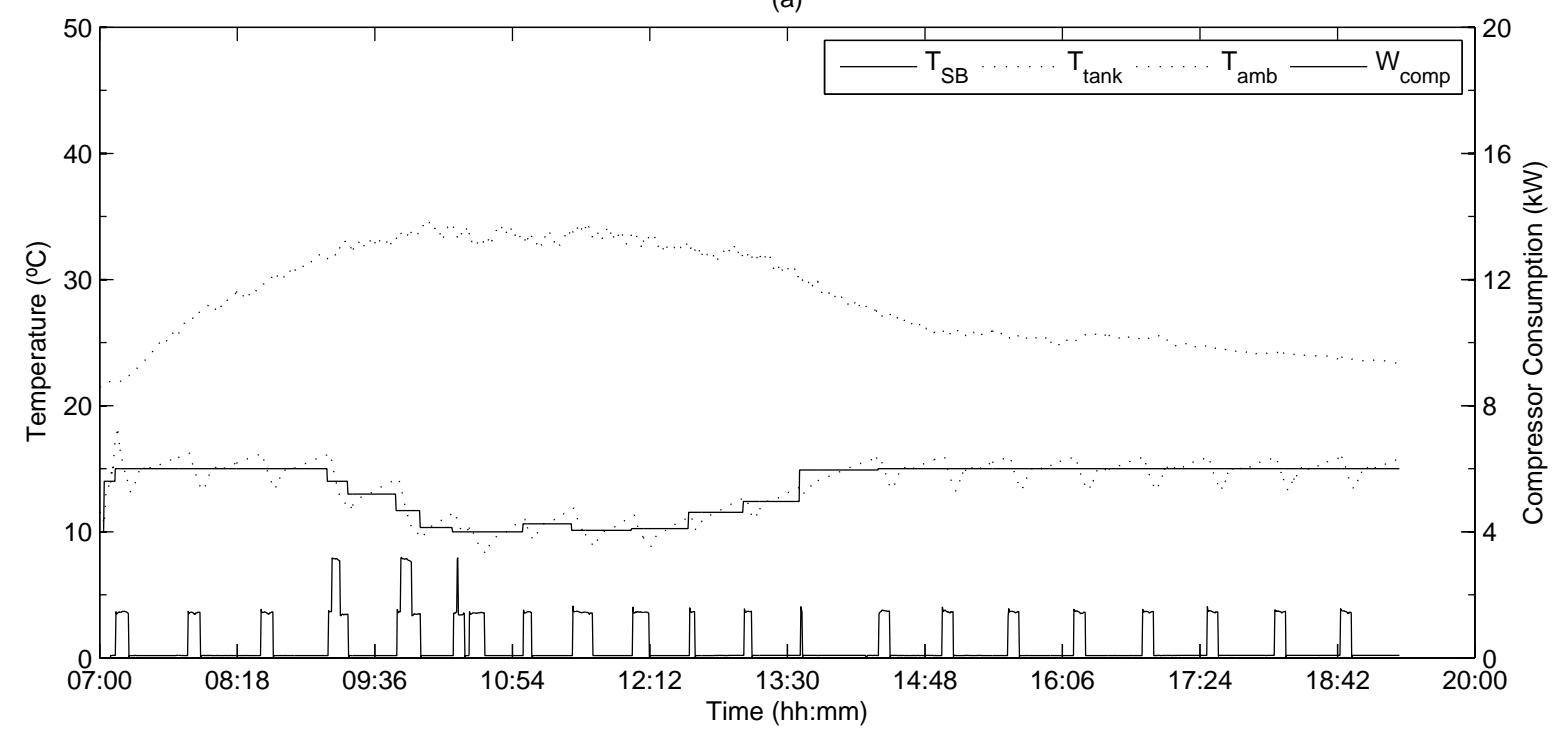

(a)

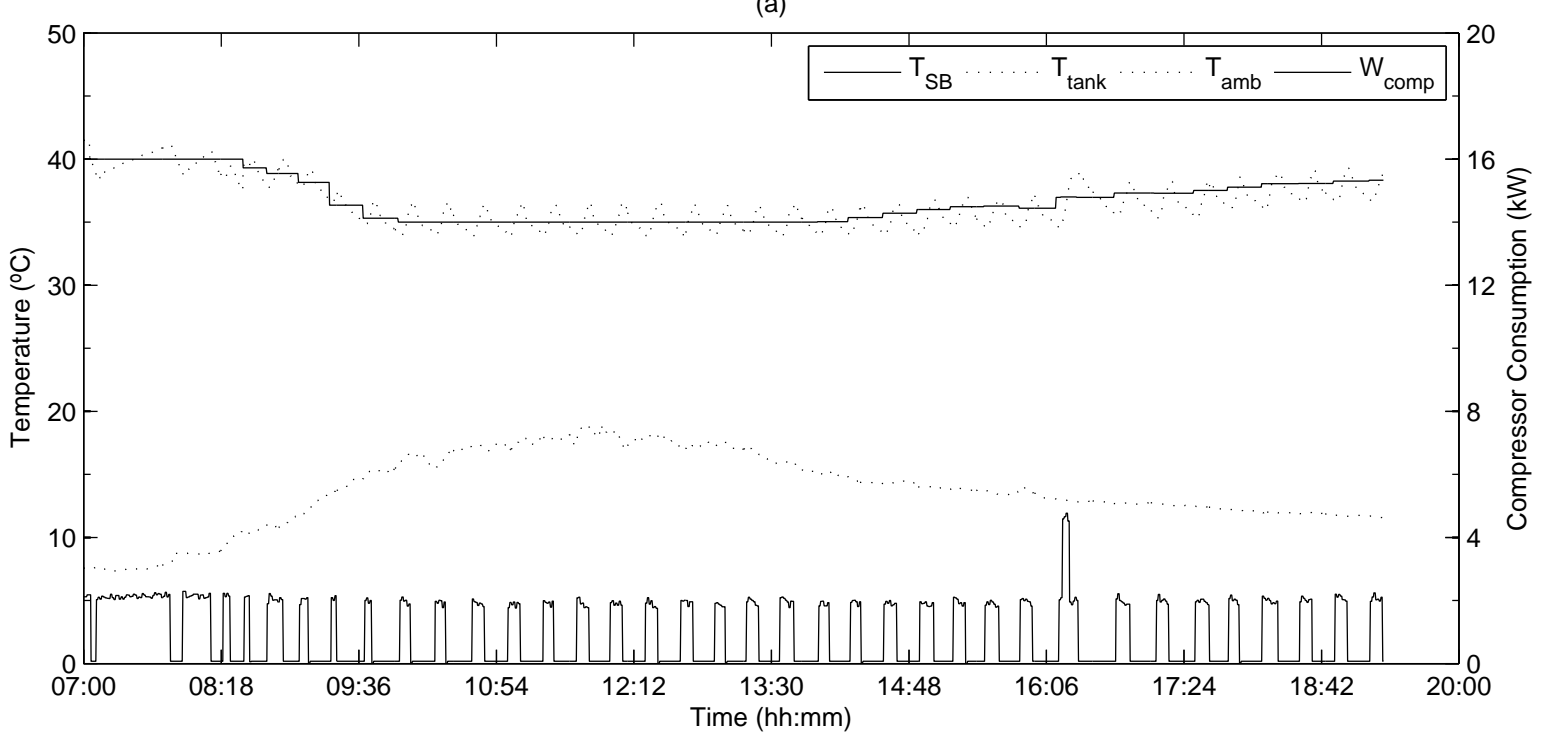

Figure 3.17: Experimental results after applying temperature compensation (outdoor temperature reset): (a) Cooling mode (2014/05/26); (b) Heating mode (2014/01/08). 
The system temperatures represented in Fig. 3.17 are the following:

- The targeted building supply temperature calculated by the temperature compensation strategy $\left(T_{S B}\right)$

- The actual building supply temperature, measured at the outlet of the buffer tank $\left(T_{\text {tank }}\right)$

- The ambient temperature $\left(T_{a m b}\right)$, which is used in the algorithm to determine the temperature setpoint to use.

The power consumption of the heat pump is also depicted in Fig. 3.17 in order to follow its operating cycles.

In the case of cooling mode, it can be observed that the ambient temperature at the beginning of the day is around $26^{\circ} \mathrm{C}$, which saturates the algorithm at a supply temperature of $15^{\circ} \mathrm{C}$ (see Fig. 3.15). This helps the system save energy, as a less demanding temperature setpoint is used. As the sun rises, the ambient temperature starts to increase, and the temperature setpoint of the heat pump is varied accordingly: the higher the ambient temperature, the lower the setpoint. This is done because a hotter ambient requires that the water is supplied to the building at a lower temperature. In the afternoon, as the ambient temperature starts to decrease, the setpoint is increased again, until the limit value of $15^{\circ} \mathrm{C}$, hence saving energy. Along the whole day, it can be observed how the actual supply temperature $\left(T_{\text {tank }}\right)$ follows the targeted supply temperature $\left(T_{S B}\right)$.

In heating mode, the effect of applying the temperature compensation strategy is analogous. The temperature setpoint decreased with the increase of the temperature, in order to improve the energy performance of the system, and increased with the decrease of the ambient temperature in order to meet the user comfort.

The temperature compensation strategy described in this section is combined with another optimization strategy consisting of varying the frequency of the water circulation pumps, and hence the flow rate, as a function of the thermal load of the building.

\subsection{In situ optimization methodology for the water circula- tion pumps frequency}

When optimizing the overall system performance of a GSHP installation, it is important to understand how the increase of the circulating water flow rate affects the performance of the heat pump and that of the entire system. In a given system, the higher the inverter frequency, the greater the circulating water flow rate. A higher water flow rate enhances the heat transfer coefficient through the heat exchanger of the heat pump and diminishes the water temperature variation across it; the same happens at the GSHX.

On the heat pump side, the increase of the water flow rate helps to reduce the temperature difference between the water and the refrigerant and, as a result, the temperature lift that 
the compressor must overcome becomes lower and the heat pump COP increases [61]. This can be observed in Fig. 3.18, which shows experimental results of the effect of varying the water flow rates (proportional to the frequencies, which were set at the same value when measuring the different experimental points) in both the heat pump COP $\left(C O P_{H P}\right)$ and the system $\mathrm{COP}\left(C O P_{\text {sys }}\right)$.

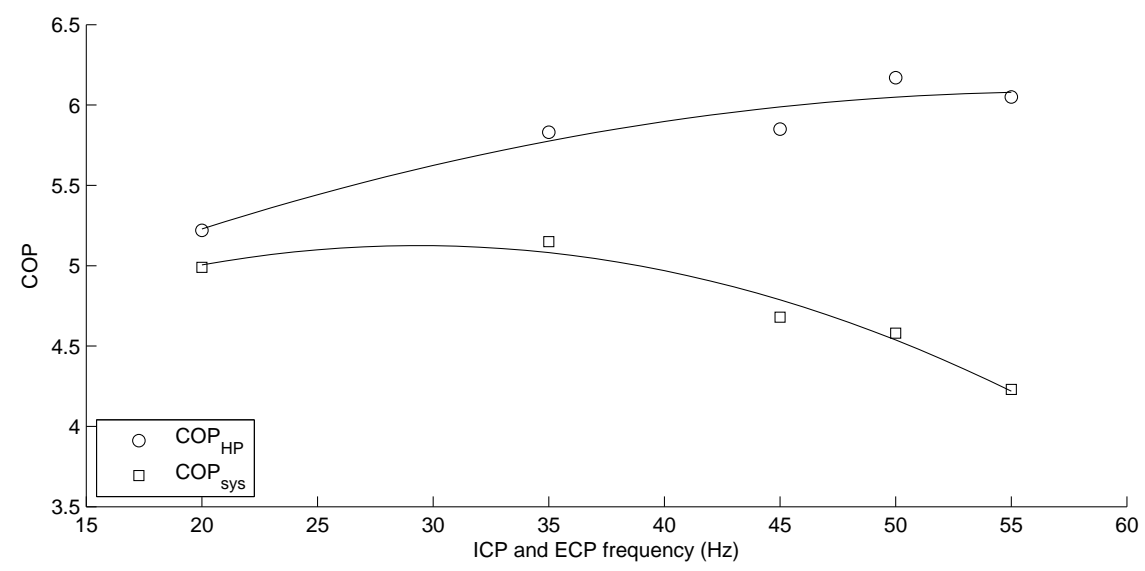

Figure 3.18: Influence of the water circulating flow rate on the heat pump and system COP.

It is clearly noted in Fig. 3.18 that the higher the flow rate at both the external and internal circuit, the better the performance of the heat pump $\left(C O P_{H P}\right)$. Nevertheless, when the whole system is considered, operating at maximum flow rates (maximum frequencies) results in a great reduction of the system COP due to the big influence of the circulation pumps consumption.

In a few words, increasing the water flow rate on both sides of the heat pump (evaporator and condenser) diminishes the compressor consumption but increases the circulation pumps consumption. These two opposite trends on energy consumption result in an optimum frequency for each one of the water loops, as the goal is to optimize the whole system and not only the heat pump.

The directors of this PhD work, J.M. Corberán and C. Montagud, in conjunction with Á. Montero, developed an in situ optimization methodology for the water circulation pumps frequency of ground source heat pump systems which employ single-stage ON/OFF controlled heat pump units [61]. In this section, this methodology is reviewed for single-stage heat pumps and upgraded for GSHP systems with multi-stage heat pump units, particularising for the unit in the geothermal plant studied in this research work: a heat pump with two compressors working in tandem (GROUND-MED heat pump).

The main advantage of this optimization methodology is that it is based on experimental measurements, thus taking into consideration the real characteristics of the heat pump and the installation when facing the determination of the optimal frequencies. There 
is no need to have a mathematical model of the different components of the system (manufacturers do not provide it). What is more, there is a full response of the system working as a whole which is extremely difficult to consider in a mathematical model (actual operation of the real components). Even with a very detailed model, it is not possible to take into account the wide group of parameters which in practice influences the performance of a geothermal installation, as for instance, the users daily activity, the ambient temperature variations along the day, the heat transfer to the ground or the fan coils at different air flow rates varied by the users... The proposed methodology is able to consider real operating conditions since it can be carried out in situ at any specific facility. It consists of three steps which are described in the following both for single-stage and multi-stage heat pump units.

\subsubsection{Single-stage case}

The in situ methodology for the water circulation pumps frequency was developed in [61] when the GEOCOOL heat pump was installed at the geothermal plant. Hence it is applicable to single-stage heat pumps with one compressor using ON/OFF regulation. It consists of the three steps explained in the following.

\section{Step 1: ON time operation characterization}

The first step consists of several experimental tests of pseudo-random sequence of frequency steps for both, internal and external circulation pumps, carried out during one single day. Fig. 3.19 shows an example of a possible test for the variation of the frequencies of the circulation pumps from $20 \mathrm{~Hz}$ to $60 \mathrm{~Hz}$.

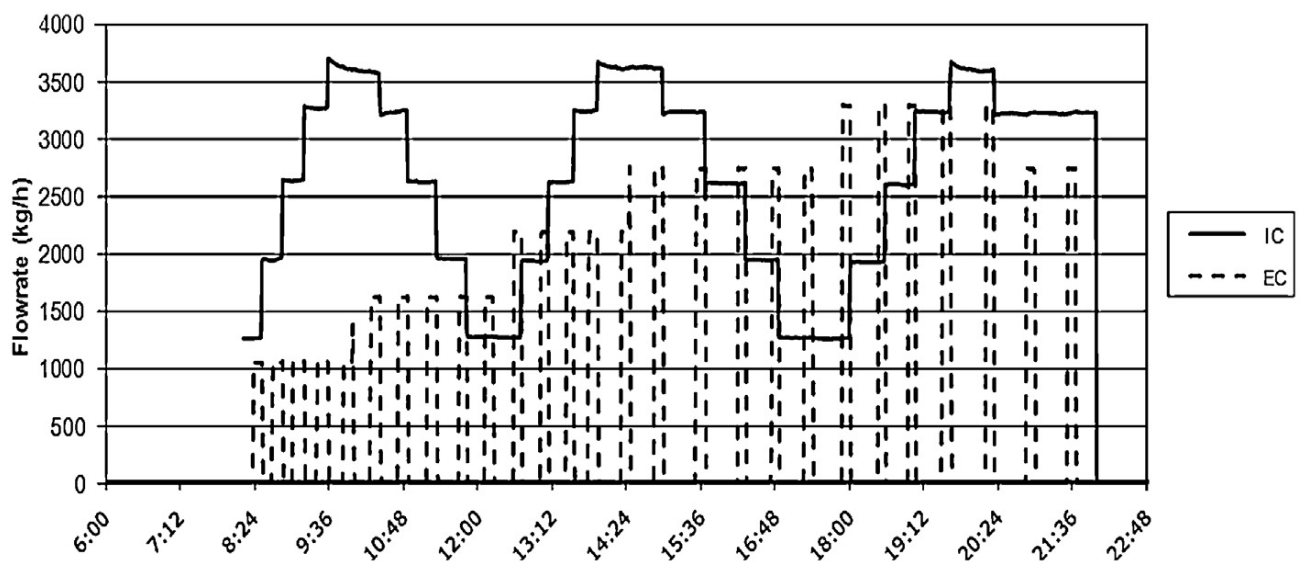

Figure 3.19: Frequency variation strategy in heating mode. Source: 61

The objective of this step is the characterization of the performance of the system during the $\mathrm{ON}$ time of the compressor at any possible combination of frequencies. 
Therefore, each pair of frequencies must be kept constant during a complete ON cycle of the heat pump, which should last 10 minutes or longer in order to obtain sufficient accuracy in the determination of the performance of the system [61].

As recommended in [61], the test should be performed during at least 4 days a year, two during the heating season and two during the cooling season. The reason to propose to repeat the test along one season is to assess the influence of the ground temperature as well as the compensation of the setting for the water return temperature, and confirm whether the optimum remains at the same zone or it requires some readjustment along the season. In the case of this geothermal plant, the optimal zone for the frequencies remains the same for different settings and ground temperatures, as it is just the absolute values of the performance factor that are different.

Once the tests are finished, the coefficients of performance can be evaluated for each ON cycle so that it will allow the construction of the performance maps of the unit as a function of both the external and internal circulation pumps frequency.

\section{Step 2: Estimation of the system COP maps}

The second step consists of the analysis of the results obtained from step 1 and the estimation of the COP of the system $\left(C O P_{\text {sys }}\right)$. In order to evaluate the performance of the system, Eq. 2.13, which provides the COP of the heat pump in quasi-steady state conditions, can be extended to the system $\mathrm{COP}\left(C O P_{\text {sys }}\right.$ or $\mathrm{COP}_{3}$ ). The resulting expression is given by Eq. 3.39 .

$$
C O P_{\text {sys }}=\frac{\int_{0}^{t_{O N}}\left(\dot{Q}_{i c}(t) \pm \dot{Q}_{I C P}(t)\right) \cdot d t}{\int_{0}^{t_{O N}}\left(\dot{W}_{c o m p}(t)+\dot{W}_{\text {par }}(t)+\dot{W}_{E C P}(t)+\dot{W}_{I C P}(t)\right) \cdot d t}
$$

The system COP can be calculated for all the test points (pairs of frequencies) obtained and represented in the form of contour maps as a function of the circulation pumps frequency. Fig. 3.20 shows the $C O P_{\text {sys }}$ maps obtained for one typical cooling (Fig. 3.20 a) and one typical heating (Fig. 3.20 b) day in the geothermal installation.

As it can be observed in Fig. 3.20, the optimum system COP corresponds to rather low pump frequencies. The maximum system COP value corresponds to an internal frequency of around $40 \mathrm{~Hz}$ and an external frequency of around $30 \mathrm{~Hz}$ for heating mode as shown in Fig. $3.20 \mathrm{k}$. In the case of cooling mode operation, the optimal pair of frequencies results approximately in $28 \mathrm{~Hz}$ for the internal circulation pump, and around $40 \mathrm{~Hz}$ for the external circulation pump (see Fig. 3.20 b). It can be observed that the optimal frequency for the internal circulation pump results in a higher value for heating mode operation. This is because the internal circulation 

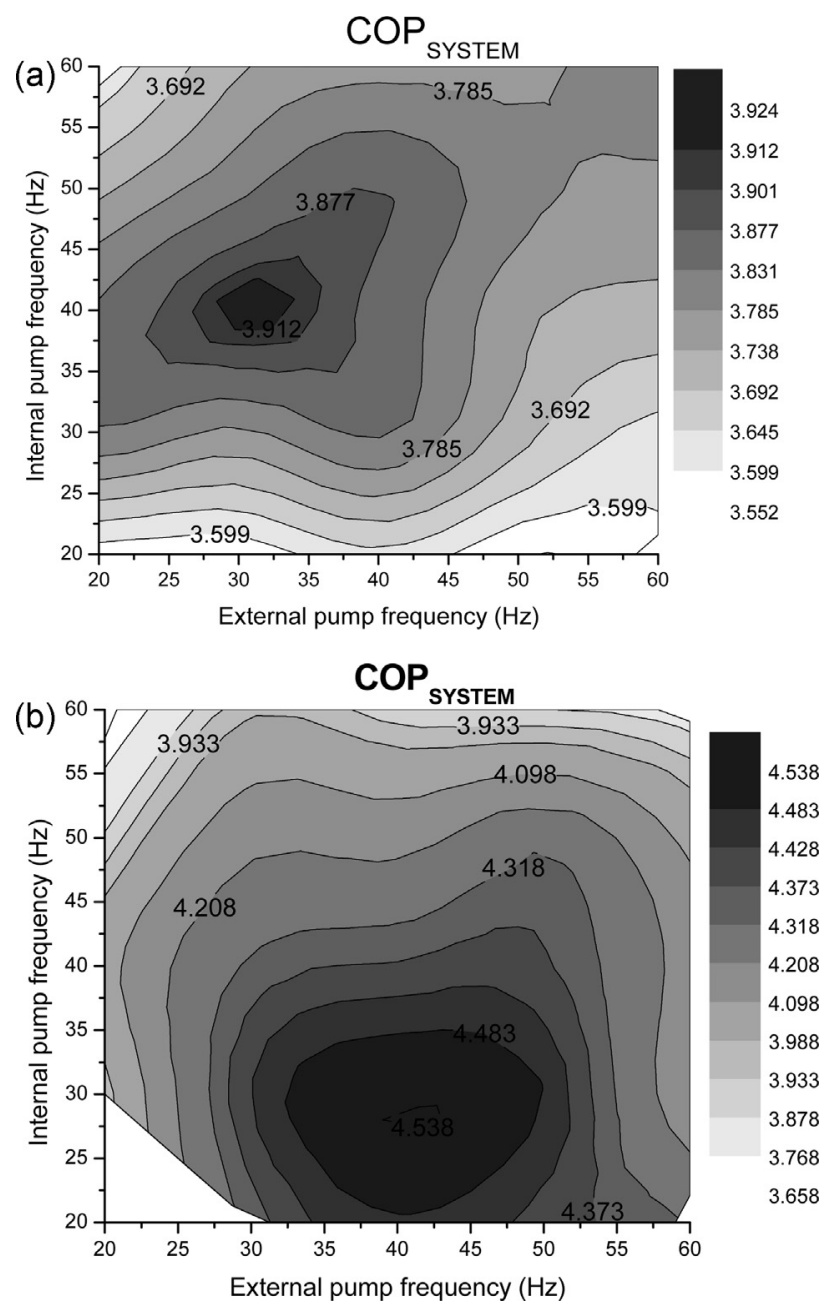

Figure 3.20: $C O P_{\text {sys }}$ quasi-steady state maps as a function of pump frequency: (a) Heating mode; (b) Cooling mode. Source: 61] 
pump consumption contributes to the heating adding a useful heat, and the other way around in cooling mode (according to Eq. 3.39).

The optimal pair of frequencies obtained from Fig. 3.20 corresponds to quasi-steady state working conditions. In practice, steady state would only happen when the building thermal load equals the heat pump capacity, what should never happen since the heat pump is designed in order to be able to satisfy the maximum peak load for heating and cooling mode and the nominal capacity is always greater than the building load.

Step 3: Estimation of the system performance maps for any thermal load

The quasi-steady state performance maps of the unit were obtained during the ON cycle time. However, during the OFF time period the power consumption is not zero, due to the internal pump operation $\left(\dot{W}_{I C P}\right)$ (since it works continuously during the 15 hour of system operation) and to the parasitic losses of the heat $\operatorname{pump}\left(\dot{W}_{\text {par }}\right)$, which can significantly degrade the performance factor of the system. This third step allows taking into account this influence and calculating, from the quasi-steady state performance maps obtained in step 2 of the methodology, the optimal frequencies as a function of the thermal load of the building, represented by the partial load ratio $(\alpha)$.

Considering a whole cycle as the integration period for Eq. $2.17\left(t_{T O T A L}=t_{O N}+\right.$ $\left.t_{O F F}\right)$, and considering the definition of the heat delivered by the internal pump given by Eq. 2.18 (where $\eta_{t h}=1$ ), Eq. 3.40 is obtained.

$$
P F_{\text {sys }}=\frac{\int_{0}^{t_{O N}+t_{O F F}}\left(\dot{Q}_{i c}(t) \pm \eta_{e l} \cdot \dot{W}_{I C P}(t)\right) \cdot d t}{\int_{0}^{t_{O N}+t_{O F F}}\left(\dot{W}_{\text {comp }}+\dot{W}_{\text {par }}(t)+\dot{W}_{E C P}(t)+\dot{W}_{I C P}(t)\right) \cdot d t}
$$

Integrating Eq. 3.40 and considering the corresponding consumptions during each time period, Eq. 3.41 is obtained.

$$
P F_{s y s}=\frac{\dot{Q}_{i c} \cdot t_{O N} \pm \eta_{e l} \cdot \dot{W}_{I C P} \cdot\left(t_{O N}+t_{O F F}\right)}{\sum \dot{W} \cdot t_{O N}+\left(\dot{W}_{p a r}+\dot{W}_{I C P}\right) \cdot t_{O F F}+\dot{W}_{E C P} \cdot t_{e x t r a}}
$$

Where: $\sum \dot{W}=\dot{W}_{c o m p}+\dot{W}_{\text {par }}+\dot{W}_{E C P}+\dot{W}_{I C P}$.

The time period called $t_{\text {extra }}$ corresponds to an extra time during which the external circulation pump is switched on but the compressor is not. This time does not exist in the current configuration of the geothermal system, which corresponds to the GROUND-MED project heat pump. More details can be found in [61].

Finally, taking into account the definition of the partial load ratio provided by Eq. 
2.31 and other considerations explained in detail in [61], Eq 3.42 is obtained.

$$
P F_{\text {sys }}=\frac{C O P_{\text {sys }} \pm \frac{1-\alpha}{\alpha} \cdot \frac{\eta_{e l} \cdot \dot{W}_{I C P}}{\sum \dot{W}}}{1+\left(C O P_{\text {sys }} \mp \frac{\eta_{e l} \cdot \dot{W}_{I C P}}{\sum \dot{W}}\right) \cdot \frac{\dot{W}_{E C P} \cdot(1-\alpha)}{V \cdot \rho \cdot c_{p} \cdot \Delta T_{d b}} \cdot t_{\text {extra }}+\frac{1-\alpha}{\alpha} \cdot \frac{\dot{W}_{p a r}+\dot{W}_{I C P}}{\sum \dot{W}}}
$$

The experimental information needed in Eq. 3.42 comes from the first step (experimental measurements varying both the internal and external circulation pumps) and the second step where the performance maps of the system at quasi-steady state conditions are built. Eq. 3.42 allows extrapolating the performance maps characterization at quasi-steady state conditions obtained in the step 2 to any partial load ratio. It should be noticed that for $\alpha=1$ the value of the performance factor coincides with the value of the $\mathrm{COP}\left(P F_{\text {sys }}=C O P_{\text {sys }}\right)$. The resulting performance maps are shown in Figs. 3.22 and 3.21 for cooling and heating mode respectively.
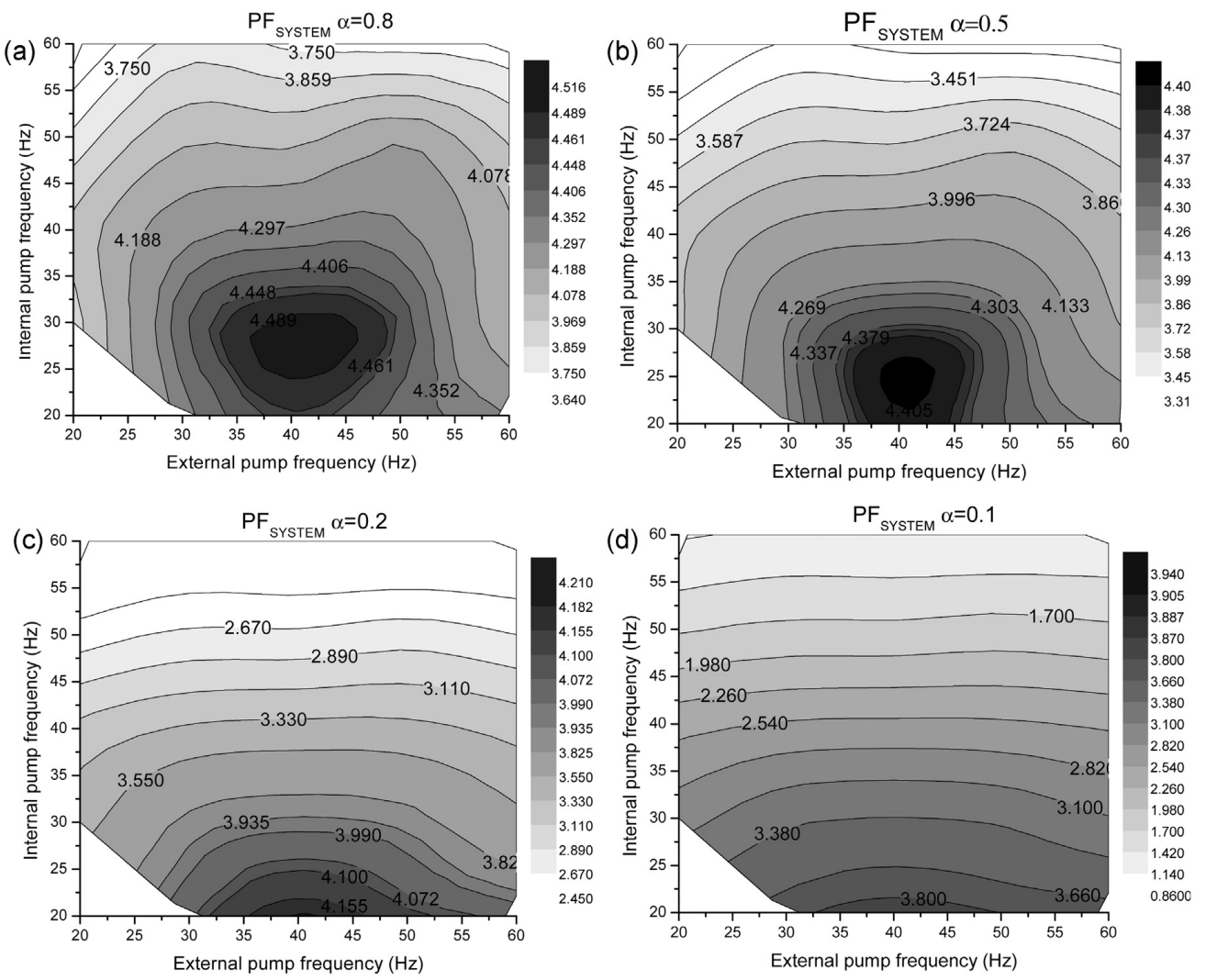

Figure 3.21: $P F_{\text {sys }}$ maps as a function of pumps frequency for cooling mode (single-stage case): (a) $\alpha=0.8$; (b) $\alpha=0.5$; (c) $\alpha=0.2$; (d) $\alpha=0.1$. Source: 61 

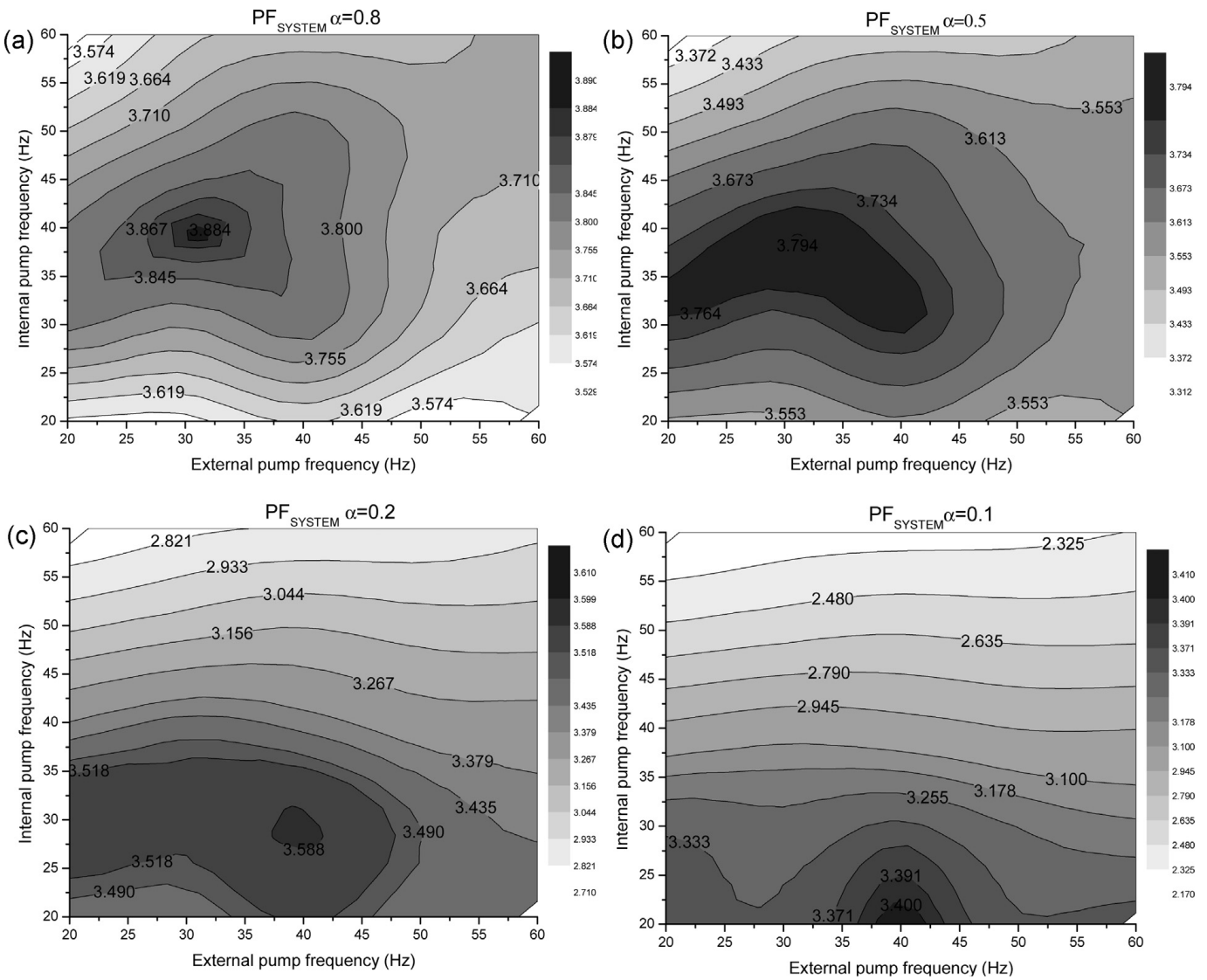

Figure 3.22: $P F_{\text {sys }}$ maps as a function of pumps frequency for heating mode (single-stage case): (a) $\alpha=0.8$; (b) $\alpha=0.5$; (c) $\alpha=0.2$; (d) $\alpha=0.1$. Source: 61 
It can be observed from Figs. 3.22 and 3.21 that low partial loads degrade the performance of the system leading to lower optimal frequencies, because the auxiliaries consumption (external and internal circulation pumps, and parasitic losses) have a great influence in the system performance factor, as it was predicted by Eq. 3.42. On the contrary, the higher the partial load ratio, the more similar the optimal frequencies are to the ones corresponding to quasi-steady state conditions represented in Fig. 3.20, because the influence of the auxiliaries consumption turn out to be practically negligible.

From the performance maps obtained in step 3, the optimal values of both circulation pumps' frequencies can be determined, for both operation modes, cooling and heating. These values are presented in table 1 in [61], which is presented in Fig. 3.23. It shows that, in general, higher partial load ratios result in higher frequencies, and thus higher flow rates. As mentioned by Montagud et al. in [61], analytical expressions could be developed from the results shown for the optimal frequencies as a function of the partial load ratio and could be programmed in the control board of the system, so that optimization control algorithms could be used to make the system run at the optimal frequency depending on the building thermal energy demand, which for sure would lead to significant energy savings along the year.

Table 1

Optimal frequencies for heating and cooling mode operation at different partial load factors.

\begin{tabular}{|c|c|c|c|c|c|c|}
\hline & & $\alpha=1$ & $\alpha=0.8$ & $\alpha=0.5$ & $\alpha=0.2$ & $\alpha=0.1$ \\
\hline \multirow[t]{2}{*}{ ICP frequency $(\mathrm{Hz})$} & Heating mode & 40 & 40 & 37.5 & 27 & 22 \\
\hline & Cooling mode & 30 & 30 & 25 & 22 & 20 \\
\hline \multirow[t]{2}{*}{ ECP frequency $(\mathrm{Hz})$} & Heating mode & 30 & 30 & 32.5 & 40 & 40 \\
\hline & Cooling mode & 40 & 40 & 40 & 40 & 40 \\
\hline
\end{tabular}

Figure 3.23: Optimal frequencies for heating and cooling mode operation at different partial load ratios. Source: 61]

\subsubsection{Multi-stage case}

The installation of the GROUND-MED heat pump during GROUND-MED project, which was a multi-stage heat pump unit with two compressors working in tandem, promoted the review of the in situ methodology developed for single-stage units in order to adapt it to multi-stage units. First, the new methodology developed for the particular case of the GROUND-MED heat pump, with two compressors working in tandem, is described. Then, a proposal in order to apply this in situ optimization methodology to any installation provided with a multi-stage heat pump consisting of whatever number of compressors $N$ is presented. This revision was presented and published in [72].

As its predecessor, the upgraded methodology consists of the same three steps, with the particularities described in the following. The three steps are summarised in the flow 
diagram presented in Fig. 3.24 for the particular case of the tandem compressors heat pump.

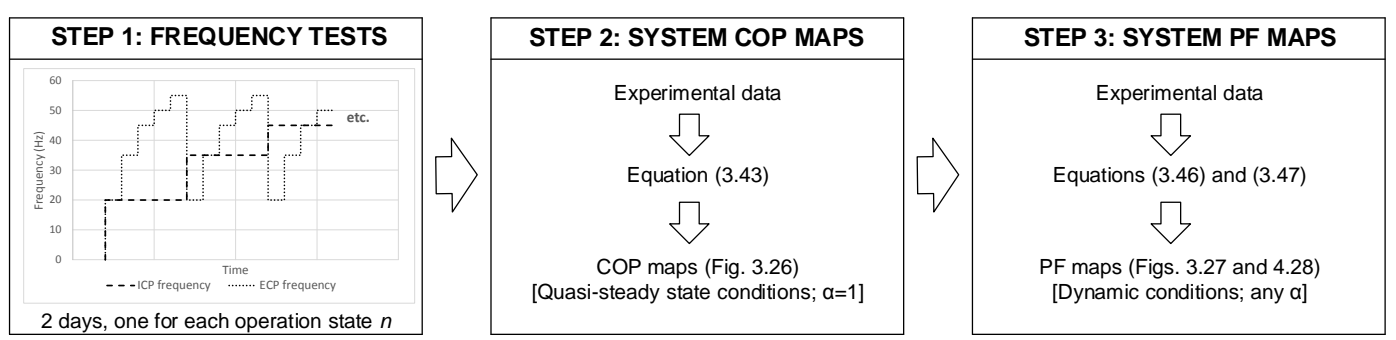

Figure 3.24: Flowchart for the in situ optimization methodology.

\section{Methodology for a multistage heat pump unit with two compressors working in tandem (experimental case)}

\section{Step 1: ON time operation characterization}

In the case of the multi-stage heat pump, given that the unit consists of two compressors in tandem, the performance will be different whether there is one or there are two compressors running, i.e. only one compressor cycling ON/OFF (state $n=1$ ) or one compressor continuously running and the other one cycling ON/OFF (state $n=2$ ). Therefore, step 1 tests must be carried out for both operation states ( $n=1$ and $n=2)$, so two different days will be required in this case to carry out the experimental tests. For this configuration of the GSHP system, it has been experimentally confirmed that the optimum frequencies are located at higher values when both compressors are running (around $45-50 \mathrm{~Hz}$ ), and hence there is no need for testing frequencies lower than $35 \mathrm{~Hz}$. In the same way, when there is one compressor running the optimum frequencies are around $35-40 \mathrm{~Hz}$ and there is no need for testing frequencies higher than $50 \mathrm{~Hz}$. This is represented in Fig. 3.25. which shows that for $n=1$ the experimental points corresponding to $55 \mathrm{~Hz}$ do not need to be considered (triangles and crosses). Likewise, for $n=2$ the points corresponding to $20 \mathrm{~Hz}$ can be disregarded (squares and crosses). This would allow decreasing the number of experimental points needed from 25 to 16 and hence reducing the required time to carry out the in situ experimental tests.

It should be noticed that, differently to the single-stage case, the experimental tests of pseudo-random sequence of frequency steps are performed for a range of frequencies from $20 \mathrm{~Hz}$ to $55 \mathrm{~Hz}$. The reason of doing this is that it was found that the circulation pumps were working in limit conditions for $60 \mathrm{~Hz}$. In order to avoid shortening their service life, $55 \mathrm{~Hz}$ was considered as the upper limit of frequency 


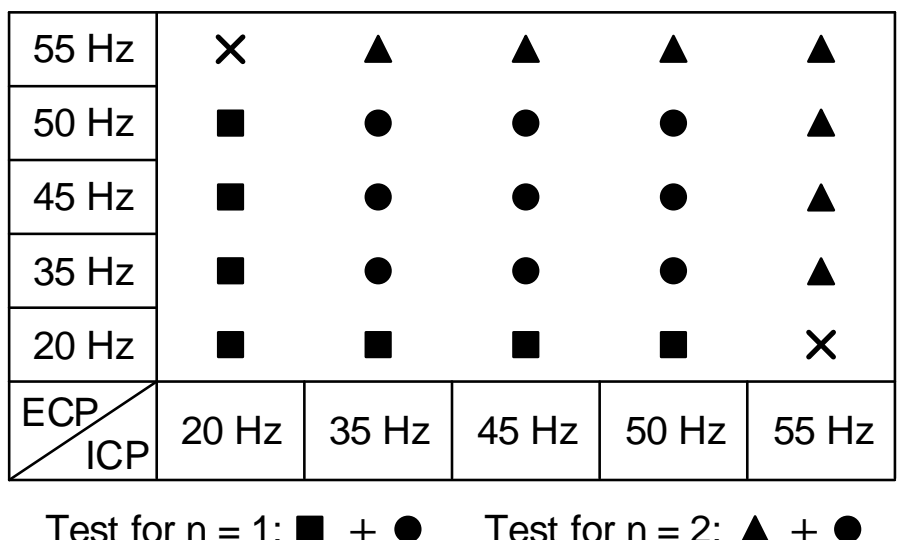

Figure 3.25: Example of a possible test for the variation of the circulation pumps frequency for a two tandem compressors heat pump unit.

for tests. Moreover, this fact was far to affect the optimal values of frequency, which rarely reach the value of $50 \mathrm{~Hz}$.

Once the tests are finished, the coefficients of performance can be evaluated for each ON cycle so that it will allow the construction of the performance maps of the unit as a function of both the external and internal circulation pumps frequency.

Step 2: Estimation of the system COP maps

The second step consists of the analysis of the results obtained from step 1, the estimation of the system COP by means of Eq. 3.43 and finally their representation in form of maps as a function of the circulation pumps frequency.

$$
C O P_{s y s(n)}=\frac{\int_{0}^{t_{O N}}\left(\dot{Q}_{i c(n)}(t) \pm \dot{Q}_{I C P}(t)\right) \cdot d t}{\int_{0}^{t_{O N}}\left(\dot{W}_{\text {comp }(n)}(t)+\dot{W}_{p a r}(t)+\dot{W}_{E C P}(t)+\dot{W}_{I C P}(t)\right) \cdot d t}
$$

It is important to notice that, in the case of multi-stage units, both the heat transferred from the heat pump to the internal circuit $\left(\dot{Q}_{i c}\right)$ and the power consumption of the compressor $\left(\dot{W}_{\text {comp }}\right)$ will depend on the number of compressors running and thus on the state, whether it is $n=1$ or $n=2$ for the particular case of the installation analysed (in this section, $n$ stands for the number of compressors running as well). They can be renamed as $\dot{Q}_{i c(n)}$ and $\dot{W}_{c o m p(n)}$ respectively.

Fig. 3.26 shows the resulting system COP maps for one typical heating (Fig. 3.26a (one compressor) and Fig. 3.26 (two compressors)) and one typical cooling day 
(Fig. 3.26 (one compressor) and Fig. 3.26 d (two compressors)). The optimal pair of frequencies shown in Fig. 3.26 for each case corresponds to quasi-steady state working conditions.

(a)

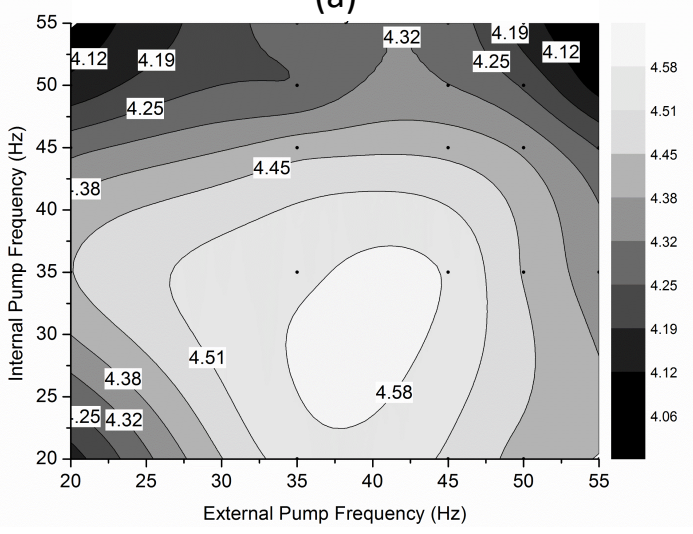

(c)

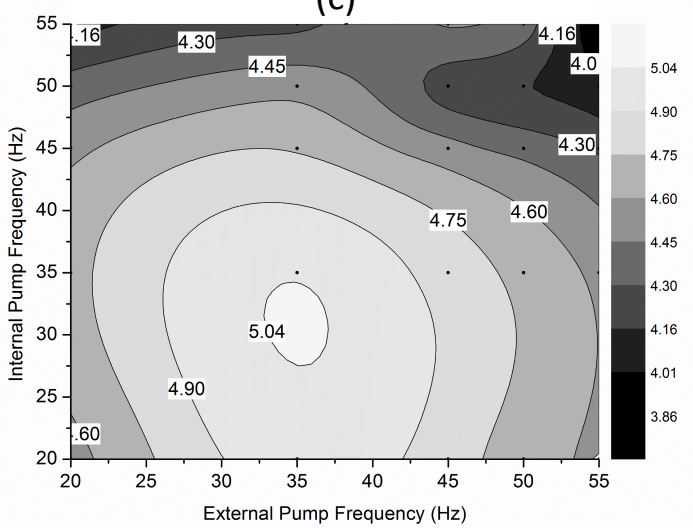

(b)

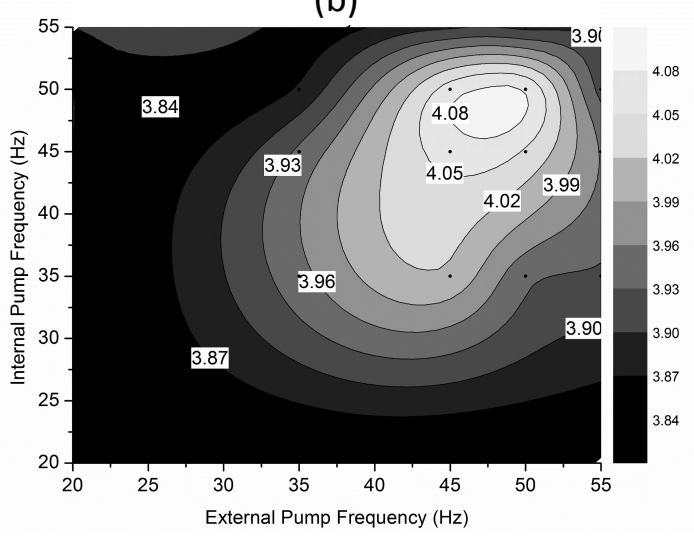

(d)

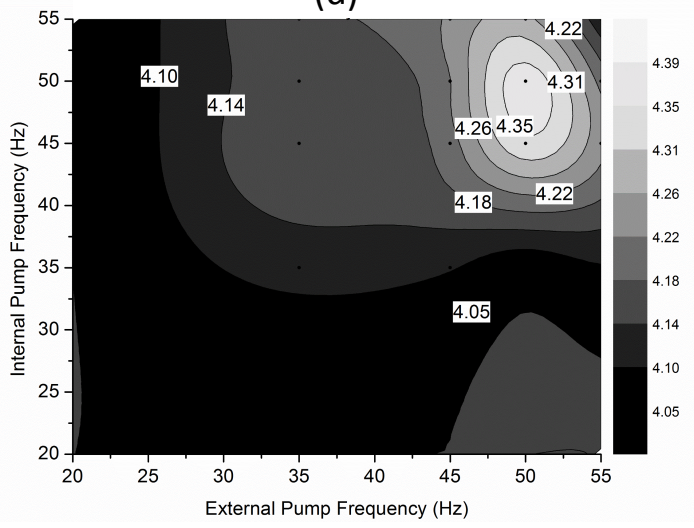

Figure 3.26: $C O P_{\text {sys }}$ quasi-steady state maps as a function of pumps frequency (tandem case): (a) Heating 1 compressor; (b) Heating 2 compressors; (c) Cooling 1 compressor; (d) Cooling 2 compressors.

Figs. 3.26a and 3.26 show the system COP maps for the heat pump operating with one compressor. It is clearly observed in Fig. 3.26 that the influence of the internal pump is higher than that of the external pump, since the latter presents a higher value of the optimal frequency, what means that the internal circulation pump consumption represents a greater penalty in the energy performance of the system. This is because, for a similar flow rate, the head losses are higher in the internal circuit due to the distribution network of 12 fan coils distributed in each of the air conditioning spaces, what results in a greater pumping power for the internal circulation pump. In general, the optimums in Figs. 3.26 and 3.26 c 
correspond to low frequencies (between $30 \mathrm{~Hz}$ and $35 \mathrm{~Hz}$ ) because the influence of the consumption of the circulation pumps is important in comparison to the total consumption, as there is only one compressor working.

In contrast, when the heat pump works with two compressors in tandem, the system COP maps become different (Figs. $3.26 \mathrm{~b}$ and $3.26 \mathrm{~d}$ ). In this case, it is observed that the influence of the circulation pumps is smaller, since the heat pump consumption is higher when both compressors are running, and the optimum frequencies move to higher values (around 45-50 Hz). The dark zone that appears on the lower left corner of Figs. $3.26 \mathrm{~b}$ and $3.26 \mathrm{~d}$ (frequencies of $20-30 \mathrm{~Hz}$ ) corresponds to the points that were removed from the test matrix. Notice that, anyhow, the optimum is clearly located on the right upper corner.

It can also be observed that the COP is higher in cooling mode (Figs. 3.26. and $3.26 \mathrm{~d}$ ) than in heating mode (Figs. $3.26 \mathrm{a}$ and $3.26 \mathrm{p}$ ). This is mainly because the temperature lift that has to overcome the compressor is higher in heating mode ( source (ground loop) temperature $=17^{\circ} \mathrm{C}$, sink temperature $=40^{\circ} \mathrm{C}$ ) than in cooling mode (source (ground loop) temperature $=25^{\circ} \mathrm{C}$ approximately, sink temperature $=10^{\circ} \mathrm{C}$ ). These source temperatures correspond to experimental measurements, being the undisturbed ground temperature $18.5^{\circ} \mathrm{C}$. Further details can be found in [61] and [55].

Several tests were carried out at the installation along the year during each working mode and, even though the system COP maps were not exactly the same, results confirmed similar trends and very similar locations for the optimums with an uncertainty of $\pm 5 \mathrm{~Hz}$.

Step 3: Estimation of the system performance maps for any thermal load

Step 2 considered only the ON time of the cycle. Step 3 considers also the OFF time in order to extrapolate the performance maps obtained in step 2 to any thermal load. In the case of the tandem heat pump, as described in step 1, the heat transferred from the heat pump to the internal circuit and the power consumption of the compressor depend on the number of compressors running. Considering this, Eq. 3.40 can be updated and Eq. 3.44 is obtained.

$$
P F_{\text {sys }(n)}=\frac{\int_{0}^{t_{O N}+t_{O F F}}\left(\dot{Q}_{i c(n)}(t) \pm \eta_{e l} \cdot \dot{W}_{I C P}(t)\right) \cdot d t}{\int_{0}^{t_{O N}+t_{O F F}}\left(\dot{W}_{c o m p(n)}+\dot{W}_{p a r}(t)+\dot{W}_{E C P}(t)+\dot{W}_{I C P}(t)\right) \cdot d t}
$$

Integrating, Eq. 3.44 results in Eq. 3.45, which is valid for whatever number of compressors running of a total of $N$ stages.

$$
P F_{s y s(n)}=\frac{\dot{Q}_{i c(n-1)} \cdot t_{O F F}+\dot{Q}_{i c(n)} \cdot t_{O N} \pm \eta_{e l} \cdot \dot{W}_{I C P} \cdot\left(t_{O N}+t_{O F F}\right)}{\dot{W}_{c o m p(n-1)} \cdot t_{O F F}+\dot{W}_{c o m p(n)} \cdot t_{O N}+\left(\dot{W}_{p a r}+\dot{W}_{E C P}+\dot{W}_{I C P}\right) \cdot\left(t_{O N}+t_{O F F}\right)}
$$

It should be noticed that in state $n=1$, during the OFF time there is neither heat transferred from the heat pump to the internal circuit $\left(\dot{Q}_{i c(0)}=0\right)$ nor power 
consumption of the compressors $\left(\dot{W}_{\text {comp }(0)}=0\right)$, since none of the compressors is running (see Fig. 2.21). It should also be noticed that in state $n=2$ the external circulation pump remains running, so there is also power consumption from this component in state $n=2$.

Finally, taking into account the definition of the partial load ratio of each stage $\left(\alpha_{1}\right)$ provided by Eq. 2.32 and solving Eq. 3.45 separately for $n=1$ and for $n=2$, Eqs. 3.46 and 3.47 are obtained. It can be checked that, when the partial load ratio of each stage tends to $1\left(\alpha_{1}=1\right)$, the system performance factors tend to take the same values as in quasi-steady state conditions $\left(P F_{\text {sys }}=C O P_{\text {sys }}\right)$.

$$
\begin{gathered}
P F_{\text {sys }(n=1)}=\frac{C O P_{\text {sys }(1)} \pm \frac{1-\alpha_{1}}{\alpha_{1}} \cdot \frac{\eta_{e l} \cdot \dot{W}_{I C P}}{\sum \dot{W}_{(1)}}}{1+\frac{1-\alpha_{1}}{\alpha_{1}} \cdot \frac{\dot{W}_{\text {par }}+\dot{W}_{I C P}}{\sum \dot{W}_{(1)}}} \\
P F_{\text {sys }(n>1)}=\frac{C O P_{\text {sys }(n-1)} \cdot \frac{1-\alpha_{1}}{\alpha_{1}} \cdot \frac{\sum \dot{W}_{(n-1)}}{\sum \dot{W}_{(n)}}+C O P_{s y s(n)}}{\frac{1-\alpha_{1}}{\alpha_{1}} \cdot \frac{\sum \dot{W}_{(n-1)}}{\sum \dot{W}_{(n)}}+1}
\end{gathered}
$$

Where:

$$
\begin{aligned}
& \sum \dot{W}_{(n)}=\dot{W}_{c o m p(n)}+\dot{W}_{\text {par }}+\dot{W}_{E C P}+\dot{W}_{I C P}, \\
& \dot{W}_{(n-1)}, \dot{W}_{(n)}, \dot{W}_{\text {par }}, \dot{W}_{E C P} \text { and } \dot{W}_{I C P} \text { correspond to power measurements } \\
& \text { obtained in step } 1 \text { of the methodology, }
\end{aligned}
$$

and $C O P_{\text {sys }(n-1)}$ and $C O P_{\text {sys }(n)}$ correspond to the quasi-steady system COP obtained in step 2 of the methodology.

Eqs. 3.46 and 3.47 provide the system performance factor as a function of the partial load ratio of each stage $\left(\alpha_{1}\right)$. However, since the aim of the step 3 of the methodology is to obtain $P F_{\text {sys }}$ as a function of the partial load ratio of the system $(\alpha)$, it is necessary to relate these two parameters. For that purpose, the relation between $\alpha$ and $\alpha_{1}$ given by Eq. 2.34 is considered. Figs. 3.27 and 3.28 show, for cooling and heating mode respectively, the system performance factor maps as a function of the water circulation pumps frequency for four different values of the partial load ratio of the system.

Figs. 3.27 and 3.28 show, for cooling and heating mode respectively, the system performance factor maps as a function of the water circulation pumps frequency for four different values of the partial load ratio of the system $(\alpha=0.1,0.3,0.5,0.8)$. Notice that the second compressor only switches on for partial load ratios greater than 0.5 , as previously shown in Fig. 2.21. This means that, while the $P F_{\text {sys }}$ maps for values of the partial load ratio up to 0.5 correspond to the heat pump working with one stage, the $P F_{\text {sys }}$ maps for values of $\alpha$ greater than 0.5 correspond to two compressors working in tandem (Figs. $3.27 \mathrm{~d}$ and $3.28 \mathrm{~d}$ ). 
(a)

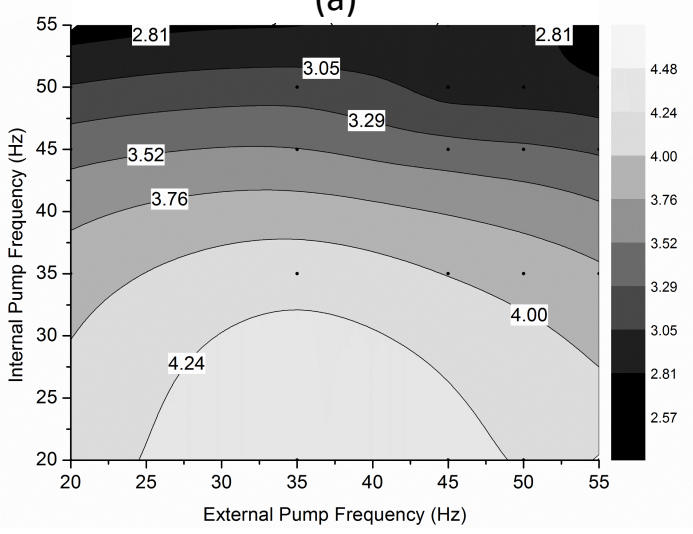

(c)

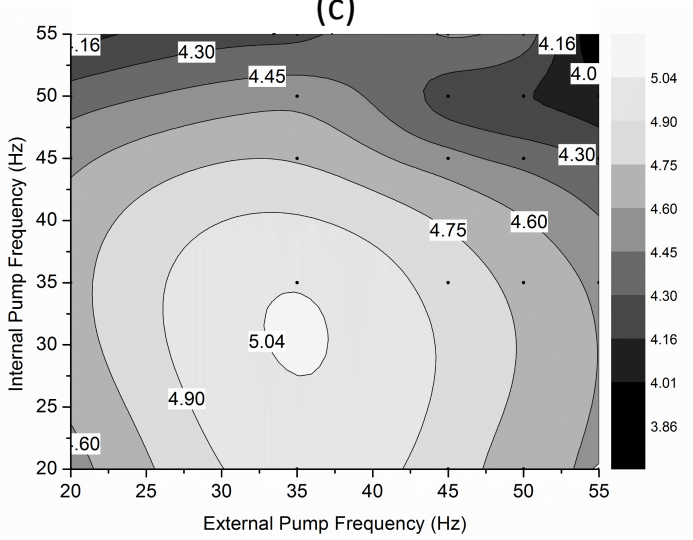

(b)

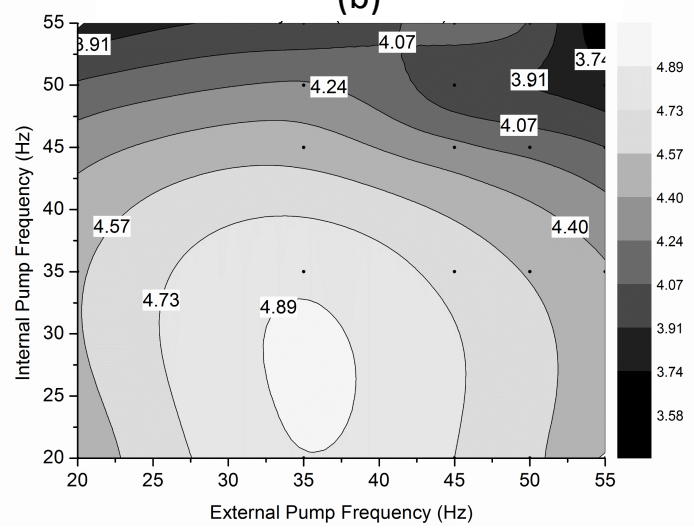

(d)

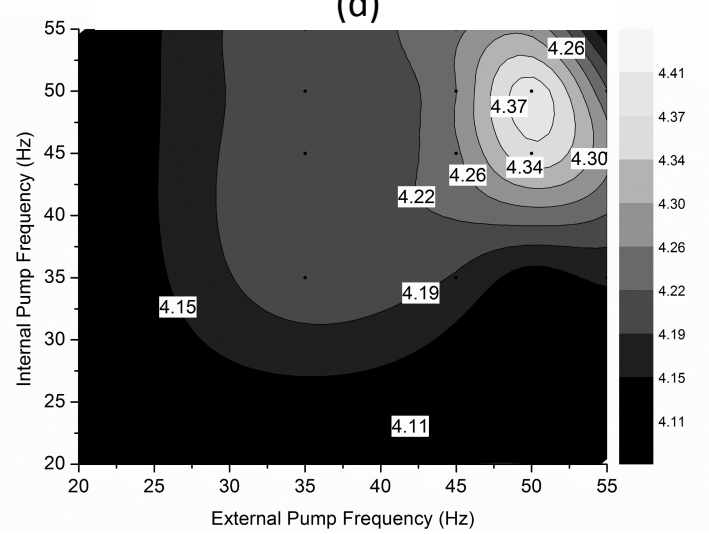

Figure 3.27: $P F_{\text {sys }}$ maps as a function of pumps frequency for cooling mode (tandem case): (a) $\alpha=0.1$; (b) $\alpha=0.3$; (c) $\alpha=0.5$; (d) $\alpha=0.8$. 
(a)

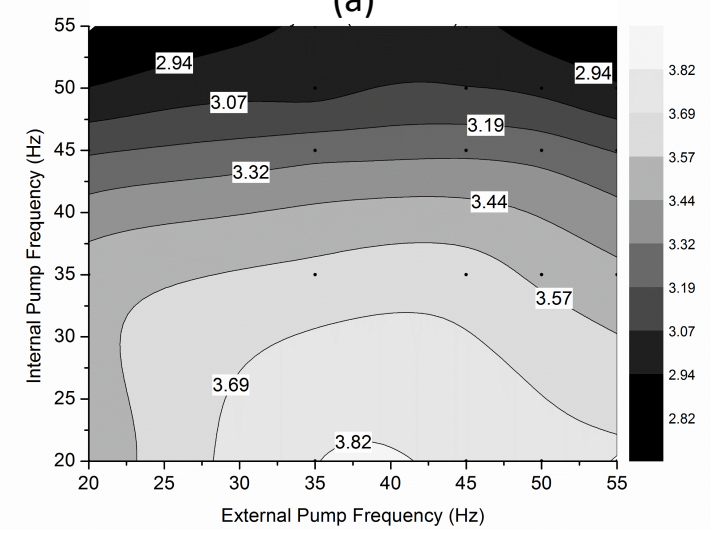

(c)

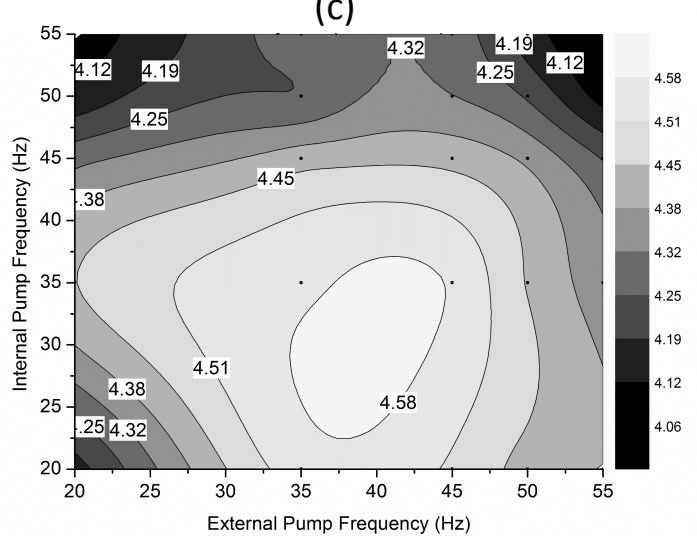

(b)

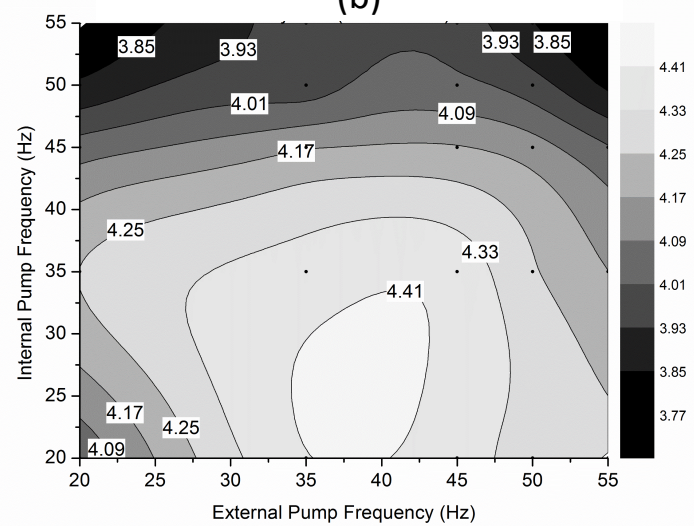

(d)

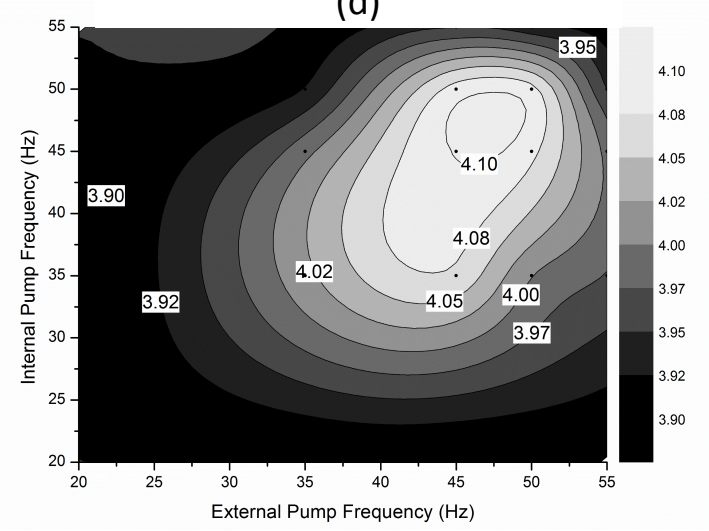

Figure 3.28: $P F_{\text {sys }}$ maps as a function of pumps frequency for heating mode (tandem case): (a) $\alpha=0.1$; (b) $\alpha=0.3$; (c) $\alpha=0.5$; (d) $\alpha=0.8$. 
Taking the example of cooling mode (Fig. 3.27), it can be observed that the performance of the system degrades for low partial load ratios (Fig. 3.27 ). This is due to the auxiliary equipment consumption(external and internal pumps consumption and parasitic losses), which have a great influence in the system performance factor. Moreover, it can be observed that the influence of the internal pump is higher than that of the external pump given the higher value of the optimal frequency for the latter. In this case, when the performance factor (instead of the COP) is considered (what means that the OFF cycle time is also considered for the calculation of the performance factor), this effect is not only due to larger head losses in the internal circuit, but also (and mainly) because of a larger time of operation for the internal pump, which is continuously running during the 13 hours per day of system operation. The study for the multi-stage heat pump was completed after the timetable of system operation was modified (from 15 hours to 13 hours of daily system operation) at the beginning of year 2013 (see Section 2.2.5).

As the partial load ratio increases, the system performance factor improves until it reaches a maximum value of 5.04 for $\alpha=0.5$ (Fig. 3.27k). The optimal frequencies are low because, as there is only one compressor running, the influence of the pumps power consumption is much greater. On the contrary, when the thermal load of the building gets higher and the second stage switches on, the optimal frequencies come to higher values, around $45-50 \mathrm{~Hz}$ (Fig. 3.27 d). This is because both compressors are running, so the consumption of the auxiliaries represents a smaller percentage of the total energy consumption. Very similar trends can be seen for heating mode. As it happened with the $C O P_{\text {sys }}$, the optimal values of $P F_{\text {sys }}$ are higher in cooling than in heating mode.

From the performance maps obtained in step 3, the optimal values of both circulation pumps' frequencies can be determined. Results are presented in Fig. 3.29, which presents the optimal frequencies for each mode (cooling and heating) and for each circulation pump (internal and external). It can be clearly observed in Fig. 3.29 that, the higher the partial load ratio, the higher the values for the optimal frequencies.

Fig. 3.29 shows the experimental results of the water circulation pumps frequency variation strategy developed both for cooling (Fig. 3.29a) and heating (Fig. 3.29p) mode.

The variation of both the internal frequency $\left(f_{I C P}\right)$ and the external frequency $\left(f_{E C P}\right)$ with the partial load ratio of the system $(\alpha)$ can be observed in Fig. 3.29 both for cooling and heating modes. It can be observed for both modes the variation depicted in the curves in Fig. 3.29 the higher the value of the partial load ratio, the higher the value of frequencies set in the frequency inverters, and vice versa.

The expressions shown in Fig. 3.29 are part of an integrated optimization algorithm in which this water circulation pumps frequency variation is combined with the temperature compensation described in Section 3.5 in order to obtain energy savings. This integrated optimization strategy is described in Section 3.7 . 


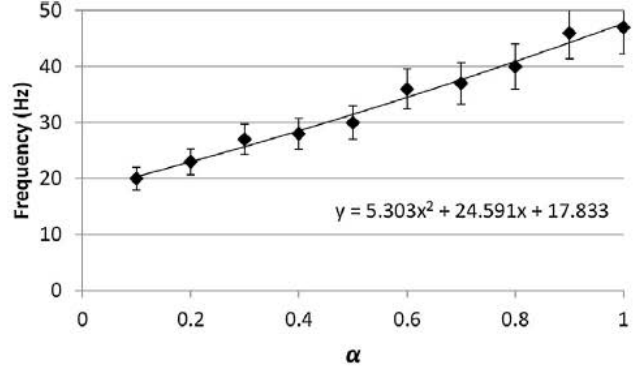

a)

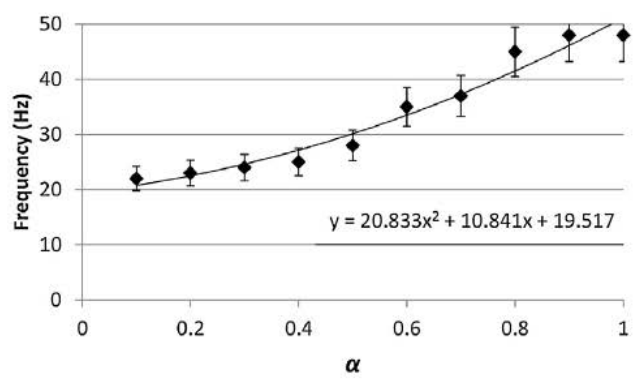

c)

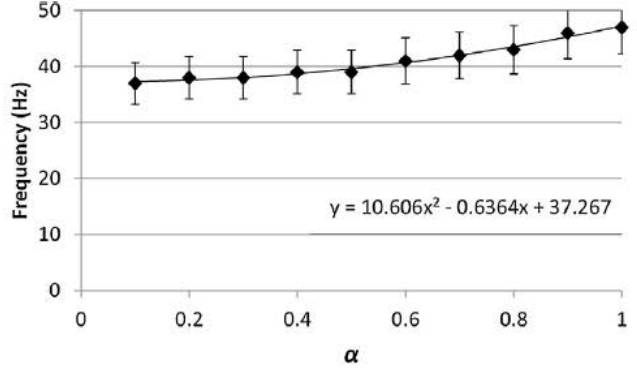

b)

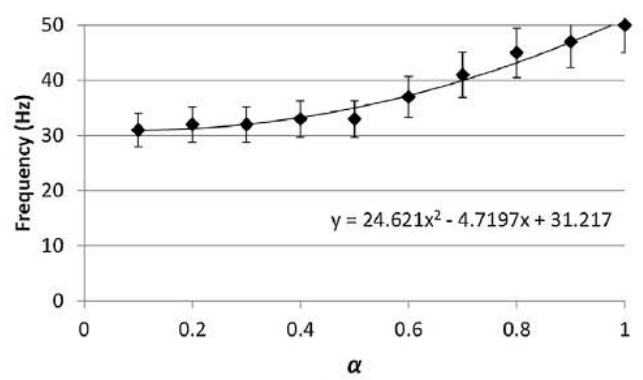

d)

Figure 3.29: Circulation pumps frequency as a function of the partial load ratio (tandem case): (a) ICP heating; (b) ECP heating; (c) ICP cooling; (d) ECP cooling. Source: 61

(a)

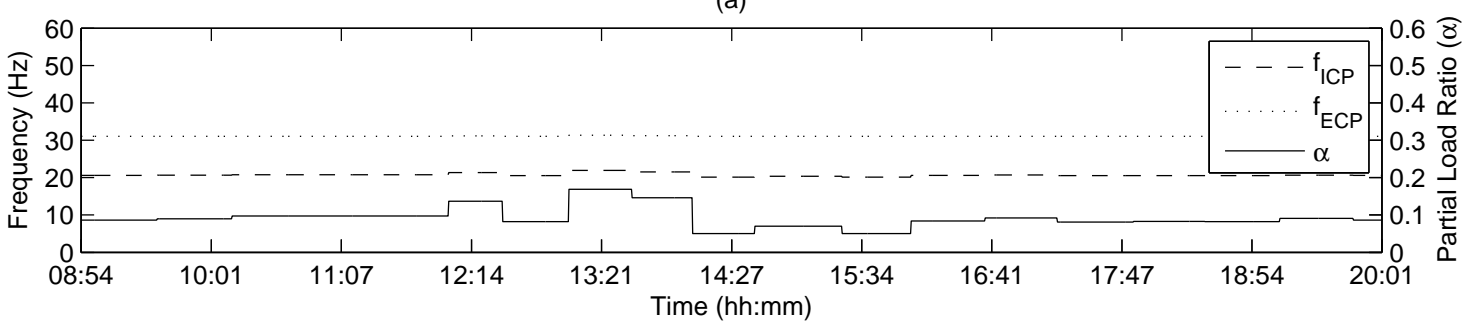

(b)

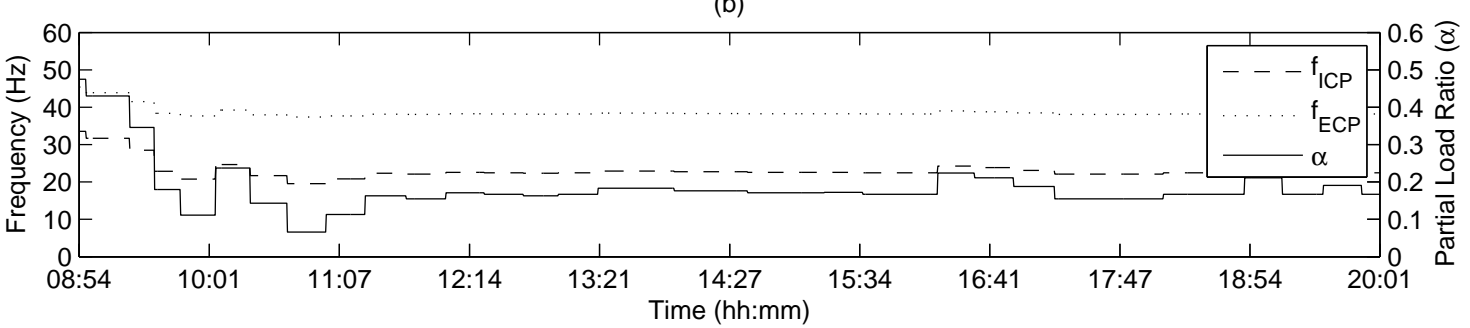

Figure 3.30: Experimental results after applying frequency variation: (a) Cooling mode (2014/05/26); (b) Heating mode (2014/01/08). 


\section{Proposed methodology for a multi-stage heat pump unit with $N$ compressors (general case)}

The optimization methodology developed was particularised for the experimental case of the geothermal plant studied in this research work, with its current configuration consisting of a multi-stage heat pump unit with two compressors of the same capacity working tandem.

Notwithstanding, it could be applied to any other installation having a multi-stage heat pump unit with more than two compressors. This section presents a proposal in order to apply the in situ optimization methodology to any installation provided with a multistage heat pump consisting of whatever number of compressors $N$. The particularities for each one of the three steps of the methodology are described next.

Step 1: ON time operation characterization

When the multi-stage heat pump unit has more than two stages, the experimental tests from step 1 of the methodology should be repeated at least three times: for the first stage $(n=1)$, for the maximum capacity of the heat pump $(n=N)$ and also for an intermediate stage. This intermediate stage can be chosen by means of Eq. 3.48 .

$$
n=\lfloor N\rfloor+1
$$

Fig. 3.31 shows the different frequency values that should be considered for each one of the three states. It should be pointed out that for the intermediate state (given by Eq. 3.48), and in order to save time, some of the experimental points represented by squares and triangles in Fig. 3.31 (preferably those close to the crosses) could be removed from the test matrix. Since the optimum is usually located at medium frequencies for values of the partial load ratio around 0.5 , this would not affect the results. However, considering a number of points less than 15 would result in a loss of resolution and in the optimum not being accurately determined. Therefore, a total number of at least 15 points is recommended.

Step 2: Estimation of the system COP maps

Given that the experimental tests from the first step should be carried out for three times, the results of step 2 for a multi-stage heat pump with $N$ compressors would be three system COP maps for each mode (heating and cooling), one for each of the three states analysed.

Step 3: Estimation of the system performance maps for any thermal load

Step 3 can be applied in the same way as for the two tandem compressors heat pump, since Eq. 3.47 was expressed in such a way that it can be applied to any number of stages $(n>1)$. 


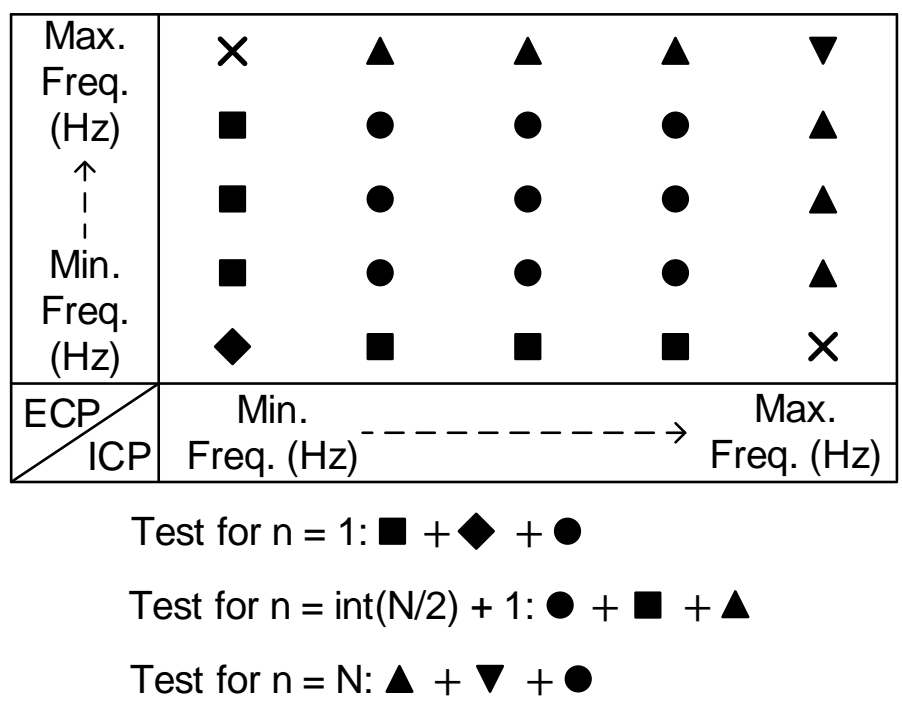

Figure 3.31: Proposed test for the variation of the circulation pumps frequency for a multi-stage heat pump unit with $N$ compressors.

\subsection{Integrated control and optimization strategies}

The first approach to a global optimised control considered, which is presented in Section 3.7.1, consisted of combining the temperature compensation strategy described in Section 3.5 and the water circulation pumps frequency variation methodology presented in Section 3.6 in an global energy optimization algorithm.

However, although an important enhancement of the energy performance of the system was observed when applying the optimization algorithm, the use along several seasons led to some complaints from the users. After analysing carefully the operation of the system and all the working conditions, it was detected that the user comfort was not met in extreme weather conditions during summer, mainly during July, as the indoor temperature and relative humidity observed in several rooms during these extreme days in summer took values around $27^{\circ} \mathrm{C}$ and $70 \%$ respectively.

Section 3.7 .2 describes the upgrade performed on the algorithm developed in order to ensure the user comfort while keeping high energy savings. Even though no complaints were received about the heating season comfort, the upgrade mentioned was also carried out on the optimization algorithm for heating mode. 


\subsubsection{Temperature compensation and frequency variation: a first ap- proach}

The temperature compensation strategy described in Section 3.5 and the water circulation pumps frequency variation methodology presented in Section 3.6 were combined in an global energy optimization algorithm in order to improve the energy performance of the system and obtain energy savings. Fig. 3.32 shows a flow diagram that indicates how this optimization algorithm works for the example case of cooling mode.

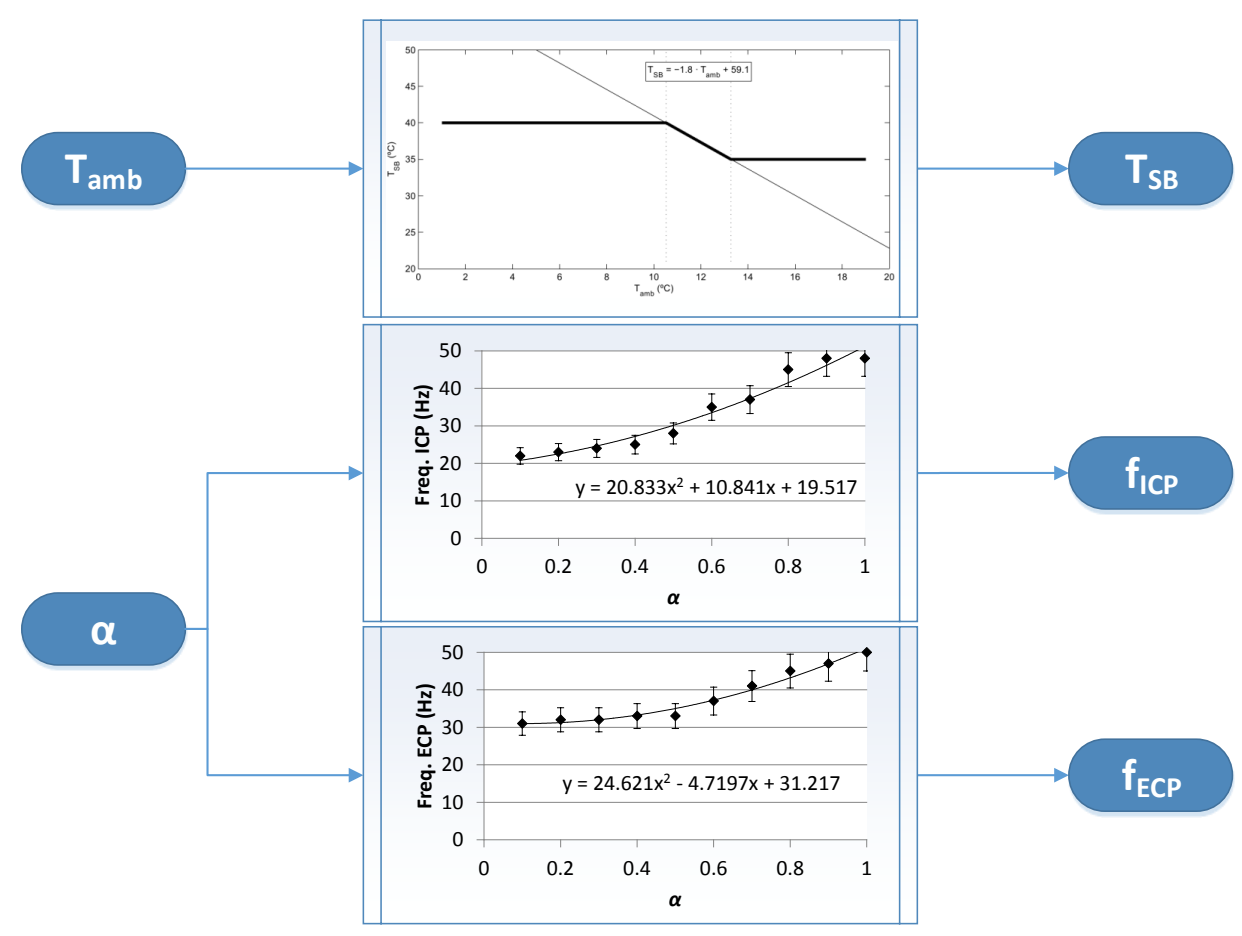

Figure 3.32: Flow diagram of the optimized control first approach (cooling mode).

As it can be observed in the flow diagram presented in Fig. 3.32 , the controlled variables are the temperature setpoint of the heat pump $\left(T_{S B}\right)$ and the frequency of both the internal $\left(f_{I C P}\right)$ and the external $\left(f_{E C P}\right)$ circulation pumps. The measured variables are the ambient temperature $\left(T_{a m b}\right)$ and the partial load ratio of the system $(\alpha)$. In fact, $\alpha$ is not a direct reading, but it is calculated as presented in Section 2.2.4.

As depicted in the flow diagram for this first approach, the temperature setpoint of the heat pump was determined as a function of the ambient temperature solely. It is observed that the higher the ambient temperature, the lower the temperature setpoint set at the heat pump controller, as it comes from the temperature compensation strategy described in Section 3.5 . 
On the other hand, the circulation pumps frequencies were calculated as a function of the partial load ratio solely, as determined from the three-step methodology described in Section 3.6. The curves used, which have $\alpha$ as input and $f_{I C P}$ and $f_{E C P}$ as outputs in Fig. 3.32, come from Figs. $3.29 \mathrm{a}$ and $3.29 \mathrm{p}$. As it can be observed, the higher the partial load ratio, the higher the values of frequency set at the frequency inverters, and hence the water flow rates circulating through the hydraulic circuits.

For heating mode the structure is the same as in Fig. 3.32 but using the curves corresponding to that mode. These curves come from Figs. 3.15 , 3.29. and $3.29 \mathrm{~d}$, from top to bottom.

All these curves were implemented in LabVIEW ${ }^{\circledR}$ for both cooling and heating modes in order to automatically set optimal frequencies at the frequency inverters and optimal temperature setpoint at the heat pump so that an optimal energy performance of the system is achieved. More details on the implementation will be presented in Section 3.8 .

The results of the optimization strategies used in this integrated control were separately shown in Fig. 3.17, for the temperature compensation strategy, and Fig. 3.30, for the water circulation pumps frequency variation. They showed the results for two different days, one for cooling mode $(2014 / 05 / 26)$ and one for heating mode $(2014 / 01 / 08)$, both with low thermal loads. Figs. 3.33 and 3.34 shows the results of this first approach to the integrated control for one cooling day (2013/07/15) and one heating day (2013/02/08) respectively. They depict the evolution with time of the measured variables and the controlled variables. The thermal load is higher in these days.

In the case of cooling mode, it can be observed that the ambient temperature at the beginning of the day is around $25^{\circ} \mathrm{C}$, which saturates the algorithm at a supply temperature of $15^{\circ} \mathrm{C}$ (Fig. 3.33 a). This helps the system save energy, as a less demanding temperature setpoint is used. As the sun rises, the ambient temperature starts to increase, and the temperature setpoint of the heat pump is varied accordingly: the higher the ambient temperature, the lower the setpoint. This is done because a hotter ambient temperature (which means a higher thermal energy demand) requires that the water is supplied to the building at a lower temperature. Moreover, this control works also when two compressors are working. In the afternoon, as the ambient temperature starts to decrease, the setpoint is increased again, until the limit value of $15^{\circ} \mathrm{C}$, hence saving energy. Along the whole day, it can be observed how the actual supply temperature $\left(T_{\text {tank }}\right)$ follows the targeted supply temperature $\left(T_{S B}\right)$. Regarding the frequencies, both the internal frequency $\left(f_{I C P}\right)$ and the external frequency $\left(f_{E C P}\right)$ increase when the value of the partial load ratio $(\alpha)$ decreases and vice versa (Fig. 3.33 ).

In heating mode, the effect of applying the integrated control is analogous (Fig. 3.34). On the one hand, the temperature setpoint moves down with the increase of the ambient temperature, in order to improve the energy performance of the system, and it moves up with the decrease of the ambient temperature in order to heat up the water in the water distribution system with a view to meet the user comfort. On the other hand, the value of the pumps frequencies vary proportionally to the value of the partial load ratio: 
(a)

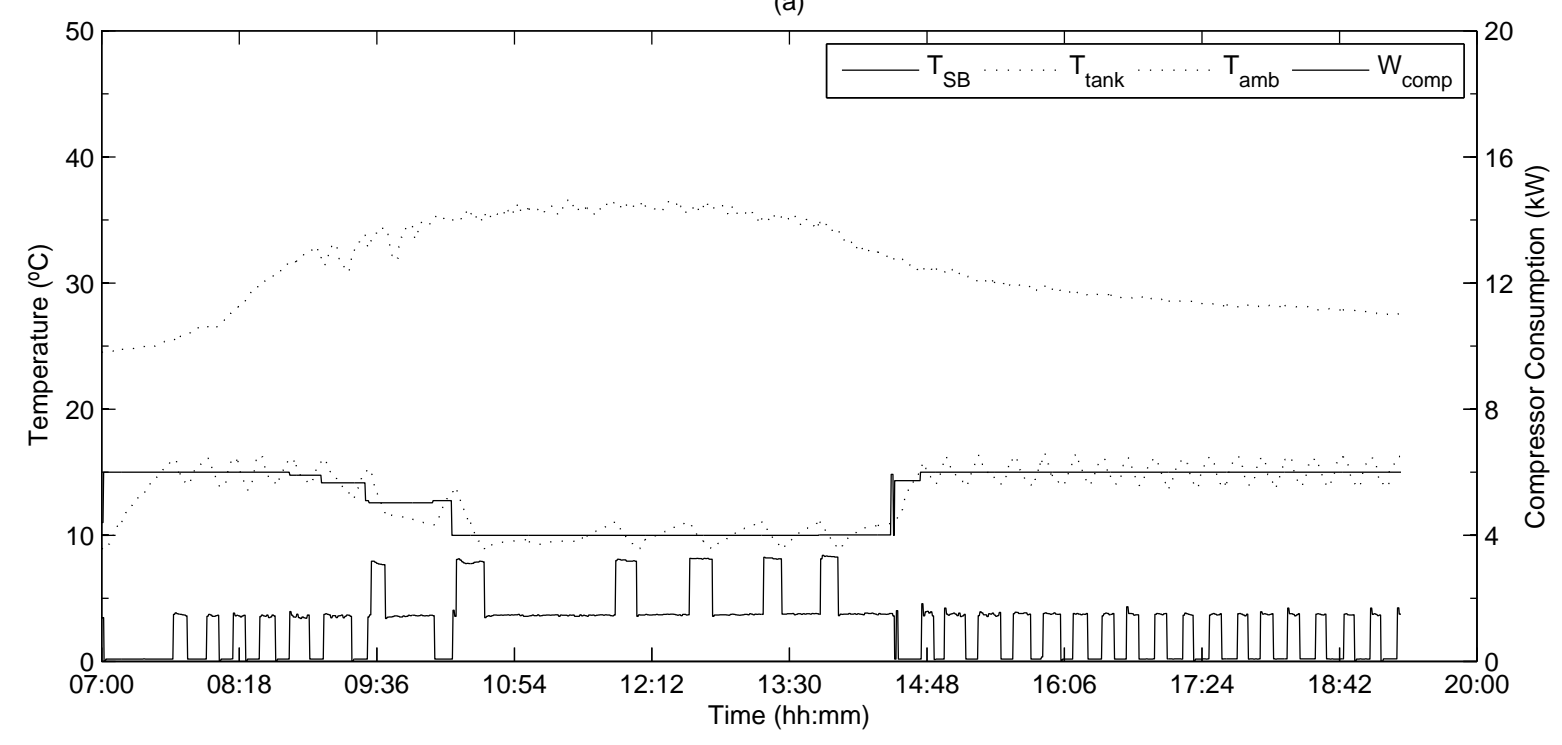

(b)

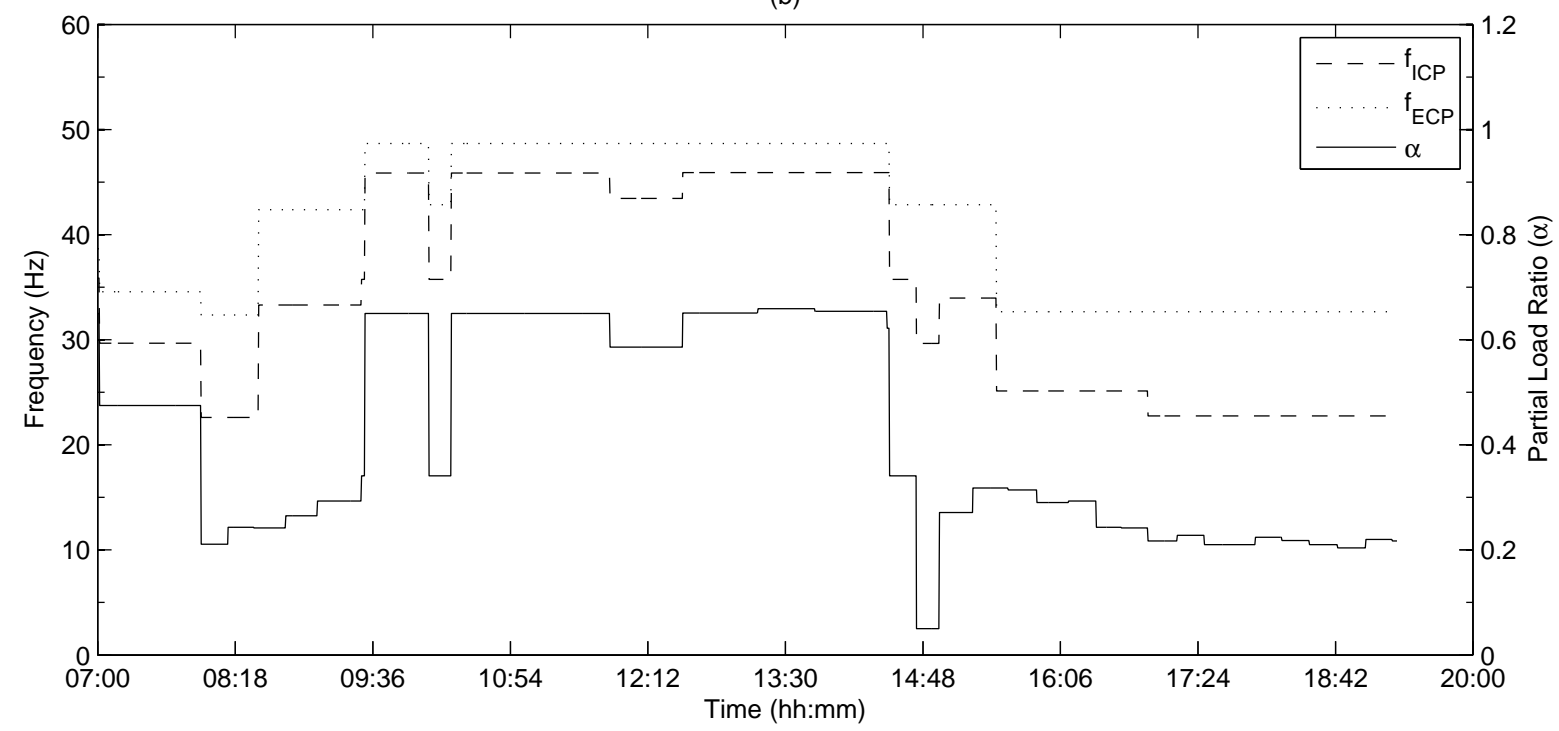

Figure 3.33: Experimental results of the integrated control first approach (cooling mode). 
(a)

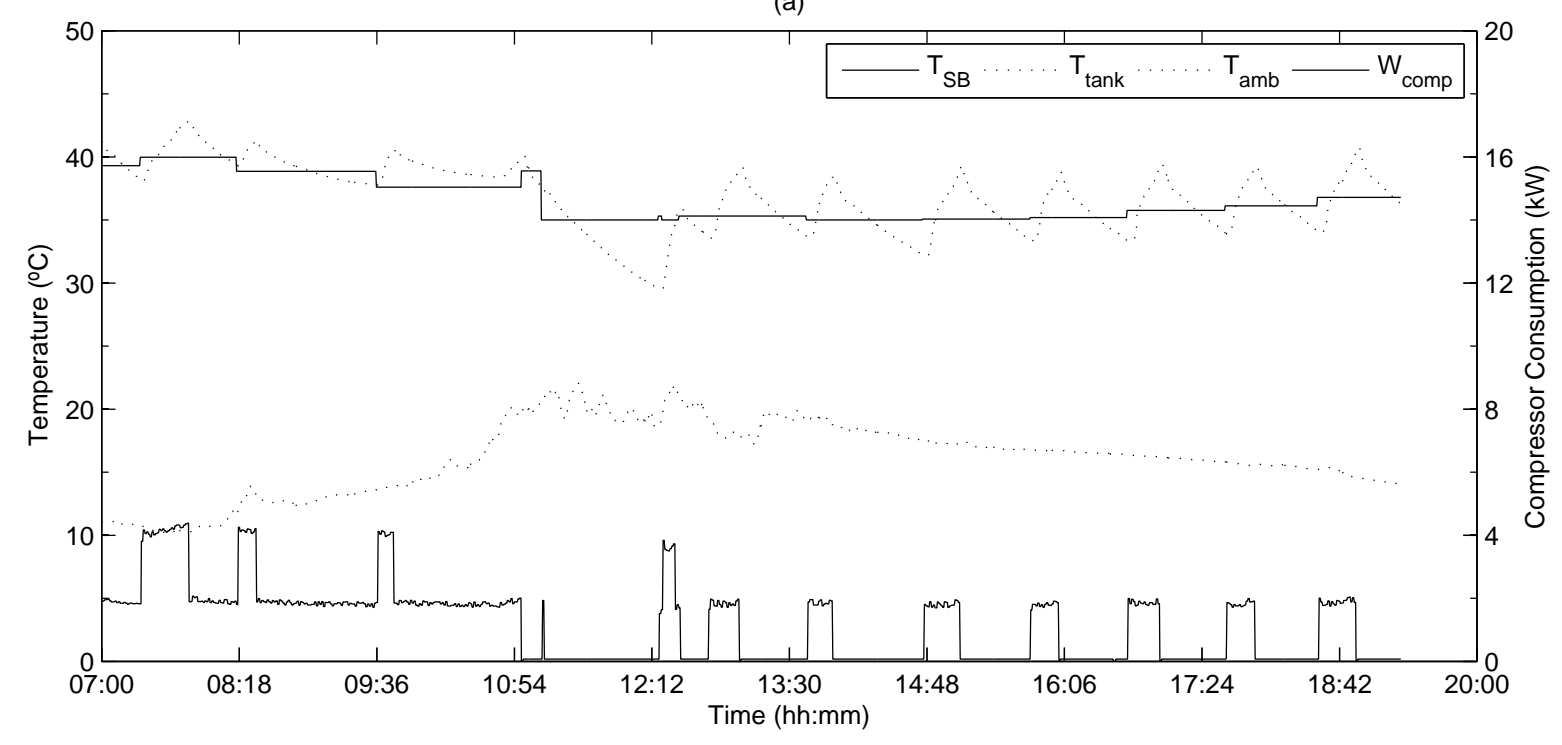

(b)

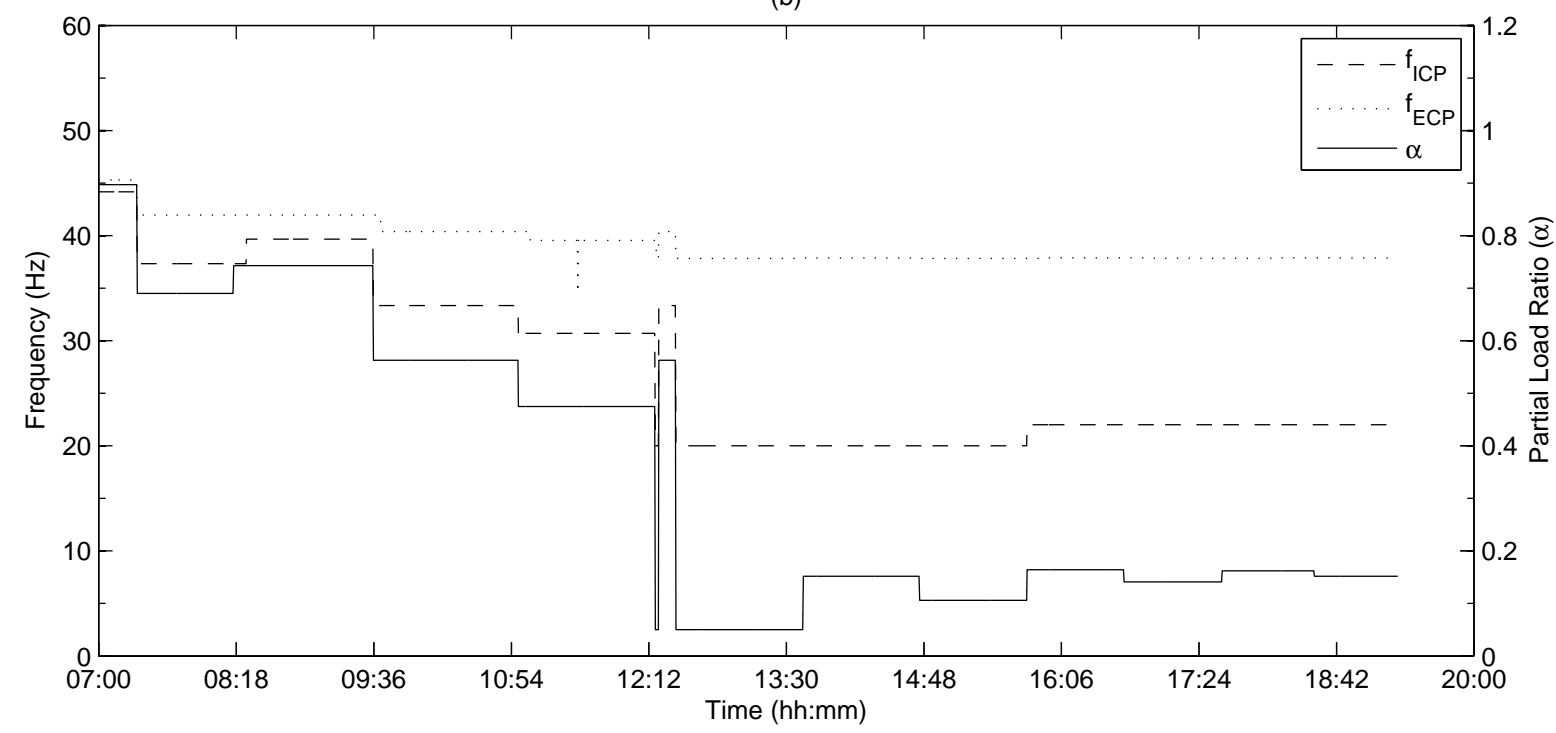

Figure 3.34: Experimental results of the integrated control first approach (heating mode). 
a higher value of $\alpha$ implies a higher value of the calculated frequency and vice versa.

The integrated optimization algorithm developed was experimentally tested on the geothermal plant for a period of several months during both, cooling and heating seasons. The performance described earlier turns into important energy savings in the geothermal plant along the seasons which are analysed in the following.

In order to perform a proper analysis and carry out a fair comparison, the optimized control was compared to a standard control. This standard control consists of keeping constant the temperature setting $\left(T_{S B}\right)$ at $10^{\circ} \mathrm{C}$, or $40^{\circ} \mathrm{C}$ (limits established in GROUNDMED project), and keeping a fixed frequency $50 \mathrm{~Hz}$ for both circulation pumps. This is how common installations work: fixed temperature setting and $50 \mathrm{~Hz}$ (the frequency of the power supply) to the circulation pumps, with no frequency inverters installed. The controller was programmed in such a way that the standard control is applied on odd days and the optimized control is used on even days. This is a good method for randomly choosing when to apply each control strategy and obtaining, in the end, 50\% of the days working with each one. Possible uncertainties related to the variation of the thermal demand of the building on different days will equally affect both controls, since the number of days of the study is large enough (a complete season).

Fig. 3.35 shows, from left to right, the daily performance factors $D P F_{1}$ (includes only heat pump consumption), $D P F_{2}$ (includes heat pump and external circulation pump consumption) and $D P F_{3}$ (includes heat pump and both circulation pumps consumption),for both types of control (standard and optimised) during the test campaign carried out in year 2013. As described in Chapter 2, the daily performance factor $3\left(D P F_{3}\right)$ corresponds to the daily performance factor of the system $\left(D P F_{\text {sys }}\right)$, since the fan coils are not included in the energy optimization strategies. The analysis covers the period from January to July 2013.

The alternation of standard and optimized days can be clearly observed in Fig. 3.35. The values of $\mathrm{DPF}_{3}$ (triangles) for standard days are between 2 and 3 in cooling mode (Fig. 3.35 a) and between 3 and 4 in the case of heating mode (Fig. 3.35p). For the days when the optimized control was applied these values are around one point higher. Through a quick and simple analysis, it is observed that this would represent an improvement between $25 \%(((5-4) / 4) \cdot 100)$ and $50 \%(((3-2) / 2) \cdot 100)$.

Fig. 3.35 shows DPFs calculated for each day in the analysed period. Getting together the standard days on one hand, and the optimized days on the other hand, a kind of Seasonal Performance Factor (SPF) can be obtained for each case. In this way the improvement achieved by the optimized control when compared to the standard control can be analysed. Fig. 3.36 presents this comparison.

It can be seen in Fig. 3.36 that the improvement in $S P F_{1}$ is not representative, as it is not the aim of the optimization algorithm to optimize the performance of the heat pump itself $\left(S P F_{1}\right)$ but the overall performance of the system including the circulation pumps $\left(S P F_{3}\right)$. Although the variation of the temperature setpoint of the heat pump can lead 
(a)

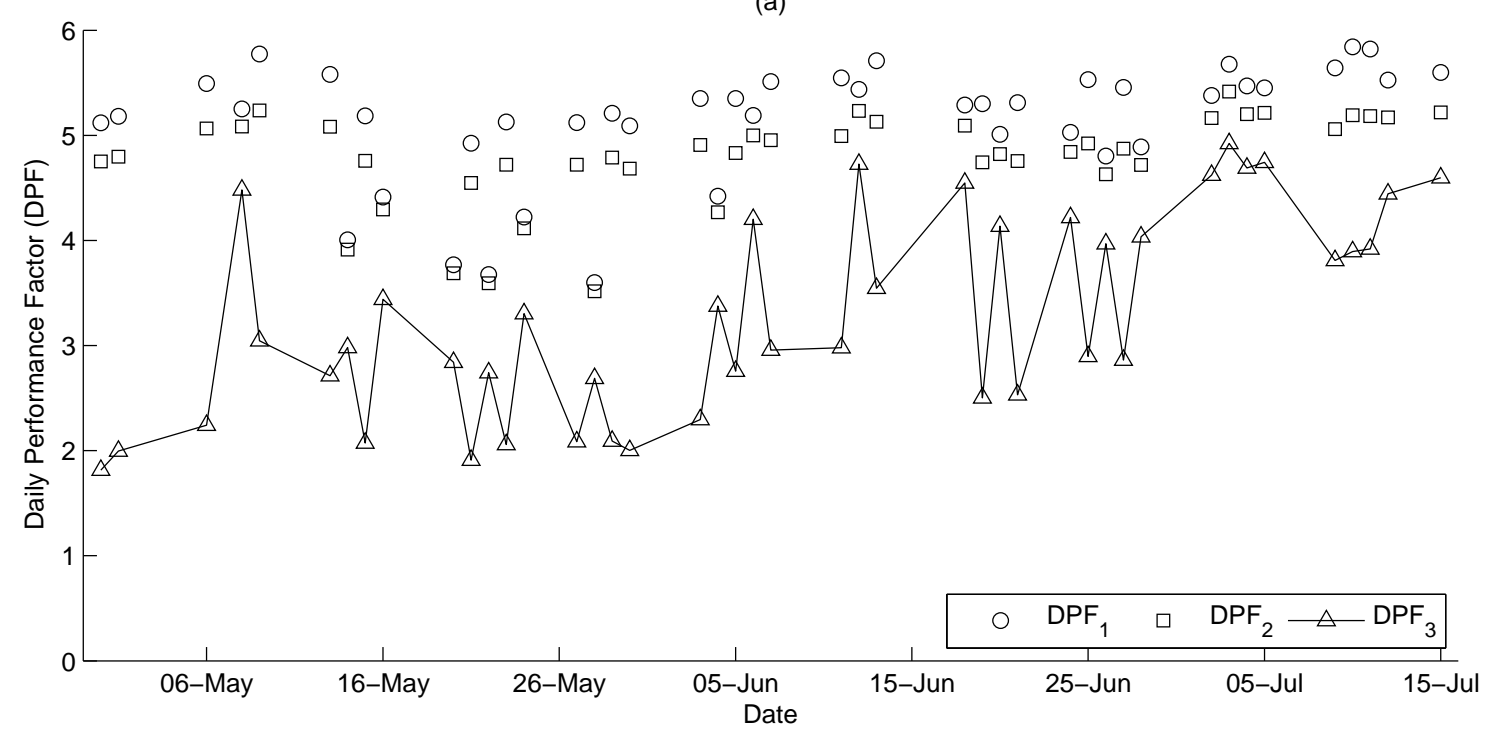

(b)

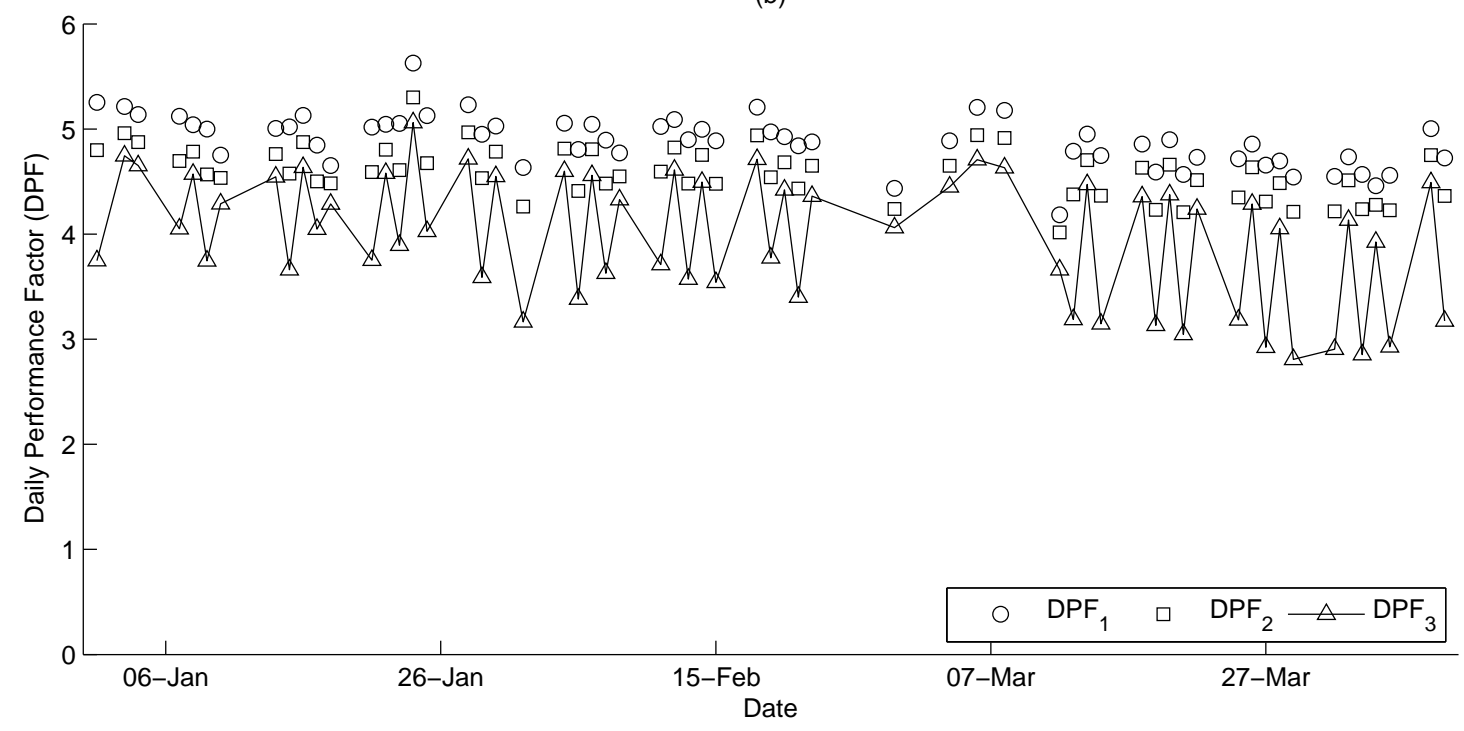

Figure 3.35: Daily performance factor (first approach): (a) cooling mode test campaign; (b) heating mode test campaign. 
(a)
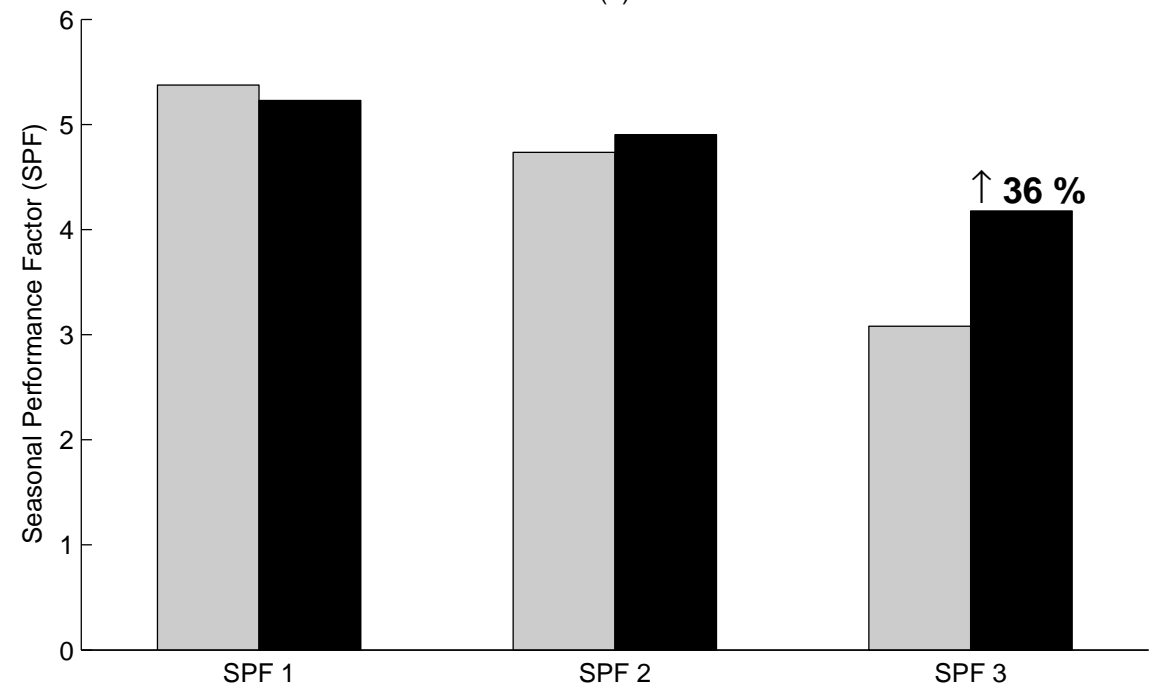

(b)
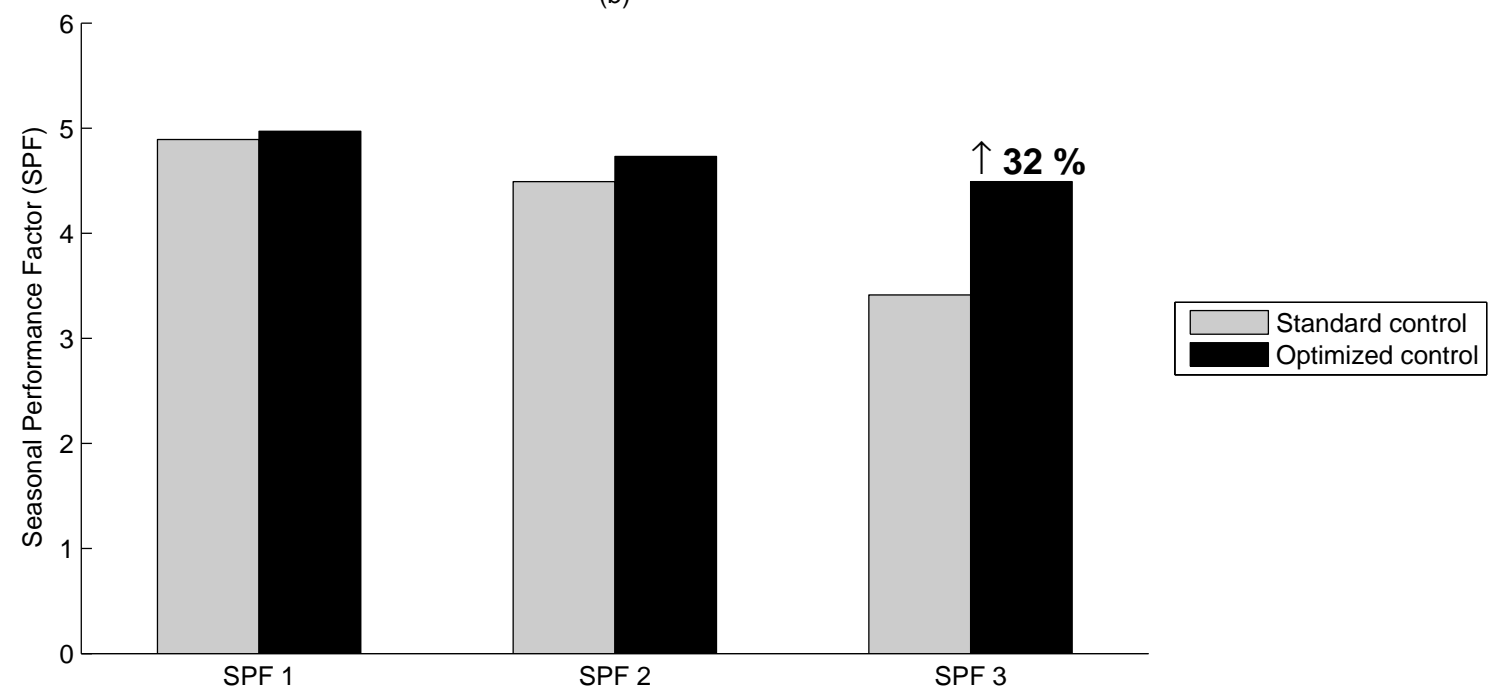

Figure 3.36: Seasonal performance factor (first approach): (a) cooling mode test campaign; (b) heating mode test campaign. 
to the heat pump consuming less energy, the flow rates of the circulation pumps are also decreased, hence making the compressor of the heat pump consume more energy. That is the reason why $S P F_{1}$ can even be lower for the optimised control than for the standard control, as it happens in the case of cooling mode (Fig. 3.36a).

The maximum improvement is observed in $S P F_{3}$ because it takes into account both circulation pumps, the consumption of which is being optimized. In fact, this is the objective of the optimization strategies regarding energy consumption: to optimize the seasonal performance factor of the system $\left(S P F_{3}=S P F_{\text {sys }}\right)$. A $36 \%$ improvement is obtained in the system $S P F$ for cooling mode (Fig. 3.36 a). In heating mode (Fig. 3.36 $\mathrm{b}$ ) the improvement is not as high, around $32 \%$.

The previous analysis points out important energy savings. However, as stated earlier, it was found that user comfort was not met in extreme weather conditions during summer. For that reason, it was necessary to upgrade the optimised control in order to fix this problem. The description of this upgrade is presented in the following section.

\subsubsection{Upgrade to ensure user comfort}

\section{Controlled variables and fan coil effectiveness}

The explanation on why the former optimized control did not meet the user comfort in extreme weather conditions during summer lies in the fan coil effectiveness. Fig. 3.37 shows, for different values of the building supply temperature, how the effectiveness of the fan coil varies with the internal flow rate, for cooling mode. The data employed in the figure come from Appendix B, where the performance of the FCUs is characterized by means of a piece of software provided by the manufacturer, which includes a model of the fan coils based on experimental data taken at their laboratories. The air flow rate in the fan coil was fixed to its nominal value $\left(\dot{m}_{a, n o m}\right)$. The analysis is presented for cooling mode here and will be described for heating mode in a separated section.

As it is observed in Fig. 3.37, the effectiveness of the fan coil decreases not only when the supply temperature increases, but also and with more significance when the internal flow rate decreases.

As presented in the previous section, when the former optimized control was applied (first approach), the setpoint of the heat pump was varied as a function of the ambient temperature, whereas the frequencies of both circulation pumps (and hence the flow rates) were varied as a function of the partial load ratio. However, both control strategies were independent from each other. This would mostly explain the lack of comfort experimented by the users. When there were few people in the building in a hot day, although they needed to meet their cooling needs, the partial load ratio of the whole system was small due to the lower occupancy level, and the control system was setting low frequencies and thus low flow rates (see Fig. 3.32). Then, if the ambient temperature was not very high, the building supply temperature was not low enough and this resulted in the decrease 


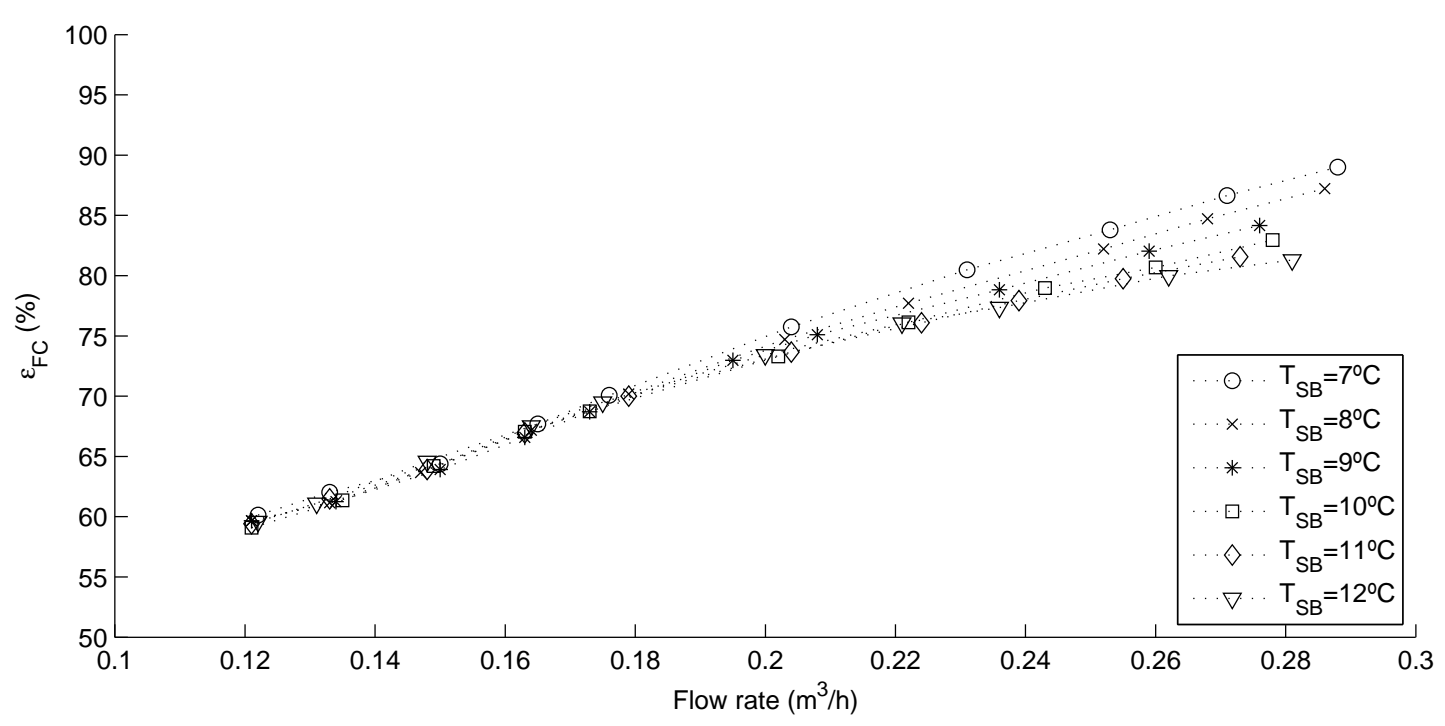

Figure 3.37: Fan coil effectiveness in cooling mode.

of the fan coil effectiveness and in the fan coil not providing enough capacity as to cover the thermal load of the room, which turned into user discomfort.

Analysing the same problem through equations, the thermal load for each room and the fan coil capacity can be expressed as in Eqs. 3.49 and 3.50 respectively. It should be noticed that some of the equations employed in this section have already appeared in Section 3.5 , when the temperature compensation strategy was described.

$$
\begin{gathered}
\dot{Q}_{\text {room }}=U A_{0} \cdot\left(T_{\text {amb }}-T_{\text {room }}\right) \\
\dot{Q}_{F C}=\dot{m}_{a} \cdot c_{p, a} \cdot \varepsilon_{F C}\left(C_{a, n o m}, C_{w}\right) \cdot\left(T_{\text {room }}-T_{S B}\right)
\end{gathered}
$$

where:

$U A_{0}$ would be the overall heat transfer conductance of the room, including the internal gains and the solar irradiation in the room,

$\dot{m}_{a}$ is the flow rate of air circulating through the coil in the fan coil,

$c_{p, a}$ is the specific heat of air at constant pressure and

$\varepsilon_{F C}$ is the effectiveness of the fan coil, which depends on the nominal heat capacity of the air $\left(C_{a, n o m}=\dot{m}_{a, n o m} \cdot c_{p, a}\right)$ and the heatcapacity of water $\left(C_{w}=\dot{m}_{w} \cdot c_{p, w}\right)$.

In order to achieve user comfort, the fan coil capacity should cover the room thermal load, as expressed in Eq. 3.51 .

$$
\dot{m}_{a} \cdot c_{p, a} \cdot \varepsilon_{F C}\left(C_{a, \text { nom }}, C_{w}\right) \cdot\left(T_{\text {room }}-T_{S B}\right) \geq U A_{0} \cdot\left(T_{a m b}-T_{\text {room }}\right)
$$


This results in a supply building temperature that, in order to provide user comfort, should be lower than a certain value which will be given by Eq. 3.52 .

$$
T_{S B} \leq T_{\text {room }}-\frac{U A_{0} \cdot\left(T_{\text {amb }}-T_{\text {room }}\right)}{\dot{m}_{a, \text { nom }} \cdot c_{p, a} \cdot \varepsilon_{F C}\left(C_{a, \text { nom }}, C_{w}\right)}
$$

Eq. 3.52 provides the limit condition. Considering the design conditions of the fan coil (maximum ambient temperature $T_{a m b, \max }$, e.g. $38^{\circ} \mathrm{C}$ in Valencia, minimum building supply temperature $T_{S B \text {, min }}$, e.g. $7^{\circ} \mathrm{C}$, and the maximum internal circulation pump flow rate), for which the fan coil has to provide comfort to the users in the worst case scenario (hottest day of the year), the equation turns into Eq. 3.53. Under these conditions, the effectiveness of the fan coil will be maximum $\left(\varepsilon_{F C, \text { max }}\right)$.

$$
T_{S B, \text { min }}=T_{\text {room }}-\frac{U A_{0} \cdot\left(T_{a m b, \text { max }}-T_{\text {room }}\right)}{\dot{m}_{a, \text { nom }} \cdot c_{p, a} \cdot \varepsilon_{F C, \text { max }}\left(C_{a, \text { nom }}, C_{w, \text { max }}\right)}
$$

The value of the overall heat transfer conductance of the room $\left(U A_{0}\right)$ in design conditions can be deduced from Eq. 3.53, resulting in Eq. 3.54.

$$
U A_{0}=\dot{m}_{a, \text { nom }} \cdot c_{p, a} \cdot \varepsilon_{F C, \text { max }}\left(C_{a, \text { nom }}, C_{w, \text { max }}\right) \cdot \frac{T_{\text {room }}-T_{S B, \text { min }}}{\left(T_{a m b, \text { max }}-T_{\text {room }}\right)}
$$

In the former control, it was assumed that both the overall heat transfer conductance of the room $\left(U A_{0}\right)$ and the fan coil effectiveness $\left(\varepsilon_{F C}\right)$ were constant. However, as a result of the variation of the internal circulation pump frequency explained earlier for the former control, the water flow through the coil is modified. Consequently, the effectiveness of the fan coil cannot be considered as constant, as it will vary dramatically with the water flow rate variation. Regarding the heat transfer conductance, it is assumed a constant value in design conditions. Replacing the value of $U A_{0}$ provided by Eq. 3.54 in Eq. 3.53 , Eq. 3.55 is obtained, which provides the building supply temperature required to achieve user comfort, as a function of the fan coil effectiveness.

$$
T_{S B} \leq T_{\text {room }}-\frac{\beta \cdot \varepsilon_{F C, \text { max }} \cdot\left(T_{a m b}-T_{\text {room }}\right)}{\varepsilon_{F C}\left(C_{a, \text { nom }}, C_{w}\right)}
$$

where $\beta$ is the relation given by Eq. 3.56 .

$$
\beta=\frac{T_{\text {room }}-T_{S B, \text { min }}}{T_{\text {amb,max }}-T_{\text {room }}}
$$

The curves presented in Fig. 3.37 were obtained by calculating some points from the software provided by the manufacturer of the fan coils. However, in order to use it for calculations later on in this paper, a mathematical expression that correlates the fan coil effectiveness with the internal frequency and the building supply temperature $\left(\varepsilon_{F C}\left(f_{I C P}, T_{S B}\right)\right)$ should be obtained. It should be noticed that, although the internal flow rate is plotted in Fig. 3.37, it is the internal frequency that is used in the correlation for the fan coil effectiveness, as it is the variable that is controlled directly by the control 
system and thus the targeted variable. After all, both variables, internal flow rate $\left(\dot{m}_{i c}\right)$ and internal frequency $\left(f_{I C P}\right)$, are proportional, as described in Section 2.1.2.

Several correlations for the fan coil effectiveness are studied in Appendix B and the one finally chosen is presented in Eq. 3.57.

$$
\varepsilon_{F C}\left(f_{I C P}, T_{S B}\right)=D_{0}+D_{1} \cdot f_{I C P}+D_{2} \cdot f_{I C P}^{2}+D_{3} \cdot T_{S B} \cdot f_{I C P}
$$

Considering the expression provided in Eq. 3.57 for the fan coil effectiveness, Eq. 3.58 provides the maximum value of the building supply temperature required to achieve user comfort, taking into account the variation in the effectiveness produced by the internal water flow variation and the building supply temperature variation. Hence the water should be supplied at a temperature lower or equal to the value given by Eq. 3.58

$$
T_{S B}=T_{\text {room }}-\frac{\beta \cdot \varepsilon_{F C, \text { max }} \cdot\left(T_{a m b}-T_{\text {room }}\right)}{\varepsilon_{F C}\left(f_{I C P}, T_{S B}\right)}
$$

\section{Integrated control}

The objective of the control algorithm is to optimize the energy performance of the system, represented by the system performance factor $\left(P F_{\text {sys }}=P F_{3}\right)$. As presented in Section 3.7.1, the value of the internal circulation pump frequency which optimizes the performance factor of the system was calculated, by means of the experimental methodology developed, in terms of the partial load ratio of the system $(\alpha)$, and the building supply temperature was determined as a function of the ambient temperature $\left(T_{a m b}\right)$ as a first control attempt. However, the influence of decreasing the internal water flow rate was not taken into account in the fan coil effectiveness, what resulted in the comfort of the user not being met. This happened because both strategies were uncoupled, that is to say, they worked independently of what each other did.

In order to find the optimal values of the controlled variables, namely the internal circulation pump frequency $\left(f_{I C P}\right)$ and the building supply temperature $\left(T_{S B}\right)$, that optimize the performance factor of the system while being able to meet the user comfort, it is necessary to couple both strategies. In the former control, the supply building temperature was calculated as a function of the ambient temperature solely $\left(T_{S B}=f(T a m b)\right)$, whereas the internal frequency was determined considering only the partial load ratio $\left(f_{I C P}=f(\alpha)\right)$. Now both control parameters need to be determined as a function of both variables, the ambient temperature and the partial load ratio of the system $\left(f_{I C P}=f\left(T_{a m b}, \alpha\right)\right)$ and $\left.T_{S B}=f\left(T_{a m b}, \alpha\right)\right)$.

For a start, the performance factor of the system will depend on the controlled variables: internal circulation pump frequency and supply building temperature $\left(P F_{\text {sys }}=\right.$ $\left.f\left(f_{I C P}, T_{S B}\right)\right)$. Its variation can be expressed as the sum of the partial derivatives of the system performance factor with each one of the variables. This is mathematically 
expressed in Eq. 3.59

$$
d P F_{\text {sys }}=\left.\frac{\partial P F_{\text {sys }}}{\partial f_{I C P}}\right|_{T_{S B}} \cdot d f_{I C P}+\left.\frac{\partial P F_{\text {sys }}}{\partial T_{S B}}\right|_{f_{I C P}} \cdot d T_{S B}
$$

Therefore, the variation of the system performance factor with the internal circulation pump frequency will be given by Eq. 3.60.

$$
\frac{d P F_{\text {sys }}}{d f_{I C P}}=\left.\frac{\partial P F_{\text {sys }}}{\partial f_{I C P}}\right|_{T_{S B}}+\left.\frac{\partial P F_{\text {sys }}}{\partial T_{S B}}\right|_{f_{I C P}} \cdot \frac{d T_{S B}}{d f_{I C P}}
$$

Finally, equating this derivative to zero and solving the resulting equation (Eq. 3.61) will provide the optimal value of the internal frequency taking into account not only the energy optimization of the system but also the user comfort.

$$
\left.\frac{\partial P F_{\text {sys }}}{\partial f_{I C P}}\right|_{T_{S B}}+\left.\frac{\partial P F_{\text {sys }}}{\partial T_{S B}}\right|_{f_{I C P}} \cdot \frac{d T_{S B}}{d f_{I C P}}=0
$$

where:

(a) $\left.\frac{\partial P F_{s y s}}{\partial f_{I C P}}\right|_{T_{S B}}$ is the partial derivative of the performance factor with the internal frequency for a given building supply temperature,

(b) $\left.\frac{\partial P F_{s y s}}{\partial T_{S B}}\right|_{f_{I C P}}$ is the partial derivative of the performance factor with the building supply temperature for a given internal frequency,

(c) and $\frac{d T_{S B}}{d f_{I C P}}$ is the derivative of the performance factor with the internal frequency.

The first addend in Eq. 3.61 would provide the optimal internal circulation pump frequency for a given supply building temperature, as resulting from the methodology developed in section 3.6, while the second one would provide the necessary correction with a view to meet the user comfort. In order to solve Eq. 3.61, each one of the addends in it should be determined first.

Term (a) stands for the variation of the performance factor with the internal frequency for a given building supply temperature $\left(T_{S B}\right)$. This variation is given by the $P F$ maps resulting from the in situ methodology described in Section 3.6. The contour maps are obtained for a constant building supply temperature $\left(40^{\circ} \mathrm{C}\right.$ in the case of heating mode and $10^{\circ} \mathrm{C}$ in cooling mode). They show how the performance factor varies in terms of the circulation pumps frequencies and provide the optimal pair of frequencies.

Since the intention is to obtain the variation of the system performance factor $\left(P F_{\text {sys }}\right)$ with the internal frequency $\left(f_{I C P}\right)$, the external frequency $\left(f_{E C P}\right)$ is fixed to its optimal value for each value of $\alpha$. Considering these optimal values of the external circulation pump frequency for each value of $\alpha$ from 0.1 to 1 , Fig. 3.38 shows, for cooling mode, the system performance factor as a function of the internal frequency.

The curves in Fig. 3.38, which show the variation of $P F_{\text {sys }}$ with the internal frequency, have been adjusted to cubic equations. The maximums in the curves turn out to be the 


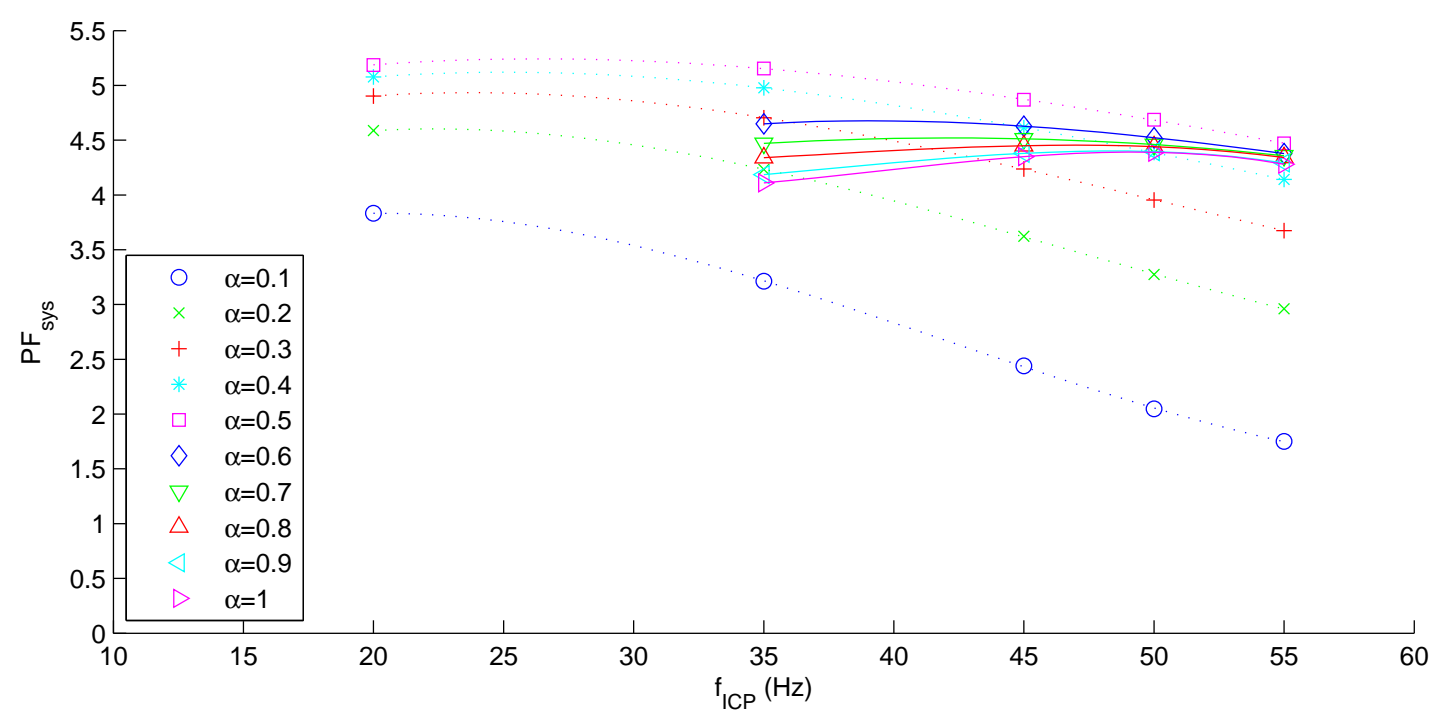

Figure 3.38: $P F_{3}$ as a function of $f_{I C P}$ for optimal $f_{E C P}$ (cooling mode).

optimal values for the internal frequency for each value of the partial load ratio resulting from the methodology described in Section 3.6 (see curve $f_{I C P}=f(\alpha)$ in Fig. 3.32). Differentiating the resulting expressions will finally provide term (a).

Term (b) stands for the variation of the performance factor with the building supply temperature for a given internal frequency. In order to calculate this term, the performance factor is determined for different values of the building supply temperature by means of Eqs. 3.46 and 3.47, which are described in Section 3.6 (see Section 3.6 for more details). This is represented in Fig. 3.39 a.

Then the expressions obtained, which are nearly linear, are differentiated to obtain term (b). In order to solve the partial derivative, the experimental correlations of the heat pump presented in Appendix $\mathrm{A}$ are considered. The result is presented in Fig. 3.39b. Looking at the vertical axis, it can be observed that the analysed partial derivative presents little variation. In order to simplify the control algorithm, an average value of 0.15 is considered for term (b). The possible deviations produced for considering this value $\left( \pm 0.4\right.$ in the value of $\left.\left.\left(\partial P F_{s y s} / \partial T_{S B}\right)\right|_{f_{I C P}}\right)$ have been checked and a slight deviation of $\pm 1 \mathrm{~Hz}$ in the resulting $f_{I C P}$ is produced. Therefore, the simplification is completely valid.

Term (c) stands for the variation of the building supply temperature with the internal frequency. This term is obtained by differentiating Eq.3.58, including the corresponding expression for the effectiveness of the fan coil for cooling mode determined in Appendix B

Considering terms (a), (b) and (c) in Eq. 3.61 and solving it for $f_{I C P}$, the optimal value of the internal frequency is obtained. It should be noticed that the resulting expression 

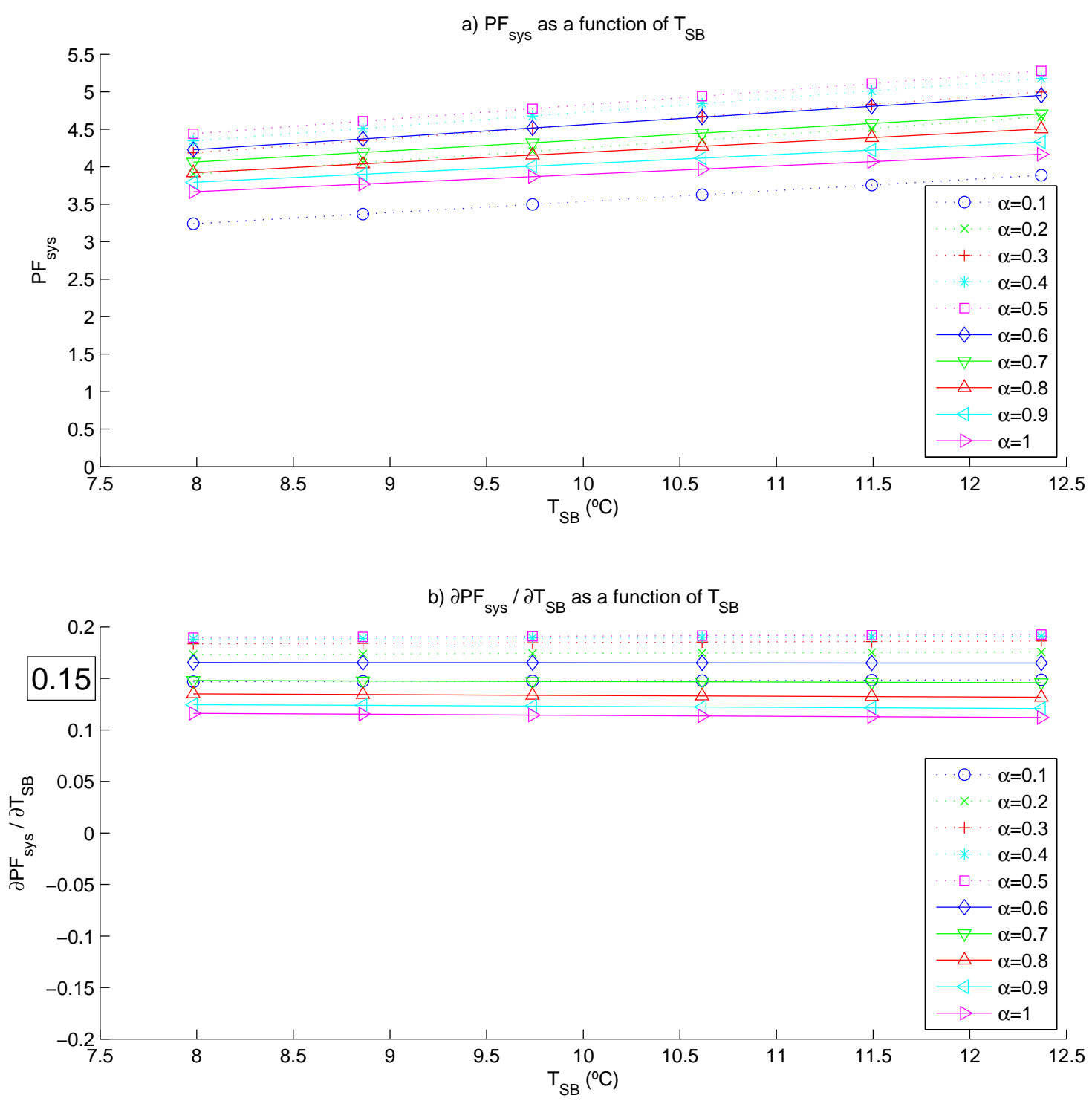

Figure 3.39: (a) $P F_{\text {sys }}$ as a function of $T_{S B}$; and (b) $\partial P F_{s y s} / \partial T_{S B}$ as a function of $T_{S B}$ (both for cooling mode). 
is a 6th order polynomial expression, hence the right root needs to be chosen.

Fig. 3.40 shows the debugging of results for an example in which values of $T_{a m b}=36^{\circ} \mathrm{C}$ for the ambient temperature and $\alpha=0.3$ for the partial load ratio are considered. Fig. 3.40 a-c show the different terms (a), (b) and (c), respectively, represented as a function of the internal frequency for the range of working frequencies, that is to say from 20 $\mathrm{Hz}$ to $55 \mathrm{~Hz}$. As it can be observed in Fig. $3.40 \mathrm{a}, \partial P F_{\text {sys }} / \partial f_{I C P}$ presents an optimal value for the internal frequency at $23.8 \mathrm{~Hz}$ (intersection with the zero line). This value corresponds to the maximum of the curve for $\alpha=0.3$ in Fig. 3.38. In fact, this would be the resulting value for the optimal internal frequency if the in situ methodology for the circulation pumps frequency is applied as described in Section 3.6 .
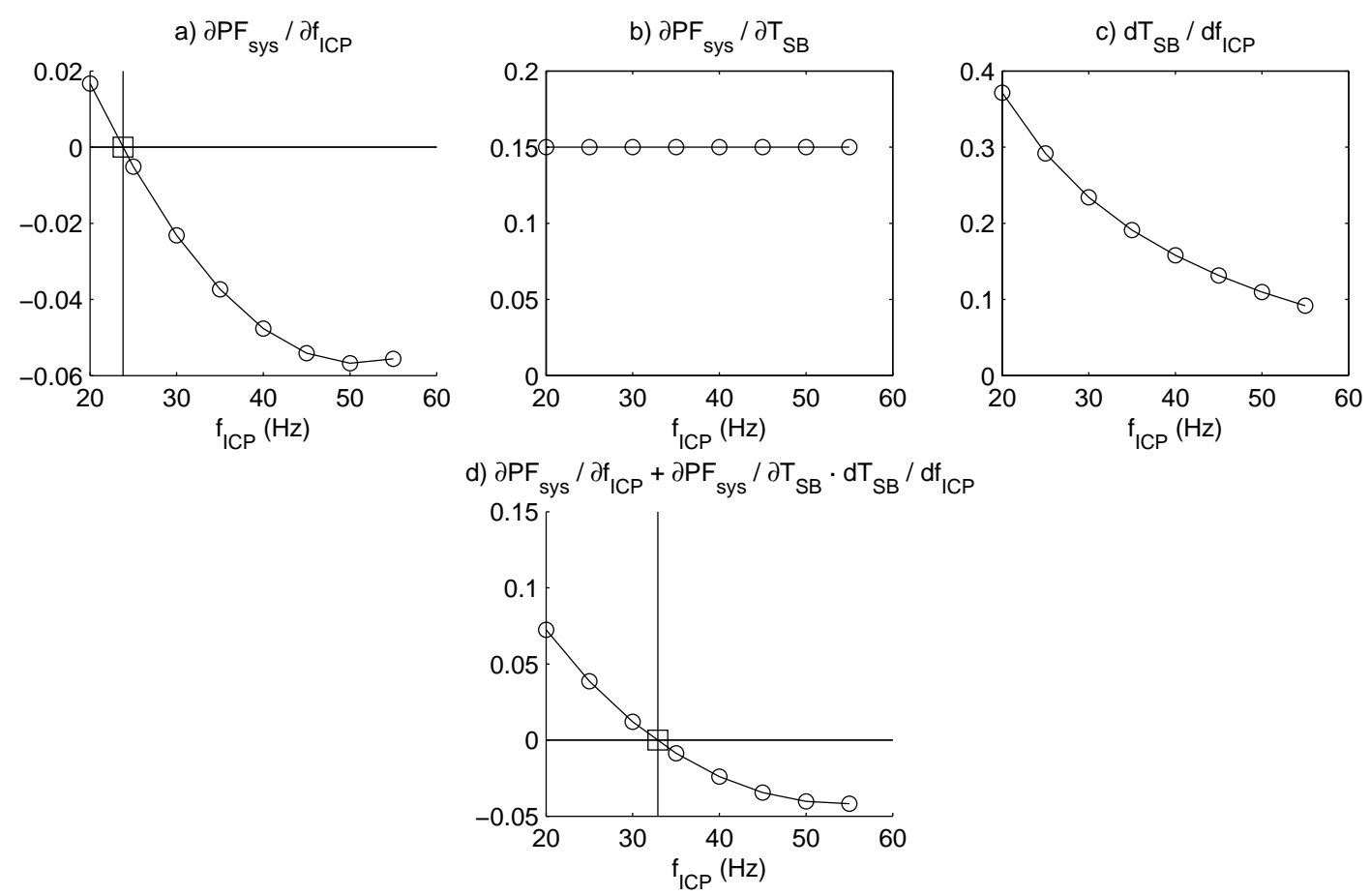

Figure 3.40: Optimal value of $f_{I C P}$ (cooling mode).

However, due to the correction introduced in order to take into account the user comfort, this value of frequency is corrected by the product of terms (b) and (c). Fig. 3.40d shows the representation of Eq. 3.61 as a function of the internal frequency, for the range of working frequencies. As it can be observed, the correction introduced turns the value of $23.8 \mathrm{~Hz}$ taken from Fig. 3.40 into an optimal value for the internal frequency of $33.7 \mathrm{~Hz}$, greater than the former one. Solving Eq. 3.61 as in the example presented, for different values of the partial load ratio $(\alpha=[0.1,0.2,0.3,0.4,0.5,0.6,0.7,0.8,0.9,1])$ and different values of the ambient temperature $\left(T_{a m b}=[24,25,26,27,28,29,30,31\right.$, $32,33,34,35,36,37,38]^{\circ} \mathrm{C}$, Fig. 3.41 can be obtained. It shows the resulting value 
of the optimal internal frequency as a function of the partial load ratio of the system. The points marked with a black square correspond to the optimal frequency as directly calculated from the methodology summarized in Section 3.6. The rest of the points represent the optimal frequency resulting from the new approach for different values of the ambient temperature in the range $24-38^{\circ} \mathrm{C}$.

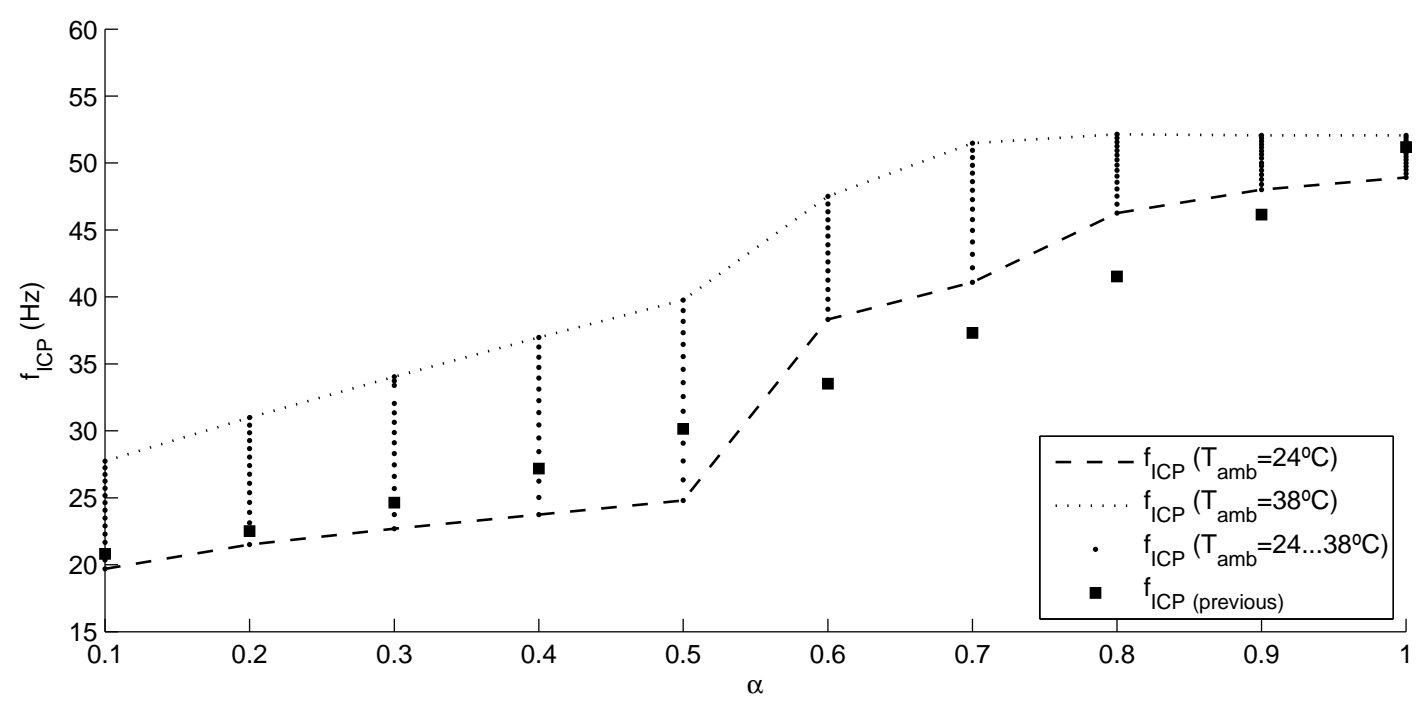

Figure 3.41: Resulting optimal $f_{I C P}$ with the new control compared to the former one (cooling mode).

It can be observed in Fig. 3.41 that the higher the partial load ratio, the higher the resulting internal frequency. This is the same trend found in the former control (black squares). However, as a result of the new control strategy, the internal frequency now depends also on the ambient temperature. As it happens with the load, the higher the ambient temperature the higher the resulting frequency. The effect of the ambient temperature becomes less important for high values of the partial load ratio (when two compressors are running for $\alpha>0.5)$.

It can also be observed that the correction of the frequency introduced in the new control is sometimes negative with respect to the former control (that is to say, the corrected frequency is lower than in the former control). This is because the ambient temperature is low and the load is not too big, so there is no need for higher flow rates that would result in higher fan coil capacity.

Once the optimal value of the internal frequency has been calculated, the next step consists of determining the corresponding value of the building supply temperature so that the user comfort is met.

Replacing the value obtained for the internal frequency in the corresponding correlation of the fan coil effectiveness and the numeric values for the rest of variables $\left(T_{\text {room }}=\right.$ 
$\left.25^{\circ} C, \varepsilon_{F C, \max }=0.838\right)$, Eq. 3.58 provides the value of the building supply temperature. Solving Eq. 3.58 for $T_{S B}$ (2nd order equation), for different values of the partial load ratio $(\alpha=[0.1,0.2,0.3,0.4,0.5,0.6,0.7,0.8,0.9,1])$ and different values of the ambient temperature $\left(T_{a m b}=[24,25,26,27,28,29,30,31,32,33,34,35,36,37,38]^{\circ} \mathrm{C}\right)$, Fig. 3.42 can be obtained.

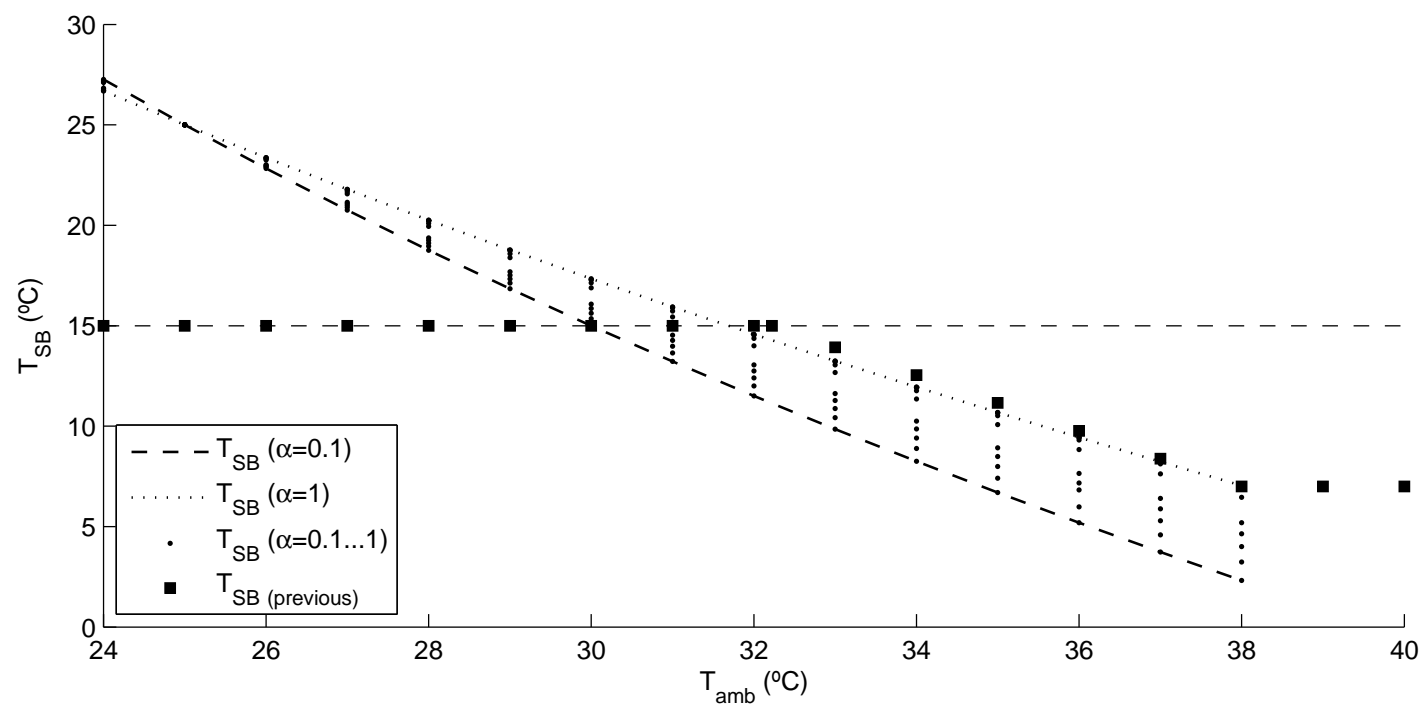

Figure 3.42: Resulting optimal $T_{S B}$ with the new control compared to the former one (cooling mode).

The striped horizontal line at $T_{S B}=15^{\circ} \mathrm{C}$ in Fig. 3.42 stands for the dew temperature in comfort conditions $\left(T_{\text {room }}=25^{\circ} \mathrm{C}, H R=50 \%\right)$. The squares correspond to the values of the building supply temperature calculated by the former algorithm, which are similar to the values obtained by the new algorithm for $\alpha=1$. Finally, the rest of the points represent the resulting $T_{S B}$ calculated by the new control for different values of the partial load ratio in the range 0.1-1. It can be observed that the higher the ambient temperature, the lower the resulting building supply temperature.

It can also be observed that the lower the partial load ratio, the lower the supply building temperature. This makes sense because lower values of the partial load ratio mean lower values of the internal frequency needed according to the optimization algorithm, what means that the building supply temperature has to decrease accordingly in order to keep the fan coil effectiveness and meet the user comfort. This resulting $T_{S B}$ represents the highest possible value to be set in the heat pump in order to achieve user comfort, hence the water should be supplied to the fan coil units at a temperature lower or equal to the calculated $T_{S B}$ values in order to meet the user comfort.

The result of combining Eqs. 3.58 and 3.61 would therefore provide the optimal values of the controlled variables, $f_{I C P}$ and $T_{S B}$. However, they are complex equations and its 
direct use in a control board would complicate the calculations. When implementing an algorithm in a controller, the simpler the better in order to avoid instability problems. That is why, instead of programming these equations, a simpler expression will be used. This expression comes from representing the points from Fig. 3.41 in a 3-dimensional graph. The target expression is a surface that fits all the points, the resulting values of the internal frequency as a function of both the partial load ratio and the ambient temperature $\left(f_{I C P}=f\left(\alpha, T_{a m b}\right)\right)$. Two different fitting surfaces for the different states in which the heat pump can work are produced: one compressor cycling on and off $(n=1)$ or one compressor continuously running and the other one cycling on and off $(n=2)$. These surfaces are presented in Fig. 3.43 . The bold square represents the optimal frequency of $33.7 \mathrm{~Hz}$ for the example of $T_{a m b}=36^{\circ} \mathrm{C}$ for the ambient temperature and $\alpha=0.3$.

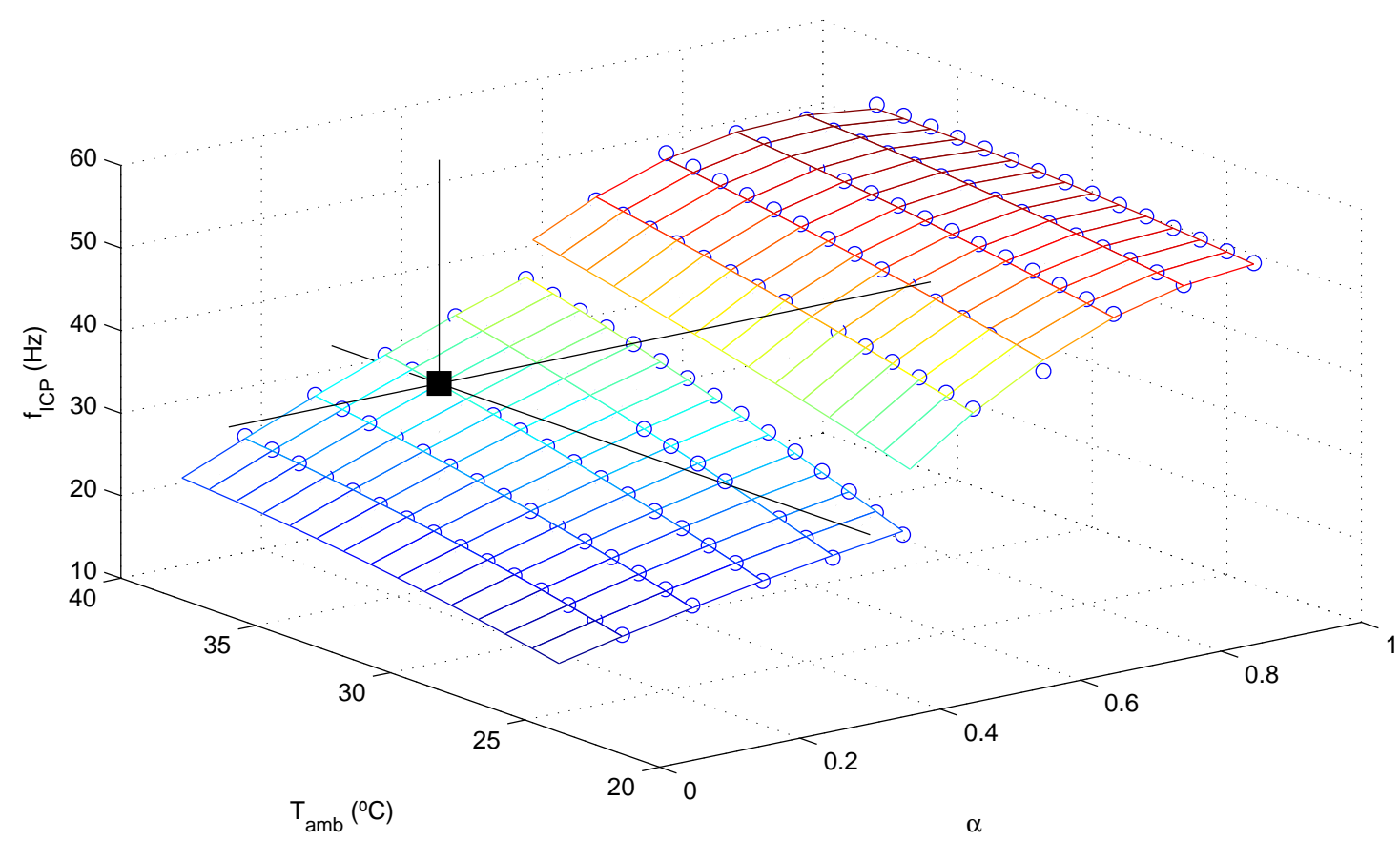

Figure 3.43: Control surfaces for $f_{I C P}$ (cooling mode).

In order to calculate the building supply temperature, the value of the internal frequency resulting from the control surfaces in Fig. 3.43 is considered and Eq. 3.58 is solved for $T_{S B}$ (2nd order equation, the negative root is the right solution). However, there are both an upper and a lower limit in the setpoint that should not be overpassed. The upper limit is $15^{\circ} \mathrm{C}$, the dew temperature. The water cannot be supplied to the building at a temperature higher than the dew temperature, otherwise the dehumidification in the rooms would not be possible. The lower limit is $7^{\circ} \mathrm{C}$. This limit is set in order to avoid freezing problems in the heat pump. It should be noticed that a value of $7^{\circ} \mathrm{C}$ is used, instead of $10^{\circ} \mathrm{C}$, as this experimental study was carried out after GROUND-MED project was finished and hence the minimum standard supply temperature recommended 
by the heat pump manufacturer was considered for standard operating conditions.

Looking at Fig. 3.42, it can be observed that the algorithm calculates values of $T_{S B}$ outside of these limits. As far as the upper limit is concerned, there is no problem in setting a temperature lower than the one calculated. The energy savings will not be so important, but the user comfort will still be met. However, if the algorithm calculates a value of $T_{S B}$ lower than $7^{\circ} \mathrm{C}$, but the setpoint is set to $7^{\circ} \mathrm{C}$, the user comfort will be unlikely to be met. That is the reason why, in case that this happens, the internal frequency should be recalculated by means of Eq. 3.58. Solving Eq. 3.61 for $f_{I C P}$ and considering a $T_{S B}=7^{\circ} \mathrm{C}$, will provide the corrected value of the frequency (higher than the previous) that will allow the system to meet the user comfort. Fig. 3.44 shows a flow diagram of the optimized control implemented on the control board of the system.

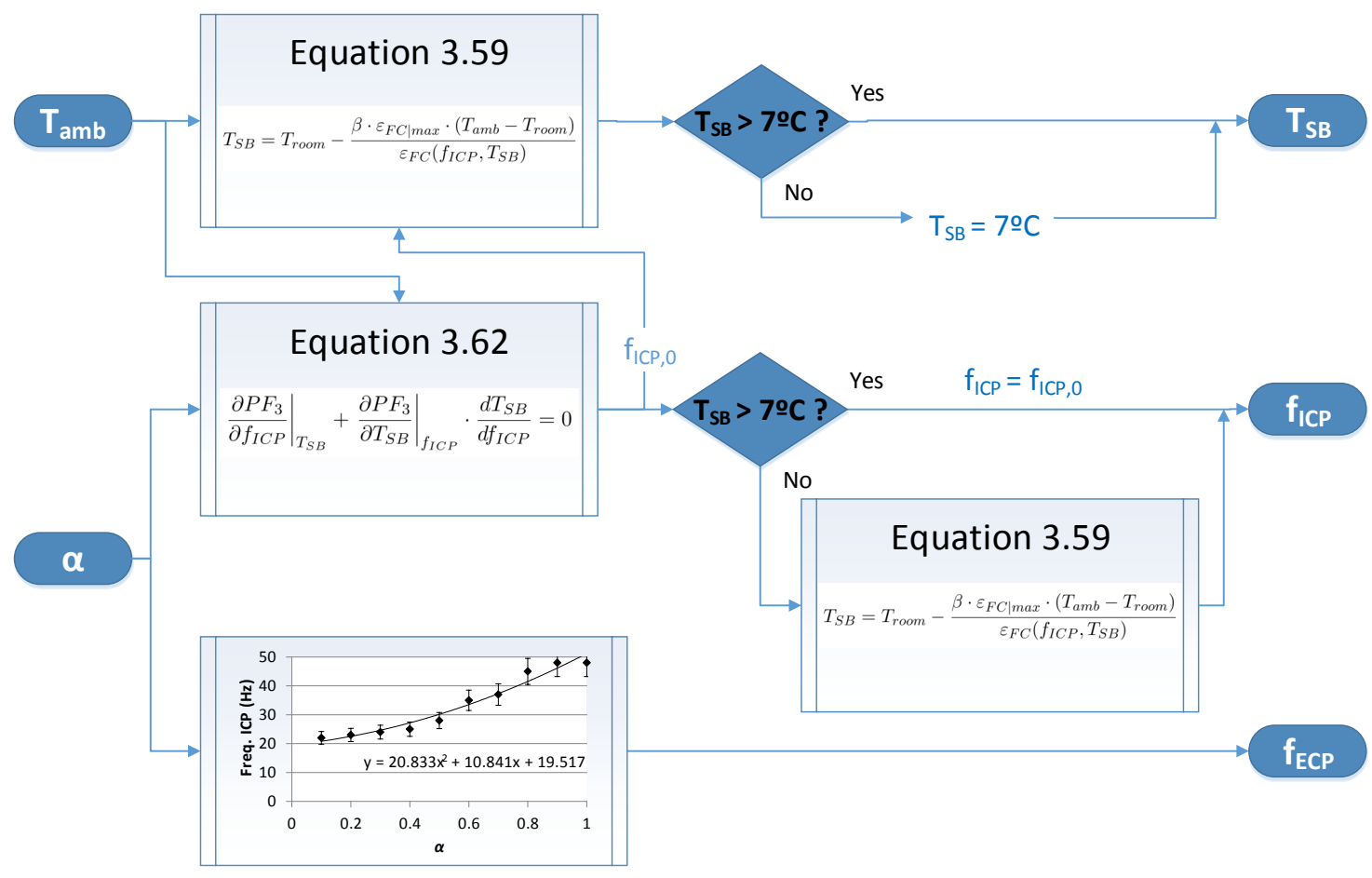

Figure 3.44: Flow diagram of the new optimized control (cooling mode).

Comparing the flow diagrams in Figs. 3.32 and 3.44 , the differences between the former and the new control are clearly observed. On the one hand, the calculation of the external frequency is not modified with respect to the former control. The original equation coming from the original performance factor maps obtained in Section 3.6 is kept. On the other hand, the calculations of $f_{I C P}$ and $T_{S B}$ are coupled, since both of them affect the effectiveness of the fan coils. First, the value of the internal frequency $\left(f_{I C P}\right)$ is determined as a function the ambient temperature $\left(T_{a m b}\right)$ and the partial load 
$\operatorname{ratio}(\alpha)$ by means of Eq. 3.61 . Then, using this value of $f_{I C P}$, the value of the building supply temperature $\left(T_{S B}\right)$ is determined, also considering the value of $T_{a m b}$, by means of Eq. 3.58 Finally, if the resulting value of $T_{S B}$ is lower than $7^{\circ} \mathrm{C}$ (limit for heat pump freezing problems), $T_{S B}$ is set to $7^{\circ} \mathrm{C}$ and $f_{I C P}$ is recalculated by means of Eq. 3.58 . The corrected value of $f_{I C P}$ will be higher in order to balance out the effect of setting a setpoint temperature lower than that calculated by the algorithm.

\section{Upgrade for heating mode}

In the case of heating mode, the first approach to the energy optimization described in Section 3.7.1 worked adequately and the user comfort was met even when the weather conditions were extreme during winter. It should be said however that the winter in Valencia is rather mild and the ambient temperature rarely goes below $5^{\circ} \mathrm{C}$.

Nevertheless, a new integrated control was also developed for heating mode following the guidelines presented in the previous section for cooling mode in order to be consistent, and to make the system work with the same control algorithm throughout the year.

Going back to de beginning of this section, Eq. 3.58 provided the value of the building supply temperature $\left(T_{S B}\right)$ as a function of the room temperature $\left(T_{\text {room }}\right)$, the ambient temperature $\left(T_{a m b}\right)$, the parameter $\beta$, the maximum effectiveness of the fan coil $\left(\varepsilon_{F C, \max }\right)$ and the correlation of the fan coil effectiveness in terms of the internal frequency and the building supply temperature $\left(\varepsilon_{F C}\left(f_{I C P}, T_{S B}\right)\right)$. The equation for heating mode is very similar, but with the followings considerations:

- The signs of the addition and subtraction will change.

- The value of parameter $\beta$ will be as presented in Eq. 3.38 in Section 3.5

- A different correlation will be used for the fan coil effectiveness, obtained from data in heating mode, which is also described in Appendix B.

Further details on the differences with respect to cooling mode can be found on the explanation for the temperature compensation strategy in heating mode in Section 3.5 Taking into account all the previous considerations Eq. 3.62 is obtained.

$$
T_{S B}=T_{\text {room }}+\frac{\beta \cdot \varepsilon_{F C, \text { max }} \cdot\left(T_{\text {room }}-T_{\text {amb }}\right)}{\varepsilon_{F C}\left(f_{I C P}, T_{S B}\right)}
$$

On the other hand, each one of the terms in Eq. 3.61 will be different, recalculated for the particular case of heating mode.

As far as term (a) is concerned, the PF maps provided in Section 3.6 corresponding to heating mode are employed in this case. As done earlier, considering the optimal values of the external circulation pump frequency $\left(f_{E C P}\right)$ for each value of $\alpha$ from 0.1 to 1 , Fig. 3.45 shows, for heating mode, the system performance factor as a function of the internal frequency. 


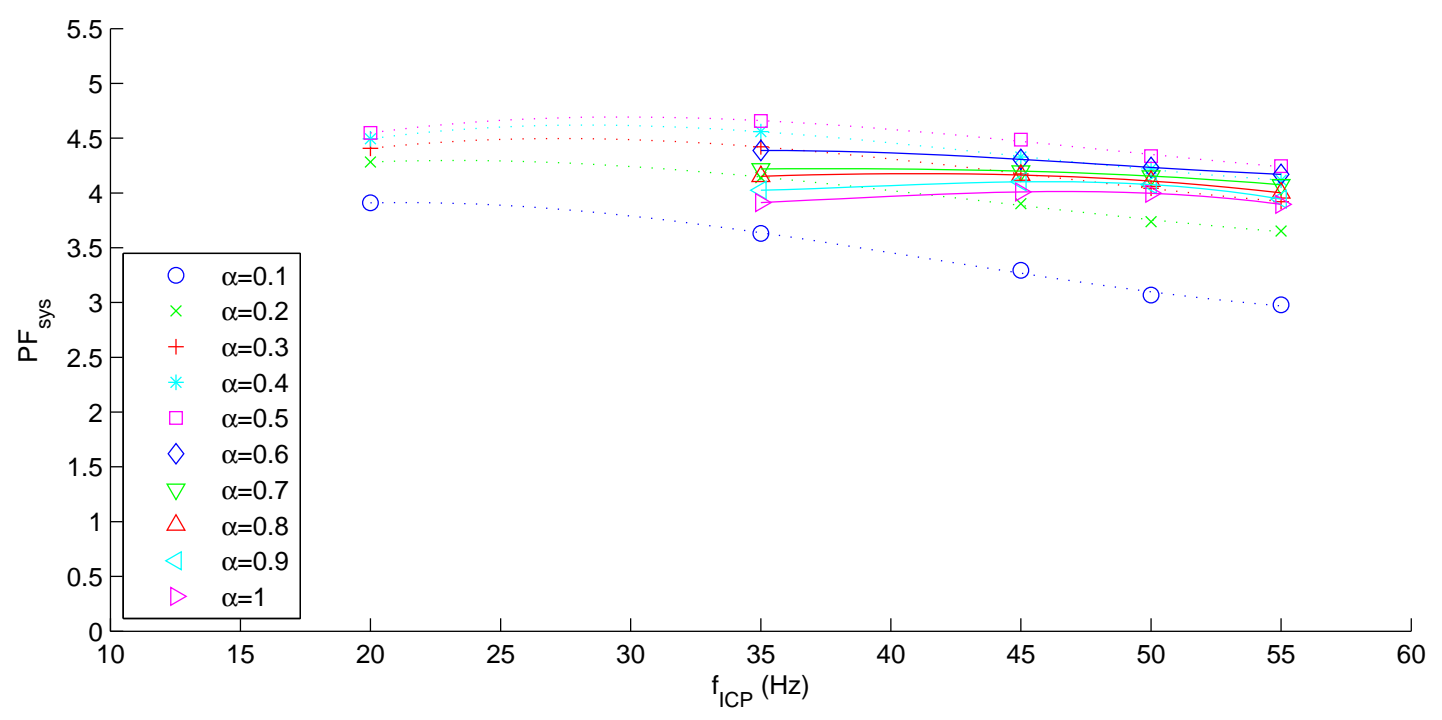

Figure 3.45: $P F_{3}$ as a function of $f_{I C P}$ for optimal $f_{E C P}$ (heating mode).

The curves in Fig. 3.45, which show the variation of $P F_{\text {sys }}$ with the internal frequency for heating mode, have been adjusted to cubic equations. The maximums in the curves turn out to be the optimal values for the internal frequency for each value of the partial load ratio resulting from the methodology described in Section 3.6. Differentiating the resulting expressions will finally provide term (a).

Regarding term (b), as done earlier for cooling mode, the performance factor is determined for different values of the building supply temperature by means of Eqs. 3.46 and 3.47 (which are described in Section 3.6), but taking into account that heating mode is considered in this case. This is represented in Fig. 3.46a.

Then the expressions obtained, which are nearly linear, are differentiated to obtain term (b). In order to solve the partial derivative, the experimental correlations of the heat pump for heating mode presented in Appendix A are considered. The result is presented in Fig. 3.46b. Looking at the vertical axis, it can be observed that, as it happened for cooling mode, the analysed partial derivative presents little variation. In order to simplify the control algorithm, an average value of -0.12 is considered for term (b). The possible deviations produced for considering this value $\left( \pm 0.3\right.$ in the value of $\left.\left.\left(\partial P F_{\text {sys }} / \partial T_{S B}\right)\right|_{f_{I C P}}\right)$ have been checked and a slight deviation of $\pm 1 \mathrm{~Hz}$ in the resulting $f_{I C P}$ is produced. Therefore, the simplification is completely valid. It should be noticed the value of term (b) in heating mode is negative (negative variation), as the performance factor increases when the supply temperature increases.

Finally, term (c), which stands for the variation of the building supply temperature with the internal frequency, is obtained by differentiating Eq.3.62, including the corresponding expression for the effectiveness of the fan coil for heating mode determined in Appendix 

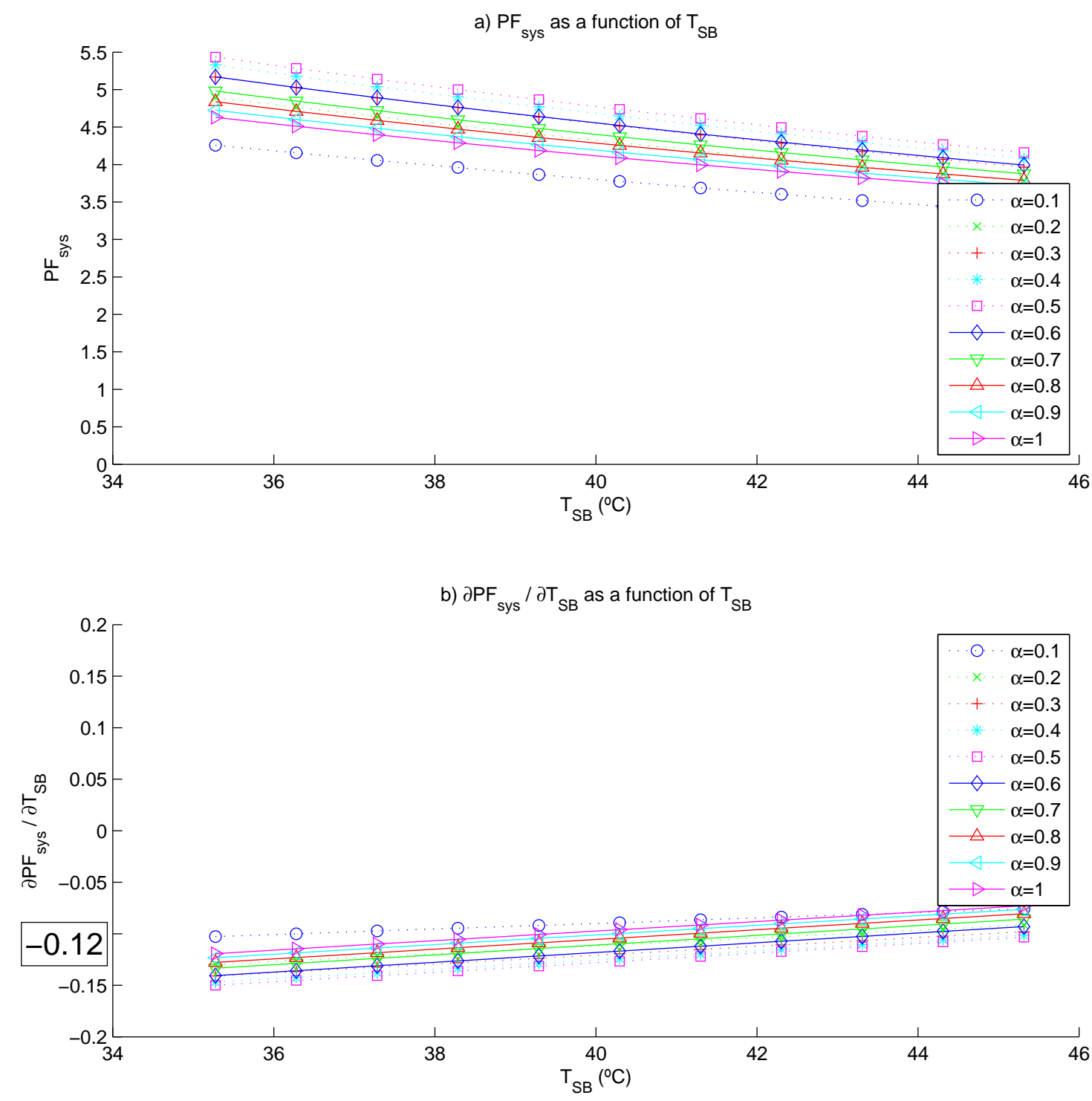

Figure 3.46: (a) $P F_{\text {sys }}$ as a function of $T_{S B}$; and (b) $\partial P F_{s y s} / \partial T_{S B}$ as a function of $T_{S B}$ (both for heating mode). 
B

Considering terms (a), (b) and (c) all together in Eq. 3.61 and solving it for $f_{I C P}$, the optimal value of the internal frequency for the case of heating mode is obtained. Once more, the right root needs to be chosen from the resulting 6th order polynomial expression.

Fig. 3.47 shows the debugging of results for an example in which values of $T_{a m b}=6^{\circ} \mathrm{C}$ for the ambient temperature and $\alpha=0.4$ for the partial load ratio are considered. Fig. 3.47 a-c show the different terms (a), (b) and (c), respectively, represented as a function of the internal frequency for the range of working frequencies, that is to say from 20 $\mathrm{Hz}$ to $55 \mathrm{~Hz}$. As it can be observed in Fig. $3.47 \mathrm{a}, \partial P F_{\text {sys }} / \partial f_{I C P}$ presents an optimal value for the internal frequency at $27.7 \mathrm{~Hz}$ (intersection with the zero line). This value corresponds to the maximum of the curve for $\alpha=0.4$ in Fig. 3.45. In fact, this would be the resulting value for the optimal internal frequency if the in situ methodology for the circulation pumps frequency is applied as described in Section 3.6
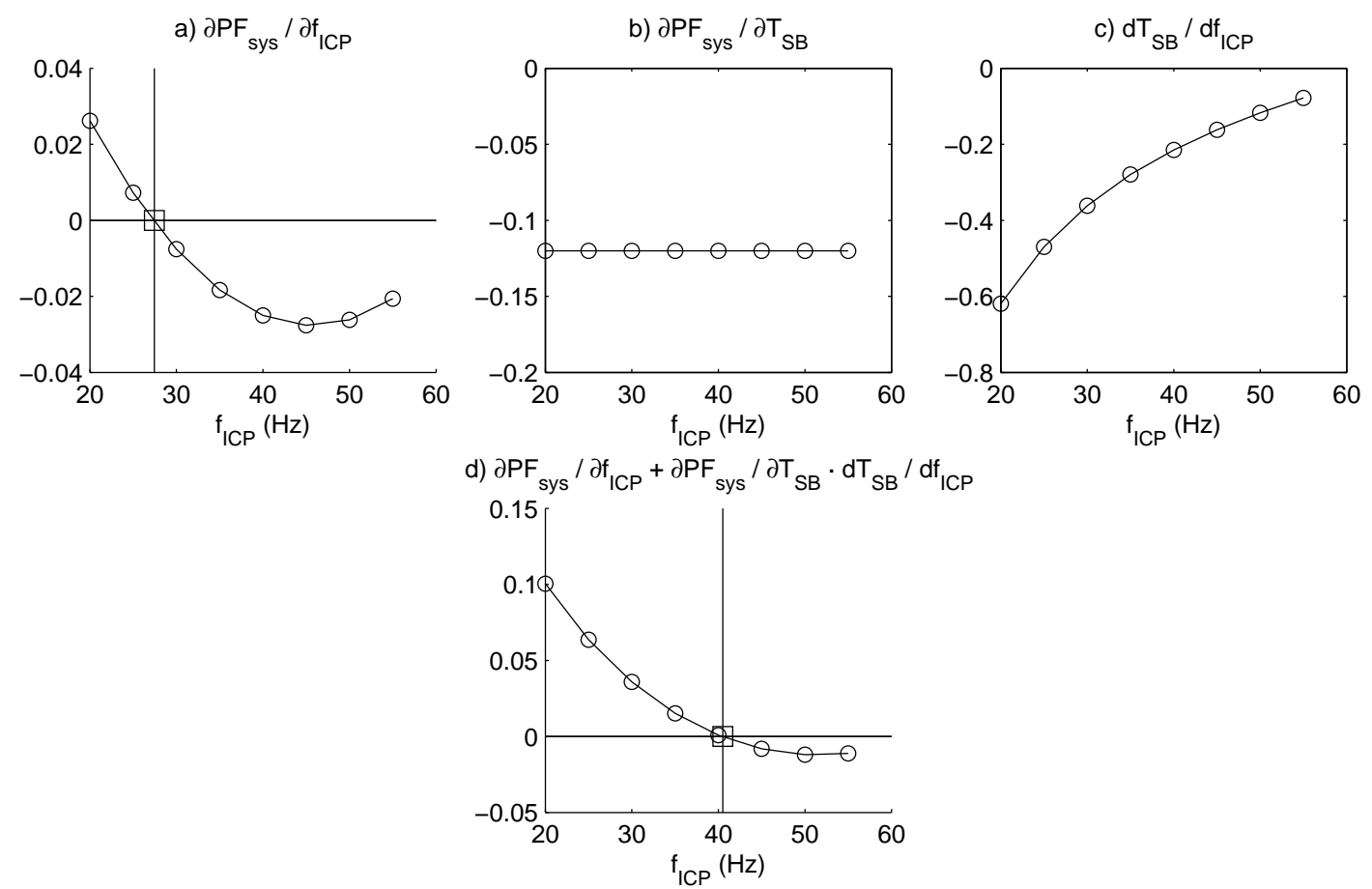

Figure 3.47: Optimal value of $f_{I C P}$ (heating mode).

However, due to the correction introduced in order to take into account the user comfort, this value of frequency is corrected by the product of terms (b) and (c). Fig. 3.47d shows the representation of Eq. 3.61 as a function of the internal frequency, for the range of working frequencies. As it can be observed, the correction introduced turns the value of $27.7 \mathrm{~Hz}$ taken from Fig. $3.47 \mathrm{a}$ into an optimal value for the internal frequency of 
$40.5 \mathrm{~Hz}$, greater than the former one. Solving Eq. 3.61 as in the example presented, for different values of the partial load ratio $(\alpha=[0.1,0.2,0.3,0.4,0.5,0.6,0.7,0.8,0.9$, 1]) and different values of the ambient temperature $\left(T_{a m b}=[4,5,6,7,8,9,10,11,12\right.$, $13,14,15,16,17,18]^{\circ} \mathrm{C}$, Fig. 3.48 can be obtained. It shows the resulting value of the optimal internal frequency as a function of the partial load ratio of the system for the case of heating mode. The points marked with a black square correspond to the optimal frequency as directly calculated from the methodology summarized in Section 3.6. The rest of the points represent the optimal frequency resulting from the new approach for different values of the ambient temperature in the range $4-18{ }^{\circ} \mathrm{C}$.

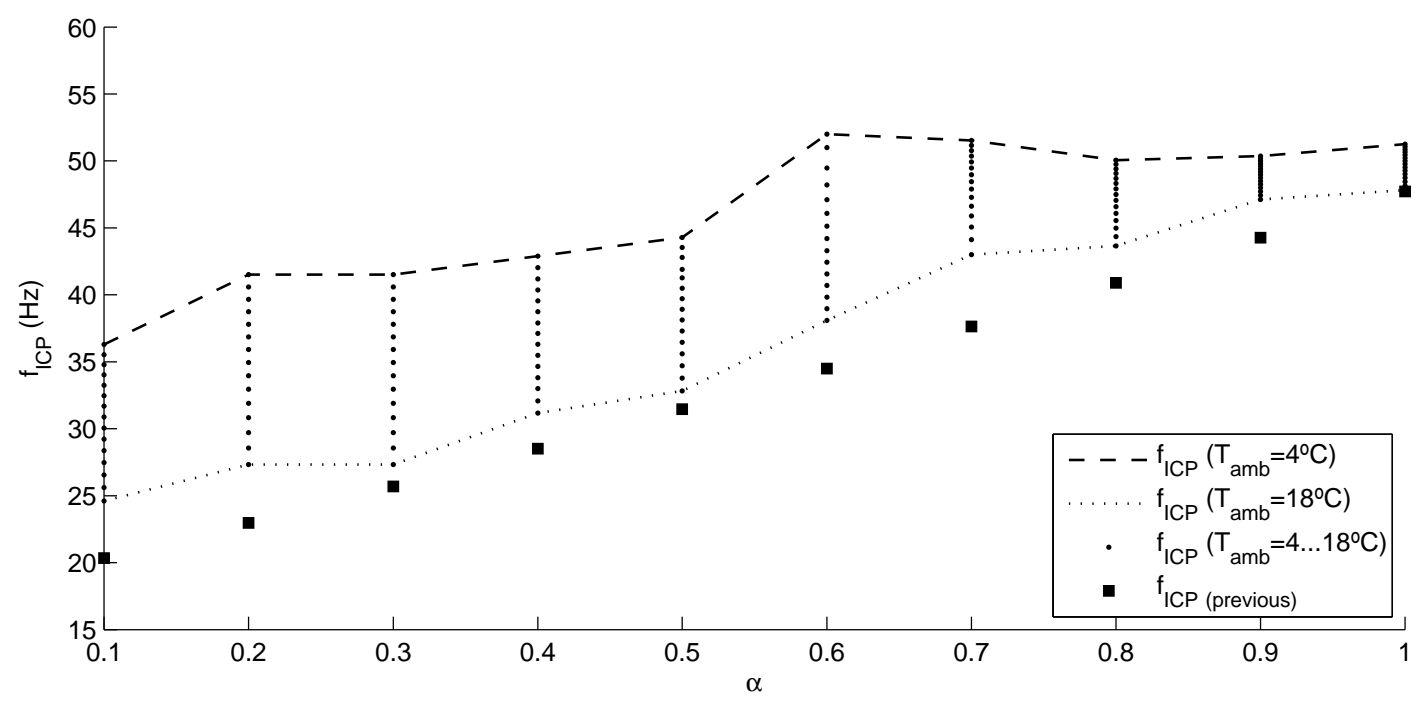

Figure 3.48: Resulting optimal $f_{I C P}$ with the new control compared to the former one (heating mode).

It can be observed in Fig. 3.48 that the higher the partial load ratio, the higher the resulting internal frequency, as it happened in the case of cooling mode. This is the same trend found in the former control (black squares). However, as a result of the new control strategy, the internal frequency now depends also on the ambient temperature. As it happens with the load, the higher the ambient temperature the lower the resulting frequency.

On the other hand, it can also be observed that the correction of the frequency introduced in the new control is always positive with respect to the former control (that is to say, the corrected frequency is always higher than in the former control). This differs from the case of cooling mode, where for low partial load ratios the correction of the frequency was negative.

Once the optimal value of the internal frequency has been calculated, the next step consists of determining the corresponding value of the building supply temperature. 
Replacing the value obtained for the internal frequency in the corresponding correlation of the fan coil effectiveness and the numeric values for the rest of variables $\left(T_{\text {room }}=21^{\circ} C, \varepsilon_{F C, \max }=0.723\right)$, Eq. 3.62 provides the value of the building supply temperature. Solving Eq. 3.62 for $T_{S B}$ (2nd order equation), for different values of the partial load ratio $(\alpha=[0.1,0.2,0.3,0.4,0.5,0.6,0.7,0.8,0.9,1])$ and different values of the ambient temperature $\left(T_{a m b}=[4,5,6,7,8,9,10,11,12,13,14,15,16,17\right.$, $18]^{\circ} \mathrm{C}$ ), Fig. 3.49 can be obtained. The squares correspond to the values of the building supply temperature calculated by the former algorithm, which are similar to the values obtained by the new algorithm for $\alpha=1$. The rest of the points represent the resulting $T_{S B}$ calculated by the new control for different values of the partial load ratio in the range 0.1-1. It can be observed that the higher the ambient temperature, the lower the resulting building supply temperature.

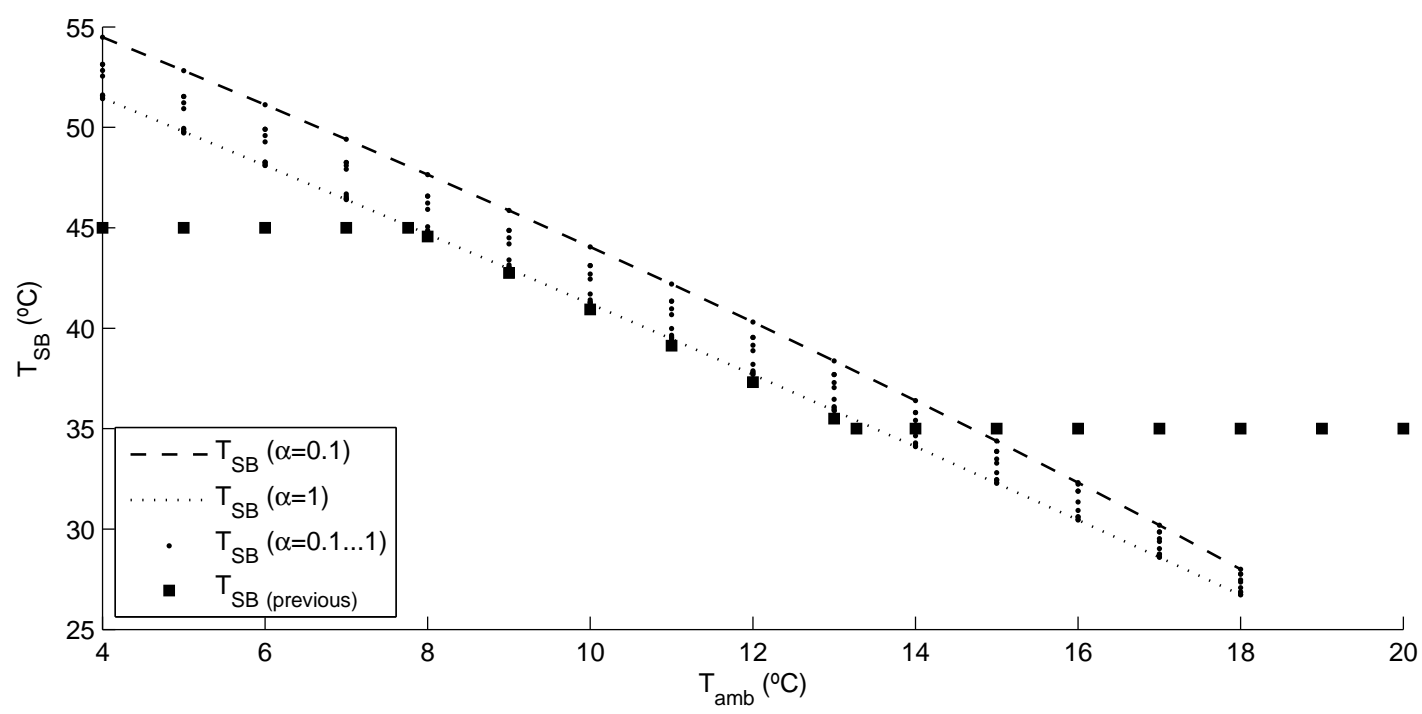

Figure 3.49: Resulting optimal $T_{S B}$ with the new control compared to the former one (heating mode).

It can also be observed in Fig. 3.49 that the lower the partial load ratio, the higher the supply building temperature. This makes sense because lower values of the partial load ratio mean lower values of the internal frequency needed according to the optimization algorithm, what means that the building supply temperature has to increase accordingly in order to keep the fan coil effectiveness and meet the user comfort. This resulting $T_{S B}$ represents the highest possible value to be set in the heat pump in order to achieve user comfort, hence the water should be supplied to the fan coil units at a temperature lower or equal to the calculated $T_{S B}$ values in order to meet the user comfort.

The result of combining Eqs. 3.61 and 3.62 would therefore provide the optimal values of the controlled variables, $f_{I C P}$ and $T_{S B}$. However, as done earlier for cooling mode, a simple expression needs to be found in order to simplify the programming of the 
control board. This expression comes from representing the points from Fig. 3.48 in a 3-dimensional graph. As done for cooling mode, two different fitting surfaces for the different states in which the heat pump can work are produced $(n=1$ and $n=2)$. These surfaces are presented in Fig. 3.50. The bold square represents the optimal frequency of $40.5 \mathrm{~Hz}$ for the example of $T_{a m b}=6^{\circ} \mathrm{C}$ for the ambient temperature and $\alpha=0.4$.

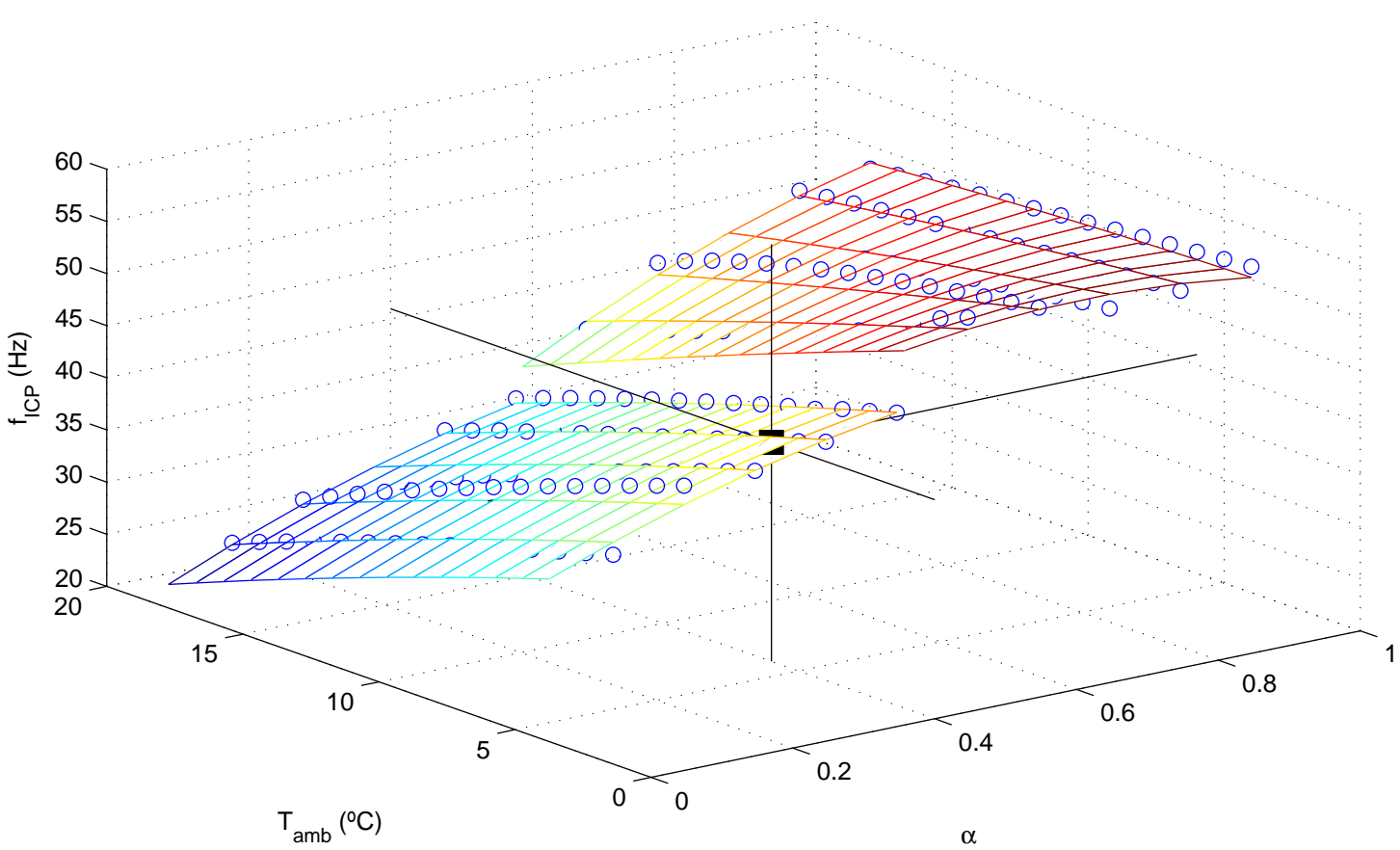

Figure 3.50: Control surfaces for $f_{I C P}$ (heating mode).

In order to calculate the building supply temperature, the value of the internal frequency resulting from the control surfaces in Fig. 3.50 is considered and Eq. 3.62 is solved for $T_{S B}$ (2nd order equation, the negative root is the right solution, as in cooling mode). However, there are both an upper and a lower limit in the setpoint that should not be overpassed. The upper limit is $45^{\circ} \mathrm{C}$. There is no need to supply the water to the building at a temperature higher than $45^{\circ} \mathrm{C}$, it would not mean any improvement in the user comfort but it would mean higher energy consumption. The lower limit is $35^{\circ} \mathrm{C}$. It does not make sense to supply the water at a temperature lower than $35^{\circ} \mathrm{C}$, as it would be better to turn off the heat pump instead.

Looking at Fig. 3.49, it can be observed that the algorithm calculates values of $T_{S B}$ outside of these limits. As far as the lower limit is concerned, there is no problem in setting a temperature higher than the one calculated. The energy savings will not be so important, but the user comfort will still be met. However, if the algorithm calculates a value of $T_{S B}$ higher than $45^{\circ} \mathrm{C}$ (which is unlikely to happen considered the mild winters in Valencia), but the setpoint is set to $45^{\circ} \mathrm{C}$, the user comfort might not be met. That is 
the reason why, in case that this happens, the internal frequency should be recalculated by means of Eq. 3.62 Solving Eq. 3.62 for $f_{I C P}$ and considering a $T_{S B}=45^{\circ} \mathrm{C}$, will provide the corrected value of the frequency (higher than the previous) that will allow the system to meet the user comfort. Fig. 3.51 shows a flow diagram of the optimized control implemented on the control board of the system for the case of heating mode.

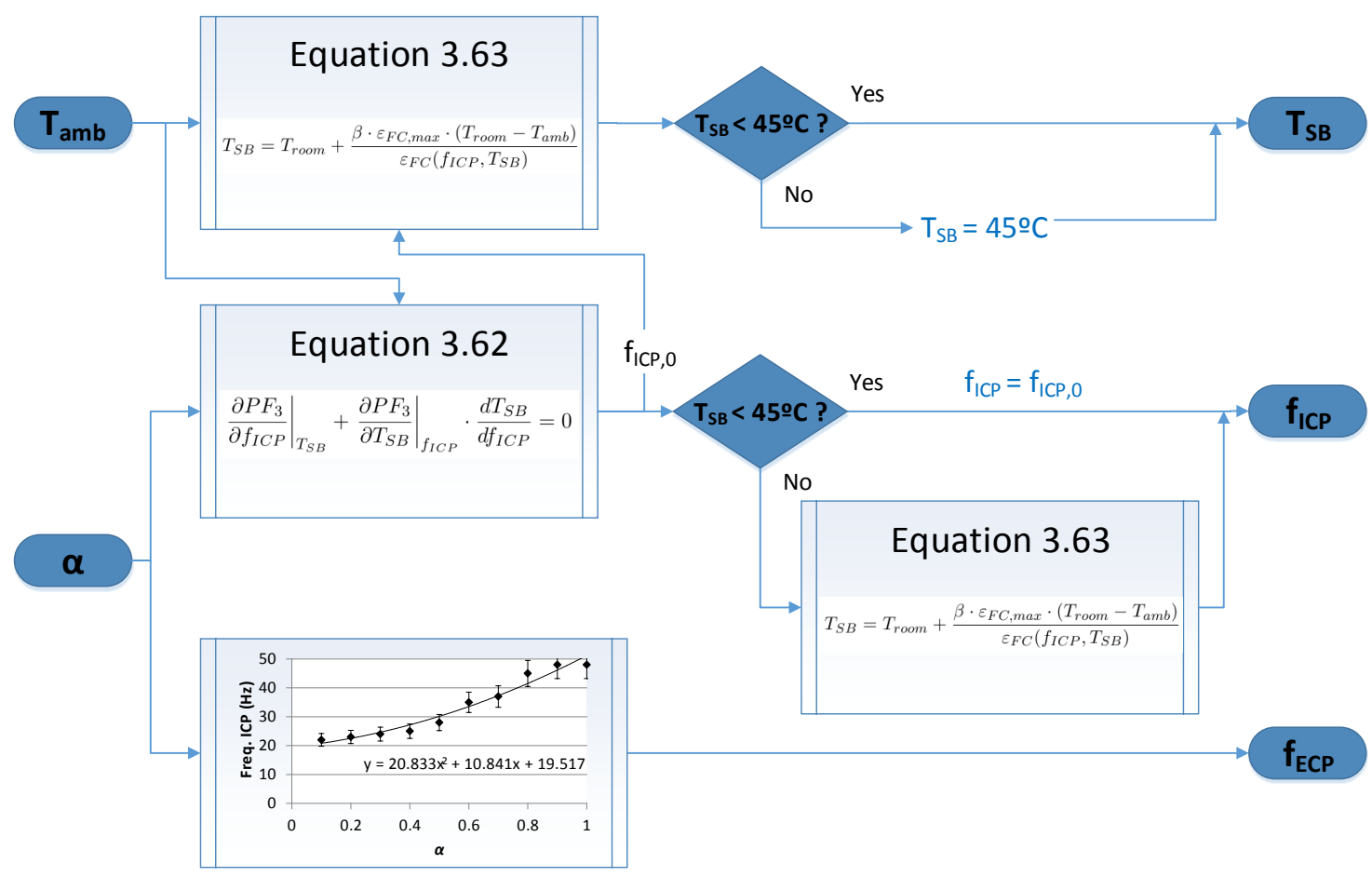

Figure 3.51: Flow diagram of the new optimized control (heating mode).

As it can be observed in Fig. 3.51, the flow digram of the new optimized control for heating mode presents the same structure than for cooling mode (see Fig. 3.44). In fact, they have the same structure. The main difference lies in the equation used for the calculation of the building supply temperature, which is Eq. 3.62 for heating mode, instead of Eq. 3.58. The other difference is the temperature limit for $T_{S B}$, which is $45^{\circ} \mathrm{C}$, instead of $7^{\circ} \mathrm{C}$.

\subsubsection{Results for upgrade to ensure user comfort}

Fig. 3.52 depicts, for a typical cooling day, how the new optimized control works. It shows the evolution with time of some variables of the system for a single day operation in cooling mode, including the controlled variables. The installation does not run continuously, but stops during the night. The period represented in Fig. 3.52 corresponds 
to $13 \mathrm{~h}$, which is the time that the installation works every day ( 7 a.m to 8 p.m.). As mentioned in Section 2.2.5, the daily time of operation of the system from January 2013 onwards is 13 hours, instead of 15 hours.

Fig. 3.52 shows the heat pump power consumption $\left(W_{\text {comp }}\right)$ on the secondary axis and the evolution of several temperatures on the primary axis: the building supply temperature calculated by the algorithm $\left(T_{S B}\right)$, the actual experimental building supply temperature $\left(T_{\text {tank }}\right)$ and the ambient temperature $\left(T_{a m b}\right) . T_{a m b, a v g}$ is the average value of the ambient temperature for the 5 min previous to the recalculation of $\alpha$. This average temperature is used in the equations instead of the instantaneous value of the ambient temperature in order to take into account the temperature variation during the cycle. This value will better represent the ambient conditions, and not just an instantaneous value that can be quite different from the average.

As it can be observed, the actual tank temperature $\left(T_{\text {tank }}\right)$ tracks the calculated building supply temperature $\left(T_{S B}\right)$, which coincides with the setpoint of the heat pump in the range of setpoint temperatures $\left(7-15^{\circ} \mathrm{C}\right)$. When the algorithm calculates a building supply temperature greater than $15^{\circ} \mathrm{C}$, the setpoint of the heat pump is set to $15^{\circ} \mathrm{C}$ due to the limit for dehumidification explained in Fig. 3.42. This can be observed at the beginning of the morning and in the afternoon: while the calculated $T_{S B}$ is greater than $15^{\circ} \mathrm{C}$, the actual tank temperature $\left(T_{\text {tank }}\right)$ cycles around $15^{\circ} \mathrm{C}$.

It can also be observed how $T_{S B}$ and $T_{a m b}$ are inversely proportional. In the morning, when the ambient temperature is lower, a higher setpoint is set in order to supply warmer water to the building thus saving energy. By midday, as the outdoor temperature gets hotter, the water is supplied at a lower temperature so that the thermal demand is met. The frequencies are higher in this period as well (see Fig. $3.52 \mathrm{~b}$ ). Finally, in the evening, as the sun sets and the ambient temperature decreases, and so does the thermal load since some of the users go back home, the algorithm calculates a higher $T_{S B}$ again in order to save energy.

On the other hand, Fig. $3.52 \mathrm{~b}$ shows, from top to bottom, the variation of the pumps frequencies $\left(f_{I C P}\right.$ and $\left.f_{E C P}\right)$ as a function of the partial load ratio $(\alpha)$, represented on the secondary axis on the right hand side. It can be observed how the variables are directly proportional: the higher the partial load ratio, the higher the frequency set in the inverters. It can be observed that the values of frequency are only modified when the partial load ratio is recalculated at the end of each characteristic cycle, that is to say, in the moment when the compressor switches on again. The cycles can be followed looking at the compressor consumption $\left(W_{\text {comp }}\right)$ in Fig. 3.52 . This also applies for the calculation of the building supply temperature explained earlier $\left(T_{S B}\right)$.

With regard to heating mode, results for one typical heating day are presented in Fig. 3.53. The structure of the figure is the same as for cooling mode. Fig. 3.53 a depicts the power consumption of the compressor and the system temperatures, whereas Fig. 3.53b shows the partial load ratio and the circulation pumps frequencies. 
(a)

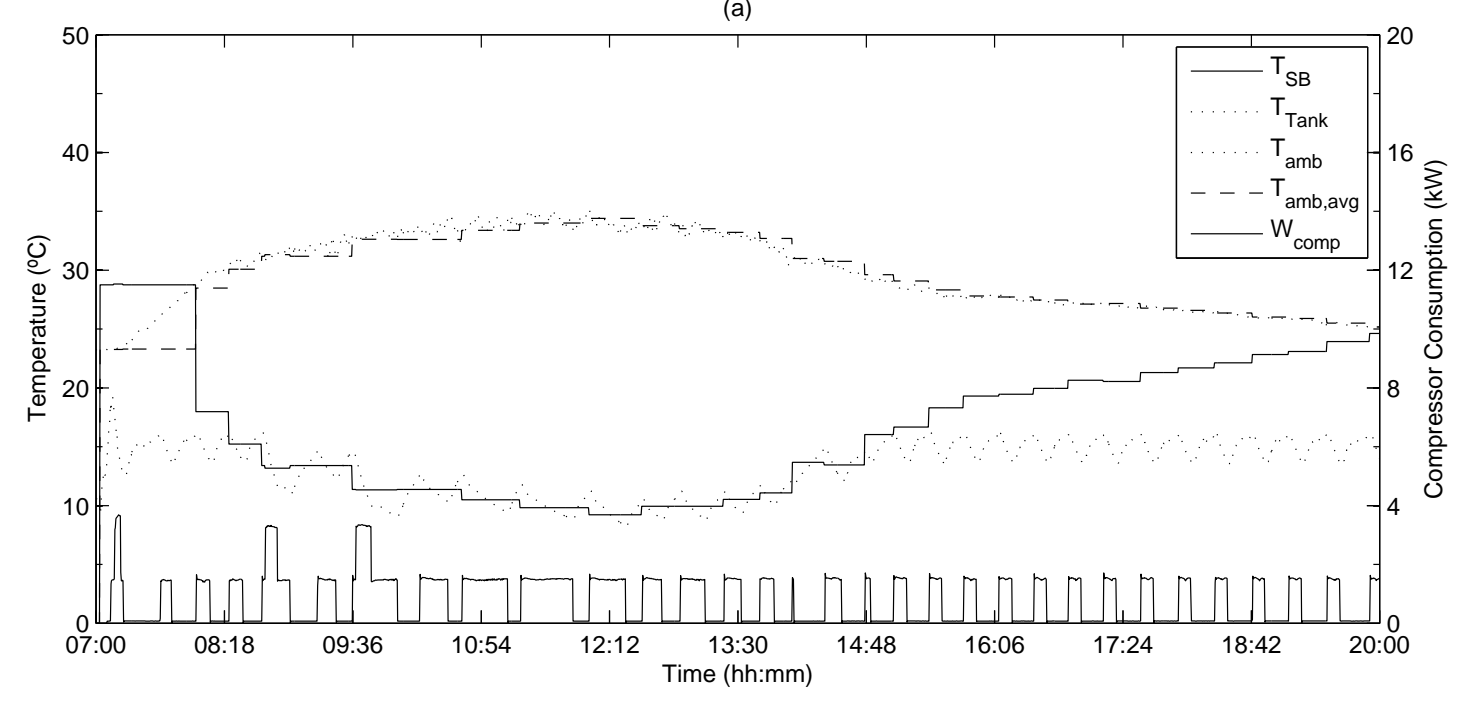

(b)

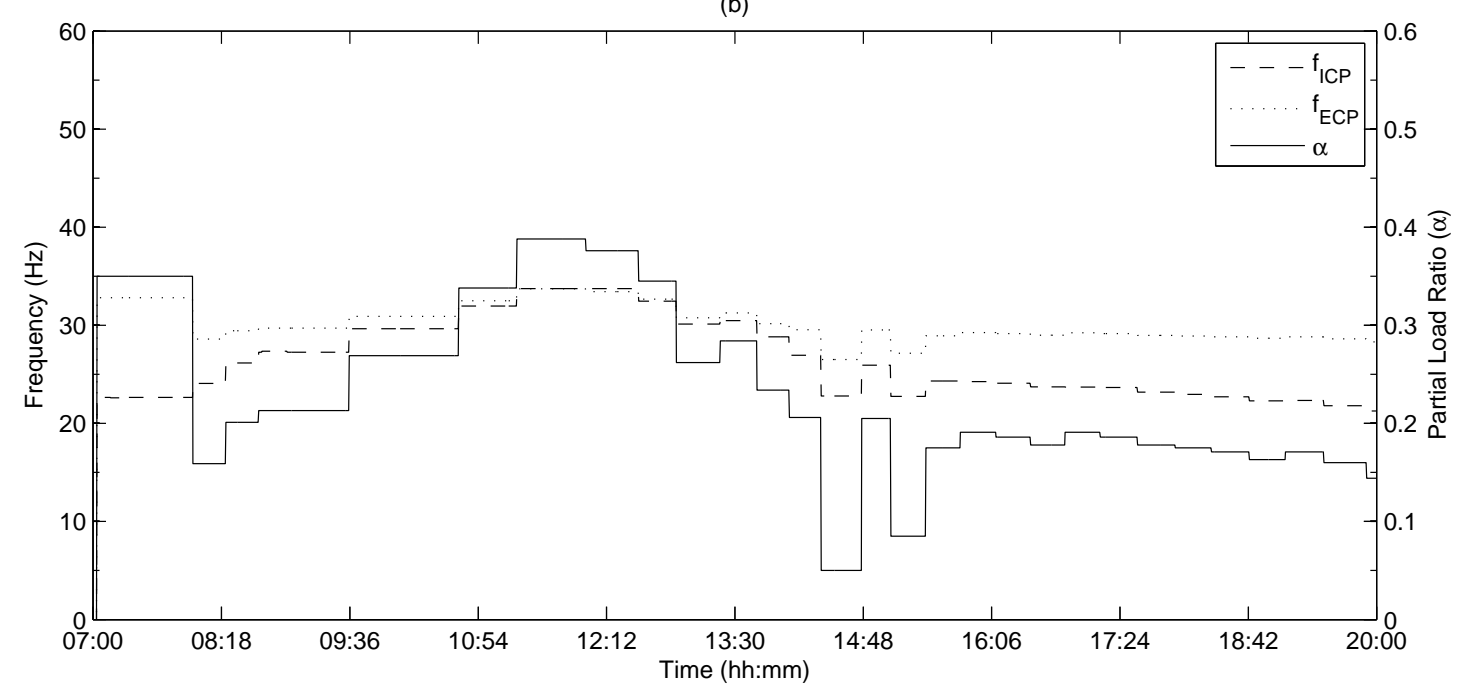

Figure 3.52: Experimental results of the upgraded integrated control (cooling mode). 
(a)

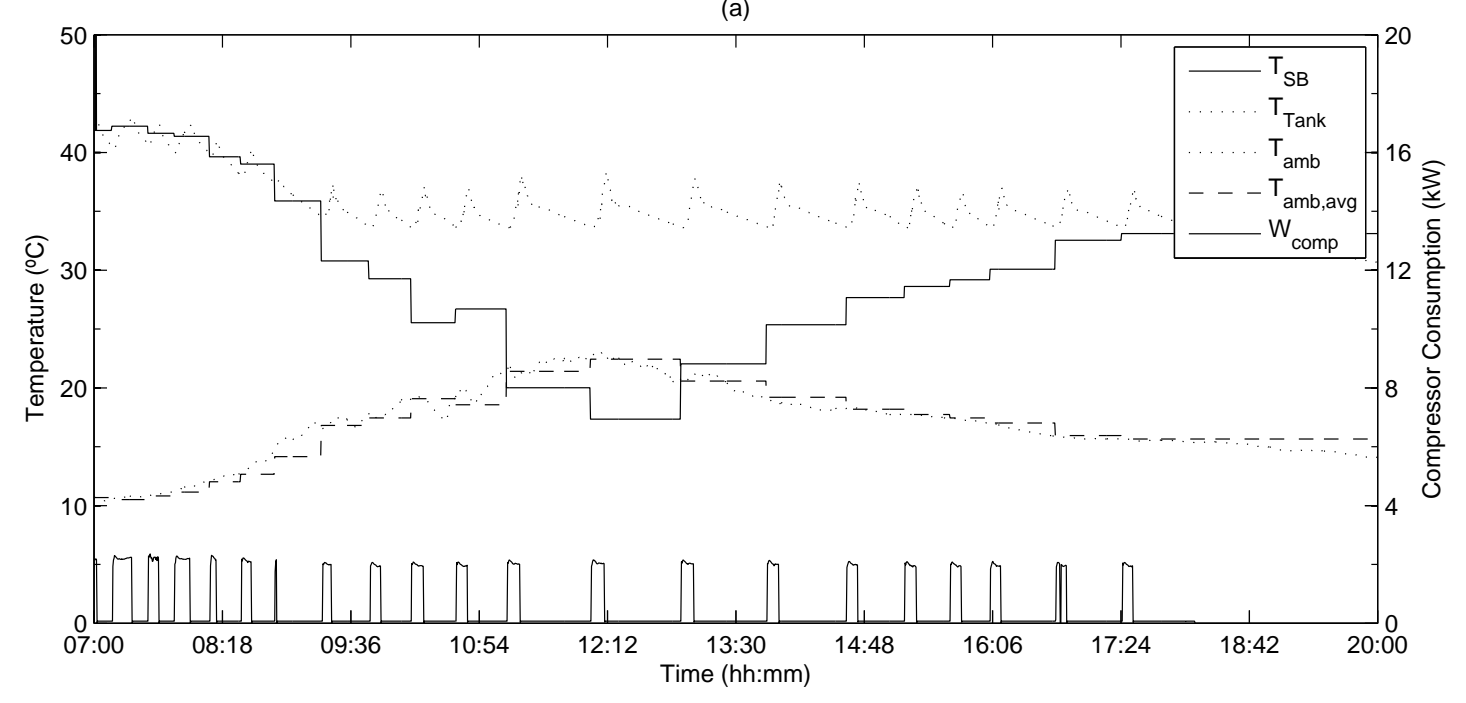

(b)

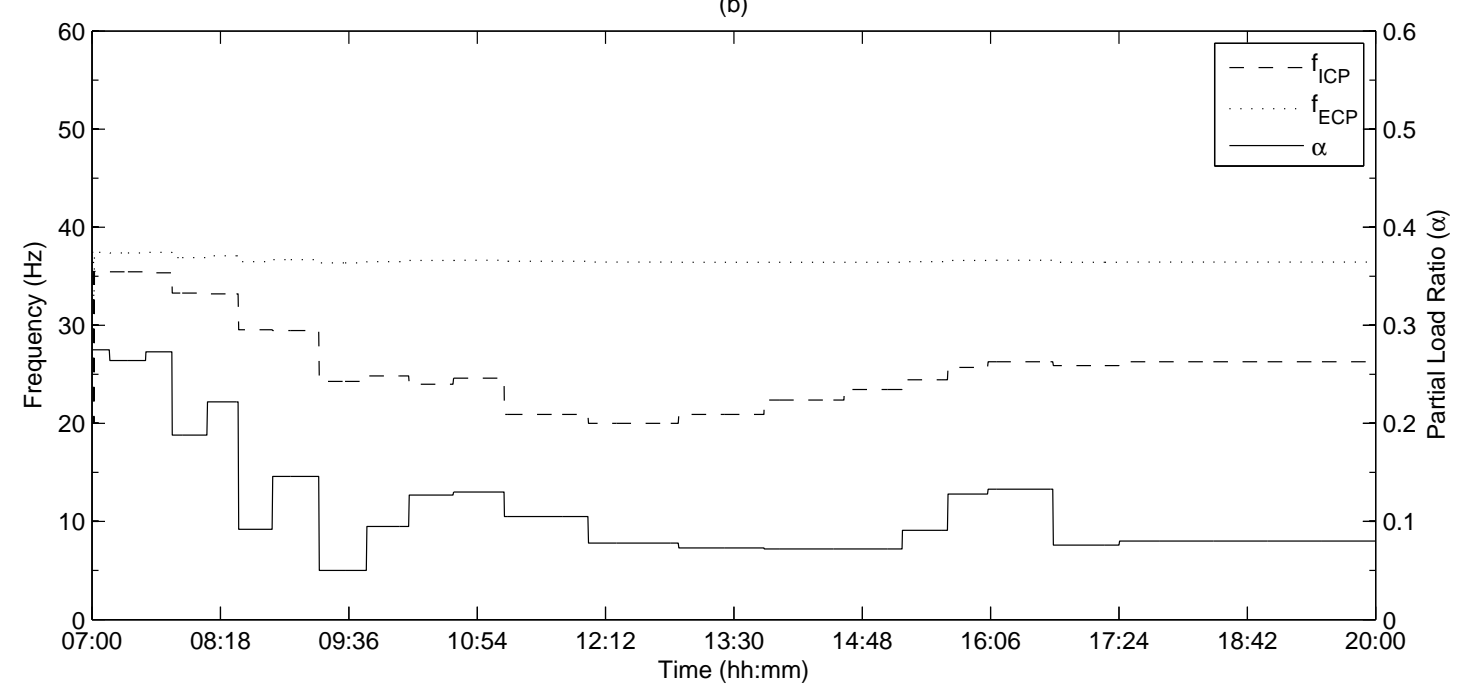

Figure 3.53: Experimental results of the upgraded integrated control (heating mode). 
As it can be observed in Fig. $3.53 \mathrm{k}$, the behaviour of the temperatures is opposite to cooling mode: the higher the ambient temperature, the lower the temperature of the water supplied to the building. When the calculated $T_{S B}$ is lower than $35^{\circ} \mathrm{C}$, the limit depicted in Fig. 3.49 applies and the actual supply temperature $\left(T_{\text {tank }}\right)$ cycles around this value of $35^{\circ} \mathrm{C}$. It can be observed that the building supply temperature does not get the limit value of $45^{\circ} \mathrm{C}$ at any time. The reason for this is that the last winter has been very mild in Valencia and there are no days in which that limit value has been reached.

Regarding the frequencies, again, the set values are directly proportional to the value of the partial load ratio. This can be observed in Fig. 3.53p.

The main target of this new optimized control was being able to meet user comfort while saving as much energy as possible. Regarding cooling mode, the upgraded optimization algorithm was implemented and programmed in the control board of the system in late April of 2015, and it has been running during the whole cooling season (May-October 2015). During the period devoted to the experimental campaign, positive feedback was received from the users in the building regarding their thermal comfort.

According to Spanish regulations [71], comfort conditions are defined as an acceptable range of indoor temperature $(T)$ and relative humidity $(R H)$ which have been defined taking into consideration the metabolic activity of the people (1.2 met for sedentary metabolic activity, being 1 met equal to $58.2 \mathrm{~W} / \mathrm{m}^{2}$ ), their grade of clothing ( 0.5 clo in summer and 1 clo in winter, being 1 clo equal to $0.155 \mathrm{~m}^{2} \mathrm{~K} / \mathrm{W}$ of clothes' thermal resistance), and the predicted percentage of dissatisfied people ( $P P D)$ between $10 \%$ and $15 \%$. According to these conditions, comfort conditions are $T=[23-25]^{\circ} \mathrm{C}$ and $R H=[45-60] \%$ for cooling mode and $T=[21-23]^{\circ} \mathrm{C}$ and $R H[40-50] \%$ for heating mode.

Fig. 3.54 presents the evolution of the temperature and relative humidity of two representative rooms when the previous control algorithm was working in a hot summer day of July. As it can be observed, the indoor temperature and relative humidity take values of $27^{\circ} \mathrm{C}$ and $70 \%$ approximately, which are not acceptable and lie outside the comfort range for cooling mode.

On the other hand, Fig. 3.54 s shows the evolution of the temperature and relative humidity for the same rooms in a similar hot day in July with the new updated control algorithm working. As it is shown, both the indoor temperature and relative humidity in the rooms correspond to comfort conditions $\left(T=[24-25]^{\circ} \mathrm{C} ; \mathrm{RH}=50 \%\right)$.

As for heating mode, the upgraded algorithm was implemented and programmed in the control board of the system in late November 2015. It has been running since for the period December 2015 - February 2016, and keeps running currently. As mentioned earlier, no complaints had been received from the users regarding their thermal comfort when the first approach to the integrated control was used. No complaints have been received with the upgraded algorithm either, always accomplishing the comfort conditions stated earlier. 

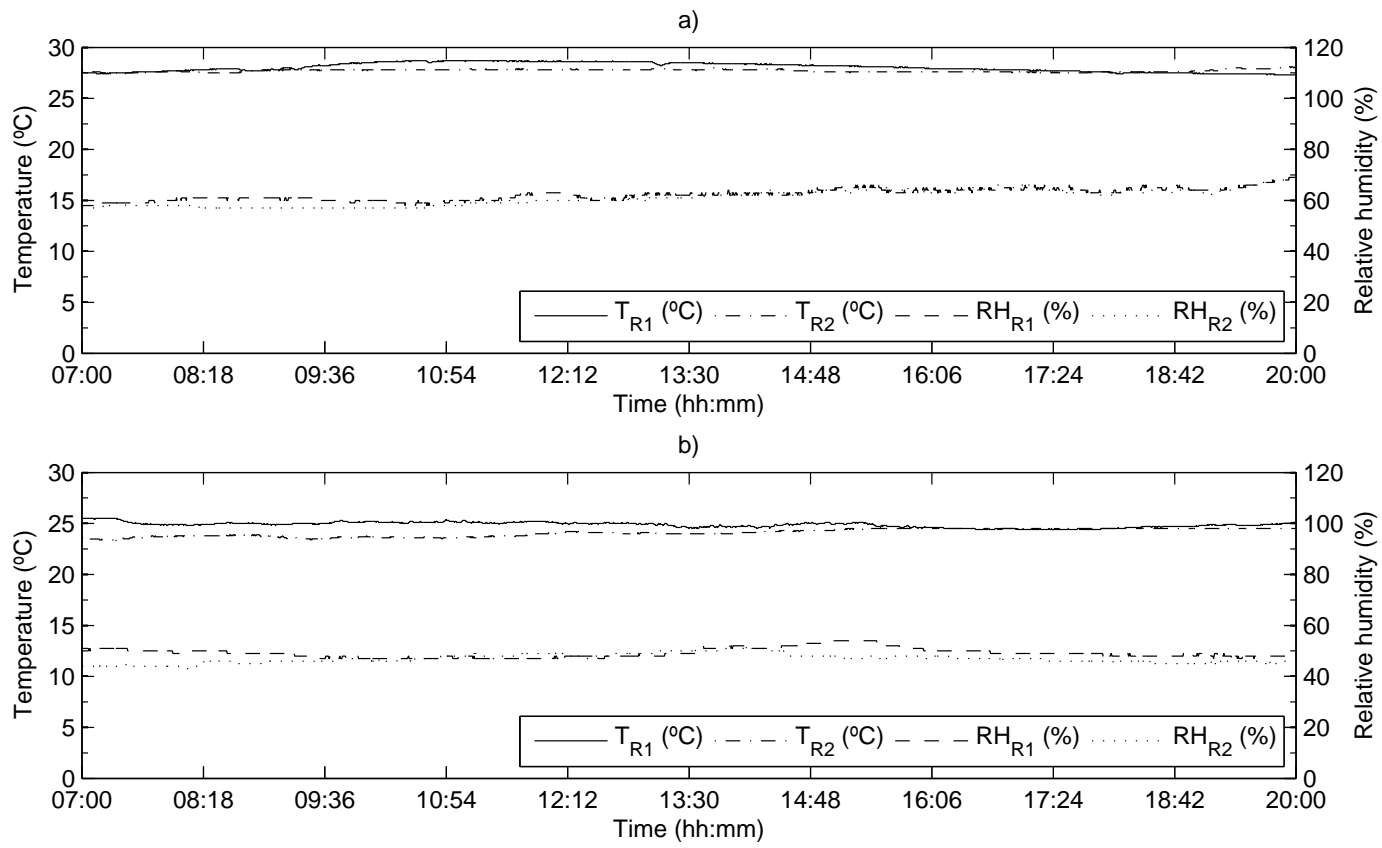

Figure 3.54: Room temperature and relative humidity measurements on a typical cooling day: (a) Values with the former control algorithm; (b) Values with the new upgraded algorithm.

Regarding energy savings, in order to carry out a proper energy optimization analysis, the optimized control has been compared to a standard control, as it was done for the first approach to the integrated control, consisting of a temperature setpoint of $7^{\circ} \mathrm{C}\left(45^{\circ} \mathrm{C}\right.$ for heating mode) and $50 \mathrm{~Hz}$ of frequency for both circulation pumps. As introduced in Section 2.2.5, this standard control is slightly different than the one employed for the first approach, due to specifications in GROUND-MED project, where the minimum setpoint allowed was $10^{\circ} \mathrm{C}$ for cooling mode and $40^{\circ} \mathrm{C}$ for heating mode, according to the targets of the project.

The same automatic control in the control board of the system has been employed in such a way that the standard control is applied on odd days and the optimized control is used on even days, in order to obtain in the end $50 \%$ of the days working with each one.

Fig. 3.55 shows the values of the DPFs from $D P F_{1}$ to $D P F_{3}$, for the period analysed, that is to say, from May 2015 to February 2016. As stated earlier, $D P F_{1}$ considers only the heat pump consumption, $D P F_{2}$ includes also the consumption of the external circulation pump and finally $D P F_{3}$ adds the consumption of the internal circulation pump, being this factor the system performance factor $\left(D P F_{\text {sys }}\right)$.

The alternation of standard and optimized days can be clearly observed in Fig. $3.55 \mathrm{a}$, which corresponds to cooling mode. For instance, looking at DPF3 (triangles), the 
(a)

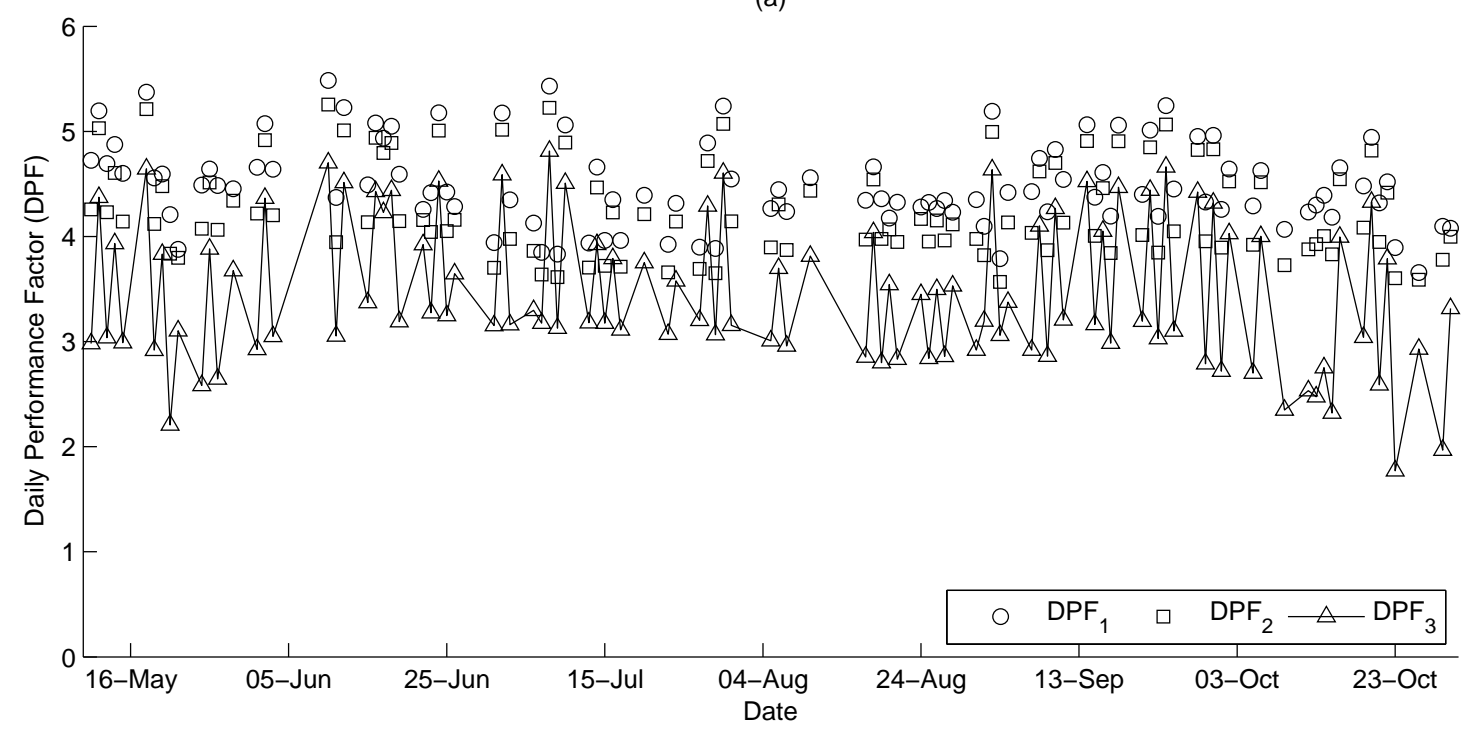

(b)

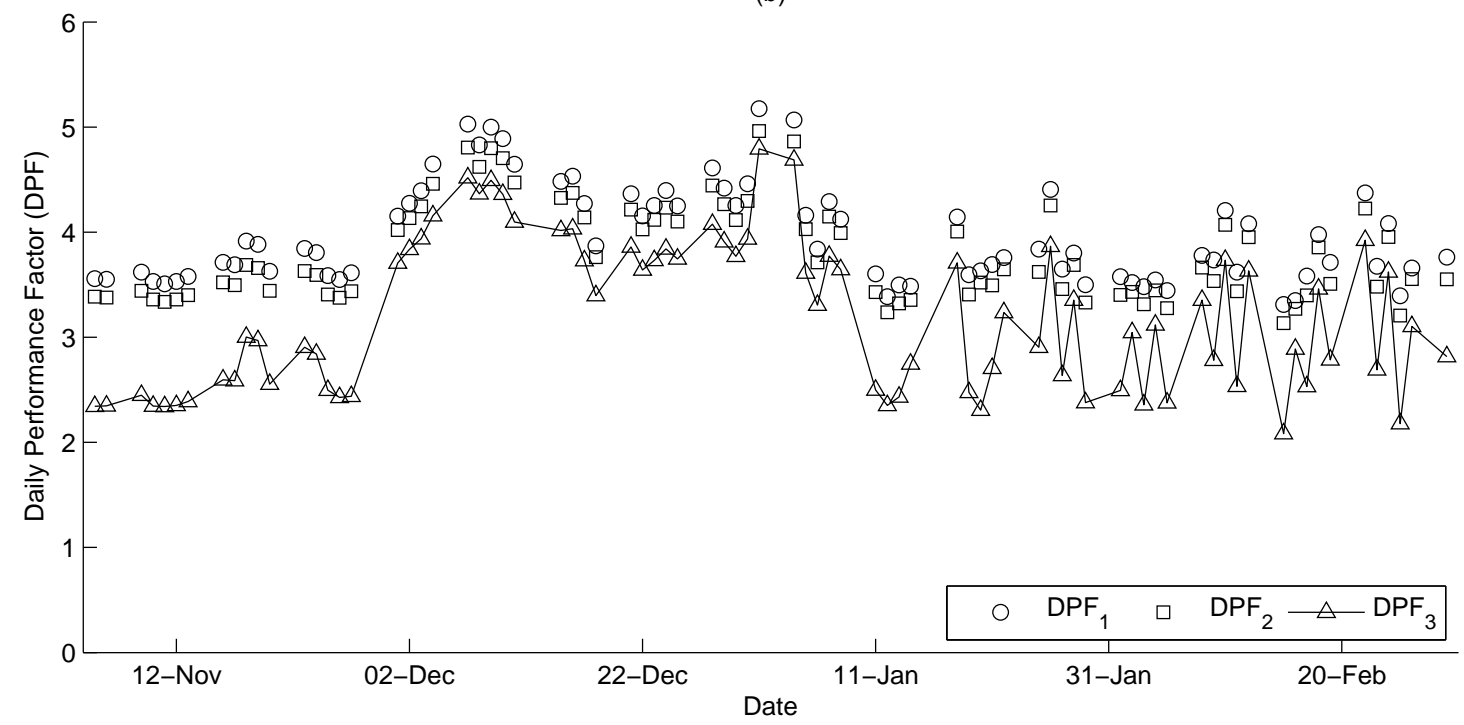

Figure 3.55: Daily performance factor (upgrade): (a) cooling mode test campaign; (b) heating mode test campaign. 
values are around 3 for the days when the standard control was applied, and around one point higher for those when the optimized control was applied, which would represent an improvement of $33 \%(((4-3) / 3) \cdot 100)$.

On the other hand, 3.55b depicts the results for heating mode. In this case, the alternation of standard and optimised days can only be seen from January onwards. The explanation to this is that the implementation and tuning up of the upgraded algorithm in the control board of the system came with a delay of one month since the beginning of the season (November). Therefore, in an attempt to equal the number of standard days obtained in November, the optimised control was applied on a daily basis during the month of December. Still, in the case of heating mode an improvement in $D P F_{3}$ similar to cooling mode can be observed (maybe higher).

Fig. 3.55 shows DPFs calculated for each day in the analysed period, separating cooling and heating modes. Getting together the standard days on one hand, and the optimized days on the other hand, a kind of Seasonal Performance Factor $(S P F)$ can be obtained for each case, as done earlier for the previous approach to the integrated control. This way, the improvement achieved by the optimized control when compared to the standard control can be analysed for both seasons.

Fig. 3.56 presents this comparison: Fig. 3.56a for cooling mode and Fig. 3.56 b for heating mode. When compared to the results of the first approach (Fig. 3.36), it can be observed that the improvement on $S P F_{1}$ (heat pump performance factor) is more representative with the upgrade. This is because a better control of the heat pump setpoint is achieved with the new optimised control.

However, the interest should be on $S P F_{3}$ which is the system seasonal performance factor, the one that expresses the energy savings in a more reliable way. In the case of cooling mode, this improvement is $35 \%$, slightly worse than with the first approach. In the case of heating mode a $53 \%$ improvement is obtained in $S P F_{3}$. It should be noticed that the difference in the percentage of improvement when compared to the first approach, above all in heating mode (which presented an improvement of $32 \%$ ), is mainly due to two reasons. First, the standard control considered in the first approach was more restrictive, due to the requirements of GROUND-MED project, whereas the one considered when the upgraded algorithm was tested was a more realistic standard control. And second, this winter season has been especially mild in Valencia, what has led to a higher improvement of the energy performance. 
(a)

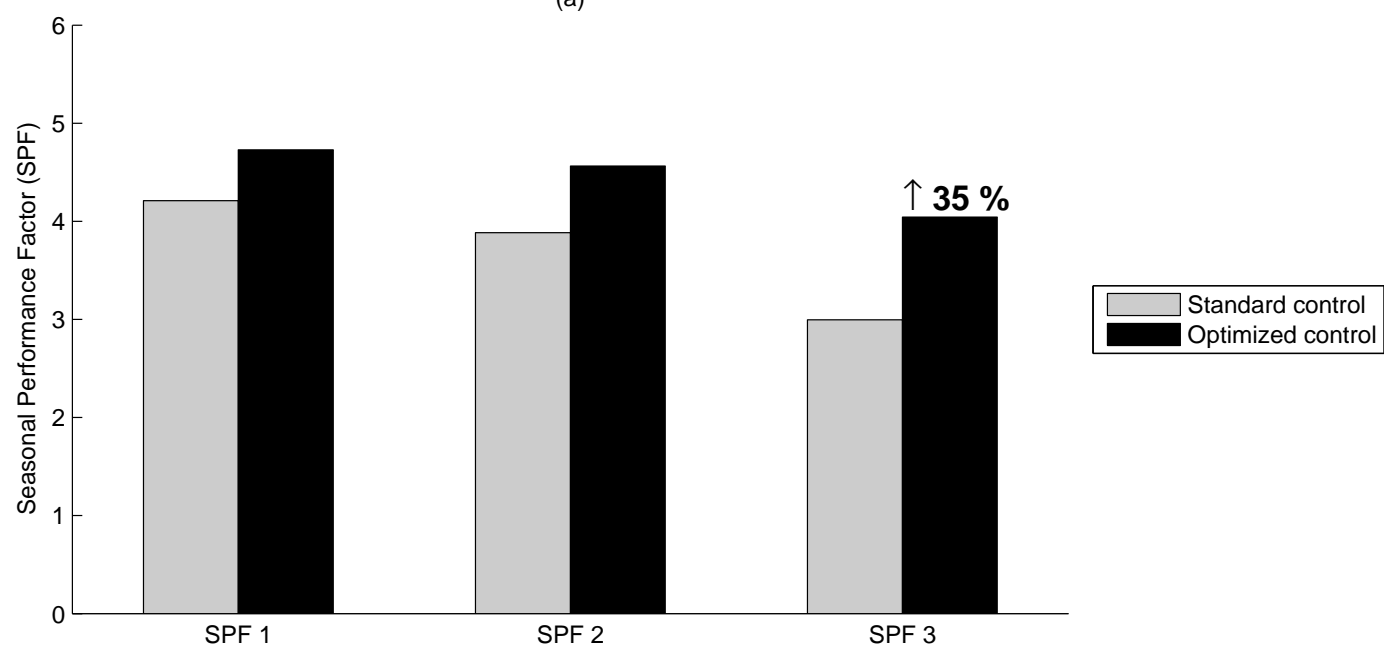

(b)

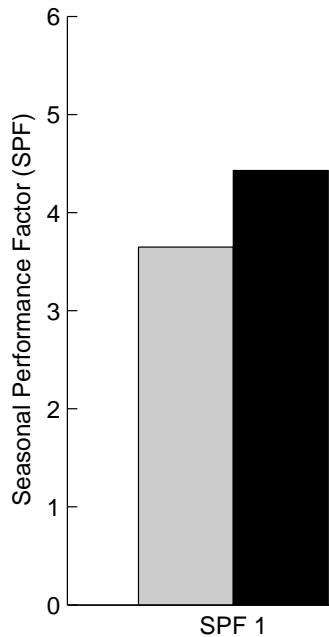

Figure 3.56: Seasonal performance factor (upgrade): (a) cooling mode test campaign; (b) heating mode test campaign. 


\subsection{Implementation in the system control board}

The data acquisition system installed in the geothermal plant was described in Section 2.1.3, where the control system was briefly introduced. This section describes the control system of the geothermal installation studied in this $\mathrm{PhD}$ work. Moreover, the main parts and the main difficulties in the implementation of the energy optimization and control algorithms are also presented.

As introduced in Section 2.1.3, the control system includes a NI CompactRIO programmable automation controller by National Instruments and the software LabVIEW ${ }^{\circledR}$ installed in a personal computer. The schematic in Fig. 3.57 shows how the different components of the control system are interconnected.

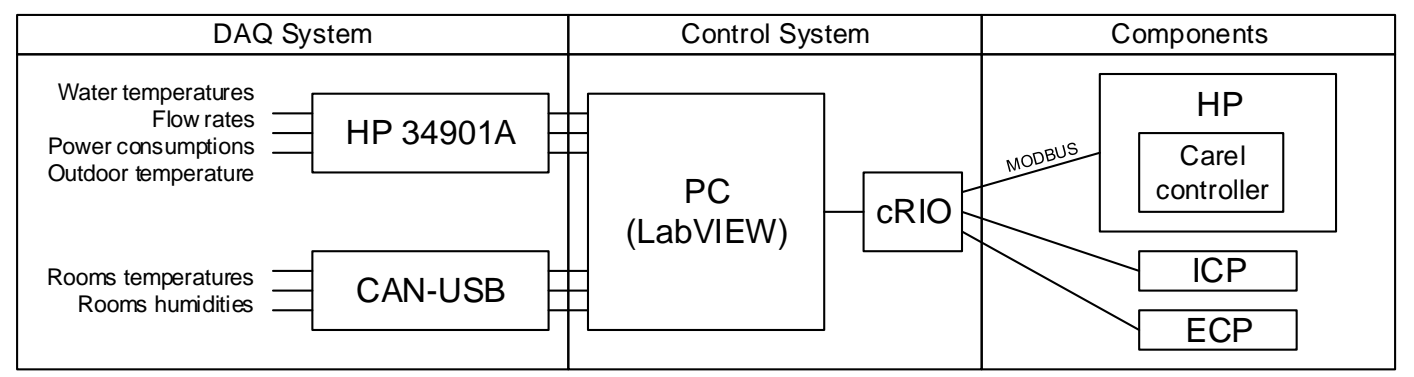

Figure 3.57: Control system schematic.

As it can be observed in Fig. 3.57, the different measured variables enter the system through the DAQ system. The measurements of water temperatures, flow rates, power consumptions and outdoor temperature are acquired by the data loggers HP 34901A by Agilent. On the other hand, the rooms temperatures and relative humidities are transmitted through CAN protocol, and later converted to USB by a home-made CAN-toUSB converter in order to enter the computer system. Then, all these data are managed by a control software developed in LabVIEW ${ }^{\circledR}$.

Apart from the computer, there is the CompactRIO controller (cRIO), which is the device connecting the computer system to the different components of the system. The heat pump (HP) controller, manufactured by Carel, communicates with the cRIO via MODBUS protocol. In order to convert the data from the Ethernet outlet of the cRIO, an Ethernet gateway model ConneXium TSXETG100 is employed. A NI 9263 analog output module is used in order to set the value of the circulation pumps (ICP and ECP) frequencies via an DC voltage signal. A NI 9481 relay module is used in order to have control over the circulation pumps operation.

The control software developed consists mainly of two main LabVIEW ${ }^{\circledR}$ programs 
The first program is devoted to the graphic user interface (GUI) of the control system. A sample of this GUI is presented in Fig. 3.58 .

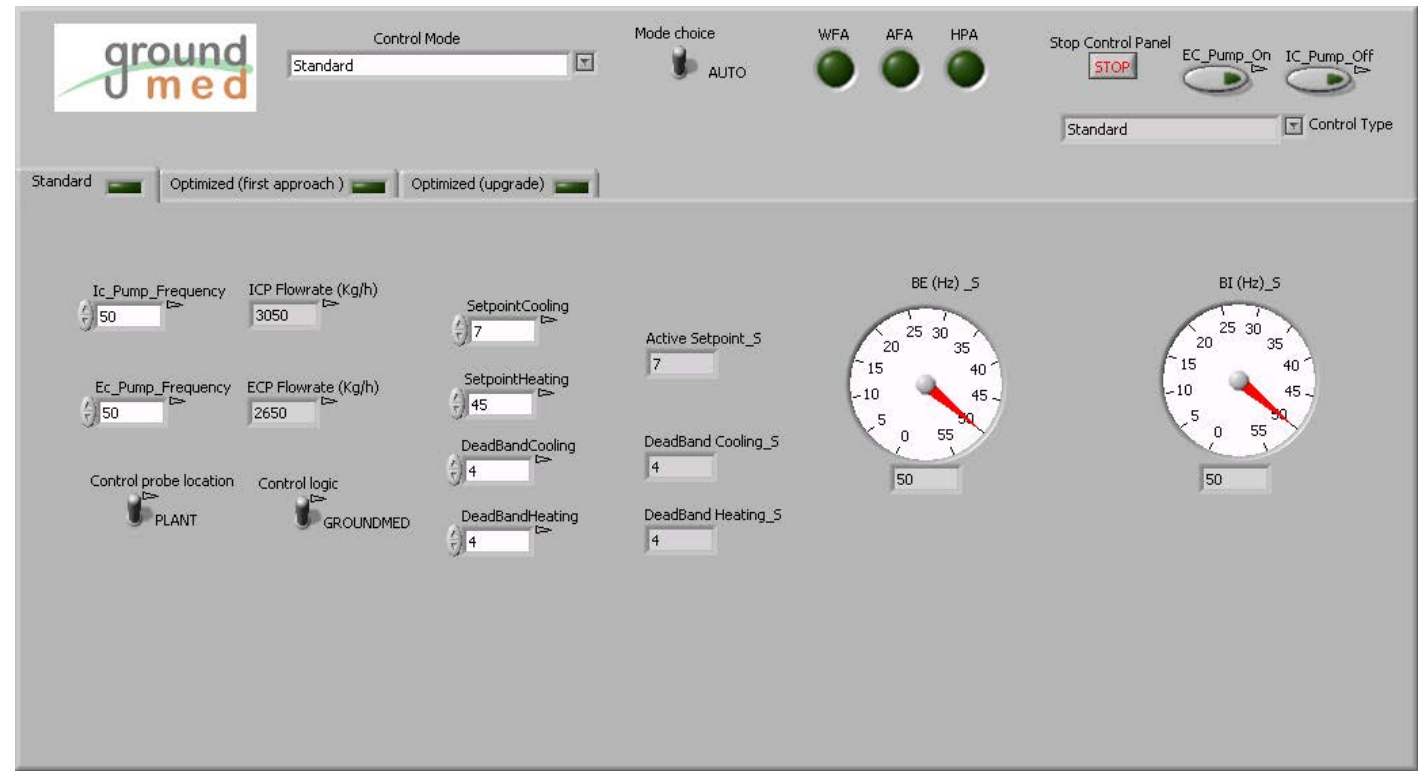

Figure 3.58: Control system GUI (Graphic User Interface).

As it can be observed in Fig. 3.58, three different control strategies are considered: Standard, Optimized (first approach) and Optimized (upgrade). These three controls correspond to those explained earlier in this chapter. A combo box (Control Mode) allows the user to manually switch among the different control strategies. In addition, a toggle switch is included in order to switch between manual control (MANUAL) or automatic control (AUTO). If the choice is MANUAL, the control strategy selected in the Control Mode box in applied. However, if the switch is in position AUTO, the automatic control described in the previous sections, in which the standard control is applied on odd days and the optimised control is employed on even days, is used. Finally, there are different kinds of displays where the values of the different variables are shown, as well as panels to manually change the value of these variables. The user interface can be accessed and controlled remotely from any computer with internet connection.

The second and main program is managed by the cRIO controller. It is the one that manages all the control system: reads and interprets the inputs, applies the different optimization and control strategies implemented, and calculates the outputs and sends the corresponding control action to the different devices. The program is executed every second, checking the inputs and applying changes to the outputs if any.

There is a different subprogram for each of the three different control strategies. The standard control (Standard) is the simplest one to implement. The inputs are directly read from the control panels located on the user interface (see Fig. 3.58) and sent to the 
corresponding outputs.

The implementation of the other two strategies (Optimized (first approach) and Optimized (upgrade)) is more complicated. Fig. 3.59 shows a simplified flow diagram of the LabVIEW ${ }^{\circledR}$ subprograms which is valid for any of these two strategies. The only difference between the two programs lies in the part dedicated to Control strategies (see Fig. 3.59). This difference applies to the way the outputs are calculated: whether following the first approach presented in Section 3.7.1 (see Fig. 3.32) or employing the upgraded control strategy described in Section 3.7 .2 (see Fig. 3.44).

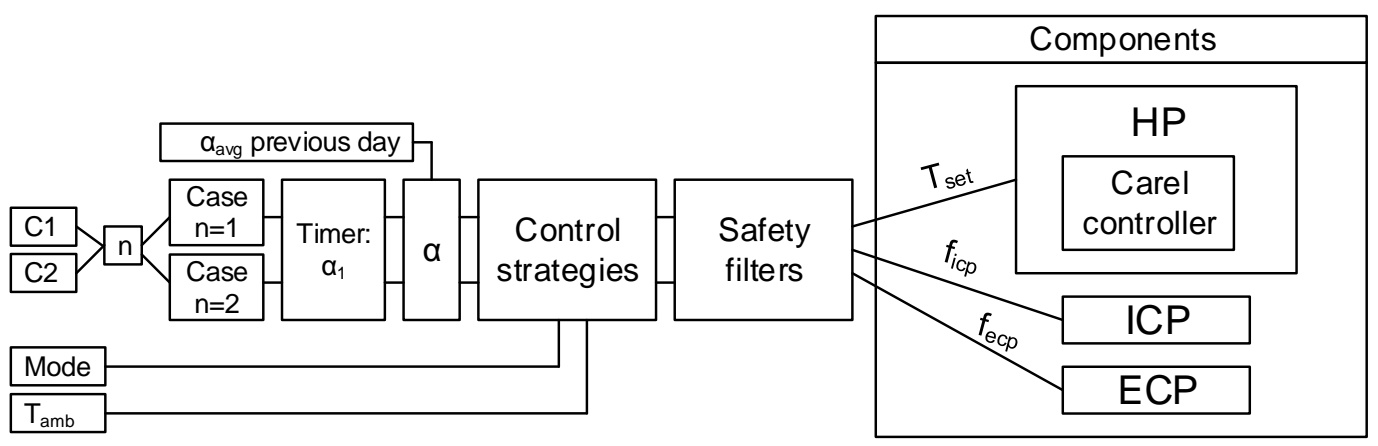

Figure 3.59: Simplified flow diagram of the main LabVIEW ${ }^{\circledR}$ program.

As it can be observed in Fig. 3.59, the first step is to determine the value of the partial load ratio, and for that, several steps are needed. First, it is necessary to find out the operation state of the heat pump, whether it is $n=1$ or $n=2$. In order to do that, the activation signals of the two compressors, which are two of the variables that can be accessed by MODBUS in the heat pump controller, are read as inputs. By means of these two variables it is possible to determine the value of $n$. According to the value of $n$, a different case in entered in a conditional loop. No matter the case entered in the program, the structure is similar and with slight variations.

The next step is to calculate the value of $\alpha_{1}$. In order to do that, a timer counts the duration in time of each of the ON and OFF cycles of the heat pump compressors. Based on these values, $\alpha_{1}$ is calculated by means of Eq. 2.32. However, as explained in Section 2.2.4, $\alpha_{1}$ does not correspond to the partial load ratio of the system, but to that of the corresponding operation state. In order to calculate the partial load ratio of the system $(\alpha)$, Eq. 2.34 is finally employed. It should be noticed that the subroutine for the calculation of the partial load ratio may sometimes provide unusual values of $\alpha$. This happens with the first cycle in the early morning which, as mentioned in Section 2.2.6, is not representative of the system behaviour. In order to avoid miscalculations of the algorithm in such cases, a reference value of $\alpha$ is considered. This reference value corresponds to the average value of the partial load ratio for the previous day. 
Once the value of $\alpha$ has been determined, the next step is to apply the control strategies as described on each of their corresponding sections: Section 3.7.1 for the first approach or Section 3.7 .2 for the upgrade. The inputs required by the algorithm are the partial load ratio of the system $(\alpha)$, the outdoor ambient temperature $\left(T_{a m b}\right)$, which is a direct reading and the mode or season, whether it is cooling or heating mode. The operation state of the heat pump $(n)$ is also an input in some of the steps of the algorithm.

The outputs of the controlled algorithm are the target variables, that is to say, the temperature setpoint for the heat pump and the frequency of both circulation pumps. Nevertheless, the calculations may provide values which are outside the accepted range for the outputs. In order to avoid possible problems, all the calculated outputs are filtered to be with in the maximum and minimum values allowed. In the case of the temperature setpoint, the maximum and minimum values are $15^{\circ} \mathrm{C}$ and $7^{\circ} \mathrm{C}$, respectively, for the case of cooling mode, and $50^{\circ} \mathrm{C}$ and $35^{\circ} \mathrm{C}$, respectively, for the case of heating mode. Regarding the frequency of the circulation pumps, the maximum and minimum values are $55 \mathrm{~Hz}$ and $20 \mathrm{~Hz}$, respectively, for both cooling and heating.

Once the outputs have been properly filtered, the are sent to the corresponding devices.

Fig. 3.60 presents a sample of the main LabVIEW ${ }^{\circledR}$ program. It particular, it is the subroutine devoted to the calculation of the targeted variables in the upgraded strategy for both cooling and heating mode.

One of the main difficulties faced when facing the implementation the optimization and control algorithms in LabVIEW ${ }^{\circledR}$ was the determination of $\alpha$. In Section 2.2.4 the calculation of the partial load ratio was thoroughly studied, reaching the conclusion that, a good way to calculate its value, in a way that it was easily implementable in a control algorithm, was an indirect calculation using the ON and OFF time periods of the compressors. However, in practice, the calculations are not that easy, as they have to be performed for the two operation states of the heat pump. This particular behaviour of the tandem compressors heat pump makes it necessary to analyse the different types of cycles that can be found in the system operation, and to make some decisions on how to consider the measured times for the calculations. Fig. 3.61 presents the different types of cycles that can be found in during the normal operation of the system.

As it can be observed in Fig. 3.61, types of cycle from 1 to 4 are defined, depending on the switching on sequence followed by the heat pump compressors. Cycles type 1 and 2 are considered as representative cycles, whereas cycles type 3 and 4 are considered as transition cycles. The different types of cycle are explained in the following.

1. One compressor representative cycle. There is only one compressor running, cycling $\mathrm{ON}$ and OFF. The number of compressors switches from 0 to 1 at the beginning of the cycle, coming back to 0 at the end of the cycle. $\alpha_{1}$ is calculated at the end of the cycle for state $n=1$, by means of Eq. 2.32, and the value is used in Eq. 2.34 in order to obtain the partial load ratio of the system $\alpha$, which will be lower than or equal to 0.5 . 


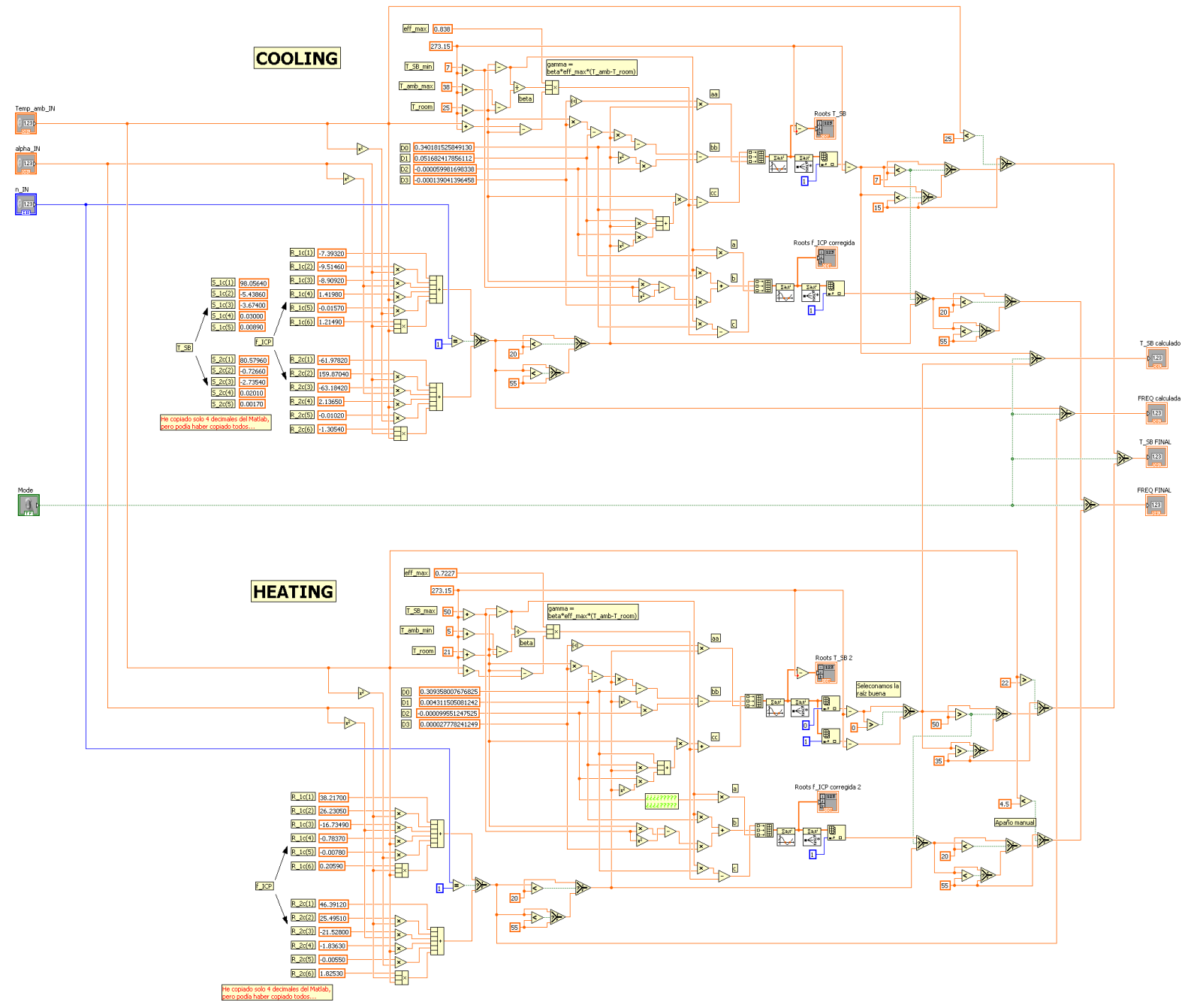

Figure 3.60: Sample of the main LabVIEW ${ }^{\circledR}$ program. 


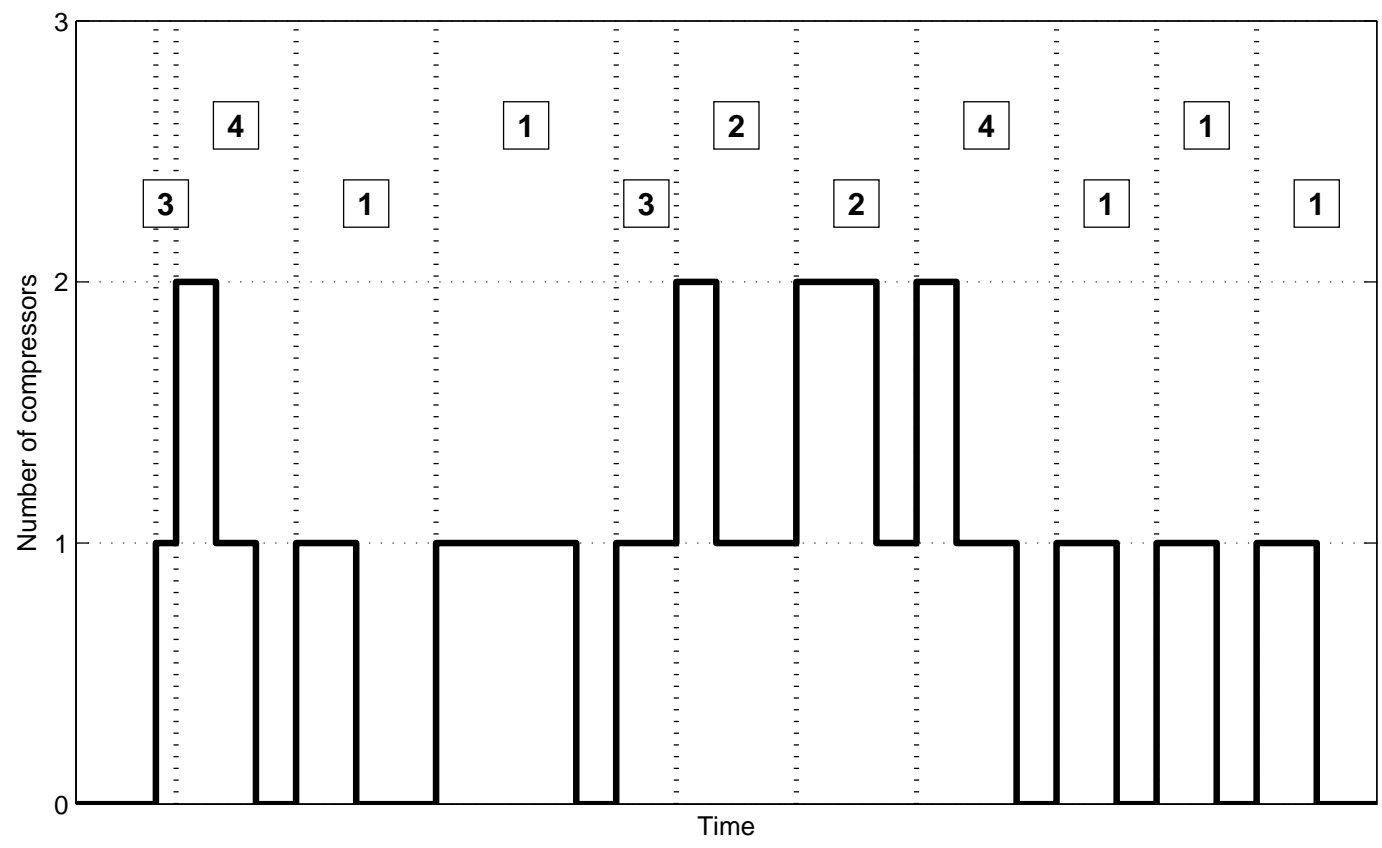

Figure 3.61: Different types of cycles performed by the GROUD-MED heat pump.

2. Two compressors representative cycle. One compressor is continuously running, and the other one is switching on and off. The number of compressors switches from 1 to 2 at the beginning of the cycle, coming back to 1 at the end of the cycle. $\alpha_{1}$ is calculated at the end of the cycle for state $n=2$, by means of Eq. 2.32, and the value is used in Eq. 2.34 in order to obtain the partial load ratio of the system $\alpha$, which will be higher than 0.5 .

3. Transition cycle 0-1-2. The cycle begins when one compressor starts, and ends when the other compressor starts too. This type of cycle may occur when the installation starts in the early morning (see Section 2.2.6), or when there is a sudden increase in the thermal load. For the first cycle in the morning, the value of the average partial load ratio of the previous day is considered as a reference value. On the other hand, when cycle type 3 is produced by an increase in the thermal load, $\alpha_{1}$ is not recalculated, but continues with the same value until a new representative cycle is completed.

4. Transition cycle 2-1-0. The cycle begins when the second compressor starts; then, a period of time later it switches off, and so does the first compressor; the cycle ends when the first compressor starts again. This type off cycle may occur when there is a sudden decrease in the thermal load. The value of $\alpha$ is not recalculated either in here, but continues with the same value until a new representative cycle is completed. 
Finally, another difficulty was the use of the ambient temperature. Several approaches were taken until the final solution was reached. First, in order to avoid the instantaneous variation of this magnitude, the five minutes average is considered. Moreover, the value of the ambient temperature is only updated when a new value of $\alpha$ is calculated, at the end of a representative cycle. This way, the variables depending on the ambient temperature (temperature setpoint and internal circulation pump frequency) are only updated when a cycle finishes and a new one starts. Otherwise, they would be updated with every reading of the ambient temperature. 



\section{Chapter 4}

\section{Conclusions}

This chapter presents the conclusions of this research work. Moreover, possible lines for further research in the field are suggested. 


\subsection{Conclusions of this research work}

The experimental study of the control and energy optimization of a ground source heat pump system for heating and cooling in an institutional building at the Universitat Politècnica de València (València, Spain) was carried out in this $\mathrm{PhD}$ dissertation.

The analysis of the state of the art showed that there is a significant potential for energy savings in ground source heat pump systems. The performance of the system was thoroughly analysed through the study of typical days of operation for both cooling and heating modes, but also along several years of operation (from 2011 to 2016), characterizing the behaviour of the installation during that period. The study includes the analysis of the power consumption of each component and their contribution to the total energy consumption, the heat generated, the operating temperatures, the energy efficiency parameters, etc.

A comprehensive study was also carried out in order to determine the best way to estimate the thermal demand of the building from the monitored data. Different options were analysed and it was concluded that the most effective way was to calculate the partial load ratio via the operating time periods of the heat pump, which contributed to achieve a more stable control.

The short-term performance analysis demonstrated from the very beginning that the power consumption of the fan coil units was fairly high. For that reason, some of the old inefficient fan coil units were replaced by new more efficient ones. With the fan coils optimized, the focus was on the other main power consumptions: the heat pump and the water circulation pumps. The analysis of the performance of the geothermal installation not only showed that the variation temperature setpoint of the heat pump played an important role on the energy performance of the system, but also confirmed that the consumption of the auxiliaries (internal and external circulation pumps) represents around $30-35 \%$ of the total energy consumption.

Prior to developing any optimization strategies, the standard thermostatic ON/OFF control was studied, as well as the influence of the thermal demand of the building on this type of control. Additionally, the adaptation of the ON/OFF control to a multistage heat pump with two compressors of the same capacity working in tandem was also analysed.

Apart from the control, some requirements need to be accomplished in order to ensure a proper return of the oil to the compressor. Therefore, a minimum ON cycle time needs to be guaranteed with this purpose. In practice, this is achieved by installing a buffer tank in the system. An analysis for the sizing of this buffer tank was carried out in this PhD work, obtaining a design guideline for this purpose. Moreover, the effect of the location of both the buffer tank and the control temperature sensor was studied. It was concluded from this study that, from the point of view of the user comfort, the best position for the buffer tank is the supply line, locating the control sensor also in the supply line, at 
Conclusions of this research work

the outlet of the tank.

Regarding the development of energy optimization and control strategies, an experimental in situ optimization methodology for the water circulation pumps frequency was developed in order to make the circulation pumps work at the optimal point from the point of view of energy optimization. Combining this strategy with a temperature compensation strategy in a first approach to an integrated control, an energy optimization algorithm was developed, implemented and tested in the geothermal heating and cooling installation. Results showed around a $36 \%$ improvement in the cooling seasonal performance factor of the system, and $32 \%$ in the case of the heating season. However, after analysing the users' feedback during a whole year of operation, it was concluded that the user comfort was not met under extreme weather conditions in summer.

For that reason, the methodology developed to obtain an optimal performance was reviewed and upgraded. This new approach is based on coupling the estimation of the optimal values of the internal circulation pump frequency and the building supply temperature so that the system is able to work under the minimum energy consumption, provided that the fan coils have a capacity such as to cover the thermal demand and meet the user comfort even in extreme weather conditions. The values of both controlled variables (internal circulation pump frequency and building supply temperature) are calculated as a function of both the ambient temperature (outdoor conditions) and the partial load ratio of the system (thermal load conditions), making the geothermal system smart and adaptive to actual operating conditions.

In brief, the energy optimization algorithm developed consists of the following steps. First, the internal circulation pump frequency is calculated as a function of the ambient temperature and the partial load ratio. Then, with this calculated value of frequency, the supply building temperature is determined in order to meet the user comfort. If the calculated building supply temperature is out of the feasible range of operation setpoint for the heat pump, it is set to the limit value and the internal frequency is corrected so that the user comfort is always met, keeping the system at its optimal point of operation.

The energy optimization methodology developed in this $\mathrm{PhD}$ work is perfectly applicable to any other ground source heat pump installations of the same type. In the case of the geothermal installation studied in this research work, the new optimized control was developed, implemented in the control board of the system and tested during one whole cooling season (May-October 2015) and the current heating season (November 2015 February 2016). Results show an improvement in the seasonal performance factor of the system of $35 \%$ in cooling mode and $53 \%$ in heating mode. The difference in the percentage of improvement when compared to the first approach, above all in heating mode, is mainly due to two reasons. First, the standard control considered in the first approach was more restrictive, due to the requirements of GROUND-MED project, whereas the one considered when the upgraded algorithm was tested was a more realistic standard control, considering the minimum standard supply temperature recommended by the heat pump manufacturer (maximum standard supply temperature for heating mode). 
And second, this winter season has been especially mild in Valencia, what has led to a higher improvement of the energy performance.

The feedback from the users about comfort has been positive, as the system was able to keep measured values of temperature and relative humidity in two selected representative rooms, inside the acceptable comfort range of $\left[23^{\circ} \mathrm{C} \ldots 25^{\circ} \mathrm{C}\right]$ and $[45 \% \ldots 60 \%]$, respectively, for cooling mode, and $\left[21^{\circ} \mathrm{C} \ldots 23^{\circ} \mathrm{C}\right]$ and $[40 \% \ldots 50 \%]$, respectively, for heating mode, according to Spanish regulations.

\subsection{Further research}

First of all, the impact on the user comfort of the control and optimization strategies developed and tested in the geothermal installation was checked based on measurements of temperature and relative humidity at only one single point in each of the rooms, which were contrasted with the values provided by the Spanish regulations. Apart from that, the feedback from the users was also taken into consideration. A more specific analysis was out of the scope of this research work. Therefore, a possible line for further research could be a thorough and extensive analysis of the impact on the user comfort of the different control strategies implemented. This more comprehensive analysis of the user comfort might include indoor air temperature and relative humidity measurements at several points in each room, air velocity, activity level of occupants, clothing insulation...

Along the years working with the experimental installation, some problems has been detected, leading to maintenance operation that prevented the system from having a normal operation, in periods of time ranging from some hours to several days. Another possible line for further research could be thus the study of fault detection in ground source heat pump systems along time, in order to be able to apply predictive maintenance operations and improve the system operation and performance. Some work on the topic of faults in heat pump systems is being done currently by Hatef Madani [73,74].

On the other hand, the in situ optimization methodology for the circulation pumps frequency has been developed for both single stage and multi-stage heat pump units with ON/OFF regulation. Further studies could be focused on the adaptation of the methodology to GSHP installations with heat pump units including variable speed compressors, in order to complete the study covering all the technologies available.

Finally, the energy optimization methodology developed in this $\mathrm{PhD}$ work has been tested in a relatively small GSHP installation. Another interesting research line could thus be studying how the algorithms developed might be integrated in a central control system which controls the heating and cooling system in bigger building. Moreover, the possibility of combining the methodology developed with energy management techniques such as scheduling techniques could be also analysed. 


\section{Bibliography}

[1] https://setis.ec.europa.eu (Last access date: January 2016)

[2] cordis.europa.eu/home_es.html (Last access date: January 2016)

[3] ec.europa.eu/index_en.htm (Last access date: January 2016)

[4] Plan de Energías Renovables 2011-2020, Instituto para la Diversificacion y el Ahorro de energía (Spanish Institute for Diversification and Saving of Energy), Madrid, 2011 (Spanish).

[5] IEA, 2011. Technology Roadmap: Energy-Efficient Buildings: Heating and Cooling Equipment. Technical report, Paris, France, IEA Publications.

[6] European Union, 2009. Directive 2010/31/EU of the European Parliament and of the Council, Official Journal of the European Union.

[7] Ozyurt, O., Ekinci, D.A., 2011. Experimental study of a vertical ground source heat pump performance evaluation for cold climate in Turkey, Applied Energy 88, pp. $1257-1265$.

[8] Onomiya, Y., Katsura, T., Nakamura, Y., 2012. Performance evaluation of net-zero energy building integrated with the ground source heat pump system, Innostock 2012.

[9] Wang, Y., Ma, Y., Liu, Q., Luo, M., 2012. Influence of intermittent Operation on Ground Thermal Balance in GCHP System, Innostock 2012.

[10] Wu, Y., Gan, G., Verhoef, A., Vidale, P.L., Garcia Gonzalez, R., 2010. Experimental measurement and numerical simulation of horizontal coupled slinky ground source heat exchangers, Applied Thermal Engineering 30, pp. 2574-2583.

[11] Norbert Fisch, M., Kühl, L., Petruszek, T., NüBle, F., Sanner, B., 2012. Optimization of ground coupled heating and cooling supply systems in office buildings reversible heat pump and free cooling, pp. Innostock 2012.

[12] Ozgener, O., Hepbasli, A., 2005. Experimental performance analysis of a solar assisted ground-source heat pump greenhouse heating system, Energy and Buildings 37, pp. 101-110. 
[13] Man, Y., Yang, H., Wang, J., 2010. Study on hybrid ground-coupled heat pump system for air-conditioning in hot-weather areas like Hong Kong, Applied Energy 87, pp. 2826-2833.

[14] Man, Y., Yang, H., Spitler, J.D., Fang, Z., 2011. Feasibility study on novel hybrid ground coupled heat pump system with nocturnal cooling radiator for cooling load dominated buildings, Applied Energy 88, pp. 4160-4171.

[15] Sagia, Z., Rakopoulos, C., Kakaras, E., 2012. Cooling dominated Hybrid Ground Source Heat Pump System application, Applied Energy 94, pp. 41-47.

[16] GEOCOOL "Geothermal Heat Pump for Cooling and Heating along European coastal Areas", 2002-2005. Contract number NNE5-2001-00847, Financed by the European Commission, FP6 Sixth Framework Programme.

[17] Hwang, Y., Lee, J., Jeong, Y., Koo, K., Lee, D., Kim, I., Jin, S., Kim, S.H., 2009. Cooling performance of a vertical ground-coupled heat pump system installed in a school building, Renewable Energy 34, pp. 578-582.

[18] Petit, P.J., Meyer, J.P., 1998. Economic potential of vertical ground source heat pumps compared to air-source air conditioners in South Africa, Energy 23(2), pp. 137-143.

[19] Urchueguía, J.F., Zacarés, M., Corberán, J.M., Montero, A., Martos, J., Witte, H., 2008. Comparison between the energy performance of a ground coupled water to water heat pump system and an air to water heat pump system for heating and cooling in typical conditions of the European Mediterranean coast, Energy Conversion and Management 49, pp. 2917-2923.

[20] Chen, X., Yang, H.X., Lu, L., 2011. Experimental studies on a ground coupled heat pump with solar thermal collectors for space heating, Energy 36 (8), pp. 5292-5300.

[21] Bakirci, K., Ozyurt, O., Comakli, K., 2011. Energy analysis of a solar-ground source heat pump system with vertical closed-loop for heating applications, Energy 36 (5), pp. 3224-3232.

[22] Eslami-nejad, P., Bernier, M., 2011. Coupling of geothermal heat pumps with thermal solar collectors using double U-tube boreholes with two independent circuits, Applied Thermal Engineering 31 (14-15), pp. 3066-3077.

[23] Kaygusuz, K., 1999. Investigation of a combined solar heat pump system for residential heating, part 1: experimental results, International Journal of Energy Research 23 (14), pp. 1213-1223.

[24] Benli, H., Durmus, A., 2009. Evaluation of ground-source heat pump combined latent heat storage system performance in greenhouse heating, Energy and Buildings 41 (2), pp. $220-228$. 
[25] Liu, W., Chen, G., Yan, B., Zhou, Z., Du, H., Zuo, J., 2015. Hourly operation strategy of a CCHP system with GSHP and thermal energy storage (TES) under variable loads: A case study, Energy and Buildings 93, pp. 143-153.

[26] Pardo, N., Montero, Á., Martos, J., Urchueguía, J.F., 2010. Optimization of hybrid - ground coupled and air source - heat pump systems in combination with thermal storage, Applied Thermal Engineering 30, pp. 1073-1077.

[27] Haniff, M.F., Selamat, H., Yusof, R., Buyamin, S., Ismail, F.S., 2013. Review of HVAC scheduling techniques for buildings towards energy-efficient and cost-effective operations, Renewable and Sustainable Energy Reviews 27, pp. 94-103.

[28] Escrivá, G., Alcázar, M., Álvarez, C., 2009. Integral Management System for the energy efficiency improvement in commercial facilities: Application to the Polytechnic University of Valencia, International Conference on Renewable Energies and Power Quality (ICREPQ09), Valencia, Spain.

[29] Huang, W.Z., Zaheeruddin, M., Cho, S.H., 2006. Dynamic simulation of energy management control functions for HVAC systems in buildings, Energy Conversion and Management 47 (7-8), pp. 926-943.

[30] Henze, G.P., Floss, A.G., 2011. Evaluation of temperature degradation in hydraulic flow networks, Energy and Buildings 43 (8), pp. 1820-1828.

[31] Fraisse, G., Virgone, J., Brau, J., 1997. An analysis of the performance of different intermittent heating controllers and an evaluation of comfort and energy consumption, HVAC\&R Research 3 (4), pp. 369-386.

[32] Fong, K.F., Hanby, V.I., Chow, T.T., 2005. HVAC system optimization for energy management by evolutionary programming, Energy and Buildings 38 (3), pp. 2020231.

[33] Fahlén, P., Karlsson, F., 2003. Improving efficiency of hydronic heat pump heating systems, 21st International Congress of Refrigeration, Washington, WA, USA.

[34] Fahlén, P., Karlsson, F., 2005. Optimizing and controlling media flows in heat pump systems, 8th IEA Heat Pump Conference, Las Vegas, NV, USA.

[35] Zhao, L., Zhao, L.L., Zhang, Q., Ding, G.L., 2003. Theoretical and basic experimental analysis on load adjustment of geothermal heat pump systems, Energy Conversion and Management 44 (1), 1-9.

[36] Lee, C.K., 2010. Dynamic performance of ground-source heat pumps fitted with frequency inverters for part-load control, Applied Energy 87, pp. 3507-3513.

[37] Madani, H., Claesson, J. Lundqvist, P., 2011. Capacity control in ground source heat pump systems part II: Comparative analysis between on/off controlled and variable capacity systems, International Journal of Refrigeration 34, pp. 1934-1942. 
[38] Madani, H., Claesson, J. Lundqvist, P., 2013. A descriptive and comparative analysis of three common control techniques for an $\mathrm{ON} / \mathrm{OFF}$ controlled ground source heat pump (GSHP) system, Energy Buildings 65, pp.1-9.

[39] Bernier, M., Bourret, B., 1999. Pumping energy and variable frequency drives, ASHRAE Journal 41, pp. 37-40.

[40] Brodrick, J.R., Westphalen, D., 2001. Uncovering auxiliary energy use, ASHRAE Journal 43, pp. 58-61.

[41] Bahnfleth, W.P., Peyer, E., 2007. Variable primary flow chilled water systems: potential benefits and application issues, HVAC\&R Research for the 21st century program, Final Report (ARTI-21CR/611-20070-01) prepared for the Air-Conditioning and Refrigeration Technology Institute (ARTI), Arlington, VA, USA.

[42] Karlsson, F., 2007. Capacity Control of Residential Heat Pump Heating Systems, Department of Energy and Environment (Ph.D. thesis), Chalmers University of Technology, Göteborg, Sweden.

[43] Granryd, E., 2010. Analytical expressions for optimum flow rates in evaporators and condensers of heat pumping systems, International Journal of Refrigeracion 33, pp. $1211-1220$.

[44] Fong, K.F., Hanby, V.I., Chow, T.T., 2006. HVAC system optimization for energy management by evolutionary programming, Energy and Buildings 38 (3), pp. 220231.

[45] Corberán, J.M., Finn, D.P., Montagud, C., Murphy, F.T., Edwards, K.C., 2011. A quasi-steady state mathematical model of an integrated ground source heat pump for building space control, Energy and Buildings 43, pp. 82-92.

[46] Pardo, N., Montero, Á., Sala, A., Martos, J., Urchueguía, J.F., 2011. Efficiency improvement of a ground coupled heat pump system from energy management, Applied Thermal Engineering 31, pp. 391-398.

[47] Edwards, K.C., Finn, D.P., 2015. Generalised water flow rate control strategy for optimal part load operation of ground source heat pump systems, Applied Energy $150,50-60$.

[48] Del Col, D., Azzolin, M., Benassi, G., Mantovan, M., 2014. Experimental analysis of optimal operation mode of a ground source heat pump system, Energy Procedia 45, pp. 1354-1363.

[49] Del Col, D., Azzolin, M., Benassi, G., Mantovan, M., 2014. Energy efficiency in a ground source heat pump with variable speed drives, Energy and Buildings 91, pp. 105-114. 
[50] GROUND-MED "Advanced ground source heat pump systems for heating and cooling in Mediterranean climate", 2009-2014. Contract number TREN/FP7EN/218895, Financed by the European Commission, FP7 Seventh Framework Programme.

[51] groundmed.eu/home (Last access date: January 2016)

[52] Magraner Benedicto, M.T., 2010 (Spanish). Validación experimental de los métodos de diseño de instalaciones de bomba de calor acoplada al terreno ( $\mathrm{PhD}$ thesis), Universitat Politècnica de València, València, Spain.

[53] http://youngphc.com/ (Last access date: January 2016)

[54] Montagud, C., Corberán, J.M., 2012. Estudio teórico de selección de componentes para el diseño de una bomba de calor geotérmica de alta eficiencia, VI Congreso Ibérico y IV Congreso Iberoamericano de Ciencias y Técnicas del Frío (CYTEF 2012).

[55] Montagud, C., Corberán, J.M., Montero, Á., Urchueguía, J.F., 2011. Analysis of the energy performance of a ground source heat pump system after five years of operation, Energy and Buildings 43 (12), pp. 3618-3626.

[56] Bandos, T.V., Montero, Á., Fernández de Córdoba, P., Urchueguía, J.F., 2011. Improving parameter estimates obtained from thermal response tests: Effect of ambient air temperature variations, Geothermics 40 (2), pp. 136-143.

[57] Ruiz-Calvo, F., Montagud, C., 2014. Reference data sets for validating GSHP system models and analyzing performance parameters based on a five-year operation period, Geothermics 51, 417-428.

[58] Ruiz-Calvo, F., Cervera-Vázquez, J., Montagud, C., Corberán, J.M. Reference data sets for validating and analyzing GSHP systems based on a eleven-year operation period. Preprint submitted to Geothermics.

[59] http://www.ni.com (Last access date: January 2016)

[60] Corberán, J.M., Donadello, D., Martínez-Galván, I., Montagud, C., 2013. Partialization losses of $\mathrm{ON} / \mathrm{OFF}$ operation of water-to-water refrigeration/heat-pump units, International Journal of Refrigeration 36 (8), pp. 2251-2261.

[61] Montagud, C., Corberán, J.M., Montero, Á., 2014. In situ optimization methodology for the water circulation pumps frequency of ground source heat pump systems, Energy and Buildings 68, pp. 42-53.

[62] Ruiz-Calvo, F., Cervera-Vázquez, J., Montagud, C., Corberán, J.M., 2014. Cálculo de parámetros de control de un sistema de climatización en tiempo real: factor de carga parcial, Congreso Iberoamericano de Ciencias y Técnicas del Frío (CYTEF 2014), pp. 645-656 (Spanish). 
[63] Ruiz Calvo, F., 2015 (Spanish). Análisis y modelado de una instalación geotérmica para climatización de un conjunto de oficinas ( $\mathrm{PhD}$ thesis), Universitat Politècnica de València, València, Spain.

[64] Cervera-Vázquez, J., Montagud, C., Corberán, J.M., 2015. Sizing of the buffer tank in chilled water distribution A/C systems, Science and Technology for the Built Environment, DOI: 10.1080/23744731.2016.1131569

[65] ASHRAE Green Guide (2006) - The Design, Construction and Operation of Sustainable Buildings, Chapter 10 - Energy Distribution Systems, pag. 201.

[66] Jaime Maciá Sánchez, Cálculo del volumen de líquido mínimo aconsejable para las instalaciones de enfriamiento mediante planta enfriadora, Boletín de formación y noticias de Interclisa (Carrier) (1987).

[67] http://www.trane.com/Commercial/Uploads/Pdf/1062/cg-prc007-en_0606.pdf (Last access date: 2013/Oct/2)

[68] http://www.engineer.trane.com/content/dam/Trane/en/Products/ Chillers/cgam_aquastream_3g/CG-PRC019-E4_1209.pdf (Last access date: $2013 /$ Oct $/ 2$ )

[69] http://www.totaline.com.tr/pdf/52/SM-SZ\%20Scroll\%20Kompresorler.pdf (Last access date: $2013 /$ Oct/2)

[70] http://www.emersonclimate.eu/europe/ProductDocuments/Copeland Literature/C060220_1111_0113_E_AGL_Ref\%20Scroll_FULL_0.pdf (Last access date: $2013 /$ Oct $/ 2$ )

[71] Real Decreto $1027 / 2007$, de 20 de julio, por el que se aprueba el Reglamentode Instalaciones Térmicas en los Edificios (RITE): IT 1.1.4.1.2. Temperaturaoperativa y humedad relativa. (Spanish regulations).

[72] Cervera-Vázquez, J., Montagud, C., Corberán, J.M., 2015. In situ optimization methodology for the water circulation pumps frequency of ground source heat pump systems: Analysis for multistage heat pump units, Energy and Buildings 88, pp. 238-247.

[73] Madani, H., 2014. The common and costly faults in heat pump systems, Energy Procedia 61, pp. 1803-1806.

[74] Madani, H., Roccatello, E., 2014. A comprehensive study on the important faults in heat pump system during the warranty period, International Journal of Refrigeration 48 , pp. $19-25$.

[75] Corberán, J.M., Gonzálvez-Macia, J., 2009. IMST-ART, a computer code to assist the design of refrigeration and air conditioning equipment, IMST, Universitat Politècnica de València, Spain, 2009, http://www.imst-art.com (Last access date: January 2016). 


\section{Nomenclature}

\section{Symbols}

\section{Symbol Description}

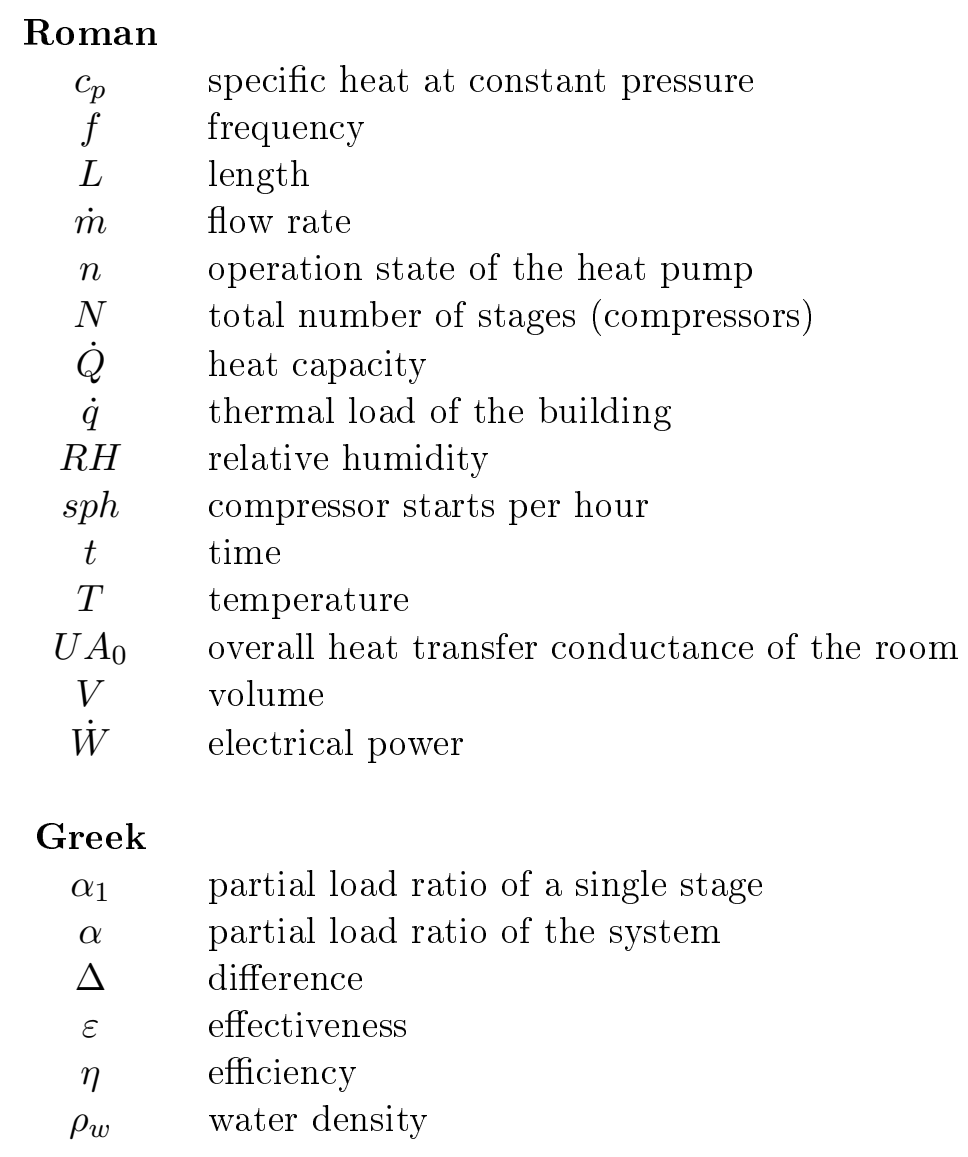

NB: SI unit used unless otherwise specified. 


\section{Subscripts}

\begin{tabular}{|c|c|}
\hline Symbol & $\begin{array}{l}\text { Description } \\
\text { air }\end{array}$ \\
\hline$a m b$ & outdoor ambient \\
\hline avg & average value \\
\hline comp & compressor \\
\hline$d b$ & dead band \\
\hline$e c$ & external circuit \\
\hline el & electrical \\
\hline$E C P$ & external circulation pump \\
\hline$H P$ & heat pump \\
\hline$i$ & inlet \\
\hline$i c$ & internal circuit \\
\hline$I C P$ & internal circulation pump \\
\hline$F C$ & fan coil \\
\hline $\max$ & maximum value \\
\hline $\min$ & minimum value \\
\hline nom & nominal value \\
\hline$o$ & outlet \\
\hline$O N$ & ON cycle \\
\hline$O F F$ & OFF cycle \\
\hline room & room \\
\hline$R 1$ & room 1 \\
\hline$R 2$ & room 2 \\
\hline sys & system \\
\hline$S B$ & building supply \\
\hline $\operatorname{tank}$ & outlet of the tank \\
\hline$t h$ & thermal \\
\hline$w$ & water \\
\hline
\end{tabular}




\section{Acronyms}

$\begin{array}{ll}\text { Acronym } & \text { Description } \\ \text { C1 } & \text { Compressor 1 } \\ \text { C2 } & \text { Compressor 2 } \\ \text { COP } & \text { Coefficient Of Performance } \\ \text { DAQ } & \text { Data Acquisition } \\ \text { DPF } & \text { Daily Performance Factor } \\ \text { ECP } & \text { External Circulation Pump } \\ \text { FCU } & \text { Fan Coil Unit } \\ \text { GSHP } & \text { Ground Source Heat Pump } \\ \text { GSHX } & \text { Ground Source Heat Exchanger } \\ \text { GUI } & \text { Graphic User Interface } \\ \text { HVAC } & \text { Heating Ventilating and Air Conditioning } \\ \text { ICP } & \text { Internal Circulation Pump } \\ \text { PF } & \text { Performance Factor } \\ \text { SPF } & \text { Seasonal Performance Factor }\end{array}$



Appendixes 



\section{Appendix A}

\section{Experimental correlations for the GROUND-MED heat pump}

The GROUND-MED heat pump is modelled by means of experimental polynomial correlations. In order to obtain the heat pump correlations, the software IMST-ART [75] was used. The determination of the experimental correlations is described in detail in 45] and [54]. These correlations provide both the heat in the evaporator and condenser, and the power consumption of the heat pump compressors, as a function of the following system variables: internal $\left(\dot{m}_{I C}\right)$ and external $\left(\dot{m}_{E C}\right)$ flow rates, and the internal $\left(T_{o, i c}\right)$ and external $\left(T_{o, i c}\right)$ return temperatures. Different correlations are considered for cooling and heating modes, and for the heat pump working with one or with two compressors. The form of the polynomial obtained is provided by Eq. A.1.

$$
\dot{C}=A_{0}+A_{1} \cdot \dot{m}_{I C}+A_{2} \cdot \dot{m}_{I C}^{2}+A_{3} \cdot \dot{m}_{E C}+A_{4} \cdot \dot{m}_{E C}^{2}+A_{5} \cdot T_{o, i c}+A_{6} \cdot T_{o, e c}
$$

Where $\dot{C}$ is either the evaporator heat $\left(\dot{Q}_{\text {evap }}\right)$, the condenser heat $\left(\dot{Q}_{\text {cond }}\right)$ or the power consumption $\left(\dot{W}_{\text {comp }}\right)$, for the corresponding mode and the corresponding number of compressors.

The value of each of the polynomial coefficients multiplying each of the system variables is shown in table A. 


\begin{tabular}{||c||c|c|c||c|c|c||}
\hline \multirow{2}{*}{$\begin{array}{c}\text { Cooling } \\
\text { coeficients }\end{array}$} & \multicolumn{3}{|c||}{1 compressor } & \multicolumn{3}{c||}{2 compressors } \\
\cline { 2 - 7 } & $\dot{Q}_{\text {evap }}$ & $\dot{Q}_{\text {cond }}$ & $\dot{W}_{\text {comp }}$ & $\dot{Q}_{\text {evap }}$ & $\dot{Q}_{\text {cond }}$ & $\dot{W}_{\text {comp }}$ \\
\hline$A_{0}$ & -38033.49 & -59183.33 & -5697.58 & -74966.59 & -102016.32 & -21654.03 \\
\hline$A_{1}$ & 3060.11 & 4569.53 & -137.36 & 4187.61 & 3800.53 & -37.19 \\
\hline$A_{2}$ & -1264.13 & -2170.79 & 72.49 & -1573.18 & -1394.59 & -13.38 \\
\hline$A_{3}$ & 945.37 & 2769.07 & -394.35 & 1299.16 & 572.29 & -590.68 \\
\hline$A_{4}$ & -27.52 & -1395.55 & 217.36 & -379.26 & -119.46 & 126.53 \\
\hline$A_{5}$ & 279.49 & 243.3 & -2.75 & 438.68 & 425.17 & 13.82 \\
\hline$A_{6}$ & -119.42 & -12.25 & 27.32 & -130.99 & -15.05 & 71.04 \\
\hline \hline \multirow{2}{*}{$\begin{array}{c}\text { Heating } \\
\text { coeficients }\end{array}$} & \multicolumn{3}{|c|}{1 compressor } & & \multicolumn{3}{|c||}{2 compressors } \\
\hline$A_{0}$ & -42734.45 & -44272.3 & -5675.55 & -55352.86 & -79418.51 & -24430.18 \\
\hline$A_{1}$ & 3121.01 & 2743.38 & -95.79 & 437.12 & 9.72 & -1003.06 \\
\hline$A_{2}$ & -1085.05 & -809.74 & 42.59 & 83.07 & 159.38 & 303.54 \\
\hline$A_{3}$ & 5135.57 & 5534.03 & -143.91 & 1680.6 & 2771.21 & -682.13 \\
\hline$A_{4}$ & -1975.21 & -2095.94 & 52.28 & 87.91 & -440.34 & 273.17 \\
\hline$A_{5}$ & -57.88 & -83.06 & 38.89 & -100.44 & 13.15 & 106.59 \\
\hline$A_{6}$ & 223.38 & 261.05 & -15.3 & 338.89 & 313.57 & -12.84 \\
\hline
\end{tabular}

Table A.1: Coefficients of the polynomial correlations for the GROUND-MED heat pump. 


\section{Appendix B}

\section{Correlations for the effectiveness of the fan coil units}

The development of the optimization algorithms studied in this research work requires a mathematical model of the performance of the fan coil units installed in the GSHP installation. In particular, a model that provides the effectiveness of the FCU in terms of both the flow rate and the temperature of the water at its inlet is required.

As mentioned in section 2.1.2, the plan is to replace the whole set of old fan coils with brand-new ones. On the other hand, the capacity of the old model (MAJOR-329 CH) is slightly higher than that of the new one (model MAJOR LINE 202D). This means that, if the comfort of the user is met with the new FCUs, it will also be met with the old ones surely. For these two reasons, and despite the fact that there are only three new FCUs installed in the system up to the moment, the new model MAJOR LINE 202D is chosen in order to develop the optimization algorithms.

The manufacturer of the fan coils provides a piece of software called Elite ${ }^{\circledR}$ which includes a model of the fan coils based on experimental data taken at their laboratories. This software was used in order to characterize the performance of the FCUs.

The first step when using the software Elite ${ }^{\circledR}$ is selecting the corresponding FCU model among all the available units. In this case model MAJOR LINE 202D is selected, as it can be observed in the selection screen shown in Fig. B.1.

Once the model is selected, the next step consists of setting all the utilization conditions, as shown in the screen presented in Fig. B.2. These conditions include the comfort temperature (recycled air temperature in Fig. B.2), the humidity and the temperature of the water at the inlet of the fan coils, that is to say, the building supply temperature in this study. The flow rate is indirectly introduced by setting the temperature difference in the "cooling coil" section.

Finally, the last step consist of calculating the performance of the fan coil unit, getting 


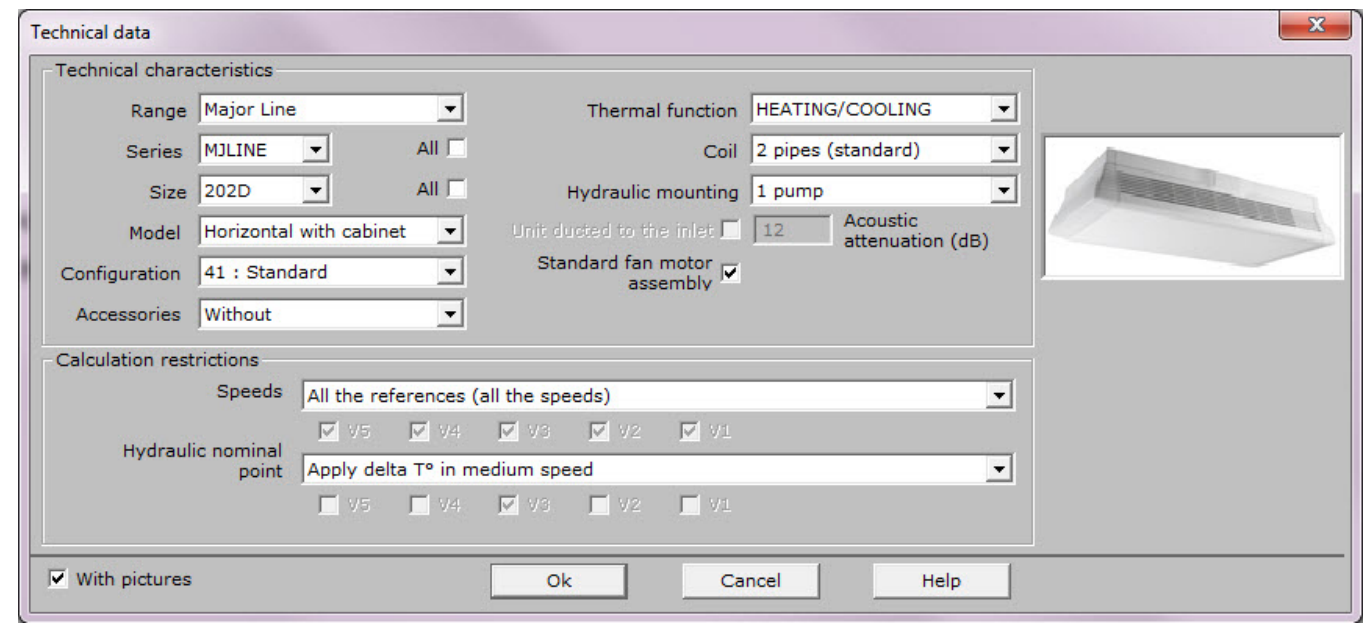

Figure B.1: Technical data screen in software Elite ${ }^{\circledR}$.

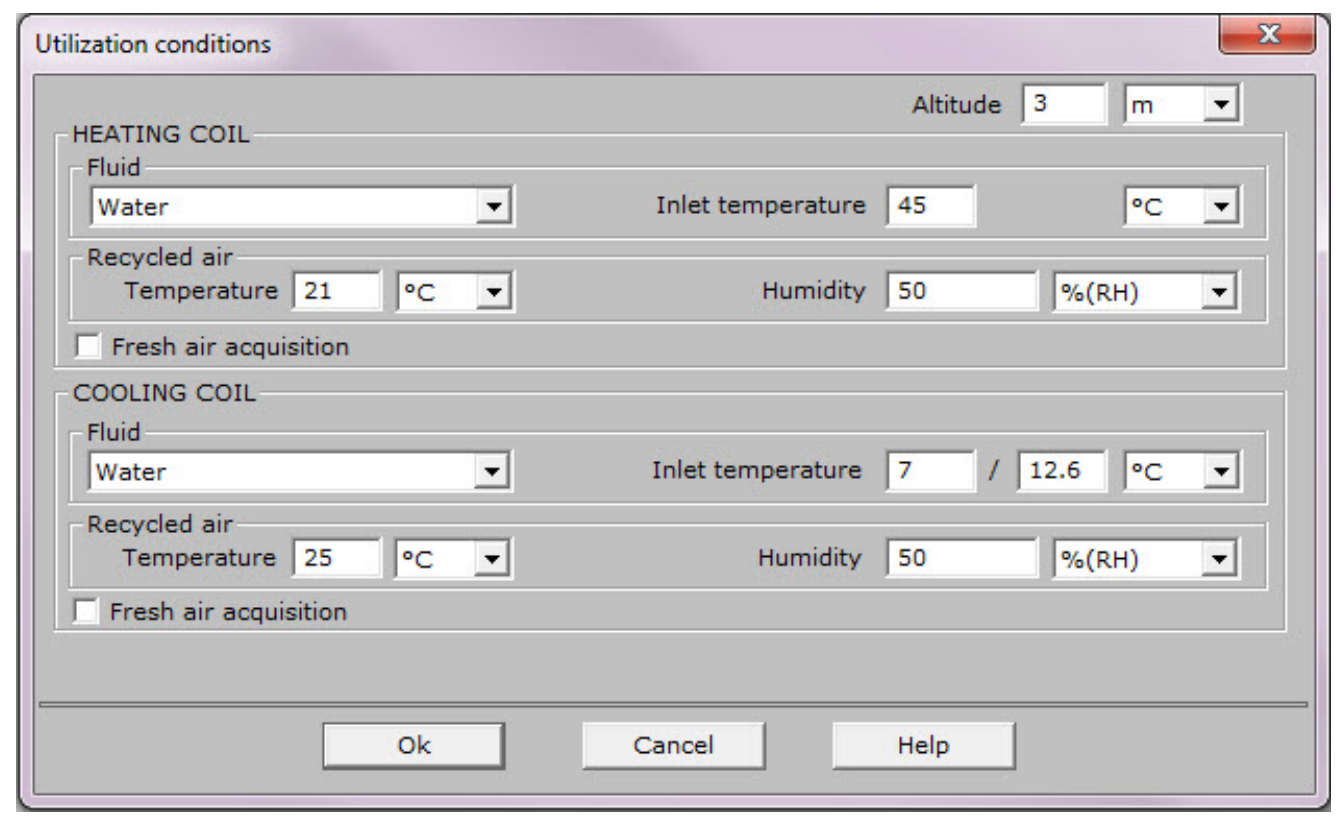

Figure B.2: Utilization conditions screen in software Elite ${ }^{\circledR}$. 
to the screen shown in Fig. B.3. The solutions include the water flow rate, the absorbed power and the cooling and heating capacities among others. Considering the values of the temperature of the water at the inlet of the fan coil (building supply temperature) and the values of the water flow rate, as well as the cooling and heating capacities, the effectiveness is calculated for both cooling and heating modes.

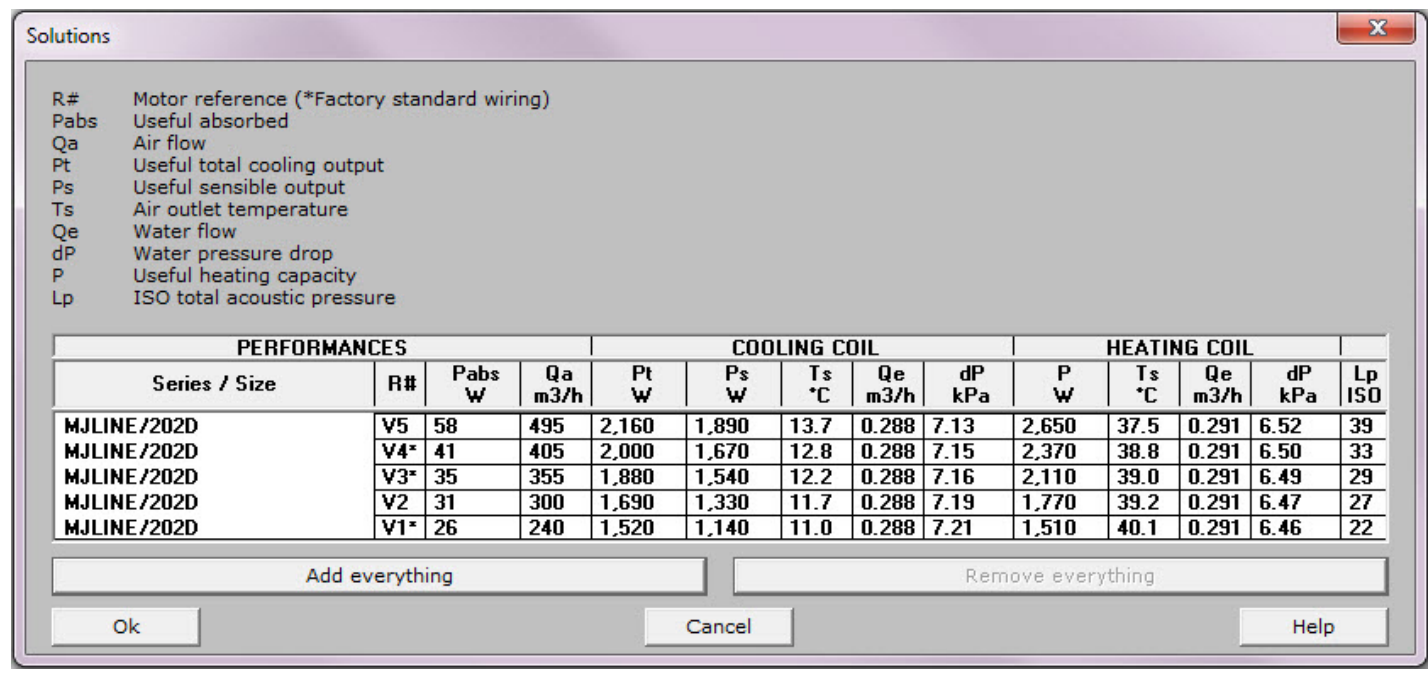

Figure B.3: Solutions screen in software Elite ${ }^{\circledR}$.

Repeating this calculation for different values of the temperature of the water at the inlet of the fan coil (building supply temperature) and different values of the water flow rate, Fig. B.4 and Fig B.6 are obtained, for cooling and heating mode respectively. They depict, for different values of the building supply temperature, how the effectiveness of the fan coil varies with the internal flow rate. 


\section{Fan coil effectiveness for cooling mode}

Analysing Fig. B.4, it can be observed that the fan coil effectiveness does not vary linearly with the flow rate, but presents a quadratic relation. However, this relation, which seems to be independent from the building supply temperature for small values of water flow rate, turns out to be different for greater flow rates. This means that it may exist a cross relation of flow rate and supply temperature. Finally, it seems that there is a linear relation of the effectiveness with the supply temperature as well.

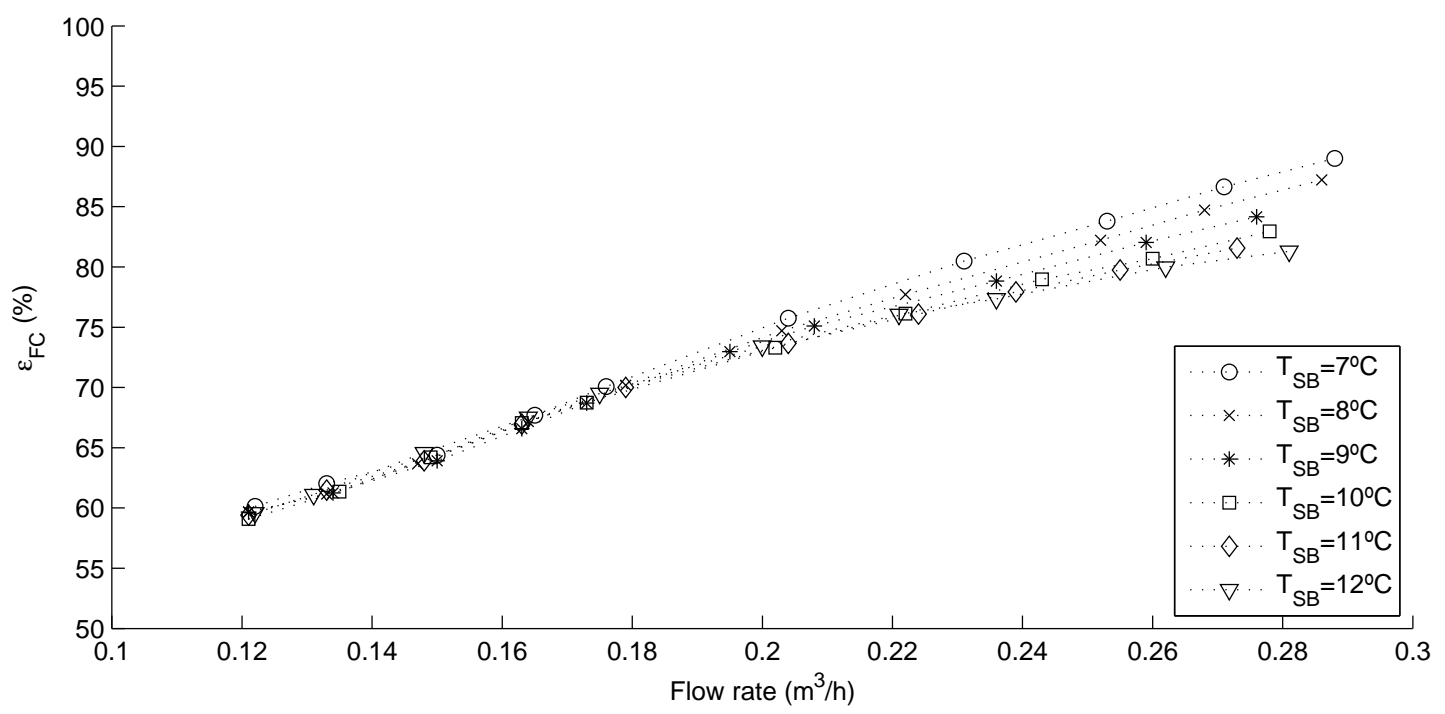

Figure B.4: Fan coil effectiveness in cooling mode.

Considering all these observations, the following three expressions are proposed in order to find the correlation that best fits the fan coil data. It should be noticed that the frequency $\left(f_{I C P}\right)$ is used instead of the flow rate, as it is the targeted variable. As described previously, these two variables are directly proportional.

$$
\begin{gathered}
\varepsilon_{F C \mid a}=D_{0}+D_{1} \cdot f_{I C P}+D_{2} \cdot f_{I C P}^{2} \\
\varepsilon_{F C \mid b}=D_{0}+D_{1} \cdot f_{I C P}+D_{2} \cdot f_{I C P}^{2}+D_{3} \cdot T_{S B} \cdot f_{I C P} \\
\varepsilon_{F C \mid c}=D_{0}+D_{1} \cdot f_{I C P}+D_{2} \cdot f_{I C P}^{2}+D_{3} \cdot T_{S B} \cdot f_{I C P}+D_{4} \cdot T_{S B} \cdot f_{I C P}^{2}
\end{gathered}
$$

The three proposed correlations are analysed in Fig. B.5. The data set calculated from Elite ${ }^{\circledR}$ is represented with circles while de correlated values are represented with triangles.

It can be observed in Fig. B.5 that correlation (a) is not able to predict accurately the values of the fan coil effectiveness for high values of the water flow rate (Fig. B.5a), 

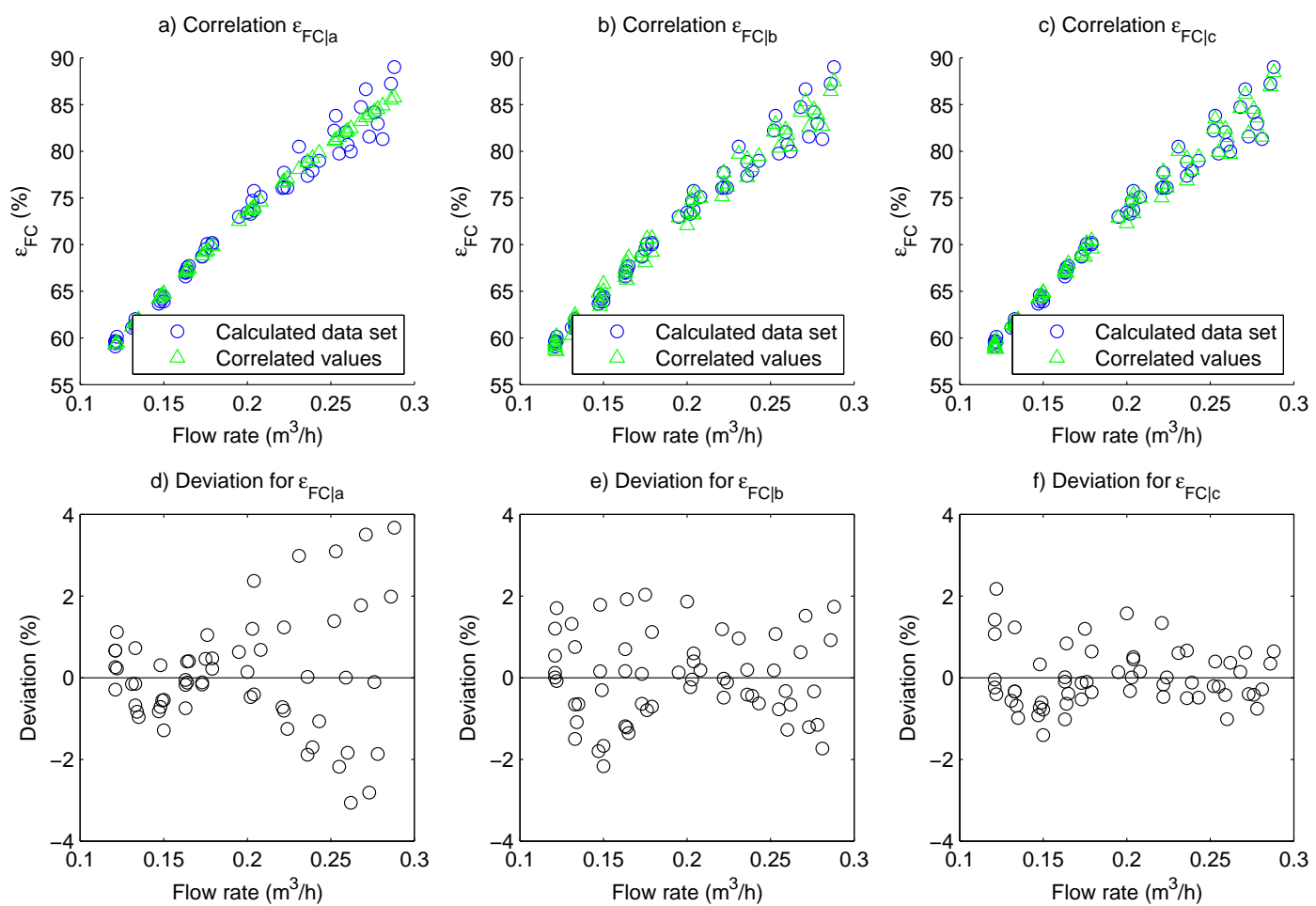

Figure B.5: Correlations for the fan coil effectiveness in cooling mode.

presenting deviations of up to $4 \%$ (Fig. B.5d). Correlation (b) corrects this effect, and is able to predict the effectiveness of the fan coil with a maximum deviation of around $2 \%$ (Fig. B.5p and B.5p). Finally, correlation (c) provides the best prediction (Fig. B.5c), with deviations below $2 \%$ (Fig. B.5).

Nevertheless, correlation (c) complicates the calculations without providing a great improvement with respect to correlation (b). Therefore, correlation (b) is finally chosen in order to model the effectiveness of the fan coil units in cooling mode. 


\section{Fan coil effectiveness for heating mode}

In the case of heating mode, analysing Fig. B.6, a behaviour similar to cooling mode is observed. The fan coil effectiveness presents a quadratic variation with the water flow rate. In this case, a slighter variation is observed for higher flow rates. In order to obtain the most suitable correlation, the same expressions presented in Eqs. B.1, B.2 and B.3 are employed.

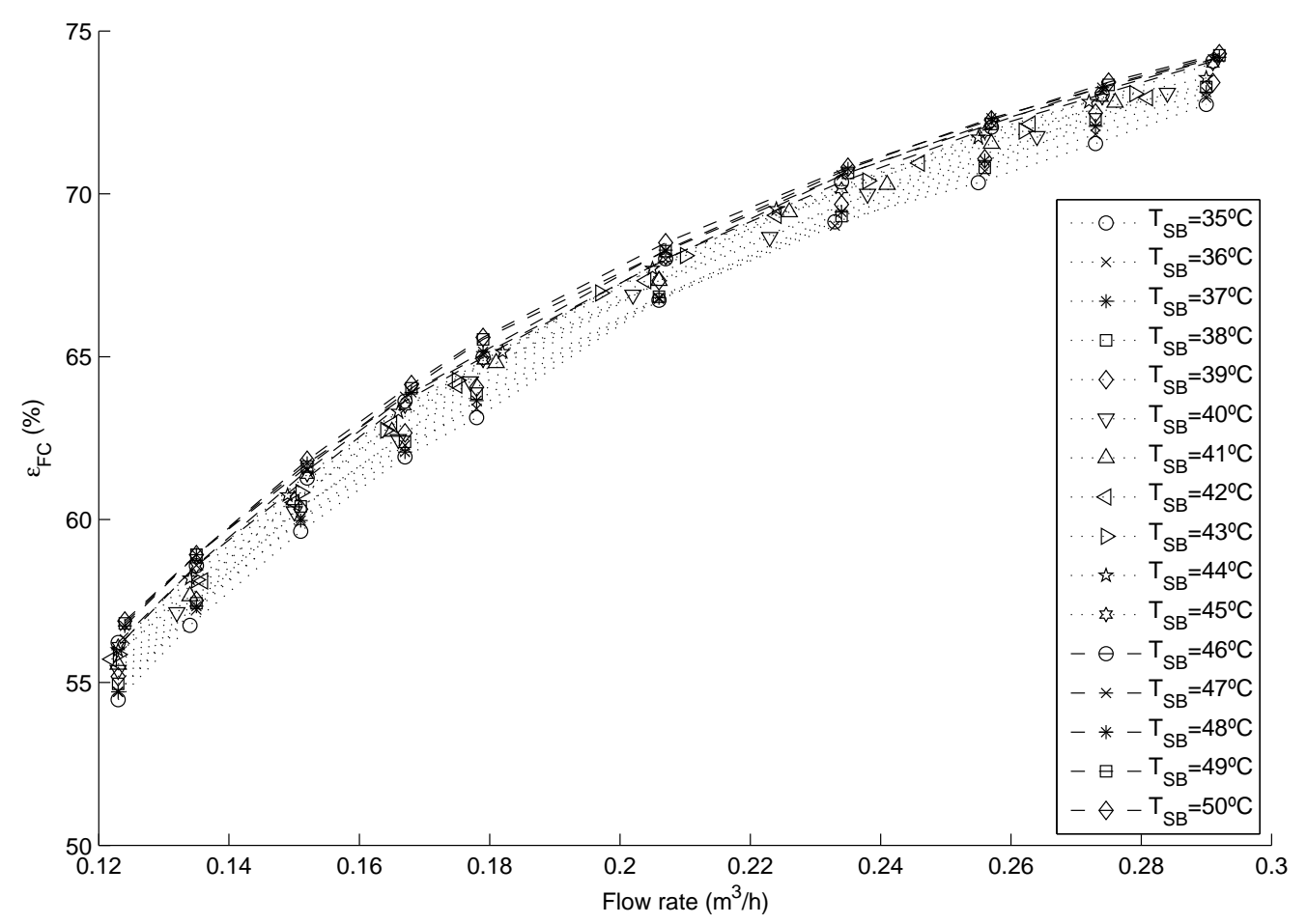

Figure B.6: Fan coil effectiveness in heating mode.

Fig. B.7 presents the results of the three correlations analysed for heating mode. In this case, all three correlations show values of deviation of around $2 \%$ or lower. The most suitable correlation however seems to be, again, correlation (b). It shows lower values of the deviation when compared to correlation (a), it provides a prediction of the values of the fan coil effectiveness as nearly as good as correlation (c), while being simpler. Therefore, as it was made for cooling mode, correlation (b) is finally chosen in order to model the effectiveness of the fan coil units in heating mode. 

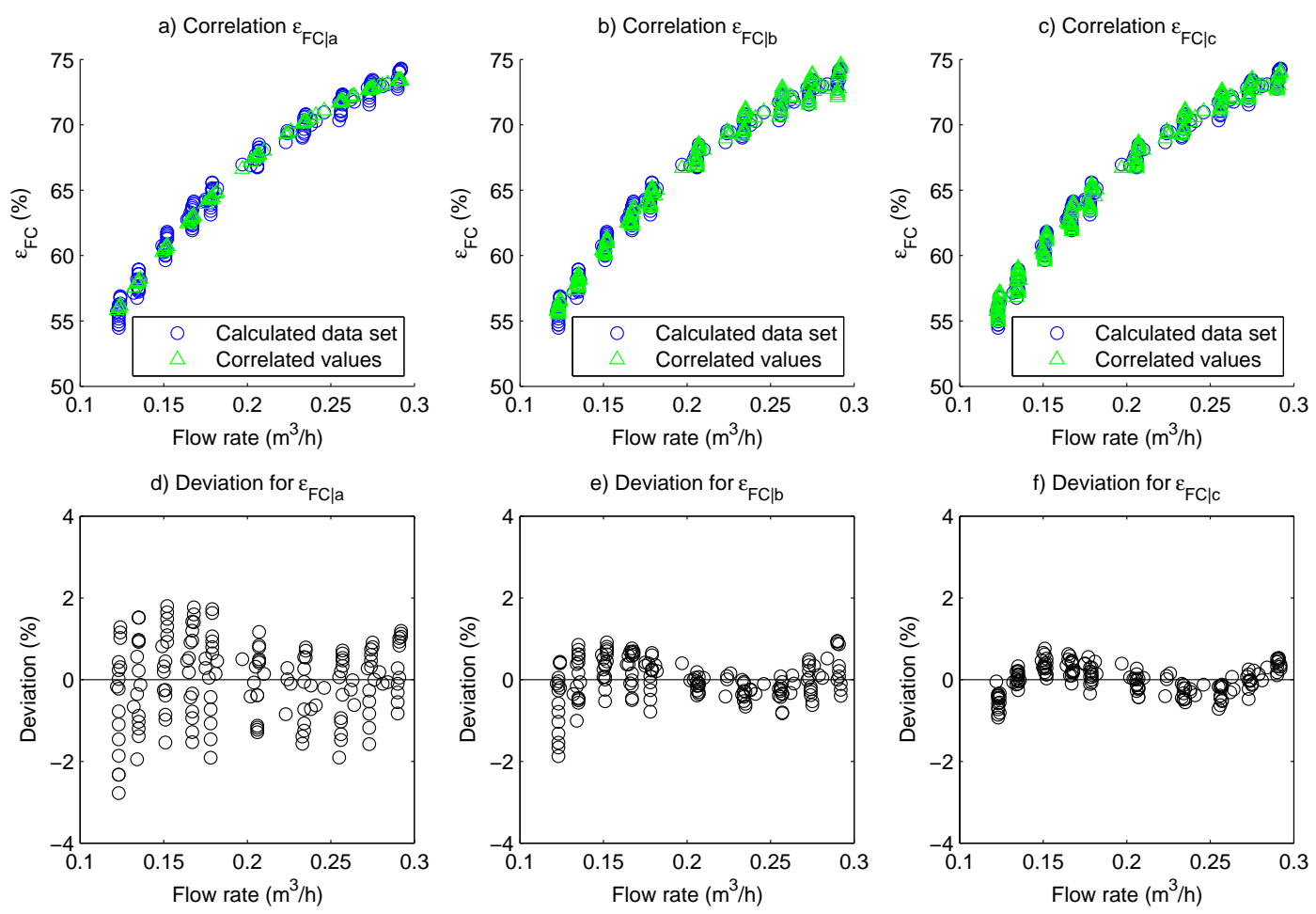

Figure B.7: Correlations for the fan coil effectiveness in heating mode. 



\section{Appendix C}

\section{Publications derived from this research work}

\section{C.1 Scientific indexed journals publications}

- Cervera-Vázquez, J., Montagud, C., Corberán, J.M., 2014. Analysis of the energy performance and control optimization of a GSHP installation, ASHRAE Transactions 120 (2), pp. 334-345.

- Cervera-Vázquez, J., Montagud, C., Corberán, J.M., 2015. In situ optimization methodology for the water circulation pumps frequency of ground source heat pump systems: Analysis for multistage heat pump units, Energy and Buildings 88, pp. 238-247.

- Cervera-Vázquez, J., Montagud, C., Corberán, J.M., 2015. In situ optimization methodology for ground source heat pump systems: Upgrade to ensure user comfort, Energy and Buildings 109, pp. 195-208.

- Cervera-Vázquez, J., Montagud, C., Corberán, J.M., 2015. Sizing of the buffer tank in chilled water distribution A/C systems, Science and Technology for the Built Environment, DOI: 10.1080/23744731.2016.1131569

\section{C.2 Workshops and conferences publications}

- Montagud, C., Cervera-Vázquez, J., Corberán, J.M., 2013. Analysis of different GSHP system configurations: tank and control sensor position and its influence on the system performance, European Geothermal Congress (EGC 2013), Pisa, Italy. 
- Montagud, C., Cervera-Vázquez, J., Corberán, J.M., 2013. Optimization methodology for GSHP installations based on the circulation pumps frequency variation, European Geothermal Congress (EGC 2013), Pisa, Italy.

- Cervera-Vázquez, J., Montagud, C., Corberán, J.M., 2013. Posición y dimensionamiento del depósito de inercia en circuitos de distribución de agua de sistemas de climatización con bomba de calor con regulación ON/OFF, Congreso Iberoamericano de Ciencias y Técnicas del Frío (CYTEF 2013), pp. 637-646 (Spanish).

- Ruiz-Calvo, F., Cervera-Vázquez, J., Montagud, C., Corberán, J.M., 2014. Cálculo de parámetros de control de un sistema de climatización en tiempo real: factor de carga parcial, Congreso Iberoamericano de Ciencias y Técnicas del Frío (CYTEF 2014), pp. 645-656 (Spanish).

- Montagud, C., Cervera-Vázquez, J., Corberán, J.M., 2014. Análisis del comportamiento y optimización energética de una instalación de bomba de calor geotérmica para climatización de edificios, Congreso de Energía Geotérmica en la Edificacion y en la Industria (GeoEner 2014), Madrid, Spain. 
